\title{
Food sustainability standards and agricultural cooperatives: implications for the small farm sector of Côte d'Ivoire
}

\author{
Dissertation \\ to obtain the doctoral degree \\ in the International Ph. D. Program for Agricultural Sciences in Goettingen (IPAG) \\ at the Faculty of Agricultural Sciences, \\ Georg-August-University Goettingen, Germany
}

Presented by

Jorge Luis Sellare

born in São Paulo, Brazil

Goettingen, March 2020 
D7

$1^{\text {st }}$ supervisor: Prof. Dr. Matin Qaim

$2^{\text {nd }}$ supervisor: Prof. Dr. Meike Wollni

$3^{\text {rd }}$ supervisor: Prof. Dr. Stephan von Cramon-Taubadel

Date of dissertation: 20 $0^{\text {th }}$ May 2020. 



\section{Summary}

Sustainability standards such as Fairtrade, UTZ, and Rainforest Alliance have recently gained importance in global value chains, with some of the major tropical commodities seeing significant increases in the share of their certified area in the last ten years. This trend is directly related to consumers in North America and Europe becoming increasingly aware of the importance of sustainable agricultural production. These consumers are concerned not only about food safety issues; they also want to support a kind of agricultural production that reduces negative environmental impacts due to the use of certain agricultural practices while improving the livelihoods of rural populations in developing countries. Increasing consumer awareness about sustainability issues fosters demand for products that can ensure that particular concerns are being addressed along the value chains. Sustainability standards are usually regarded as an effective mechanism to do so. Against this background, products certified under sustainability standards have moved from niche to mainstream markets.

Despite differences in their requirements and the extent to which they focus on socioeconomic and environmental goals, all major sustainability standards claim that they are beneficial to smallholder farmers and workers. These benefits can be in terms of better income, access to more secure markets and credit, improvements in food and nutrition security, reduction of child labor, among others. A growing body of literature has sought to evaluate the extent to which the claims from standards-setting bodies hold, but the results are mixed. This literature is already quite comprehensive in terms of the standards, countries, crops, and outcome variables covered, but there are still several shortcomings in terms of methodologies and empirical approaches used.

Previous studies relied on data from only a few purposively selected cooperatives, which reduces the external validity of these studies. Certification in the small farm sector typically takes place through group approaches to reduce the high transaction costs that would otherwise be prohibitive for individual farmers. Therefore, one would expect that the benefits drawn from group membership and the benefits from being certified are closely correlated. In this dissertation, I analyze the effects of sustainability standards (with a particular focus on Fairtrade) on economic, social, and environmental indicators using a sampling design that better accounts for the institutional heterogeneity in agricultural cooperatives. This sampling design allows to control for some important confounding factors at the cooperative level and, due to the large institutional heterogeneity captured in the data, present results that have greater 
external validity. The three articles presented here are based on primary data from 1,000 certified and non-certified farmers and rural workers randomly sampled from 50 cocoa cooperatives in Côte d'Ivoire. I focus in particular on Fairtrade certification because, contrary to other sustainability standards, Fairtrade gives special emphasis to agricultural cooperatives.

In the first article, I analyze whether farmers benefit from Fairtrade certification also when accounting for cooperative effects. Furthermore, I discuss the importance of using a sampling design that sufficiently accounts for institutional heterogeneity in agricultural cooperatives. Using regression models with instrumental variables, I show that Fairtrade certification has a positive and significant effect on yields, prices and living standards of farmers. These results are robust to alternative model specifications in which I additionally control for some key cooperative characteristics. However, the magnitude of the estimates changes, with substantial differences in the effects on yields. These results show that Fairtrade is beneficial to farmers even after controlling for cooperative effects. I also conclude that not accounting for institutional heterogeneity leads to omitted variable bias, which underlines that institutional characteristics matter and that such heterogeneity deserves more explicit focus in the design of future studies.

In the second article, I focus on the effects of Fairtrade certification on the environmental impacts of agricultural production and the health of farmers and workers. Certification can lead to some important changes in agricultural practices, especially concerning chemical input use. Contrary to previous studies that focused only on the intensity of agrochemical input use, I use two measures of aggregated pesticide toxicity - namely the Environmental Impact Quotient (EIQ) and the Hazard Quotient (HQ) - to proxy potential impacts on the environment and health. In the empirical analyses, I use double-hurdle regression models to estimate the effect of Fairtrade on agrochemical input use and aggregated toxicity, and Poisson regression models to estimate effects on the incidence of acute pesticide-related health symptoms. Instrumental variables are employed to reduce potential endogeneity issues. Fairtrade increases chemical input quantities and aggregated levels of toxicity. Nevertheless, Fairtrade reduces the incidence of pesticide-related acute health symptoms among farmers and workers.

In the third article I explore how cooperatives use the Fairtrade social premium - a sum that is paid to cooperatives in addition to the agreed price to be used in projects to strengthen the cooperative and to benefit the community in the villages more broadly. I use descriptive statistics to discuss the communities' main social needs as voiced by survey respondents and to 
analyze in what kind of projects the social premium is actually invested. Using principal component analysis (PCA), I analyze which kinds of cooperatives are more likely to invest in what kinds of projects. I find that larger investments in projects related to education, water, and other community infrastructure are correlated with cooperative characteristics like the number of assets owned and the number of years that the cooperative has been certified. To illustrate the potential benefits of the social premium to the local community, I use regression analysis to evaluate if (i) being certified and (ii) living in a village where an education project was financed through the social premium have effects on household education expenditures. I find evidence that being certified has a positive effect on household education expenditures among farmers and cooperative workers. However, living in a village where an educational project was implemented has a positive effect only among farmers.

Two main findings of this dissertation should be highlighted. First, I find evidence that sustainability standards have positive effects in the small farm sector, even when taking cooperative effects into account. Second, heterogeneity among agricultural should be more explicitly taken into account in future studies focusing on the effects of certification. Sustainability standards have the potential to engender changes in agrifood systems to make them more sustainable. However, local stakeholders (e.g. development agencies, nongovernmental organizations, extension agencies) should provide support to cooperatives to help them first meet the requirements for certification and then reap the benefits in a profitable manner. Furthermore, state-led initiatives should ensure the existence of a well-functioning institutional environment that builds synergies between private and public-led programs that foster the adoption of more sustainable farming and business practices. 


\section{Acknowledgements}

I would like to start by thanking my supervisor, Prof. Dr. Matin Qaim for granting me the opportunity to take this very important step in my career. Your encouragement, support, and extremely fast feedback throughout these past three years have been always highly appreciated. I can say with confidence that your mentorship was a key ingredient for me to mature as a researcher and I hope in the future we will have plenty of opportunities to collaborate in new projects.

I cannot emphasize enough the important role that Dr. Eva-Marie Meemken had in my Ph.D. project. From helping me develop the main research idea to doing fieldwork and co-authoring papers, working with you has been an enriching experience. It is very inspiring to see someone with such motivation and dedication. Thank you very much for all your support. And I would like to additionally thank Dr. Christophe Kouamé (ICRAF), who opened many doors for us in Côte d'Ivoire.

I would like to express my gratitude for all the support provided through the RTG GlobalFood. Prof. Dr. Meike Wollni and Prof. Dr. Stephan von Cramon-Taubadel for accepting to be members of my examination committee and for all the feedback provided during my doctoral seminars. Dr. Melanie Grosse, Kathrin Pape, and Ann-Kathrin Fahlbusch for helping me navigate the German bureaucracy. All my colleagues from GlobalFood, especially to Anette Ruml, Denise Hörner, Jessie Lin, Dr. Lisa Jäckering, and Nina Graßnick for your friendship, exchange of ideas, and the many glasses of wine we shared. I'm sure we will keep in touch long after our time in Göttingen has ended. And of course, I would like to acknowledge that this dissertation would not have been possible without the financial support from the German Research Foundation (DFG) and the Foundation fiat panis.

Too often those who are really the key people in research do not receive enough appreciation from us. First, I want to thank the cooperative leaders, farmers, and rural workers who took the time to participate in my long surveys, even though they are the ones least likely to receive any direct benefit from this research. Second, a very special thanks goes to my field coordinator, Roland Aka, who made it possible for the data collection to work out as planned. Lastly, I want to thank the amazing group of enumerators who worked very hard under the harshest circumstances and yet are often kept anonymous. Attoubou Marline, Dobe Inès, Edjagne Eric, 
Ehui Joel, Godie Octave, Horo Yannick, Koffi Florence, Seri Venance, Togba Eloise, Yapi Henri, and Yeo Leon, you have my deepest appreciation and gratitude.

Several other people have contributed immensely not only during my doctoral studies but throughout the whole journey that took me here. First, I would like to thank Kauê de Sousa for being such a good friend and constant willingness to help with anything (especially coding!). Second, I cannot properly express in words how thankful I am for the humor de mi vida, Andrea Pacheco. Thank you for being such a loving and caring partner and for making me laugh even during the most stressful times. Can't wait to see where this journey together will take us next. Lastly, I would like to thank my sister, Julia, for your unconditional support in literally everything, and my parents, Marlene and Luis. Obrigado pelo seu amor, carinho, e por terem me dado tantas oportunidades na vida. Esta dissertaçāo é de vocês. 


\section{Table of contents}

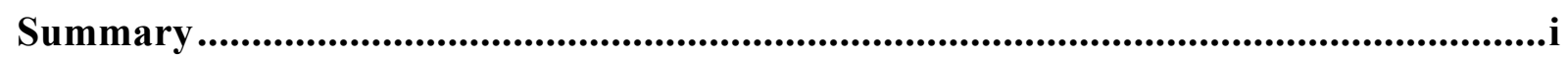

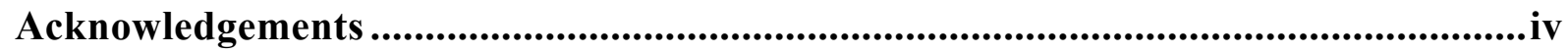

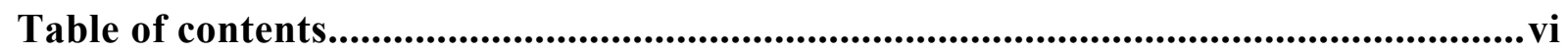

List of tables................................................................................................................................. ix

List of figures..............................................................................................................................ii

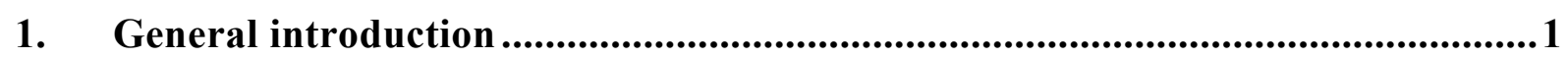

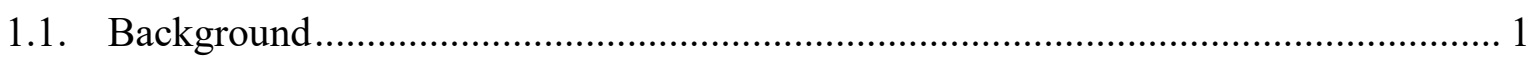

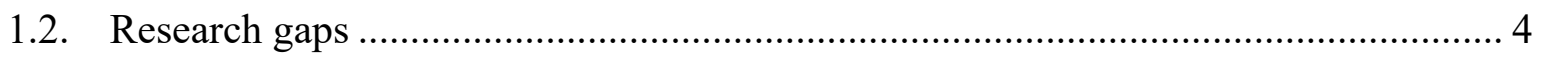

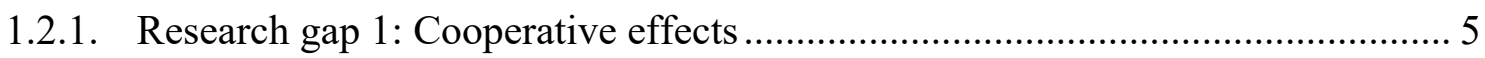

1.2.2. Research gap 2: Input use and access to services ........................................ 5

1.2.3. Research gap 3: The Fairtrade social premium ............................................ 6

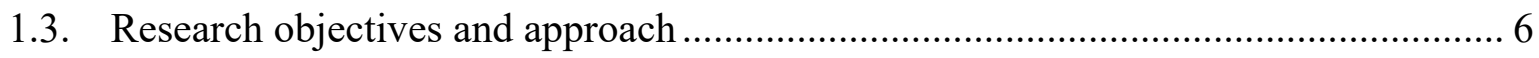

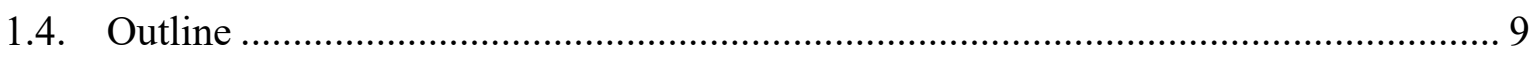

2. Do sustainability standards benefit smallholder farmers also when accounting

for cooperative effects? Evidence from Côte d'Ivoire .................................................11

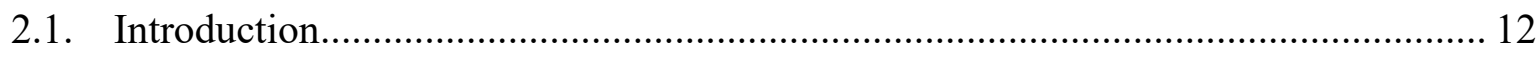

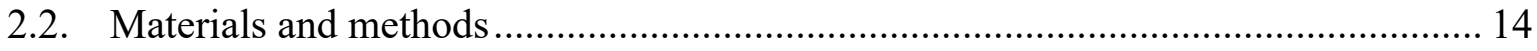

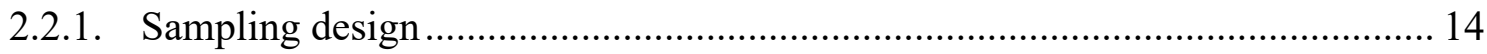

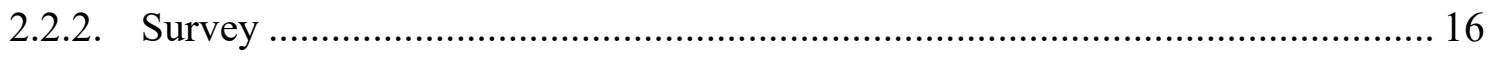

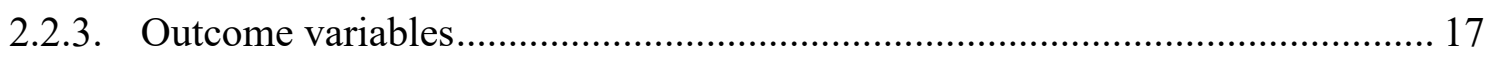

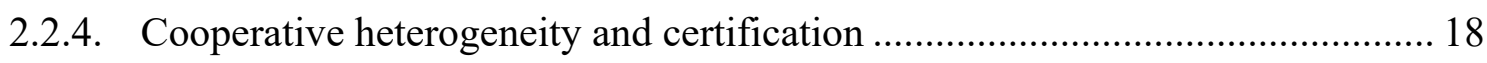

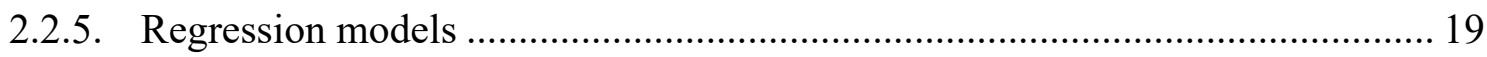

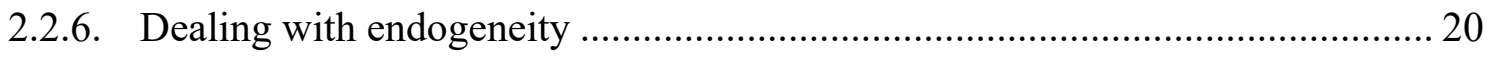

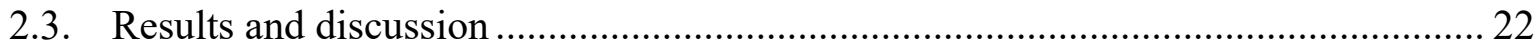

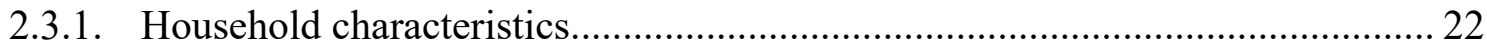

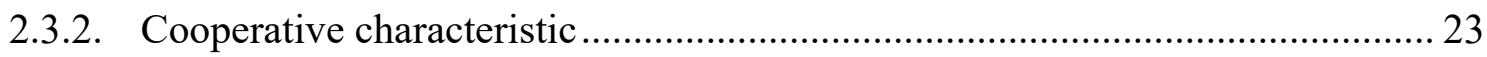

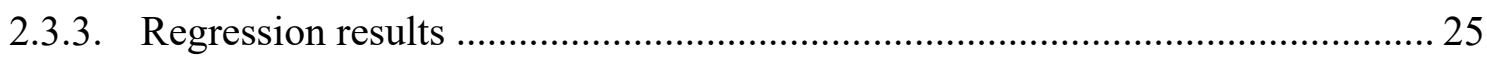

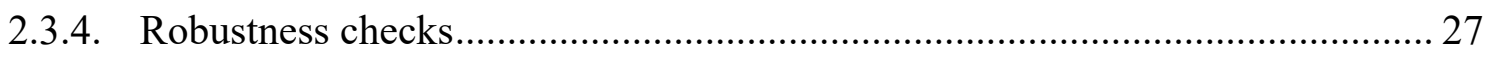




\section{Fairtrade, agrochemical input use, and effects on human health and the} environment...

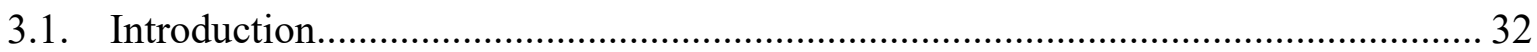

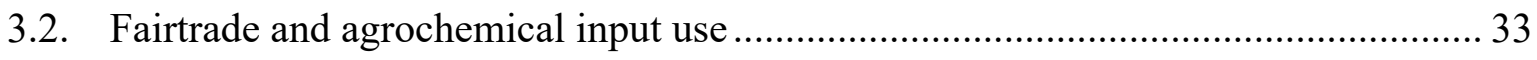

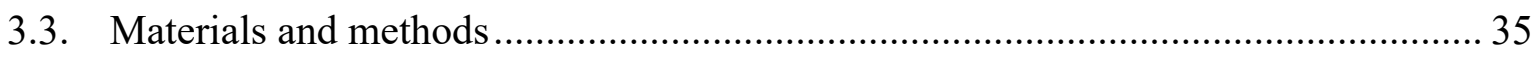

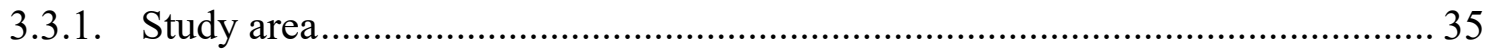

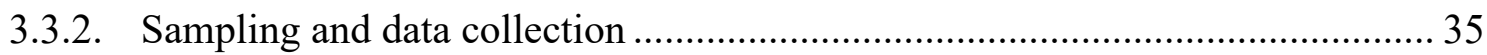

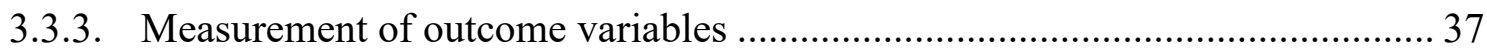

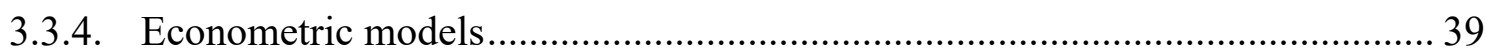

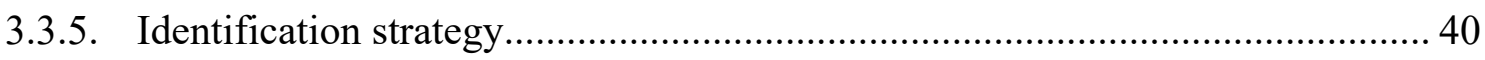

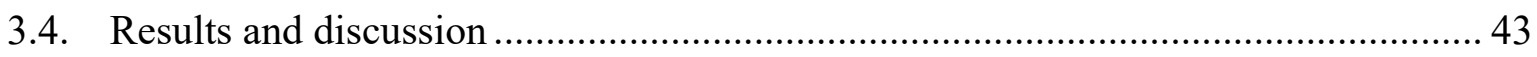

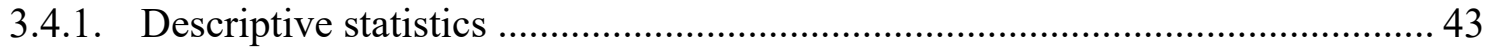

3.4.2. Effects on the intensity of agrochemical use................................................ 47

3.4.3. Effects of Fairtrade on aggregated pesticide toxicity..................................... 49

3.4.4. Effects of Fairtrade on pesticide-related health symptoms .............................. 50

3.4.5. Effects of Fairtrade at the cooperative level .................................................... 50

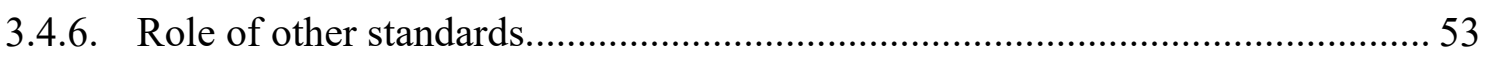

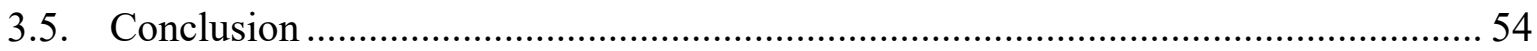

4. New insights on the use of the Fairtrade social premium ...............................57

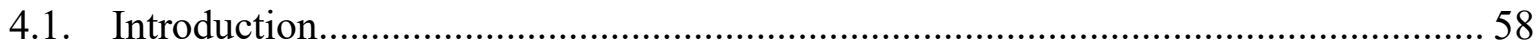

4.2. Fairtrade, the social premium, and child education ............................................... 59

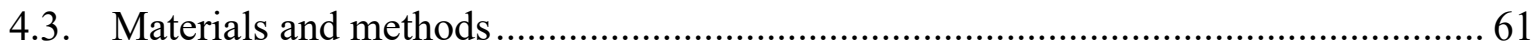

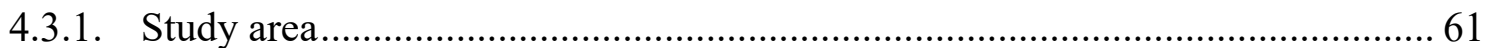

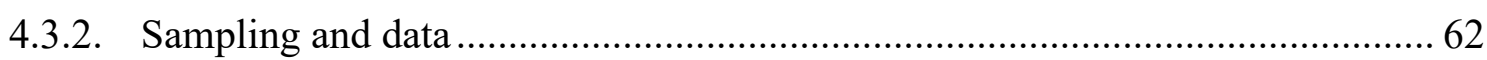

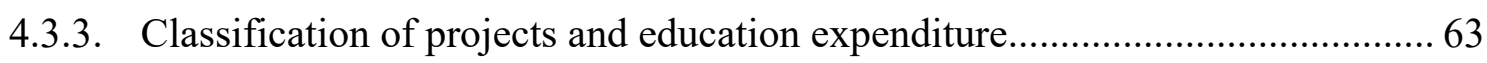

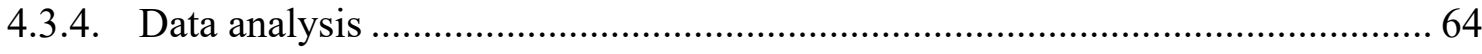

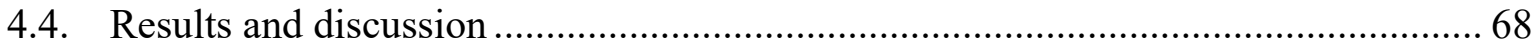

4.4.1. Village needs and participation in the premium's decision-making .................. 68

4.4.2. Projects implemented with the Fairtrade social premium................................ 70

4.4.3. Cooperative characteristics and the use of the Fairtrade social premium .......... 71

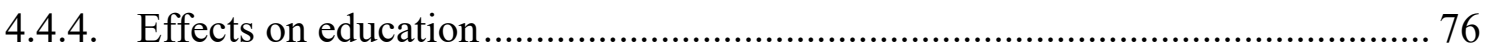




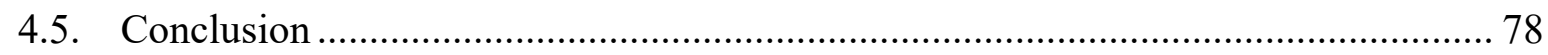

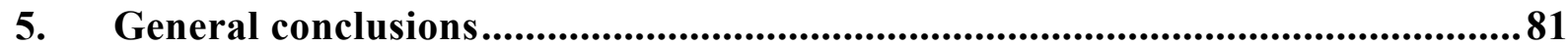

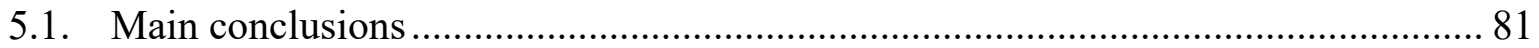

5.2. Limitations and considerations for future research …......................................... 82

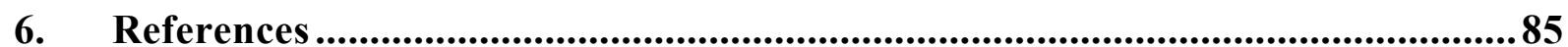

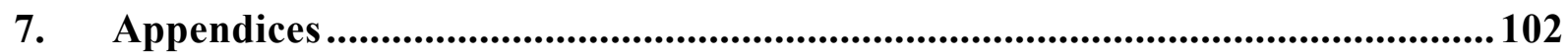

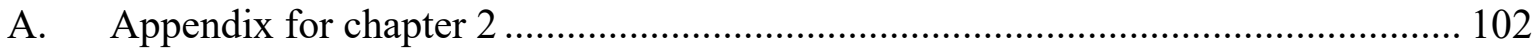

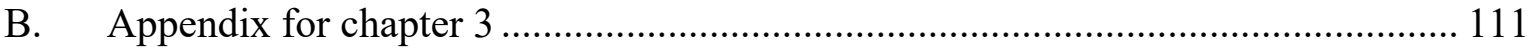

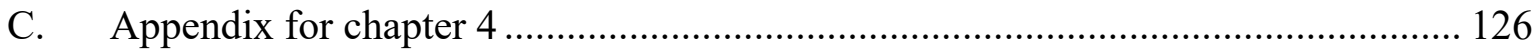




\section{List of tables}

Table 1. Descriptive statistics for outcome variables and poverty incidence by

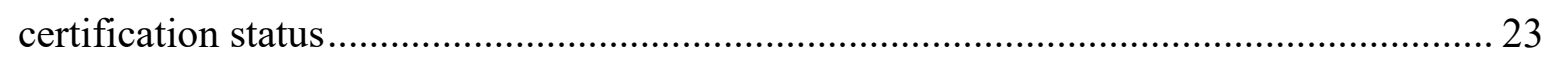

Table 2. Descriptive statistics for cooperative characteristics by certification status ............. 24

Table 3. Correlation between cooperative characteristics, certification status, and

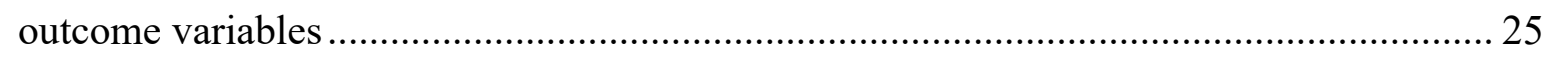

Table 4. Effect of Fairtrade certification on outcome variables ........................................... 26

Table 5. Effects of Fairtrade certification on outcome variables controlling for other

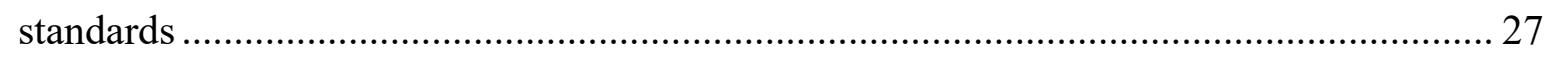

Table 6. Agrochemical input use and related indicators by Fairtrade certification status ....... 44

Table 7. List of pesticide active ingredients used by farmers and various toxicity classifications 45

Table 8. Effects of certification on agrochemical input use (double-hurdle

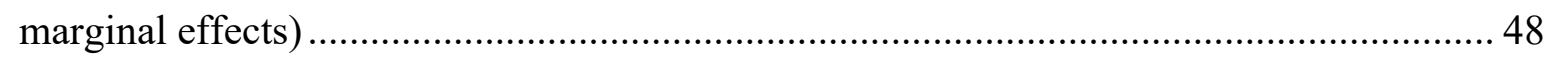

Table 9. Effects of certification on aggregated pesticide toxicity (double-hurdle marginal effects)

Table 10. Effects of certification on the number of pesticide-related acute health symptoms. 50

Table 11. Effects of Fairtrade on agrochemical input use, toxicity, and health

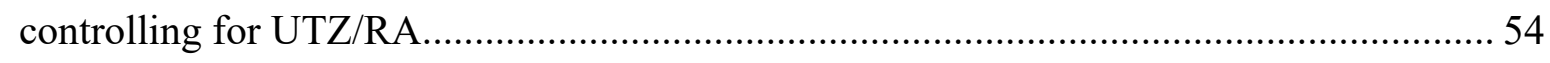

Table 12. Classification of projects financed with the Fairtrade social premium ................... 64

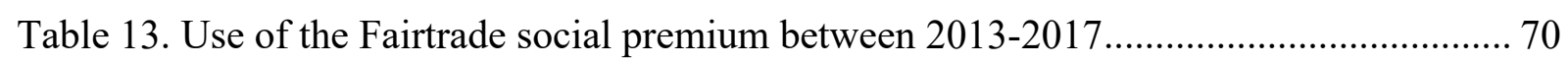

Table 14. Descriptive statistics for the cooperative characteristics used in

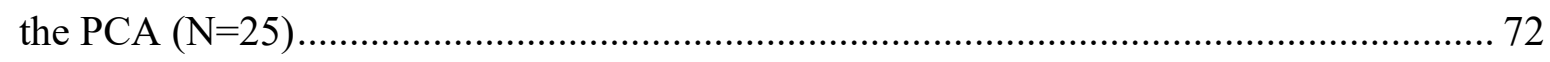

Table 15. Correlation between variables and the five main dimensions of the PCA............... 73 
Table 16. Descriptive statistics for variables at the household level

Table 17. Effects of certification and education projects on household education expenditure $(\log )$ 78

Table 18. Spillover effects of education projects on household education expenditure (log) 78

Table A1. Agroecological characteristics by district 102

Table A2. Correlation matrix between certification and instruments 102

Table A3. First-stage IV regression and instrument falsification tests 103

Table A4. Correlation between instruments and other regional factors that could influence welfare 104

Table A5. Effects of Fairtrade certification on cocoa yield ( $\mathrm{kg} / \mathrm{ha})$ 105

Table A6. Effects of Fairtrade certification on cocoa price (CFA/kg). 106

Table A7. Effects of Fairtrade certification on per capita consumption expenditure (log).... 107

Table A8. descriptive statistics for household characteristics by certification status 108

Table A9. Effects of Fairtrade certification on outcome variables controlling for other standards

Table A10. Effects of Fairtrade certification on outcome variables without controlling for number of service providers 110

Table B1. Comparison between tobit and double-hurdle models (likelihood ratio tests) ...... 111

Table B2. First-stage of IV models and instrument falsification tests

Table B3. Effects of certification on the number of pesticide-related acute

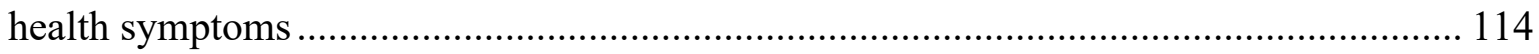

Table B4. Significance of generalized residuals in double-hurdle models ( $p$-values) ........... 115

Table B5. Descriptive statistics for control variables by certification status (farmer sample).

Table B6. Descriptive statistics for control variables by certification status (worker sample) 
Table B7. Effect of certification on agrochemical input use (double-hurdle models).....

Table B8. Marginal effects of certification on agrochemical input use (double-hurdle models)

Table A9. Marginal effects of certification on agrochemical input use controlling for potential pathways (double-hurdle models)

Table B10. Effects of certification on aggregated toxicity (double-hurdle models) 120

Table B11. Marginal effects of certification on aggregated toxicity (double-hurdle models)

Table B12. Marginal effects of Fairtrade on agrochemical input use controlling for UTZ/RA (double-hurdle models)

Table B13. Marginal effects of Fairtrade on aggregated toxicity controlling for UTZ/RA (double-hurdle model) 123

Table B14. Effects of Fairtrade on health symptoms controlling for UTZ/RA 124

Table C1. Instrument falsification test

Table C2. Effects of certification and education projects on household education expenditure $(\log )$ 127

Table C3. Spillover effects of education projects on household education expenditure $(\log ) 129$ 


\section{List of figures}

Figure 1. Geographical distribution of sampled farmers by certification status. 16

Figure 2. Incidence of pesticide-related acute health symptoms among respondents who were exposed to pesticides $(\mathrm{N}=255)$. 46

Figure 3. Share of cooperatives offering services related to input provision and training by certification status.

Figure 4. Principal component analysis on cooperative characteristics (in black) and their correlation with cooperatives' investments using the Fairtrade social premium (in blue) (Dim. 1 and Dim. 2)

Figure 5. Principal component analysis on cooperative characteristics (in black) and their correlation with cooperatives' investments using the Fairtrade social premium (in blue) (Dim. 1 and Dim. 3) 75

Figure 6. Principal component analysis on cooperative characteristics (in black) and their correlation with cooperatives' investments using the Fairtrade social premium (in blue) (Dim. 2 and Dim. 3)

Figure B1. Correlation matrix between certification and all active ingredients in the dataset 125

Figure C1. Most pressing needs of the villages that should be addressed 130

Figure C2. Scree plot of the principal component analysis 130

Figure C3. Biplot of the principal component analysis. Cooperatives are indicated by red dots. 


\section{General introduction}

\subsection{Background}

Voluntary private sustainability standards have been gaining importance for the production and marketing of some of the major tropical commodities (Lernoud et al., 2018; Potts et al., 2014). Currently there are around 400 standards that are classified as "sustainability standards", with some of them being set by single organizations (e.g. 4C and C.A.F.E. Practices), some set by multi-stakeholder platforms (e.g. Roundtable on Sustainable Palm Oil), and others that have their origins in non-governmental organizations, such as Fairtrade (Bennett, 2017). Some of these standards are crop specific (e.g. Bonsucro and Better Cotton Initiative), while others cover a broad range of agricultural and forestry products (e.g. Rainforest Alliance and Organic). Although requirements vary from one standard to another, most of them address issues of social, economic, and environmental sustainability across value chains to some extent.

Worldwide there are around 80 million hectares of agricultural land that are certified under at least one sustainability standard, which represents no more than $2 \%$ of the total agricultural land (Lernoud et al., 2018). However, looking at these figures disaggregated by commodity reveals some important trends. Around $25 \%$ of the agricultural land used for cocoa production is certified, followed by coffee (23\%), and tea (16\%). Cotton and cocoa were the two commodities that saw the biggest growth in their share of certified area between 2013 and 2017, which increased by $172 \%$ and $114 \%$ respectively (Willer et al., 2019). These figures suggest that products that are compliant with internationally recognized sustainability standards have moved from niche to mainstream markets. ${ }^{1}$

Such figures mirror global trends related to sustainability concerns and increased consumer awareness about the importance of supporting a kind of agricultural production that upholds values of social and environmental justice (Iweala et al., 2019; Ladhari \& Tchetgna, 2015). In fact, sustainability standards tap on many of the issues highlighted in the 2030 Agenda for Sustainable Development, such as poverty alleviation (SDG1), decent work conditions (SDG8),

\footnotetext{
${ }^{1}$ It is relatively easy to obtain figures related to the supply of certified products, as most labelling organizations have data on the exact number of certified farmers, their farm size, and quantity produced. However, data on the actual demand is significantly more challenging to access, as only part of the certified production is actually sold as such; the rest is traded in uncertified markets (Potts et al., 2014).
} 
inequality reduction (SDG10), and sustainable consumption and production (SDG12). As such, sustainability standards have the potential to affect several actors in agricultural value chains (from consumers to processors and producers) and address some of the issues faced by the rural population in developing countries.

Following Bonroy and Constantatos (2015) and Swinnen et al. (2015), we can theorize how the introduction of a standard affects the functioning of markets and the welfare of different actors across the value chain. Standards address market failures by reducing information asymmetries related to credence features, i.e. characteristics of a product that cannot be observed by consumers. Guaranteeing such features that consumers value increases willingness to pay for the products and overall utility derived from consuming them. On the producers' side, standards can affect profits positively by increasing the price that farmers receive (as a result of consumers' increased willingness to pay for the reduction in information asymmetries), and negatively due to the costs of implementing the standards. From a distributional perspective, the bargaining power between producers and processors (or retailers) over the distribution of the surplus generated with the introduction of the standard plays a crucial role. This bargaining power, in turn, is affected by market imperfections (e.g. farmers' access to credit and technology) and institutional configurations (e.g. different forms of vertical coordination).

When empirically analyzing the efficiency and equity effects of standards, several additional issues should be taken into account. The costs associated with standards go well beyond those incurred by farmers to make the necessary changes to meet the requirements. Cooperatives and other kinds of farmer organizations often have to cover the certification fees and other administrative and organizational costs associated with certification (Snider et al., 2017), while processors are often required to handle certified and non-certified products separately, thus increasing management costs. Depending on the institutional organization of value chains and specific market setups, these actors in the middle of the value chain can capture most of the price premium paid by consumers (Minten et al., 2018). These factors can affect the extent to which sustainability standards have an impact on development and poverty (Swinnen, 2016).

Monitoring is another key issue in the functioning of standards and relates to some of the costs that different actors incur. In large plantations, certification is often done individually, in which case monitoring is relatively straightforward. In the small farm sector, group certification is the more common approach and is often done through cooperatives or other farmer organizations (Snider et al., 2017). Some of these organizations have a large number of members, whose farms 
might be scattered across a big geographic area, which makes the costs for on-site monitoring prohibitive. Although standards setting bodies often call for unannounced third-party external audits and internal audits, these are not carried out as often as they should, and reports about internal auditors cheating are not uncommon (Ansah et al., 2020). Monitoring intermediary actors in the value chain can be equally challenging. Some suppliers and retailers might have incentives to engage in food adulteration and sell conventional products as if they were certified. Such actions can undermine consumers' trust in certification and decrease demand for such products (Lau et al., 2020).

In addition to consumers' interest in certified products, other stakeholders are also invested in promoting sustainability standards. NGOs and development agencies, for example, have been supporting farmers and cooperatives to help them comply with these standards as a means to foster sustainable development (Kersting \& Wollni, 2012; Oelofse et al., 2010). Given the interest of these stakeholders, a large number of studies has sought to identify the effects of sustainability standards on smallholder farms in developing countries. This body of literature is quite broad in its scope, covering many different standards, crops, countries, and outcome variables (DeFries et al., 2017; Oya et al., 2018). Whether and to what extent farmers benefit from sustainability standards, however, remains an open question. Some studies have found that certification does bring economic benefits to farmers (Akoyi \& Maertens, 2018; Chiputwa et al., 2015; Meemken et al., 2017; Mitiku et al., 2017). These are often due to increases in yields and prices, which can be explained by easier access to inputs and training on better agricultural practices and by the price premiums received for selling in certified channels. However, other studies have found that certification has little to no economic effect (Beuchelt \& Zeller, 2011; Jena et al., 2012; Ruben \& Fort, 2012), which is often explained by increases in costs outweighing the benefits from increased prices and yields.

Focusing exclusively on economic outcomes does not provide a full picture of the effects of sustainability standards, as many of them have a strong emphasis on environmental and social outcomes. Several studies have reported that certification helps to reduce deforestation (Takahashi \& Todo, 2013) and can be an effective mechanism to protect local biodiversity, both on-farm (Vanderhaegen et al., 2018) and at the landscape scale (Hardt et al., 2015; Tscharntke et al., 2015). Rainforest Alliance (RA) is the standard that is most often associated with such environmental effects, as it has very strict rules regarding deforestation (Newton et al., 2015). Certification has also been often associated with the adoption of more sustainable farming 
practices, such as application of organic inputs, maintenance of on-farm tree diversity, and mulching (Blackman \& Naranjo, 2012a; Haggar et al., 2017; Ibanez \& Blackman, 2016).

The number of studies that focus on social outcomes such as nutrition, gender, health, and child education is considerably smaller. A few studies have focused on household nutrition with positive findings (Becchetti \& Costantino, 2008; Chiputwa \& Qaim, 2016; Meemken et al., 2017), which are likely a result of better overall income. In terms of women empowerment, certification improves intra-household distribution of assets, but it does not facilitate access to credit for female-headed households (Meemken \& Qaim, 2018b). The effect of certification on health is also not clear-cut, as there is evidence to support that certification has positive effects (Asfaw et al., 2010) as well as negative effects (Ehlert et al., 2014). The evidence of the effects on child education is more homogeneous, as most studies find that certification has a positive effect (Akoyi et al., 2018; Becchetti et al., 2013; Gitter et al., 2012; Meemken et al., 2017). Nonetheless, a few studies do not find statistically significant effects of sustainability standards on child education (Becchetti \& Costantino, 2008; Dragusanu \& Nunn, 2018).

The existing studies are often quite nuanced, and some of them have tried to explain under which circumstances and for whom certification is beneficial. Chiputwa et al. (2015) highlighted the importance of taking into account differences between standards and showed that Fairtrade, UTZ, and Organic standards have different effects on farmers' livelihoods. Similarly, Haggar et al. (2017) and Vanderhaegen et al. (2018) showed that different combinations of standards can either result in positive or negative effects in terms of economic and environmental outcomes, highlighting a clear trade-off between the two sustainability dimensions. Meemken et al. (2019) analyzed the effect of Fairtrade certification on the welfare of rural workers in the small farm sector and found that, while cooperative workers benefit from participating in a certified value chain, farm workers do not. Lastly, Jena et al. (2012) was among the first studies to emphasize the possible relationship between the quality of cooperatives and the benefits that farmers draw from certification.

\subsection{Research gaps}

Measuring the impact of sustainability standards is a daunting challenge. Certification usually involves several actors across value chains. How standards are implemented and managed can be influenced by national institutional arrangements and policies. All of these factors play a role in determining how benefits are distributed. The complexity of the topic poses conceptual and 
methodological challenges to identify causal pathways and suitable counterfactuals. Given these challenges and the current state of the literature, I have identified the following three research gaps.

\subsubsection{Research gap 1: Cooperative effects}

As described above, the evidence regarding the effects of sustainability standards in the small farm sector is rather mixed. The differences in results can be partially attributed to differences in the standards, crops, years, and countries under consideration. However, recent studies have pointed out that differences in the cooperatives from which respondents are sampled can exert an equally important influence on the results (Jena et al., 2012; Mitiku et al., 2017). The literature on cooperatives has long established that cooperative membership provides a series of benefits to farmers, such as higher prices and dividends, access to inputs, training, and other services, and reduction in transactions costs (Abdul-Rahaman \& Abdulai, 2018; Grashuis \& Su, 2019; Ragasa \& Golan, 2014; Wossen et al., 2017). However, cooperative membership can also affect whether farmers participate in certified value chains and to what extent they benefit. Because certification in the small farm sector is usually done through cooperatives, it is likely that the benefits derived from cooperative membership and the benefits from certification are strongly correlated. Previous studies have not tried to take cooperative effects into account when estimating the effects of certification. By not explicitly focusing on the role of cooperatives, these studies suffer from limited internal and external validity.

\subsubsection{Research gap 2: Input use and access to services}

All major sustainability standards have requirements related to input use. Organic standards are the most restrictive in this regard, as they completely ban the use of chemical inputs. Other standards, such as Fairtrade, UTZ, and Rainforest Alliance are less stringent, but they still regulate which products are allowed, which safety measures should be implemented, and recommend alternative means to control pests and diseases (Tayleur et al., 2017). These regulations can affect the profitability of farms and the extent to which agriculture impacts the environment and human health. A few studies have analyzed the effects of certification on input use and other agricultural practices (Elder et al., 2013; Haggar et al., 2017; Ibanez \& Blackman, 2016; Vanderhaegen et al., 2018). However, these studies have two important limitations. First, these studies use simple quantity based approaches to measure input use, which do not accurately capture environmental and health risks (Möhring et al., 2019, 2020). Second, no 
previous study has looked into how certification changes input and service provision at the cooperative level. Farmers often have access to inputs through their cooperatives, and the cooperatives also provide training and other services related to agrochemical input use (Grashuis \& Su, 2019). Therefore, cooperatives can have an important role in influencing how farmers use agrochemicals. The effect that certification has on agrochemical use and how they affect the environment and human health might be influenced by cooperative effects.

\subsubsection{Research gap 3: The Fairtrade social premium}

Several studies that look at Fairtrade certification attribute their findings, at least partially, to the use of the Fairtrade social premium (Jena \& Grote, 2017; Meemken et al., 2017; Van den Broeck et al., 2017; van Rijn et al., 2019). This is a sum of money paid to the cooperatives on top of the agreed price that can be used for various purposes and it is one of the main differences between Fairtrade and other sustainability standards. Although Fairtrade does not give cooperatives specific guidelines on how to use the premium, it is often assumed that a significant share of this money is used for projects related to community development (Lernoud et al., 2018). In fact, previous research has shown that consumers in developed countries tend to associate Fairtrade with broader community development. Some studies have qualitatively discussed a few important issues related to the premium, such as who benefits from it (Cramer et al., 2017) and how democratic the decision-making processes are (Dolan, 2010). However, these studies were based on a very limited number of cooperatives, which also limits what kind of analyses can be done with the data. Given the importance of the premium for Fairtrade's theory of change and image vis a vis the consumers, it is important to better understand what kind of projects this money is being spent on, which factors influence the decision-making processes, and how effectively the money is spent.

\subsection{Research objectives and approach}

To address the research gaps identified above, I use a novel sampling strategy that better accounts for institutional heterogeneity at the cooperative level. Previous studies on sustainability standards have been designed in one of the following three ways. First, a few early studies from this body of literature have compared certified farmers organized into cooperatives with non-certified farmers who were not members of any cooperative (Becchetti et al., 2013). This kind of study design is rather problematic, as certification and cooperative membership are perfectly correlated, and their effects cannot be disentangled. A second group 
of studies sampled certified and non-certified farmers who are members of the same cooperative (Chiputwa et al., 2015; Meemken et al., 2017). This approach has advantages over the first one, but suffers from very limited external validity, as the chosen cooperative might have some idiosyncratic characteristics that are not representative of the whole population. Furthermore, this approach is often not feasible, because in most cases cooperative members are either all certified or not. Most studies use a third approach, i.e. they compare farmers who are members of a certified cooperative with farmers who are members of a non-certified cooperative (Mitiku et al., 2017; van Rijsbergen et al., 2016; Vanderhaegen et al., 2018). These studies are thus based on a relatively large random sample of farmers who are members of two (or at best a few) purposively selected cooperatives. This is problematic because these cooperatives might not be similar. Even when authors claim to have chosen certified and non-certified cooperatives based on a few simple criteria such as number of members, these cooperatives may still differ substantially in other dimensions. These differences can influence how well these cooperatives function, which can affect outcomes, regardless of certification.

In this dissertation, I follow this third approach, but I aim to capture as much cooperative heterogeneity in the data as possible. This was done by first randomly selecting a large number of certified and non-certified cooperatives and then randomly sampling a few members from each cooperative. This approach has at least two advantages over those used in previous studies. First, having data with high variability on a large number of cooperative characteristics allows me to control for confounding factors at the cooperative level in the analyses, thus increasing the internal validity of the results. Second, with a large sample of certified and non-certified cooperatives, I ensure that my results are valid across a large number of organizational configurations, thus increasing the external validity of my study.

To implement this sampling strategy, I selected the cocoa sector of Côte d'Ivoire as study context. In 2017, there were more than 600 registered cooperatives in Côte d'Ivoire (MADR, 2017), out of which around 150 were Fairtrade certified (Fairtrade, 2019b). Fairtrade is not the most prominent standard in the cocoa sector, ranking second in terms of certified area behind UTZ (Willer et al., 2019). However, unlike UTZ and other standards, Fairtrade gives explicit focus to cooperatives (Dietz et al., 2018). All cocoa cooperatives in Côte d'Ivoire commercialize their product with the same level of post-harvesting processing, i.e. fermented and dried beans. This setting is ideal for the implementation of the sampling strategy described above because it presents a large pool of cooperatives to choose from and because they all commercialize the same type of product. To reduce logistics costs, I limited the study area to 
the Southeast of the country, because it is a traditionally important area for cocoa production and has a large concentration of certified and non-certified cooperatives. The data were collected in 2018 and contain information on 1,000 farmers and rural workers (cooperative workers and farm workers) sampled from 50 cooperatives, half certified under the Fairtrade standard and the other half not certified under Fairtrade or any other standard.

Having this specific dataset allows me to address the three research gaps identified above. The sampling strategy in itself solves part of the issues described in the first research gap, as sampling farmers from a large number of cooperatives increases external validity. To account for possible cooperative effects in the estimation of certification effects, I control for a set of cooperative characteristics in the regression analyses. By estimating models with and without controlling for this set of variables, I provide evidence of the importance of explicitly taking into account cooperative heterogeneity when estimating certification effects. I further increase the internal validity of my analyses by using instrumental variables (IVs) at the cooperative and household levels to deal with farmers' and cooperative's self-selection into certification.

All certified cooperatives in my sample are Fairtrade certified, and two thirds of those are additionally certified for UTZ and/or Rainforest Alliance. Since none of the cooperatives follow Organic standards, I can analyze how Fairtrade affects agrochemical input use, which, as mentioned in the second research gap, previous studies have not done. Furthermore, I analyze the risks associated with pesticides using two measures of aggregated pesticide toxicity - the Environmental Impact Quotient (Kovach et al., 1992) and the Hazard Quotient (Kniss, 2017) and assess the effects of Fairtrade certification on the health of farmers and workers. Here, I estimate treatment effects using double hurdle and Poisson regression models coupled with IVbased approaches to deal with endogeneity issues. I additionally use statistical tests to analyze differences between certified and non-certified cooperatives in terms of what kinds of inputs, training, and other services related to input use they offer to farmers.

Lastly, I tackle the third research gap using detailed information on the use of the Fairtrade social premium. Because of the cooperative heterogeneity in the dataset, I can use multivariate statistical methods such as principal component analysis (PCA) to analyze if and how the use of the premium is correlated with the characteristics of these cooperatives. I complement these analyses by using linear regressions to assess if farmers and workers benefit from being certified and from living in a village where projects financed with the Fairtrade premium were implemented. 


\subsection{Outline}

The remainder of this dissertation comprises three essays in the form of journal articles and a general conclusion. In chapter 2, I discuss the importance of using a sampling strategy that better accounts for cooperative heterogeneity when designing studies that estimate the causal effects of sustainability standards and analyze whether smallholder farmers benefit from certification also when accounting for cooperative effects. In chapter 3, I focus on how Fairtrade certification can affect agrochemical input use and analyze its effects on aggregated pesticide toxicity. Furthermore, I analyze the effects of Fairtrade on the incidence of pesticide-related acute health symptoms among farmers and rural workers and discuss the role of cooperatives in providing services related to the use of agrochemical. The essay in chapter 4 focuses on the use of the Fairtrade social premium. I analyze the relationship between the allocation of the premium into different kinds of projects and the organizational structure of the certified cooperatives. To illustrate how the local population may benefit from the social premium, I further analyze if living in a village where an education project financed with the premium affects households' expenditure with child education. To conclude, in chapter 5 I summarize the main results of the three essays, discuss the main lessons learned and their policy implication, and give some directions for future studies on sustainability standards. 


\title{
2. Do sustainability standards benefit smallholder farmers also when accounting for cooperative effects? Evidence from Côte d'Ivoire ${ }^{2}$
}

\begin{abstract}
While many studies analyzed effects of sustainability standards - such as Fairtrade or Rainforest Alliance - on smallholder farmers in developing countries, most did not sufficiently account for systematic differences between certified and non-certified farmers. Certified farmers are typically organized in cooperatives. When sampling only from a small number of cooperatives, as previous studies did, it is not easy to disentangle certification effects from possible cooperative effects. Here, we address this shortcoming by randomly sampling from a large number of cooperatives, thus better capturing existing institutional heterogeneity. In particular, we collect and use data from cocoa farmers in Côte d'Ivoire that are organized in Fairtrade-certified and non-certified cooperatives. Regression models with instrumental variables show that Fairtrade has positive and significant effects on cocoa yields, prices, and living standards. These effects remain significant also after controlling for cooperative characteristics, but the magnitude of the estimates changes. We draw two conclusions. First, in Côte d'Ivoire Fairtrade certification benefits farmers economically. Second, and more generally, cooperative characteristics are jointly correlated with certification and relevant outcomes, which needs to be accounted for to avoid bias when evaluating the benefits of sustainability standards in the small farm sector.
\end{abstract}

Key words: Certification, cocoa, cooperatives, Côte d'Ivoire, Fairtrade, sustainability standards

2 This chapter is published in the American Journal of Agricultural Economics (https://doi.org/10.1002/ajae.12015). It is co-authored by Eva-Marie Meemken (E.-M.M.), Christophe Kouamé (C.K.) and Matin Qaim (M.Q.). I (J.S.) developed the research idea, conducted the data analysis, and wrote the paper. J.S., E.-M.M., and M.Q. designed the study. J.S. and E.-M.M. collected the data with support from C.K. E.M.M., and M.Q. commented at the various stages of the research. 


\subsection{Introduction}

Sustainability standards - such as Fairtrade and Rainforest Alliance - are claimed to be effective mechanisms to link smallholder farmers in developing countries to high-value markets while promoting environmentally-friendly and socially acceptable production and trading patterns. Many studies tried to test these claims by analyzing whether or not certification under sustainability standards actually leads to benefits for farmers. Empirical research was conducted in various countries of Africa, Asia, and Latin America (DeFries et al., 2017; Dragusanu et al., 2014; Oya et al., 2018). The results are mixed. While several studies suggest that sustainability standards contribute to higher prices and incomes for participating farmers (Bacon, 2005; Chiputwa \& Qaim, 2016; Jena et al., 2012; Meemken et al., 2017; Mitiku et al., 2017; Tran \& Goto, 2019), other studies find very small or no effects at all (Akoyi \& Maertens, 2018; Beuchelt \& Zeller, 2011; Chiputwa et al., 2015; Ibanez \& Blackman, 2016; Valkila, 2009). To some extent, differences in effects can be explained by the fact that the studies refer to different countries, different years, and partly also to different standards. As is well known, the effects of standards can vary between settings with different conditions (Oya et al., 2018). However, even within one setting the estimated effects may be unreliable when not properly controlling for confounding factors, such as institutional heterogeneity.

Existing studies on the effects of sustainability standards in developing countries differ substantially in terms of the methodologies used. While much of the early work was rather qualitative and descriptive (Bacon, 2005; Muradian \& Pelupessy, 2005; Raynolds, 2002; Raynolds et al., 2004; Valkila, 2009), more recent studies tried to evaluate the net effects of standards through larger samples and more sophisticated tools of quantitative data analysis (Akoyi \& Maertens, 2018; Becchetti et al., 2013; Chiputwa et al., 2015; Haggar et al., 2017; Ibanez \& Blackman, 2016; Jena et al., 2012; Meemken et al., 2017; Ruben \& Fort, 2012; Vanderhaegen et al., 2018). However, even these more recent studies did not sufficiently account for systematic differences between certified and non-certified farmers, which may lead to biased impact estimates. One possible source of bias is related to the fact that certification in the small farm sector usually happens through agricultural cooperatives (Fenger et al., 2017; Oelofse et al., 2010; Snider et al., 2017). Oftentimes, being member of a cooperative is a precondition for smallholders to participate in certification, as the transaction costs can otherwise be prohibitive. However, cooperative membership can influence farm performance and household welfare also without certification (Bernard \& Spielman, 2009; Ragasa \& Golan, 2014; Verhofstadt \& Maertens, 2014). Hence, when evaluating the effects of certification, it is 
important to account for cooperative effects, which is only possible through proper sampling designs.

Previous studies used different approaches to sample and compare certified and non-certified farmers. Some compared certified farmers that are organized in a cooperative with non-certified farmers that are not member of a cooperative (Becchetti et al., 2013). In that case it is not possible to disentangle certification effects from possible cooperative effects, as cooperative membership and certification are perfectly correlated. Other studies compared farmers in a certified cooperative with farmers in a non-certified cooperative (van Rijsbergen et al., 2016), or they compared observations from a few certified and non-certified cooperatives (Akoyi \& Maertens, 2018; Haggar et al., 2017; Ibanez \& Blackman, 2016; Jena et al., 2012; Mitiku et al., 2017; Ssebunya et al., 2018). While this has clear advantages, bias through cooperative effects can still occur, because cooperatives differ in terms of how they are endowed and how well they function, which may affect outcomes irrespective of certification. A few studies included certified and non-certified farmers from the same cooperative (Chiputwa \& Qaim, 2016; Meemken et al., 2017). While this is a neat approach to control for cooperative effects, it is rarely possible to sample in this way, because in most cases all farmers belonging to the same cooperative are either certified or not certified. ${ }^{3}$ In all cases, the number of sampled cooperatives was small, and the few cooperatives included were not selected randomly. Without random selection of cooperatives, external validity may suffer, especially when the criteria for selecting cooperatives are not well explained. For instance, it is possible that sustainability standards have beneficial effects for farmers in cooperatives with very specific characteristics, but that these results are not representative for cooperatives on average. We are not aware of previous studies that were able to properly control for cooperative effects. ${ }^{4}$ This is a major drawback, as sustainability standards are strongly promoted by various types of public and private sector organizations (Dragusanu et al., 2014; Meemken et al., 2019). Hence, it is important to better understand whether standards actually deliver on their promise to help smallholder farmers.

Here, we contribute to the literature by using a sampling design that better accounts for the institutional heterogeneity in agricultural cooperatives. In particular, we collected data from certified and non-certified farmers in a large number of randomly selected cocoa cooperatives

\footnotetext{
${ }^{3}$ Exceptions can occur in large cooperatives where certification is sometimes implemented only for subgroups of the total membership. However, such comparisons within the same cooperative can suffer from limited external validity, unless a larger number of cooperatives is included.

${ }^{4}$ Recent studies with panel data, such as Meemken et al. (2017) and van Rijsbergen et al. (2016), improved the identification of certification effects by better controlling for unobserved heterogeneity at the household level, but not at the cooperative level.
} 
in Côte d'Ivoire, West Africa, to analyze the effects of Fairtrade certification. As our sample includes cooperatives with a broad range of characteristics, we reduce the possibility that the results only hold under very specific institutional conditions. In other words, our sampling design increases external validity. Moreover, by comparing results with and without controlling for cooperative characteristics we can test to what extent ignoring institutional heterogeneity can lead to omitted variable bias.

Côte d'Ivoire is the largest cocoa-producing country in the world with a global production share of over $40 \%$ (ICCO, 2018). As in other tropical countries, the role of sustainability standards has grown substantially in the Ivorian cocoa sector, with Fairtrade being the most important standard in terms of the number of certified cooperatives and farmers. The aim of Fairtrade is to improve the livelihoods of smallholder producers (Fairtrade, 2019b). If a cooperative wants to be certified, it has to hand in an application and is physically inspected against the Fairtrade standards, which involve certain rules on labor conditions and agricultural practices, as well as recommendations for capacity building and community development (Chiputwa et al., 2015). Fairtrade certification guarantees producers a minimum floor price (for the quantities sold in certified markets) and a Fairtrade premium that is paid to the cooperative to support collective services, such as input supply, agricultural extension, or other cooperative activities. We hypothesize that Fairtrade certification has positive effects on cocoa yields, prices, and living standards of smallholder farm households. Furthermore, we hypothesize that cooperative characteristics are jointly correlated with certification and the outcome variables, so that not controlling for cooperative characteristics leads to omitted variable bias.

\subsection{Materials and methods}

\subsubsection{Sampling design}

Our survey of cocoa cooperatives and farmers was conducted in the Southeast of Côte d'Ivoire, covering the country's traditional cocoa belt. Most of the cocoa farmers in this region are members of cooperatives, which provide inputs and other agricultural services to farmers and through which the cocoa is marketed (Foundjem-Tita et al., 2017). Farmers sell their cocoa directly to the cooperatives that they are members of; side-selling to other traders or middlemen is rare in this region. Important to note is that farmers can choose which cooperative to join, meaning that membership is not determined by geographic location alone. Farmers may decide which cooperative to join based on expected costs and benefits. If a chosen cooperative does 
not meet the expectations, farmers are free to leave and join a different cooperative operating in their vicinity. ${ }^{5}$ However, the benefits of membership are not always easy to observe, especially when they relate to parameters other than output price, such as cooperative services in input supply and technical training. In this context, kinship and existing social ties are also important criteria for farmers when they decide which cooperative to join.

In order to capture a wide range of institutional heterogeneity, we randomly sampled 50 cooperatives in the Southeast of Côte d'Ivoire, differentiating between Fairtrade certified and non-certified cooperatives. For the sampling procedure, we first compiled complete lists of all active cocoa cooperatives in this part of the country, using official national registries (MADR, 2017) as well as data and information from Fairtrade and regional extension offices. We also called all listed cooperative headquarters to verify that the cooperative is active and to identify additional cooperatives that might have been missed on the official lists. The final list included 59 Fairtrade certified cooperatives and 74 non-certified cooperatives located in three districts of Southeast Côte d'Ivoire, namely Comoe, Lacs, and Lagunes. From this list we randomly selected 25 certified and 25 non-certified cooperatives. Among the 25 Fairtrade certified cooperatives, 16 were additionally certified under UTZ or Rainforest Alliance. We will test for the effect of these other standards in a robustness check. All 25 cooperatives that were sampled as "non-certified" were not certified under any sustainability standard.

In Côte d'Ivoire, cooperatives are organized in sections, which are non-legal geographic groupings that can comprise one or several villages. All cooperatives provided us complete membership lists by section. In small cooperatives with only one section, we randomly selected 10 farmers in that section. However, most of the cooperatives had more than one section. In those cases, we first randomly selected two sections in each cooperative, and then randomly selected five farmers in each section. Hence, in total we sampled 500 farmers from the 50 cooperatives: 250 that are Fairtrade certified and 250 that are non-certified. ${ }^{6}$ The locations of the sample farmers are shown in the map in Figure 1. In all three districts, there are overlaps of certified and non-certified cooperatives, meaning that certification is not perfectly correlated with regional characteristics, which is an advantage for the evaluation of certification effects.

\footnotetext{
${ }^{5}$ While geographical closeness to the cooperative headquarters is not a precondition to join, long distances are impracticable to deliver the cocoa and benefit from cooperative services.

${ }^{6}$ Power calculations had indicated that a sample with 500 observations and 50 cooperatives (half in treatment, half in control) is sufficient to identify a $10 \%$ treatment effect for yield and living standard at a confidence level of $95 \%$ and a power of $80 \%$. For cocoa price, even a $1 \%$ effect could be identified with this sample size due to the small observed standard deviation for price in Cote d'Ivoire.
} 
Moreover, Table A1 in the Appendix shows that the three districts are very similar in terms of average climate and soil conditions.

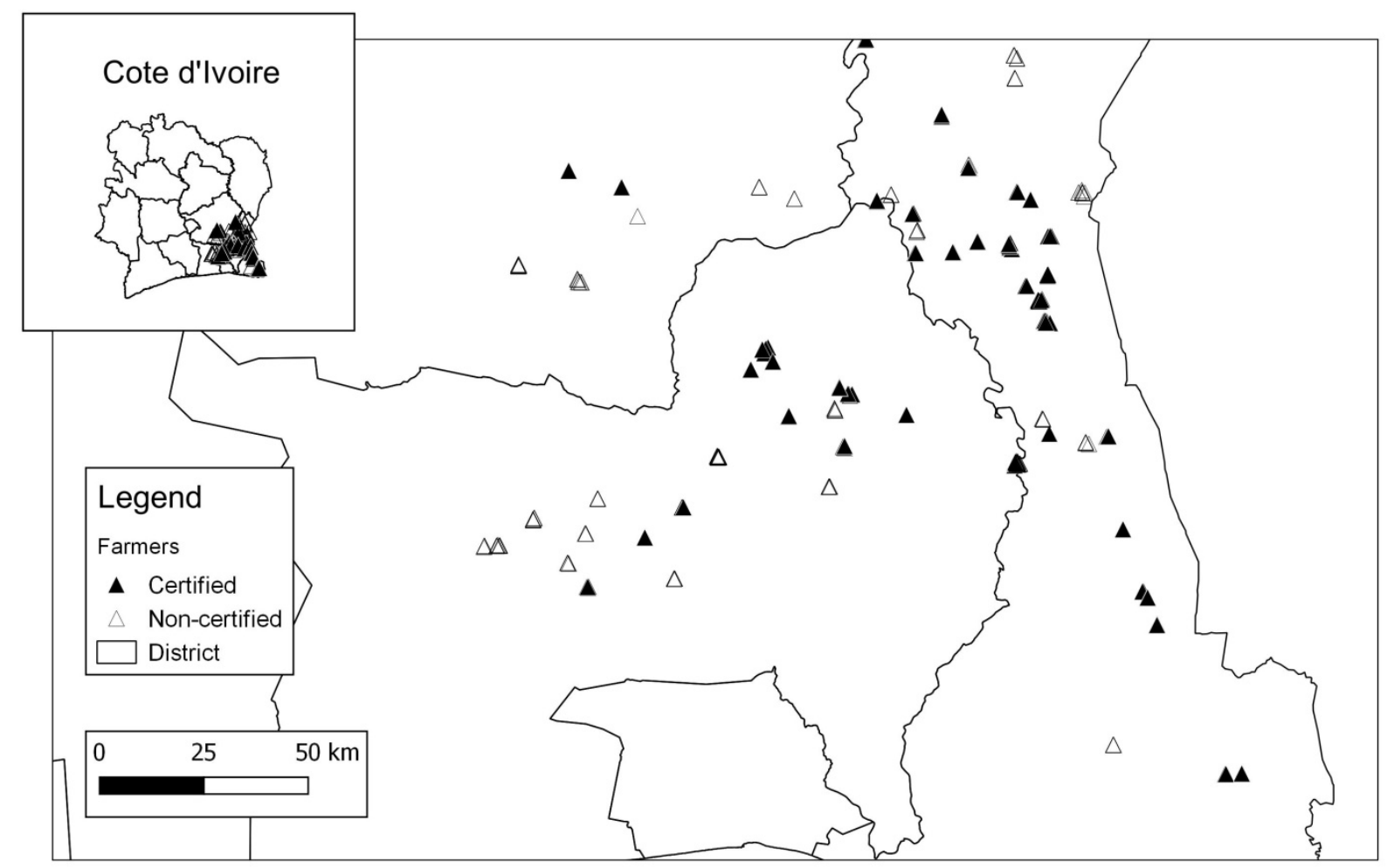

Figure 1. Geographical distribution of sampled farmers by certification status.

\subsubsection{Survey}

All sampled farm households were visited for a personal interview using a structured questionnaire designed and pre-tested for this purpose. The questionnaire was programmed with ODK (Open Data Kit) for use with tablet computers. The interviews were conducted by local enumerators who were carefully trained and supervised by the researchers. The questionnaire included sections on general household characteristics, asset ownership, production and marketing of cocoa and other agricultural activities, non-agricultural economic activities, as well as infrastructure and institutional details. To capture household living standards, we asked for details of food and non-food consumption expenditures (including consumption of ownproduced goods). The interviews were conducted with the household head. For the part on food consumption, the person in the household responsible for food purchases and food preparation was additionally asked to join the interview.

In addition to the household interviews, we also designed a cooperative-level questionnaire for interviews with the cooperative leader (director, president, or vice president) in each of the 50 
cooperatives. The cooperative questionnaire captured data on personal characteristics of the leader and detailed information on the cooperative's size, governance structure, asset ownership, service provision, sustainability certification, operational costs, and cocoa commercialization for the last 12 months prior to the interview. The farm household and cooperative-level interviews were conducted in May and June 2018.

\subsubsection{Outcome variables}

We want to analyze the effects of Fairtrade certification on cocoa yields, prices, and farm household living standards. Cocoa yields are measured in $\mathrm{kg}$ harvested per ha during the 12 months prior to the survey, as reported by farmers during the interviews. As Fairtrade encourages agricultural training and the adoption of better agricultural practices (Fairtrade, 2017), and the Fairtrade premium can be used by cooperatives to provide inputs and other services to their members (Loconto et al., 2019; Meemken \& Qaim, 2018b), we expect certification to have a positive effect on yield.

Cocoa prices are measured in West African Francs (CFA) per kg. Farmers deliver their cocoa to the cooperative and receive a price that is set by the government independent of product quality. All farmers receive this fixed price at the time of delivery. Later on, certain additional payments can be made by the cooperative based on dividends from selling in certified markets or other types of profits made by better-performing cooperatives (Meemken et al., 2019). Our price calculations include these additional payments per $\mathrm{kg}$ of cocoa on top of the base price that is set by the government. Given that certified cooperatives often use the Fairtrade premium to make direct payments to their members (Chiputwa et al., 2015; Loconto et al., 2019), we expect certification to have a positive effect on cocoa prices.

Household living standard is measured in terms of consumption expenditure expressed in CFA per capita and day. Consumption expenditure is a widely used indicator of household welfare and living standard in the development economics literature (Klasen, 2000). We calculate expenditure as the value of all food and non-food goods and services consumed by the household for specified recall periods. Food consumption was captured through a 7-day recall, covering all food items consumed by the household regardless of whether these were purchased, home-produced, or obtained from other sources. For non-food goods and services, we used 30day or 12-month recall periods, depending on the particular items considered and typical expenditure patterns. We asked about expenditures for housing, education, clothing, 
transportation, healthcare, fuel, entertainment, and other items relevant in the local context. As cocoa is the main source of income for most sample households, we expect that cocoa yield and price gains through Fairtrade certification will also result in positive effects on consumption expenditure, as was previously shown in other geographical contexts (Chiputwa et al., 2015; Meemken et al., 2017; Tran \& Goto, 2019).

\subsubsection{Cooperative heterogeneity and certification}

Agricultural cooperatives can be very heterogeneous in terms of their size, structure, asset ownership, capacity of the leadership, decision-making rules, types of services provided, and various other characteristics. This is also true for cocoa cooperatives in Côte d'Ivoire. Many of these cooperative characteristics may jointly influence farm and household-level outcomes and also whether or not a cooperative is certified. Hence, not controlling for cooperative characteristics in the impact evaluation may possibly lead to omitted variable bias. To test and control for such bias, we consider a set of cooperative-level variables for which data were obtained through the cooperative leadership survey. In particular, we consider the age and the size of the cooperative, the education level of the leader, whether or not the leader grows cocoa himself/herself, as well as the number of vehicles owned centrally as a proxy of physical capital. In addition, we look at the number of agricultural service providers (inputs, training, etc.) to the cooperative and the share of cooperative decisions made democratically.

We also collected data for various other cooperative-level variables, many of which proved to be closely correlated with the mentioned ones. Hence, we feel that the chosen set of cooperative characteristics captures the existing institutional heterogeneity quite comprehensively. One aspect that is important to note is that cooperative characteristics cannot only influence certification, but can also be influenced by certification. For instance, cooperatives may grow in size after certification through new members entering, or they may intensify their membership services. We tried to define and measure the cooperative variables in such a way that issues of reverse causality are reduced. For instance, we consider cooperative size at the time prior to certification and measure the number of service providers rather than service intensity. Nevertheless, reverse causality for some of the cooperative characteristics cannot be ruled out completely, which should be kept in mind when interpreting the results. 


\subsubsection{Regression models}

In order to evaluate the effects of Fairtrade certification, we estimate regression models of the following type:

$$
Y_{i j k}=\alpha+\beta F T_{j k}+\gamma \boldsymbol{X}_{i j k}+\theta \boldsymbol{D}_{k}+\varepsilon_{i j k}
$$

where $Y_{i j k}$ is the outcome variable of interest (yield, price, consumption expenditure) for household $i$ in cooperative $j$ and district $k . \boldsymbol{X}_{\boldsymbol{i j k}}$ is a vector of household-level control variables, $F T_{j k}$ is a dummy variable that indicates whether or not cooperative $j$ is Fairtrade certified, and $\boldsymbol{D}_{\boldsymbol{k}}$ is a set of district dummies. Even though the three districts are very similar in terms of agroecological conditions, district dummies capture possible differences in terms of infrastructure, market access, and other possible regional factors. $\varepsilon_{i j k}$ is a random error term. For the estimates, standard errors are clustered at the cooperative level.

For the cocoa yield and price models, equation (1) is estimated in linear form. For the consumption expenditure model, the dependent variable is log-transformed due to its skewed distribution. Of particular interest in all models is the coefficient $\beta$. If our hypotheses are true and Fairtrade has positive effects on cocoa yields, prices, and consumption expenditures, this should be reflected in $\gamma$ being positive and statistically significant.

Equation (1) is estimated without controlling for cooperative characteristics. However, as mentioned above, cooperative characteristics may be jointly correlated with $Y_{i j k}$ and $F T_{j k}$, which may lead to omitted variable bias in the estimate of $\beta$. Therefore, in a second set of regressions we estimate models of the following type:

$$
Y_{i j k}=\alpha+\beta F T_{j k}+\gamma \boldsymbol{X}_{i j k}+\theta \boldsymbol{D}_{k}+\delta \boldsymbol{W}_{j k}+\varepsilon_{i j k}
$$

where $\boldsymbol{W}_{\boldsymbol{j} \boldsymbol{k}}$ is a vector of cooperative characteristics, and the other variables are as defined before. Here, we are not particularly interested in the estimate for $\delta$, as our intention is not to analyze the role of cooperative characteristics for farm performance and household welfare per $s e$. Rather, we are interested in whether or not the effects of Fairtrade certification $(\gamma)$ remain positive and significant also after controlling for cooperative characteristics. Comparing the estimates for $\gamma$ in equations (1) and (2) can furthermore provide an indication of the direction of bias when not controlling for cooperative characteristics. If $\gamma$ in equation (2) is smaller than in equation (1), this would indicate that better-endowed or better-performing cooperatives 
benefit more from certification than less-endowed cooperatives, so that the certification effect in equation (1) would be overestimated. ${ }^{7}$

\subsubsection{Dealing with endogeneity}

As cooperatives choose whether or not they apply for Fairtrade certification, and farmers choose the cooperative they want to be member of (i.e., they choose if they want to be member of a certified cooperative), $F T_{j k}$ in equations (1) and (2) may be endogenous, which could lead to biased estimates of $\beta$. The most likely source of endogeneity is unobserved heterogeneity, although reverse causality can also not be ruled out without additional tests. Inclusion of cooperative characteristics in equation (2) may reduce issues of unobserved heterogeneity at the cooperative level. At the farmer level, in addition to standard control variables - such as total land owned, education, age, and market access - we also include measures of farmers' risk aversion (Dohmen et al., 2011) and trust (Naef \& Schupp, 2009) that may proxy for unobserved factors related to personality.

In addition to including a broad set of control variables, we also use an instrumental variable (IV) approach to test and control for endogeneity. This requires finding at least one exogenous instrument that is correlated with Fairtrade certification but does not influence the outcome variables through other mechanisms. We use two instruments. The first instrument is the cellphone network provider of the leader in the cooperative that the particular farmer is member of. The second instrument is the share of Fairtrade certified farmers in a specified neighborhood radius around the respective farmer himself/herself. Both instruments are explained and tested for validity below.

There are three cellphone network providers in the study region - namely Orange, MTN, and Moov - that all offer similar services at similar costs. For the individual, the choice which provider to use is mainly a question of the strength of the network signal in the particular location and the provider that peers in the own social network use. Positive network externalities occur because all three phone providers offer price discounts for calls and text messages exchanged within the provider's network (Meemken et al., 2019). Hence, it is fair to assume that more information is exchanged within one network than across the networks of different

\footnotetext{
${ }^{7}$ As mentioned, several of the Fairtrade certified cooperatives are also certified under UTZ and/or Rainforest Alliance. To test whether these other sustainability standards have additional effects, or change the effects of Fairtrade, we carry out a robustness check where the models in equation (2) are re-estimated with an additional dummy to control for double or triple certification.
} 
providers. Our data show a significantly positive correlation between the cooperative leader using Orange and the cooperative and individual farmer of interest being Fairtrade certified (Table A2 in the Appendix). ${ }^{8}$ We attribute this to informal flows of information about Fairtrade that are more intense among people using Orange than among people using other cellphone providers. And better access to information about Fairtrade increases the likelihood of certification. In principle, causality could also run in the opposite direction, meaning that Fairtrade certification would affect the choice of which phone provider to use. However, this is unlikely in our case, as people do not seem to switch their phone provider frequently. Out of the 25 leaders of certified cooperatives in our sample, only three stated that they had switched their phone provider during the last few years, after their cooperative became certified.

The second instrument, the share of certified neighbors in a $5 \mathrm{~km}$ radius around each farmer, was calculated using GPS data. ${ }^{9}$ The instrument also captures social network effects, as farmers located closer to several certified farmers are more likely to learn about certification and its possible advantages. Even though farmers cannot get Fairtrade certified individually, they can decide to join (or leave) a Fairtrade certified cooperative, as discussed above. As one would expect, our data show a positive and significant correlation between the share of certified farmers in the neighborhood and own certification (Table A2). Hence, both instruments pass the test of instrument relevance. ${ }^{10}$

For the instruments to be valid it is also required that they are both not correlated with the outcome variables. Due to some geographic clustering of Fairtrade cooperatives and farmers, it is generally possible that these "Fairtrade" settings have stronger economic activities, better flows of information, or more favorable access to infrastructure and markets. It is also possible that farmers benefit from the agricultural knowledge of their certified neighbors through farmerto-farmer exchange, even when they are not certified themselves. However, the map in figure 1 shows that the geographic clustering of certified and non-certified farmers is not very pronounced. Moreover, in the models we control for regional effects through district dummies and variables measuring the distance to roads and other infrastructure elements. Using the falsification test proposed by Di Falco et al. (2011), we show that both instruments do not

\footnotetext{
${ }^{8}$ In some cases, cooperative leaders used more than one network provider. In those cases, we asked to specify the main provider that they use for most of their cellphone calls and text messages.

${ }^{9} \mathrm{We}$ also tested smaller $(2 \mathrm{~km})$ and larger $(10 \mathrm{~km})$ radii to construct the instrument with very similar results.

10 The share of certified farmers is more strongly correlated with own certification than the cellphone network provider of the cooperative leader (Table A2), so our IV approach primarily controls for farmer-level heterogeneity. Cooperative-level heterogeneity is controlled for through the inclusion of cooperative characteristics in equation (2).
} 
influence cocoa yields, prices, and household consumption expenditures through mechanisms other than certification (Table A3 in the Appendix). In addition, we verified that both instruments are not significantly correlated with other regional variables that could affect household welfare, such as distance to schools, distance to roads, or average rainfall in a location (Table A4 in the Appendix). Finally, as we have two instruments for one endogenous variable, we performed formal tests of the over-identifying restriction (Tables A5-A7 in the Appendix). The null hypothesis that the instruments are uncorrelated with the error term cannot be rejected in any of the models. Hence, we conclude that the two instruments are valid.

\subsection{Results and discussion}

\subsubsection{Household characteristics}

General descriptive statistics for the set of socioeconomic variables that we use as householdlevel controls in the regression models are shown in Table A8 in the Appendix. The two groups of certified and non-certified farmers are very similar in terms of most variables, including total land owned, household size, farmer's age, and education.

More notable differences between Fairtrade certified and non-certified farmers are observed for the outcome variables, which are shown in Table 1. We see statistically significant differences for all three outcome variables. Mean cocoa yields are around $540 \mathrm{~kg} / \mathrm{ha}$, which is similar to other recent yield estimates for cocoa in Côte d'Ivoire (Wessel \& Quist-Wessel, 2015). Cocoa yields of Fairtrade certified farmers are around 13\% higher than those of non-certified farmers. Fairtrade farmers also obtain higher prices for their cocoa, with a $4 \%$ difference on average. While this price difference is small in magnitude, certification seems to be one of the few opportunities to achieve a significant price markup at all. As mentioned, in Côte d'Ivoire the base price is fixed by the government without any quality differentiation. At the time of the survey, the government price was set at $700 \mathrm{CFA} / \mathrm{kg}$. 
Table 1. Descriptive statistics for outcome variables and poverty incidence by certification status

\begin{tabular}{|c|c|c|c|c|}
\hline & $\begin{array}{c}\text { (1) } \\
\text { Full sample }\end{array}$ & $\begin{array}{c}\text { (2) } \\
\text { Certified }\end{array}$ & $\begin{array}{c}\text { (3) } \\
\text { Non-certified }\end{array}$ & $\begin{array}{c}\text { (4) } \\
\text { Mean } \\
\text { difference }\end{array}$ \\
\hline Cocoa yield (kg/ha) & $\begin{array}{c}540.31 \\
(250.36)\end{array}$ & $\begin{array}{c}573.58 \\
(265.70)\end{array}$ & $\begin{array}{c}507.03 \\
(229.76)\end{array}$ & $66.55^{* * *}$ \\
\hline Cocoa price (CFA/kg) & $\begin{array}{l}717.34 \\
(39.69)\end{array}$ & $\begin{array}{l}731.04 \\
(46.13)\end{array}$ & $\begin{array}{l}703.20 \\
(24.82)\end{array}$ & $27.84^{* * *}$ \\
\hline Consumption expenditure (CFA/capita) & $\begin{array}{l}1074.64 \\
(901.43)\end{array}$ & $\begin{array}{l}1173.04 \\
(974.47)\end{array}$ & $\begin{array}{c}976.24 \\
(812.03)\end{array}$ & $196.80^{* *}$ \\
\hline Below poverty line $(1 / 0)$ & $\begin{array}{c}0.45 \\
(0.50)\end{array}$ & $\begin{array}{c}0.37 \\
(0.48)\end{array}$ & $\begin{array}{c}0.52 \\
(0.50)\end{array}$ & $-0.15^{* * *}$ \\
\hline Observations & 500 & 250 & 250 & 500 \\
\hline
\end{tabular}

Note: Mean values are shown with standard deviations in parentheses. $* \mathrm{p}<0.1,{ }^{*} \mathrm{p}<0.05, * * * \mathrm{p}<0.01$

Finally, we also observe a difference of around $20 \%$ in per capita consumption expenditures between Fairtrade certified and non-certified households. For both groups, mean expenditures are above the national poverty line of 737 CFA per capita and day (World Bank, 2018). Nevertheless, $45 \%$ of the farm households live below the poverty line, with poverty rates being significantly higher in the group of non-certified households (Table 1).

\subsubsection{Cooperative characteristic}

Table 2 shows descriptive statistics for the cooperative characteristics, also differentiating by certification status. The average cocoa cooperative is around 8 years old and has more than 400 members. Fairtrade certified cooperatives are significantly older than non-certified cooperatives. Certified cooperatives also have better educated leaders, own more physical assets, and have more providers of services to their members. In terms of democratic decisionmaking, no statistically significant differences are observed. Noteworthy in Table 2 are also the relatively large standard deviations for several of the cooperative characteristics. Large standard deviations imply considerable institutional heterogeneity within and across groups, which cannot be captured when only sampling from a small number of cooperatives, as previous studies did. 
Table 2. Descriptive statistics for cooperative characteristics by certification status

\begin{tabular}{|c|c|c|c|c|}
\hline & $\begin{array}{c}\text { (1) } \\
\text { Full sample }\end{array}$ & $\begin{array}{c}(2) \\
\text { Certified }\end{array}$ & $\begin{array}{c}(3) \\
\text { Non- } \\
\text { certified }\end{array}$ & $\begin{array}{c}\text { (4) } \\
\text { Mean diff. }\end{array}$ \\
\hline Age of the coop (yrs.) & $\begin{array}{c}7.70 \\
(5.04)\end{array}$ & $\begin{array}{c}9.48 \\
(4.55)\end{array}$ & $\begin{array}{c}5.92 \\
(4.97)\end{array}$ & $3.56^{* *}$ \\
\hline Coop members before certification (number) & $\begin{array}{c}420.12 \\
(399.42)\end{array}$ & $\begin{array}{c}511.28 \\
(533.55)\end{array}$ & $\begin{array}{c}328.96 \\
(154.04)\end{array}$ & 182.32 \\
\hline Share of decisions made democratically & $\begin{array}{c}0.39 \\
(0.15)\end{array}$ & $\begin{array}{c}0.41 \\
(0.16)\end{array}$ & $\begin{array}{c}0.37 \\
(0.13)\end{array}$ & 0.04 \\
\hline Education of coop leader (yrs.) & $\begin{array}{l}14.34 \\
(3.13)\end{array}$ & $\begin{array}{l}15.60 \\
(2.78)\end{array}$ & $\begin{array}{l}13.08 \\
(2.98)\end{array}$ & $2.52^{* * *}$ \\
\hline Leader grows cocoa $(1 / 0)$ & $\begin{array}{c}0.72 \\
(0.45)\end{array}$ & $\begin{array}{c}0.56 \\
(0.51)\end{array}$ & $\begin{array}{c}0.88 \\
(0.33)\end{array}$ & $-0.32^{* *}$ \\
\hline $\begin{array}{l}\text { Service providers for inputs, training etc. } \\
\text { (number) }\end{array}$ & $\begin{array}{c}1.56 \\
(1.49)\end{array}$ & $\begin{array}{c}2.24 \\
(1.45)\end{array}$ & $\begin{array}{c}0.88 \\
(1.20)\end{array}$ & $1.36^{* * *}$ \\
\hline Coop vehicles (number) & $\begin{array}{c}5.00 \\
(6.03) \\
\end{array}$ & $\begin{array}{c}8.48 \\
(6.85) \\
\end{array}$ & $\begin{array}{c}1.52 \\
(1.48)\end{array}$ & $6.96^{* * *}$ \\
\hline Observations & 50 & 25 & 25 & 50 \\
\hline
\end{tabular}

Note: Mean values are shown with standard deviations in parentheses. ${ }^{*} p<0.1,{ }^{* *} p<0.05,{ }^{* * *} p<0.01$

The comparison between certified and non-certified cooperatives in Table 2 suggests that several of the cooperative characteristics are correlated with Fairtrade certification. This is confirmed in column (1) of Table 3. As the cooperative characteristics are not normally distributed, we show Spearman's correlation coefficients. Certification is positively and significantly correlated with the age of the cooperative, the education of the leader, physical capital, and the number of service providers, and it is negatively and significantly correlated with the leader of the cooperative growing cocoa himself/herself. At the same time, several of the cooperative characteristics are also significantly correlated with the outcome variables cocoa yield, price, and consumption expenditure - as is shown in columns (2) to (4) of Table 3. This joint correlation means that the estimated effects of certification on the outcome variables may be biased when not controlling for cooperative characteristics. 
Table 3. Correlation between cooperative characteristics, certification status, and outcome variables

\begin{tabular}{|c|c|c|c|c|}
\hline Cooperative characteristics & $\begin{array}{c}(1) \\
\text { Certified }^{a}\end{array}$ & $\begin{array}{c}(2) \\
\text { Yield }\end{array}$ & $\begin{array}{c}(3) \\
\text { Price }\end{array}$ & $\begin{array}{c}\text { (4) } \\
\text { Expenditure }\end{array}$ \\
\hline Age of the coop (yrs.) & $\begin{array}{c}0.421^{* * *} \\
(0.002)\end{array}$ & $\begin{array}{c}0.052 \\
(0.245)\end{array}$ & $\begin{array}{l}0.351^{* * *} \\
(0.000)\end{array}$ & $\begin{array}{c}-0.047 \\
(0.299)\end{array}$ \\
\hline Coop members before certification (number) & $\begin{array}{c}0.115 \\
(0.426)\end{array}$ & $\begin{array}{c}-0.107^{* *} \\
(0.016)\end{array}$ & $\begin{array}{l}-0.052 \\
(0.249)\end{array}$ & $\begin{array}{l}-0.090^{* * *} \\
(0.045)\end{array}$ \\
\hline Share of decisions made democratically & $\begin{array}{c}0.227 \\
(0.113)\end{array}$ & $\begin{array}{l}-0.026 \\
(0.555)\end{array}$ & $\begin{array}{l}0.281^{* * *} \\
(0.000)\end{array}$ & $\begin{array}{c}0.137^{* * *} \\
(0.002)\end{array}$ \\
\hline Education of coop leader (yrs.) & $\begin{array}{l}0.445^{* * *} \\
(0.001)\end{array}$ & $\begin{array}{l}-0.002 \\
(0.972)\end{array}$ & $\begin{array}{l}0.129^{* * *} \\
(0.004)\end{array}$ & $\begin{array}{l}0.139^{* * *} \\
(0.002)\end{array}$ \\
\hline Leader grows cocoa $(1 / 0)$ & $\begin{array}{c}-0.356^{* *} \\
(0.011)\end{array}$ & $\begin{array}{c}0.072 \\
(0.107)\end{array}$ & $\begin{array}{c}-0.098^{* *} \\
(0.029)\end{array}$ & $\begin{array}{l}-0.047 \\
(0.292)\end{array}$ \\
\hline $\begin{array}{l}\text { Service providers for inputs, training etc. } \\
\text { (number) }\end{array}$ & $\begin{array}{l}0.517^{* * *} \\
(0.000)\end{array}$ & $\begin{array}{c}0.012 \\
(0.796)\end{array}$ & $\begin{array}{l}0.437^{* * *} \\
(0.000)\end{array}$ & $\begin{array}{l}0.168^{* * *} \\
(0.000)\end{array}$ \\
\hline Coop vehicles (number) & $\begin{array}{l}0.673^{* * *} \\
(0.000)\end{array}$ & $\begin{array}{c}0.066 \\
(0.142) \\
\end{array}$ & $\begin{array}{l}0.471^{* * *} \\
(0.000)\end{array}$ & $\begin{array}{l}0.133^{* * *} \\
(0.003)\end{array}$ \\
\hline Observations & 50 & 500 & 490 & 500 \\
\hline
\end{tabular}

Note: Spearman's correlation coefficients are shown with $p$-values in parentheses. $* p<0.1, * * p<0.05,{ }^{* * *} p<0.01$

${ }^{\text {a }}$ Correlations in this column calculated at the cooperative level.

\subsubsection{Regression results}

Full results of the regression models to estimate the effects of Fairtrade certification on cocoa yield, prices, and per capita consumption expenditure - obtained with OLS and IV estimators are shown in Tables A5-A7 in the Appendix. We show specifications with and without controlling for cooperative characteristics. For all models, the Hausman test indicates that the OLS and IV estimates do not differ significantly, so that the OLS estimates also seem to be consistent (and more efficient than the IV estimates).

The estimated effects of Fairtrade certification on the three outcome variables are summarized in Table 4. Columns (1) and (2) show effects without controlling for cooperative characteristics. The IV estimates suggest that certification increases cocoa yield by $70 \mathrm{~kg} / \mathrm{ha}$, which is a gain of $14 \%$ compared to the mean yield of non-certified farmers. This yield effect can be explained by certified cooperatives offering more services to their members, thus improving farmers' access to agricultural inputs, information, and training. Large yield-increasing effects through Fairtrade certification were also shown in a few previous studies (Jena et al., 2017; van Rijsbergen et al., 2016). Other studies that analyzed effects of Fairtrade-Organic double certification found no effects on yield (Jena et al., 2012; Mitiku et al., 2017), or even negative effects (Vanderhaegen et al., 2018), probably because Organic prohibits the use of yieldincreasing chemical inputs. 
Fairtrade certification also increases the average cocoa price that farmers receive by about 29 $\mathrm{CFA} / \mathrm{kg}$, equivalent to a gain of $4 \%$ over the mean price received by non-certified farmers. As mentioned, Fairtrade certification seems to be one of the few opportunities for cocoa farmers in Côte d'Ivoire to achieve a price higher than the government-fixed price at all. Finally, Fairtrade certification has a significantly positive effect on per capita consumption expenditure, raising household living standards by $18 \%$. This gain in living standard reflects the combined effects of both higher cocoa yields and higher prices.

Table 4. Effect of Fairtrade certification on outcome variables

\begin{tabular}{lcccc}
\hline & \multicolumn{2}{c}{$\begin{array}{c}\text { Not controlling for cooperative } \\
\text { characteristics }\end{array}$} & \multicolumn{2}{c}{$\begin{array}{c}\text { Controlling for cooperative } \\
\text { characteristics }\end{array}$} \\
\cline { 2 - 5 } Outcome variables & $(1)$ & $(2)$ & $(3)$ & $(4)$ \\
& OLS & IV & $11.75^{* * *}$ & $106.61^{* *}$ \\
\hline Cocoa yield $(\mathrm{kg} / \mathrm{ha})$ & $63.32^{* *}$ & $69.60^{* *}$ & $(37.27)$ & $(49.66)$ \\
& $(27.20)$ & $(35.27)$ & $22.11^{* * *}$ & $25.18^{* * *}$ \\
Cocoa price (CFA/kg) & $26.52^{* * *}$ & $29.27^{* * *}$ & $(3.38)$ & $(3.69)$ \\
Per capita consumption expenditure $(\log )$ & $(3.86)$ & $(4.23)$ & $0.15^{*}$ & 0.13 \\
& $0.14^{*}$ & $0.17^{*}$ & $(0.08)$ & $(0.10)$ \\
\hline Household controls included & $(0.08)$ & $(0.09)$ & Yes & Yes \\
Cooperative controls included & Yes & Yes & Yes & Yes \\
\hline
\end{tabular}

Note: Coefficient estimates for the effect of Fairtrade certification (1/0) are shown with cluster robust standard errors in parentheses. Separate models were estimated for each of the three outcome variables. Yield and per capita consumption expenditure models were estimated with 500 observations; price models were estimated with 490 observations. Full model results are shown in Tables A5-A7 in the Appendix. ${ }^{*} p<0.1,{ }^{* *}$ $p<0.05,{ }^{* * *} p<0.01$

Columns (3) and (4) of Table 4 show the effects of Fairtrade certification with the cooperative characteristics included as additional controls. The first important result of these alternative model estimates is that certification has positive and significant effects also after controlling for cooperative characteristics. That is, the benefits of Fairtrade certification for farmers are not solely driven by certified cooperatives being systematically different from non-certified cooperatives. This is an important result, as previous research on Fairtrade was not able to disentangle certification effects from cooperative effects.

The second important result of these alternative specifications is that some of the estimates in columns (3) and (4) are notably different from those in columns (1) and (2) of Table 4. This means that the estimates in columns (1) and (2) suffer from omitted variable bias, as expected, given the joint correlation of cooperative characteristics with certification and the outcome variables. More surprising may be the direction of the bias. For cocoa yield, the effects increase after controlling for cooperative characteristics. Interpreting the IV estimates, the yield gain increases from $70 \mathrm{~kg} / \mathrm{ha} \mathrm{(14 \% )} \mathrm{in} \mathrm{column} \mathrm{(2)} \mathrm{to} 107 \mathrm{~kg} / \mathrm{ha}(21 \%)$ in column (4). This implies that farmers in cooperatives with less favorable initial conditions (physical capital, leadership 
education, service providers, etc.) actually benefit more from certification than farmers in cooperatives with more favorable initial conditions. One could have expected the opposite, namely that farmers in better-endowed cooperatives would benefit over-proportionally from certification. However, our results are not implausible: better-endowed cooperatives are more beneficial for farmers with and without certification, but the net effect of certification seems to be larger in less-endowed cooperatives. This is a welcome finding from an equity perspective.

\subsubsection{Robustness checks}

As mentioned, several of the cooperatives that are Fairtrade certified are also certified under UTZ and/or Rainforest Alliance (RA). In the analysis so far we have ignored such double and triple certification, so that it is not clear whether the observed effects are really due to Fairtrade alone. In order to test whether certification under one of the other standards changes the findings, we run alternative models in which we control for UTZ/RA through an additional dummy variable on top of the regular household-level and cooperative-level controls. These alternative estimates are shown in Table A9 in the Appendix, with the main results summarized in Table 5. UTZ and/or RA certification is not significant in any of the models, whereas the Fairtrade effects on all three outcome variables remain positive, significant, and in the same magnitude as in Table 4. We conclude that double or triple certification does not change our findings concerning the effects of Fairtrade.

Table 5. Effects of Fairtrade certification on outcome variables controlling for other standards

\begin{tabular}{lcccccc}
\hline & \multicolumn{2}{c}{ Cocoa yield $(\mathrm{kg} / \mathrm{ha})$} & \multicolumn{2}{c}{ Cocoa price $(\mathrm{CFA} / \mathrm{kg})$} & \multicolumn{2}{c}{$\begin{array}{c}\text { Per capita consumption } \\
\text { expenditure }(\mathrm{log})\end{array}$} \\
\cline { 2 - 7 } & $(1)$ & $(2)$ & $(3)$ & $(4)$ & $(5)$ & $(6)$ \\
& OLS & IV & OLS & IV & OLS & IV \\
\hline Fairtrade certified (1/0) & $116.92^{* * *}$ & $109.21^{* *}$ & $22.74^{* * *}$ & $25.95^{* * *}$ & $0.17^{* *}$ & 0.14 \\
& $(41.60)$ & $(54.52)$ & $(3.57)$ & $(4.32)$ & $(0.08)$ & $(0.11)$ \\
UTZ and/or RA certified (1/0) & -15.98 & -11.91 & -1.93 & -3.60 & -0.09 & -0.07 \\
& $(49.49)$ & $(49.72)$ & $(4.10)$ & $(4.76)$ & $(0.14)$ & $(0.13)$ \\
\hline Household controls included & Yes & Yes & Yes & Yes & Yes & Yes \\
Cooperative controls included & Yes & Yes & Yes & Yes & Yes & Yes \\
Observations & 500 & 500 & 490 & 490 & 500 & 500 \\
\hline
\end{tabular}

Note: Coefficient estimates are shown with cluster robust standard errors in parentheses. Full model results are shown in Table A9 in the Appendix. ${ }^{*} p<0.1,{ }^{* *} p<0.05,{ }^{* * *} p<0.01$

Given that UTZ focuses on the adoption of improved farming practices, one could have expected that controlling for UTZ would possibly reduce the effects of Fairtrade, especially on yield. However, van Rijsbergen et al. (2016) showed with data from Kenya that there is no difference in yield between farmers who are Fairtrade certified and Fairtrade-UTZ double 
certified. Chiputwa et al. (2015) used data from Uganda and also found no additional benefit when Fairtrade farmers were Fairtrade-UTZ double certified.

Another robustness check relates to possible reverse causality between the cooperative characteristics and Fairtrade certification. As mentioned, in the choice of cooperative characteristics we tried to avoid reverse causality to the extent possible. But changes in cooperative services seem to be particularly relevant for the Fairtrade effect on yield, and we included the number of service providers as one of the cooperative characteristics. We ran additional models in which we controlled for cooperative characteristics but excluded the number of service providers. These additional results, which are shown in Table A10 in the Appendix, are very similar to the ones discussed above.

\subsection{Conclusion}

In this article, we have analyzed whether Fairtrade certification has beneficial effects on smallholder farmers also when controlling for cooperative characteristics. Most of the certification for sustainability standards in the small farm sector happens through cooperatives or other types of farmer groups. Cooperatives differ in terms of their size, structure, human and physical capital endowment, and other institutional characteristics. These cooperative characteristics may influence farm productivity and income with and without certification. At the same time, they may also determine whether or not a cooperative is certified. Hence, not controlling for cooperative characteristics may lead to omitted variable bias when analyzing the net effects of certification. Previous research on the effects of Fairtrade and other sustainability standards could hardly control for cooperative characteristics. Even when using a large number of farm observations, existing studies had typically sampled these observations from only a small number of purposively selected cooperatives. We have added to the literature by using a more suitable sampling design. In particular, we randomly sampled farmers from a large number of randomly selected cooperatives. This approach has two advantages. First, it allows controlling for cooperative characteristics in the estimated impact models. Second, due to the large institutional heterogeneity that our data capture, external validity is increased. In other words, we can rule out that our results are driven by the peculiarities of a small number of cooperatives.

The empirical research has focused on the cocoa sector in Côte d'Ivoire, where large numbers of Fairtrade certified and non-certified cooperatives exist in the same regions. Regression 
models have shown that Fairtrade certification contributes to higher cocoa yields, higher cocoa prices, and higher household living standards (measured in terms of per capita consumption expenditures). The estimated benefits for farmers remain positive and significant also after controlling for cooperative characteristics. However, the magnitude of the effects differs with and without controlling for cooperative characteristics, confirming that estimates that do not account for institutional heterogeneity suffer from omitted variable bias.

Interesting is also the direction of the bias. Better-endowed cooperatives are more beneficial for member farmers than less-endowed cooperatives, which is true independent of certification. But better-endowed cooperatives are also more likely to be certified, which might mean that the benefits of certification might be overestimated when not controlling for cooperative characteristics. However, we find bias in the opposite direction, that is, the estimated effects of certification increase after controlling for cooperative characteristics. This is especially true for cocoa yield, where the effect of Fairtrade certification increases from $14 \%$ to $21 \%$ after controlling for cooperative characteristics. This unexpected effect can be explained by farmers in less-endowed cooperatives benefiting more from certification than farmers in better-endowed cooperatives, which is good news from an equity perspective and is actually quite plausible in the local context. Better-endowed cooperatives can offer more beneficial services to their members - such as input provision and training - also when not being Fairtrade certified. Hence, the additional effect of certification is smaller than in less-endowed cooperatives where an increase in service provision is possible only through the Fairtrade premium, the better prices in Fairtrade markets, and certification-related organizational support.

The result on the direction of bias may be specific to Côte d'Ivoire and should not be generalized. But the finding that cooperatives and their institutional characteristics matter, and that institutional heterogeneity deserves more explicit focus in future research on the effects of sustainability standards in the small farm sector, is certainly true also beyond the concrete study setting. Improved sampling frameworks - such as suggested here - should be used for data collection to facilitate disentangling certification effects from cooperative effects.

In closing, we mention two limitations of our study that could be addressed in follow-up research. First, while we have controlled for cooperative characteristics, we have not analyzed in more detail what particular cooperative characteristics matter most for the size and distribution of certification benefits. This could be a useful extension to better understand under what institutional conditions sustainability standards are most successful in terms of meeting 
their socioeconomic and environmental objectives. Second, cooperative characteristics influence the benefits of certification, but - on the other hand - they may also be influenced by certification. For instance, certification may lead to capital accumulation and to a higher intensity of cooperative services. While we tried to measure cooperative characteristics in a way that reduces issues of reverse causality, we cannot rule out completely that some level of endogeneity remains. Noteworthy in this connection is that - if some of the benefits of certification were channeled through changes in the variables that we used for measuring cooperative characteristics - the estimated effects of certification should decrease after controlling for cooperative characteristics. In our models, the opposite is true, namely the effects increase after controlling for cooperative characteristics. This is not a proof that issues of reverse causality do not exist, but it clearly suggests that any related bias would unlikely overturn the finding that Fairtrade certification benefits farmers also after controlling for cooperative effects. Dealing with endogeneity more rigorously would require panel data with observations of farm, household, and cooperative characteristics before and after certification. 


\title{
3. Fairtrade, agrochemical input use, and effects on human health and the environment ${ }^{11}$
}

\begin{abstract}
It is often assumed that voluntary sustainability standards - such as Fairtrade - could not only improve the socioeconomic wellbeing of smallholder farmers in developing countries but could also help to reduce negative health and environmental impacts of agricultural production. The empirical evidence is thin, as most previous studies on the impact of sustainability standards only focused on economic indicators, such as prices, yields, and incomes. Here, we argue that Fairtrade and other sustainability standards can affect agrochemical input use through various mechanisms with possible positive and negative health and environmental effects. We use data from farmers and rural workers in Cote d'Ivoire to analyze effects of Fairtrade certification on fertilizer and pesticide use, as well as on human health and environmental toxicity. Fairtrade increases chemical input quantities and aggregated levels of toxicity. Nevertheless, Fairtrade reduces the incidence of pesticide-related acute health symptoms among farmers and workers. Certified cooperatives are more likely to offer training and other services related to the safe handling of pesticides and occupational health, which can reduce negative externalities in spite of higher input quantities. These results suggest that simplistic assumptions about the health and environmental effects of sustainability standards may be inappropriate.
\end{abstract}

Key words: Agrochemicals; certification; Fairtrade; pesticides; sustainability standards; toxicity

\footnotetext{
${ }^{11}$ This chapter is published in Ecological Economics (https://doi.org/10.1016/j.ecolecon.2020.106718). It is coauthored by Eva-Marie Meemken (E.-M.M.) and Matin Qaim (M.Q.). I (J.S.) developed the research idea, conducted the data analysis, and wrote the paper. J.S., E.-M.M., and M.Q. designed the study. J.S. and E.-M.M. collected the data. E.-M.M., and M.Q. commented at the various stages of the research.
} 


\subsection{Introduction}

Global food demand will continue to grow in the coming decades with concomitant challenges for sustainable agricultural supply (Gouel \& Guimbard, 2019). In the past, several factors have contributed to growth in agricultural supply, with substantial differences across geographic regions. In many parts of the world, production increases during the last 50 years were strongly associated with a more intensive use of agrochemicals (Christiaensen, 2017; Meemken \& Qaim, 2018a). While chemical fertilizers and pesticides help to increase crop yields, their misuse can lead to soil, water, and air pollution causing serious problems for the environment and human health (Elahi et al., 2019; Li et al., 2019; Sheahan et al., 2017; Stoner \& Eitzer, 2013). Appropriate public policies can reduce negative environmental and health externalities. In addition, voluntary sustainability standards - such as Fairtrade, Organic, UTZ, or Rainforest Alliance - could potentially help, especially in developing countries where related public policies are often absent or poorly enforced.

During the last decade, voluntary sustainability standards grew in importance for all major tropical food commodities, with cocoa seeing the biggest increase in its share of certified area (Willer et al., 2019). However, to what extent sustainability standards actually deliver on their promises remains an open question (Meemken, 2020; Oya et al., 2018). Several studies analyzed effects of sustainability standards on economic indicators, such as crop yields, prices, profits, and household income (Akoyi \& Maertens, 2018; Beuchelt \& Zeller, 2011; Chiputwa et al., 2015; Jena et al., 2017; Meemken et al., 2017; Sellare, Meemken, Kouamé, et al., 2020; van Rijsbergen et al., 2016; Vanderhaegen et al., 2018). Effects on environmental and health indicators were analyzed much less.

A few studies on selected environmental effects exist for Organic standards, suggesting that Organic certification (sometimes in combination with other standards) leads to more environmentally-friendly production and decreases in the use of chemical fertilizers and pesticides (Blackman \& Naranjo, 2012b; Ibanez \& Blackman, 2016; Vanderhaegen et al., 2018). However, Organic standards have a particular focus on the environment and ban the use of any chemical inputs, which is not the case for most other sustainability standards. Hence, these effects cannot be generalized. We are aware of only two studies that analyzed effects of sustainability standards other than Organic on environmental indicators with somewhat mixed results: Vanderhaegen et al. (2018) used data from farmers in Uganda showing that UTZRainforest Alliance-4C triple certification increases the likelihood of farmers using 
agrochemicals, whereas Elder et al. (2013) used data from Rwanda concluding that Fairtrade certification has no effect on chemical input use.

We add to this existing literature by analyzing effects of Fairtrade on chemical fertilizer and pesticide use with data from farmers and rural workers in Cote d'Ivoire, the world's largest exporter of cocoa. Unlike previous studies, we do not only look at chemical input quantities, but also at toxicity by calculating the pesticide environmental impact quotient (EIQ) and the hazard quotient (HQ). In addition, we evaluate effects of Fairtrade on pesticide-related health symptoms as reported by farmers and rural workers, similar to the approach used by Asfaw et al. (2010) in their analysis of the health effects of GlobalGAP certification in Kenya.

While less stringent than Organic, Fairtrade involves certain regulations and measures to reduce negative environmental and health effects of agrochemicals. For instance, certain types of toxic pesticides are banned (Fairtrade, 2014, 2019a). At the same time, it is possible that Fairtrade increases agrochemical input use through price incentives, agricultural extension, and other services often provided by Fairtrade-certified cooperatives. Which of these effects dominates is an important question that we address empirically with our data from Cote d'Ivoire. Most previous studies on the effects of sustainability standards used data from only a small number of purposively selected cooperatives. We use data from 50 randomly selected cooperatives, which facilitates the analysis of cooperative-level mechanisms and also adds to external validity. Possible issues of endogeneity in the impact evaluation are addressed through instrumental variable approaches.

\subsection{Fairtrade and agrochemical input use}

It is often assumed that Fairtrade and other sustainability standards lead to reductions in the use of chemical fertilizers and pesticides, but this is not necessarily true in every situation. In fact, there are various mechanisms through which Fairtrade could affect the use of agrochemical inputs and their effects on human health and the environment. In this section, we briefly discuss the different mechanisms, before evaluating the effects empirically in subsequent sections.

First, Fairtrade standards have several concrete regulations related to agrochemical input use that must be met by certified cooperatives and their member farmers (Fairtrade, 2014, 2019a). Chemicals marked as 'red' in Fairtrade's list of hazardous materials are prohibited. This list mainly refers to pesticides and is based on classification systems of the World Health Organization (WHO) and other internationally accepted institutions (Fairtrade, 2018a). In 
addition, Fairtrade farmers receive training on integrated pest management, in order to learn about economic thresholds and non-chemical measures of pest control. These regulations are expected to reduce chemical input use, at least in situations where pesticide use is commonplace.

Second, Fairtrade certification also requires training of farmers on the safe utilization of hazardous materials and the use of protective clothes by all persons handling pesticides. Furthermore, Fairtrade regulations involve a buffer zone for the application of pesticides of at least 10 meters from other human activity (Fairtrade, 2019a). While these measures do not necessarily reduce chemical input quantities, they are expected to reduce the direct human exposure to pesticides and thus negative health impacts.

Third, Fairtrade cooperatives often provide general agricultural extension and agronomic training to help farmers increase their crop productivity (Meemken \& Qaim, 2018b; Sellare, Meemken, Kouamé, et al., 2020). Such extension services are frequently financed through the Fairtrade premium, an amount of money paid to certified cooperatives dependent of the quantity of produce marketed through Fairtrade channels. In addition, cooperatives often use the Fairtrade premium to facilitate farmers' access to inputs through bulk purchases, subsidized distribution, and sometimes other forms of financial or credit assistance (Loconto et al., 2019). Smallholders in Africa often use low amounts of purchased inputs due to human and financial capital constraints. In such situations, the services offered by Fairtrade cooperatives may increase agrochemical input use.

Fourth, Fairtrade offers a floor price for the certified output, which is usually higher than the free market price. Higher output prices increase the profit-maximizing levels of input use. Hence, this mechanism may lead to an increase in the quantities of agrochemical inputs.

Which of these mechanisms dominates in a particular context depends on various farm-, household-, and cooperative-level variables and on the broader socioeconomic context. In the following, we analyze the situation in the cocoa sector of Cote d'Ivoire. 


\subsection{Materials and methods}

\subsubsection{Study area}

This study uses data from a survey conducted in 2018 in the Southeast of Cote d'Ivoire, a region that is part of the old West African cocoa belt. This region was selected because of the large number of Fairtrade certified and non-certified cocoa cooperatives operating there. The Southeast of Cote d'Ivoire is characterized by relatively old cocoa plantations, depleted soils, and a high incidence of various pests and diseases, such as mirids, black pods, stem borers, and the swollen shoot virus (Foundjem-Tita et al., 2017). Most cocoa farmers use chemical pesticides to control pests and diseases, even though affordable access to agrochemicals is often difficult for the smallholder producers. Cocoa farmers are typically organized in cooperatives, which offer certain services to their members and through which the cocoa is also marketed (Foundjem-Tita et al., 2017). Usually, several cooperatives are operating in the same locations. Farmers are free to choose which of the cooperatives in their vicinity they want to be members of. In addition to logistical considerations and expected costs and benefits, factors related to kinship and other social ties often influence the decision of which cooperative to join (Sellare, Meemken, Kouamé, et al., 2020).

One important service that many cooperatives provide to their members is facilitating access to agricultural inputs. Agrochemicals are not generally subsidized in Cote d'Ivoire, but the Conceil $d u$ Café et du Cacao (CCC) distributes certain quantities of agrochemicals through the cooperatives, which then further distribute these inputs to their members at subsidized rates. However, the quantities are rationed, and irregularities in the distribution are commonplace. Beyond their role in input provision, cooperatives sometimes also provide agricultural extension services and awareness building for the safe use of agrochemicals. Such training services are often implemented together with government extension agencies, development organizations, or other public and private partners. Some of the cooperatives also offer pesticide spraying services for member farmers, meaning that farmers can consult a cooperative specialist who supports them in scouting their cocoa fields for pests and implements the spraying operations.

\subsubsection{Sampling and data collection}

One of the key objectives of our study design was to capture a lot of heterogeneity at the cooperative level, in order to increase external validity and be able to analyze cooperative-level 
mechanisms. Hence, we decided to sample from a larger number of cooperatives than previous studies on the effects of sustainability standards had done. With the help of different international, national, and local organizations, we compiled a list of all active cocoa cooperatives in the Southeast of Cote d'Ivoire. From this list, we randomly selected 25 Fairtrade certified and 25 non-certified cooperatives, leading to a total of 50 cooperatives. ${ }^{12}$ In each of the 50 cooperatives, we interviewed the cooperative leader in order to collect data on cooperative characteristics and the types of services offered to their members. In addition, in each cooperative we randomly sampled 10 farmers and 10 workers, leading to a total sample of 500 farmers and 500 workers.

Farmers decide what types and quantities of inputs are applied on their cocoa fields. Hence for the analysis of input use, we do not include the data from the workers. However, workers may apply pesticides or be affected otherwise by exposure to agrochemicals, so for the analysis of pesticide-related health symptoms, we use both the data from farmers and workers. There are two different types of workers, namely farm workers (locally known as aboussant) and cooperative workers (Meemken et al., 2019). Farm workers are employed by farmers to carry out field operations, and they typically live near to the cocoa fields. The group of cooperative workers is more heterogeneous and includes cooperative staff working in administration, logistics, and agriculture-related tasks. Many of the cooperative workers are hardly exposed to agrochemicals, but especially those involved in spraying services are exposed to pesticides to a significant extent.

The personal interviews with all respondents were conducted between May and June 2018 by a team of local enumerators, who were selected, trained, and monitored by the researchers. The structured questionnaires were programmed for use with tablet computers. We used separate questionnaires for farmers and workers, although some of the modules - such as those related to general household characteristics, income, asset ownership, and exposure to pesticides - were identical.

Questions on details of agrochemical input use were included only in the farmer questionnaire. Farmers reported the types and quantities of fertilizers and pesticides (insecticides, fungicides,

\footnotetext{
${ }^{12}$ Of the 25 Fairtrade certified cooperatives in our sample, 16 were additionally certified under UTZ and/or Rainforest Alliance (RA). We cannot analyze the effects of UTZ and/or RA separately, because we did not sample cooperatives that are only UTZ/RA certified without also being Fairtrade certified. However, in the statistical analysis we test whether UTZ/RA has additional effects or changes the effects of Fairtrade in any way. Note that in 2018, UTZ and RA legally merged under the name Rainforest Alliance. However, as of April 2020 the new joint standard has not been launched in practical terms.
} 
and herbicides) they had used in their cocoa fields during the past 12 months. For the pesticides used, the brand names or local names of all substances used were also captured. For each substance, we later verified active ingredients with the help of local agronomists and input dealers. For the analysis of pesticide use, out of the total of 500 farmer observations we had to drop 31 because respondents did not remember the quantities of the pesticides applied.

In order to obtain information about pesticide-related health symptoms, we first asked farmers and workers whether they had been exposed to pesticides directly during the last 12 months or they had entered a cocoa field within three days after spraying. Of the 500 farmers, 130 reported such type of exposure. Of the 500 workers, 125 (104 farm workers and 21 cooperative workers) were exposed to pesticides. For these 255 exposed respondents, we followed up by asking whether they had experienced any pesticide-related health symptoms during a period of 24 hours after exposure. For these questions we used a list of common health symptoms as further explained below.

\subsubsection{Measurement of outcome variables}

In order to evaluate how Fairtrade affects the use of agrochemical inputs and their impacts on the environment and human health, we use three sets of outcome variables, namely (i) agrochemical input quantities, (ii) aggregated pesticide toxicity, and (iii) pesticide-related health symptoms. Agrochemical input quantities are calculated separately for chemical fertilizers and pesticides and are measured in $\mathrm{kg}$ per hectare of cocoa. Pesticide quantities include the quantities of insecticides, fungicides, and herbicides used.

There is no uniform measure of pesticide toxicity, as impacts on soils, plants, aquatic organisms, insects, and mammals differ. We use two indicators of aggregated pesticide toxicity, namely the environmental impact quotient (EIQ) and the hazard quotient (HQ). EIQ is a multidimensional measure of the environmental and health effects of pesticides and was developed by Kovach et al. (1992). It was extensively used in the recent literature to evaluate environmental and health effects of various pest control strategies (Abedullah et al., 2015; Kromann et al., 2011; Midingoyi et al., 2019; Veettil et al., 2017). The EIQ is calculated as:

$$
E I Q=\sum_{a i=1}^{N} E I Q_{a i} *\left[\text { dosage }_{\text {ha }}{ }^{-1}\right] * \text { Proportion }_{a i}
$$

where $E I Q_{a i}$ is the base EIQ for each active ingredient, dosage $h^{-1}$ is the amount of formulation in $\mathrm{kg}$ per hectare, and Proportion $a i$ is the proportion of each active ingredient in the pesticide 
formulation. The higher the EIQ, the greater is the aggregated environmental and health toxicity of the pesticides used.

The EIQ combines different types of toxicity and environmental impacts (soil, water, aquatic organisms, mammals, etc.) in one indicator, which can be seen as an advantage. However, in doing so, it assigns scales and weights to the various components, which can also lead to possible misinterpretation, depending on what the concrete purpose is (Kniss \& Coburn, 2015; Peterson \& Iii, 2014). The HQ is narrower, as it only considers toxicity to mammalian species (including humans), but is easier to interpret and uses more straightforward data for the measurement of acute toxicity, such as the lethal dose of a substance to kill $50 \%$ of the test animals (LD50) (Kniss, 2017; Nelson \& Bullock, 2003; Stoner \& Eitzer, 2013). We calculate HQ as follows:

$$
H Q=\sum_{a i=1}^{N} \frac{\text { Amount }_{a i}}{\text { Toxicity }_{a i}}
$$

where $N$ is the total number of pesticide active ingredients applied to cocoa, Amount $_{a i}$ is the quantity of each active ingredient applied, and Toxicity $y_{a i}$ is the acute rat $\mathrm{LD}_{50}$ via oral administration, expressed in mg per $\mathrm{kg}$ of animal weight. ${ }^{13} \mathrm{~A}$ smaller $\mathrm{LD}_{50}$ means higher toxicity. However, as toxicity appears in the denominator, a larger HQ indicates a more toxic combination of pesticides.

Pesticide-related health symptoms are indicators of actual human health effects, which are not only a function of pesticide toxicity but also of handling practices. We analyze the self-reported number of acute health symptoms experienced by farmers and workers, similar to what has been used in other studies on the health effects of pesticide use (Asfaw et al., 2010; Kouser \& Qaim, 2011). In particular, the following symptoms are considered: general weakness, vomiting, excessive sweating, stomach pain, sleeplessness, skin irritation, headache, fever, eye irritation, diarrhea, coughing, breathlessness, other respiratory problems, and other symptoms to be specified. Our outcome variable is the sum of the number of all symptoms reported by each respondent.

\footnotetext{
${ }^{13}$ Note that other measures of toxicity can be used in principle to calculate the HQ, also including measures of chronic toxicity (Kniss, 2017). We concentrate on acute toxicity, as reliable data on chronic toxicity are not available for many of the active ingredients relevant in the local context.
} 


\subsubsection{Econometric models}

We analyze the effect of Fairtrade on the outcome variables using regression models of the following type:

$$
y_{i j k}=\alpha+\beta F T_{j k}+\gamma \boldsymbol{X}_{i j k}+\theta \boldsymbol{D}_{\boldsymbol{k}}+\delta \boldsymbol{W}_{j k}+\varepsilon_{i j k}
$$

where $y_{i j k}$ is the respective outcome variable for household $i$ belonging to cooperative $j$ in district $k$. We estimate separate models for each of the outcome variables (i.e., quantity of fertilizer and pesticides, EIQ, HQ, number of health symptoms). The main explanatory variable of interest is $F T_{j k}$, which is a dummy variable indicating whether or not cooperative $j$ is Fairtrade certified. A statistically significant $\beta$ would imply that Fairtrade has an effect on the respective outcome variable, also after controlling for possible confounding factors. In the estimations, we control for a vector of exogenous household-level variables, $\boldsymbol{X}_{\boldsymbol{i j k}}$, such as farmer age, education, and asset ownership. Furthermore, we control for cooperative characteristics, $\boldsymbol{W}_{\boldsymbol{j} \boldsymbol{k}}$, such as the age of the cooperative and the number of service providers, as these may also affect farmers' behavior with and without Fairtrade certification (Sellare, Meemken, Kouamé, et al., 2020). Lastly, we include a set of district dummies, $\boldsymbol{D}_{\boldsymbol{k}}$, to account for possible geographical differences in terms of infrastructure and market access. In all estimations the error term, $\varepsilon_{i j k}$, is clustered at the cooperative level.

Depending on the particular outcome variable, we use different model specifications and functional forms. Some of the farmers do not use any fertilizers and pesticides, so that the variables measuring agrochemical quantities and toxicity levels are censored at zero. Such corner solution models can be estimated with a double-hurdle specification as follows (RickerGilbert et al., 2011):

$$
\begin{gathered}
q_{i j k}^{d}=\pi_{0}+\pi_{1} F T_{j k}+\pi_{2} \boldsymbol{X}_{i j k}+\pi_{3} \boldsymbol{W}_{j k}+\pi_{4} \boldsymbol{D}_{\boldsymbol{k}}+u_{i j k}, \text { where } q_{i j k}^{d}=\left\{\begin{array}{l}
1 \text { if } q_{i j k}>0 \\
0 \text { otherwise }
\end{array}\right. \\
q_{i j k}=\omega_{0}+\omega_{1} F T_{j k}+\omega_{2} \boldsymbol{X}_{\boldsymbol{i j k}}+\omega_{3} \boldsymbol{W}_{\boldsymbol{j} \boldsymbol{k}}+\omega_{4} \boldsymbol{D}_{\boldsymbol{k}}+v_{i j k}, \text { given } q_{i j k}^{d}=1
\end{gathered}
$$

In the first hurdle in equation (6), $q_{i j k}^{d}$ is a dummy variable that represents the farmer's choice whether or not to use the particular type of agrochemical. In the second hurdle in equation (7), $q_{i j k}$ is a continuous variable representing the quantity of agrochemicals used (or their toxicity), 
conditional on the first hurdle being passed. $u_{i j k}$ and $v_{i j k}$ are normally distributed and independent error terms. ${ }^{14}$

The number of pesticide-related health symptoms is a count variable drawn from a Poisson distribution. Therefore, we use an exponential conditional mean model as follows:

$$
y_{i j k}=\exp \left(\alpha+\beta F T_{j k}+\gamma \boldsymbol{X}_{i j k}+\theta \boldsymbol{D}_{\boldsymbol{k}}+\delta \boldsymbol{W}_{\boldsymbol{j} \boldsymbol{k}}+\varphi \boldsymbol{R}_{\boldsymbol{i j k}}\right)+\varepsilon_{i j k}
$$

As this model includes observations from farmers, farm workers, and cooperative workers, we include an additional set of two dummy variables, $\boldsymbol{R}_{\boldsymbol{i j k}}$, indicating to which group the particular observation belongs. We use the group of farmers as the reference category.

\subsubsection{Identification strategy}

As Fairtrade certification is not randomly assigned to cooperatives and farmers, the variable $F T_{j k}$ in the regression models is potentially endogenous, which could lead to biased estimates. Cooperatives decide whether or not they want to be certified, and farmers decide which cooperative they want to be member of. In all specifications, we control for several cooperative characteristics and also include farmer-level measures such as individual risk aversion (Dohmen et al., 2011) that proxy for possible unobserved heterogeneity. Nevertheless, correlation between $F T_{j k}$ and the error terms cannot be ruled out, so that we use instrumental variable (IV) approaches to test and control for endogeneity.

In particular, we use three instruments for $F T_{j k}$, building on previous work by Meemken et al. (2019) and Sellare et al. (2020) and exploiting different dimensions of social networks that influence the certification decision. These instruments are: (i) the share of Fairtrade certified farmers in a $5 \mathrm{~km}$ radius; (ii) the distance to the closest Fairtrade certified cooperative; and (iii) the mobile phone provider of the cooperative leader. These instruments are further explained and tested for validity in the following.

The first instrument, the share of certified farmers in a $5 \mathrm{~km}$ radius, captures household-level social network effects, as farmers located closer to other certified farmers are more likely to

\footnotetext{
${ }^{14}$ The tobit model is a specific case of the double-hurdle model where the influencing factors in both hurdles are identical. Table B1 in the Appendix shows likelihood ratio tests, the results of which suggest that in most cases the two-equation double-hurdle model is preferred over the single-equation tobit specification.
} 
learn about certification and its possible advantages. ${ }^{15}$ Farmers cannot get Fairtrade certification individually, but they can decide to join (or leave) a Fairtrade certified cooperative. Our data confirm a significant correlation between the share of certified farmers in the neighborhood and own certification (Table B2 in the Appendix), which is the key condition for instrument relevance. In addition, for an instrument to be valid, it must not affect the outcome variables directly. One could expect that locations with more Fairtrade certified cooperatives and farmers are those that also have more extension offices or better infrastructure and access to markets, all of which could influence farmers' input use independent of own certification. However, government extension offices are spread throughout the study area. Moreover, our data show that there is no pronounced geographic clustering of certified cooperatives, meaning that certified and non-certified cooperatives are found in the same locations. Using a simple falsification test, as proposed by Di Falco et al. (2011), we find that the share of certified farmers in a $5 \mathrm{~km}$ radius is not significantly correlated with agrochemical input use or pesticide toxicity (Table B2). ${ }^{16}$

Our second instrument, the distance to the headquarters of the closest Fairtrade certified cooperative, is defined with respect to the respondent's household and also captures network effects. Farmers who live close to the headquarters of a certified cooperative are more likely to learn about Fairtrade and join this cooperative. Also for workers, the closer they live to the headquarters of a certified cooperative, the more likely they will work there. Table B2 in the Appendix confirms the expected negative correlation between this distance measure and own Fairtrade certification status, whereas the instrument is not significantly correlated with any of the outcome variables. Even though living closer to the headquarters of a certified cooperative can be associated with better access to inputs and training, this effect works through cooperative membership and therefore own certification, as cooperatives rarely offer related services to nonmembers.

The third instrument, the mobile phone provider of the cooperative leader, captures network effects at the cooperative level. In total, there are three network providers operating in the study area, namely Orange, MTN, and Moov. All three offer similar services at similar costs, so the choice for the individual mainly depends on the strength of the network signal in a particular

\footnotetext{
${ }^{15}$ Some of the cooperative workers, whose observations are included in the analysis of health symptoms, live elsewhere (e.g., in a nearby city). In those cases, we do not consider the location of the own household but use the cooperative mean of the share of certified farmers in a $5 \mathrm{~km}$ radius.

${ }^{16}$ While the instrument is individually significant in the health symptom regression, the falsification test shows that all three instruments together are jointly insignificant at the 5\% level (Table B2).
} 
location and on which provider others in the personal social network are subscribed to. There are economic advantages of communicating with people who have the same network provider, since the providers offer discounts for calls and text messages exchanged within their networks. Our data show that cooperatives whose leader is subscribed to Orange are more likely to be certified. Hence, it is likely that more information about Fairtrade is exchanged within the Orange network than within other networks. Table B2 in the Appendix confirms the positive correlation between the cooperative-level instrument and own certification status. One could argue that the decision of the cooperative to become certified might have influenced the leader's decision of the mobile phone provider, which would make the instrument endogenous. However, this is not the case in our context, as people rarely switch their mobile phone providers. In fact, only three of the 25 certified cooperative leaders in our sample switched their phone provider after the cooperative became certified. The instrument is not directly correlated with any of the outcome variables (Table B2).

Using a Wald test we also show that our three instruments are jointly correlated with Fairtrade certification (Table B2). Furthermore, we show that the three instruments are not jointly correlated with any of the outcome variables at the 5\% significance level. As we have more instruments than endogenous regressors, we can also test whether our instruments are uncorrelated with the error term with a test of over-identifying restrictions. Hansen's J test statistic indicates that our instruments are valid (Table B3).

For the double-hurdle models to analyze agrochemical input quantities and toxicity levels, we use the three instruments in a control function (CF) framework (Wooldridge, 2015). The CF approach entails first regressing the endogenous variable on the instruments and all exogenous covariates. The residuals from this first-stage regression are then included in the outcome models. The significance of the residuals in the outcome models tests for endogeneity. If the residuals are insignificant, the exogeneity hypothesis cannot be rejected and estimation without the residuals included leads to consistent and more efficient results. If the residuals are statistically significant, however, the exogeneity hypothesis is rejected and inclusion of the residuals controls for endogeneity bias. Following previous research (Benali et al., 2018; Rao \& Qaim, 2013; Ricker-Gilbert et al., 2011; Woldeyohanes et al., 2017), we test for endogeneity in both hurdles of the double-hurdle model (Table B4 in the Appendix) and include the residuals in those cases where the exogeneity hypothesis is rejected at the 5\% level. 
For the exponential model to analyze pesticide-related health symptoms, we use a nonlinear IV approach based on the generalized method of moments estimator (IV-GMM) (Cameron \& Trivedi, 2013; Hirvonen \& Hoddinott, 2017). This is an appropriate approach for nonlinear models, even when the model is over-identified with clustered errors (Mullahy, 1997; Wooldridge, 2001). The exogenous instruments are used to create additional moment conditions and solve a minimization problem, namely that the correlation between the endogenous variable and the error term is as close to zero as possible.

\subsection{Results and discussion}

\subsubsection{Descriptive statistics}

Table 6 shows descriptive statistics for agrochemical input use and related indicators by certification status. Fairtrade certification is associated with significantly higher chemical input quantities per hectare of cocoa. On average, certified farmers use almost twice as much fertilizer as non-certified farmers. Certified farmers also use $25 \%$ more pesticides (total quantities of insecticides, fungicides, and herbicides) than non-certified farmers. This is not necessarily an indication that certified farmers overuse agrochemicals, as it is also possible that non-certified farmers underuse fertilizers and pesticides. Higher input intensities contribute to higher cocoa yields, as can also be seen in Table 6 . Nevertheless, they potentially also contribute to higher levels of environmental and health toxicity. 
Table 6. Agrochemical input use and related indicators by Fairtrade certification status

\begin{tabular}{|c|c|c|c|c|c|}
\hline & $\begin{array}{l}\text { (1) } \\
\mathrm{N}\end{array}$ & $\begin{array}{c}\text { (2) } \\
\text { Full sample }\end{array}$ & $\begin{array}{c}\text { (3) } \\
\text { Certified }\end{array}$ & $\begin{array}{c}(4) \\
\text { Non- } \\
\text { certified }\end{array}$ & $\begin{array}{c}(5) \\
\text { Mean } \\
\text { difference } \\
\end{array}$ \\
\hline Number of fertilizer applications & 500 & $\begin{array}{c}0.94 \\
(0.95)\end{array}$ & $\begin{array}{c}1.20 \\
(0.98)\end{array}$ & $\begin{array}{c}0.67 \\
(0.84)\end{array}$ & $0.54^{* * *}$ \\
\hline Fertilizer (kg/ha) & 492 & $\begin{array}{c}37.91 \\
(78.67)\end{array}$ & $\begin{array}{c}48.49 \\
(78.48)\end{array}$ & $\begin{array}{c}27.49 \\
(77.62)\end{array}$ & $21.00^{* * *}$ \\
\hline Number of pesticide applications & 500 & $\begin{array}{c}2.51 \\
(1.41)\end{array}$ & $\begin{array}{c}2.62 \\
(1.46)\end{array}$ & $\begin{array}{c}2.40 \\
(1.36)\end{array}$ & $0.23^{*}$ \\
\hline Total pesticide use $(\mathrm{kg} / \mathrm{ha})$ & 469 & $\begin{array}{c}1.92 \\
(2.09)\end{array}$ & $\begin{array}{c}2.14 \\
(2.50)\end{array}$ & $\begin{array}{c}1.71 \\
(1.61)\end{array}$ & $0.43^{* *}$ \\
\hline Insecticides (kg/ha) & 489 & $\begin{array}{c}1.01 \\
(0.82)\end{array}$ & $\begin{array}{l}1.14 \\
(0.94)\end{array}$ & $\begin{array}{c}0.89 \\
(0.66)\end{array}$ & $0.24^{* * *}$ \\
\hline Fungicides (kg/ha) & 476 & $\begin{array}{c}0.66 \\
(1.65)\end{array}$ & $\begin{array}{c}0.84 \\
(2.09)\end{array}$ & $\begin{array}{c}0.49 \\
(1.07)\end{array}$ & $0.35^{* *}$ \\
\hline Herbicides (kg/ha) & 487 & $\begin{array}{c}0.27 \\
(0.76)\end{array}$ & $\begin{array}{c}0.18 \\
(0.67)\end{array}$ & $\begin{array}{c}0.36 \\
(0.83)\end{array}$ & $-0.18^{* *}$ \\
\hline Cocoa yields (kg/ha) & 500 & $\begin{array}{c}540.31 \\
(250.36)\end{array}$ & $\begin{array}{c}573.58 \\
(265.70)\end{array}$ & $\begin{array}{c}507.03 \\
(229.76)\end{array}$ & $66.55^{* * *}$ \\
\hline Environmental impact quotient (EIQ) & 469 & $\begin{array}{c}20.20 \\
(36.41)\end{array}$ & $\begin{array}{c}23.98 \\
(45.19)\end{array}$ & $\begin{array}{c}16.71 \\
(25.39)\end{array}$ & $7.27^{* *}$ \\
\hline Hazard quotient (HQ) & 469 & $\begin{array}{c}747.01 \\
(1157.08)\end{array}$ & $\begin{array}{c}864.66 \\
(1355.52)\end{array}$ & $\begin{array}{c}638.53 \\
(927.42)\end{array}$ & $226.12^{* *}$ \\
\hline Number of acute health symptoms ${ }^{\text {a }}$ & 255 & $\begin{array}{c}1.83 \\
(2.69)\end{array}$ & $\begin{array}{l}1.20 \\
(2.61)\end{array}$ & $\begin{array}{c}2.30 \\
(2.66)\end{array}$ & $-1.10^{* * *}$ \\
\hline
\end{tabular}

${ }^{a}$ Health symptoms refer to both farmers and workers. Data are shown only for those that reported having been exposed to pesticides.

We identified 20 different pesticide active ingredients that cocoa farmers commonly use in different combinations. These active ingredients are listed in Table 7 together with their Fairtrade color classifications, WHO classifications, and levels of toxicity in terms of EIQ and $\mathrm{LD}_{50}$. Interesting to note is that EIQ and $\mathrm{LD}_{50}$ values are not significantly correlated. As explained above, $\mathrm{LD}_{50}$ only looks at mammalian toxicity, whereas EIQ also tries to evaluate other environmental risks. For some of the active ingredients in Table 7, notable disparities are observed. For instance, of the products considered, the fungicide Carbendazim has one of the highest toxicity levels when evaluated with the EIQ, but the lowest toxicity level in terms of $\mathrm{LD}_{50}$. Hence, both indicators are not directly comparable, and the $\mathrm{LD}_{50}$ (as well as the HQ) should not be used to draw conclusions about toxicity for non-mammalian organisms (Kniss, 2017). 
Table 7. List of pesticide active ingredients used by farmers and various toxicity classifications

\begin{tabular}{llcccc}
\hline Active ingredients & Main use & $\begin{array}{c}\text { FT } \\
\text { classification }\end{array}$ & $\begin{array}{c}\text { aHO } \\
\text { classification }^{\mathbf{b}}\end{array}$ & EIQ & LD50 $_{\mathbf{5}} \mathbf{m g ~ k g}^{\mathbf{- 1}} \mathbf{c}^{\mathbf{c}}$ \\
\hline Acetamiprid & Insecticide & - & II & 28.73 & 146 \\
Bifenthrin & Insecticide & Orange & II & 44.35 & 54.5 \\
Chlorantraniliprole & Insecticide & Orange & U & 18.34 & 5000 \\
Cypermethrin & Insecticide & Orange & II & 36.35 & 250 \\
Deltamethrin & Insecticide & Orange & II & 28.38 & 135 \\
Diazinon & Insecticide & Yellow & II & 44.03 & 300 \\
Imidaclopride & Insecticide & Orange & II & 36.71 & 450 \\
Lambda-cyhalothrin & Insecticide & Orange & II & 44.17 & 56 \\
Profenofos & Insecticide & Yellow & II & 59.53 & 358 \\
Thiacloprid & Insecticide & Yellow & II & 31.33 & 396 \\
Thiamethoxam & Insecticide & Orange & II & 33.3 & 1563 \\
Mefanoxam, metalaxyl-M & Fungicide & - & II & 19.07 & 670 \\
Carbendazim & Fungicide & Orange & U & 50.5 & 10000 \\
Copper hydroxide & Fungicide & Yellow & II & 33.2 & 1000 \\
Copper oxide & Fungicide & - & U & 33.2 & 7792 \\
Mancozeb & Fungicide & Orange & U & 25.72 & 8000 \\
Mandipropamid & Fungicide & - & U & 27.14 & 5000 \\
2.4-D dimethylamine & Herbicide & - & II & 20.67 & 625 \\
Glyphosate & Herbicide & Orange & III & 15.33 & 4230 \\
Paraquat & Herbicide & II & 24.73 & 150 \\
\hline
\end{tabular}

a In the Fairtrade classification, red means 'prohibited,' orange means 'restricted,' and yellow means 'flagged'.

${ }^{\mathrm{b}} \mathrm{II}=$ Moderately hazardous; III = Slightly hazardous; $\mathrm{U}=$ unlikely to present acute hazard

${ }^{\mathrm{c}}$ Lethal dose for $50 \%$ of the population based on the acute toxicity for rats via oral administration.

Comparing actually applied quantities of each active ingredient between certified and noncertified cocoa farmers in our sample reveals that Fairtrade certification is associated with significantly higher aggregated toxicity, measured in terms of both EIQ and HQ (Table 6). At the same time, Fairtrade certification is associated with a significantly lower number of pesticide-related acute health symptoms experienced by farmers and rural workers. Fewer health problems in spite of higher levels of pesticide toxicity in Fairtrade certified cocoa point at safer pesticide application practices. Figure 2 shows a breakdown of the data by health symptom. Certified farmers and workers reported lower frequencies of health problems for almost all symptoms considered. 
A Full sample

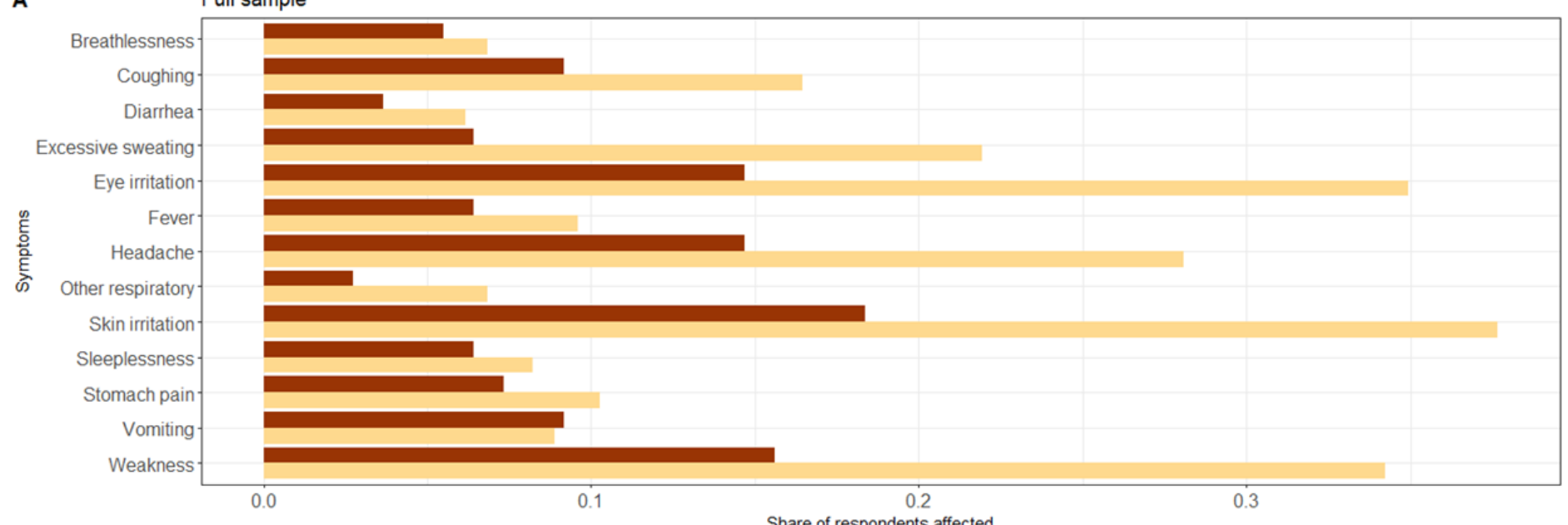
Share of respondents affected

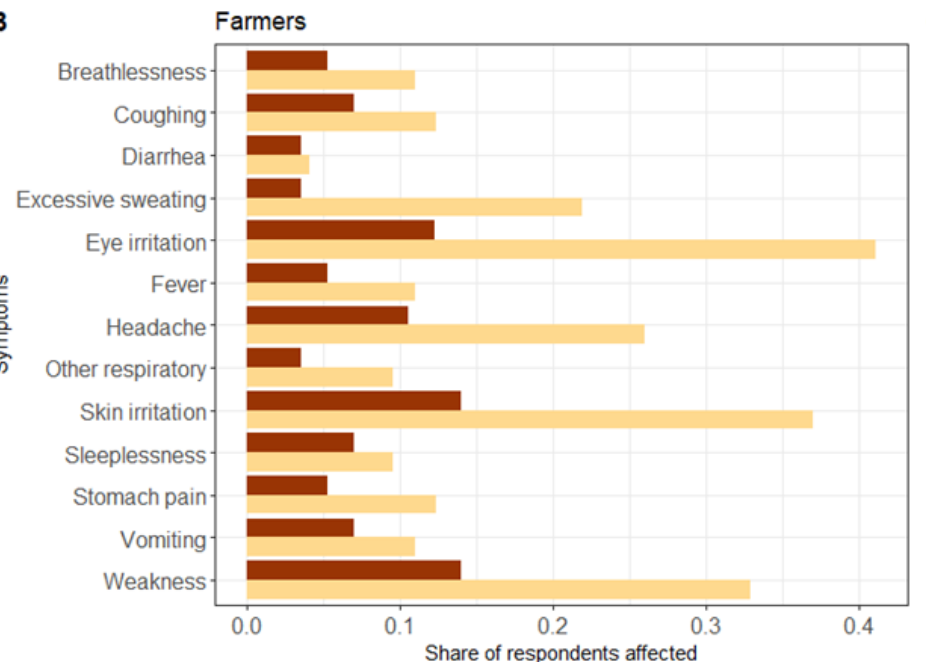

Workers

(2)
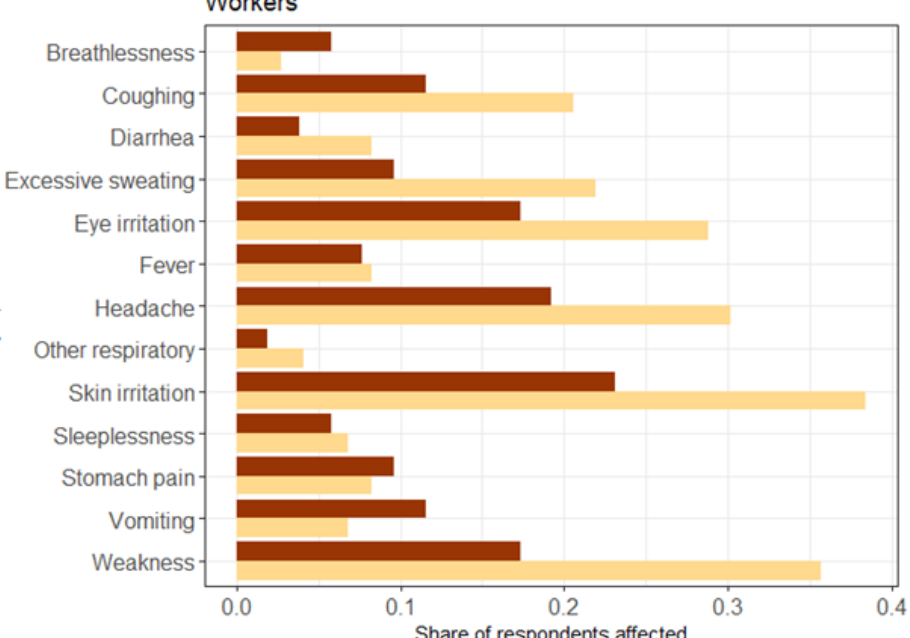

Certified

Figure 2. Incidence of pesticide-related acute health symptoms among respondents who were exposed to pesticides $(\mathrm{N}=\mathbf{2 5 5})$. 
A bit more context about the local division of labor and farmers' and workers' exposure to chemical pesticides may be useful for the interpretation of the results. In the study area in Cote d'Ivoire, many of the routine operations in cocoa production, such as pruning, fertilization, and harvesting, are carried out by farm workers (aboussant) with lesser involvement by the farmers themselves (Meemken et al., 2019). In principle, farm workers also apply chemical pesticides, but for pest control, farmers often also use spraying services offered by many cooperatives, meaning that the pesticides are applied by cooperative field workers or extension agents. In our sample, only $15 \%$ of the farmers and $25 \%$ of the farm workers mentioned that they were directly involved in pesticide applications during the 12 months prior to the survey. However, farmers and farm workers may also be exposed to pesticides more indirectly. Most farmers live in villages that are typically located at some distance to the cocoa fields. In contrast, farm workers often live in houses or huts near the cocoa fields, increasing the likelihood of being exposed to pesticides. Indeed, $41 \%$ of the farm workers in our sample reported having been exposed to pesticides directly or indirectly, compared to only $26 \%$ of the farmers in the sample.

Tables B5 and B6 in the Appendix show descriptive statistics for the control variables used in the regression analysis. For farmers (Table B5), a few significant differences between certified and non-certified can be observed in terms of household and cooperative characteristics (Table B5). For instance, Fairtrade certified cooperatives are older than non-certified cooperatives. Also, certified cooperatives make a larger share of the decisions democratically, and they cooperate with more external partners to provide inputs, training, and other services to their members. In terms of cocoa farm characteristics, such as the size of the landholdings, pest infestation levels, or age of the cocoa trees, most of the differences are small and not statistically significant. For the sample of workers (Table B6), no significant differences are observed.

\subsubsection{Effects on the intensity of agrochemical use}

Table 8 shows marginal effects of Fairtrade certification on fertilizer and pesticide quantities, as derived from double-hurdle model estimation. We start the discussion with fertilizer. The first-hurdle estimation results suggest that certification increases the probability of using chemical fertilizer by 18 percentage points. This is a relatively large effect. Many of the noncertified farmers do not use any chemical fertilizer on their cocoa fields, often because fertilizers 
are inaccessible or too expensive for them. The estimation results suggest that Fairtrade certification improves farmers' access to chemical fertilizers. However, the second-hurdle estimates for fertilizer are not statistically significant, suggesting that certification has no effect on fertilizer quantity. The conditional marginal effect (ME) is conditional on the first-hurdle being passed; the estimate is positive but relatively small in magnitude. The unconditional ME considers both hurdles together. The estimate for the unconditional ME is much larger, suggesting that certification possibly increases fertilizer quantities, but the standard error is also relatively large, so the estimate is not statistically significant.

Table 8. Effects of certification on agrochemical input use (double-hurdle marginal effects)

\begin{tabular}{|c|c|c|c|c|}
\hline & & & $\begin{array}{c}\text { (1) } \\
\text { Fertilizer use }\end{array}$ & $\begin{array}{c}\text { (2) } \\
\text { Pesticide use }\end{array}$ \\
\hline \multirow[b]{2}{*}{$\begin{array}{l}\text { Certification } \\
(1 / 0)\end{array}$} & $\begin{array}{l}\text { First hurdle } \\
(1 / 0)\end{array}$ & Probit ME & $\begin{array}{c}0.18^{* * *} \\
(0.06)\end{array}$ & $\begin{array}{c}-9 \mathrm{e}-3 \\
(0.03)\end{array}$ \\
\hline & $\begin{array}{l}\text { Second hurdle } \\
(\mathrm{kg} / \mathrm{ha})\end{array}$ & $\begin{array}{l}\text { Conditional ME } \\
\text { Unconditional ME }\end{array}$ & $\begin{array}{c}4.33 \\
(26.96) \\
21.12 \\
(14.55) \\
\end{array}$ & $\begin{array}{c}0.35^{* *} \\
(0.18) \\
0.31^{*} \\
(0.18)\end{array}$ \\
\hline Observations & & & 492 & 469 \\
\hline
\end{tabular}

We now look at the results for pesticides in Table 8. Fairtrade certification does not significantly affect the probability of using pesticides (first hurdle), but - conditional on using pesticides certification increases the quantity of pesticides by $0.35 \mathrm{~kg} / \mathrm{ha}$ (second hurdle). The unconditional ME suggests additional pesticide use of $0.31 \mathrm{~kg} / \mathrm{ha}$, which is equivalent to an $18 \%$ increase over the mean pesticide use by non-certified farmers. These results are plausible in the local context. Due to high pest and disease pressure, over $90 \%$ of the sample farmers use chemical pesticides in cocoa production anyway, with or without certification. But certification raises farmers' awareness and knowledge about pest control, facilitates access to pesticides, and provides incentives to use additional quantities. According to local agronomists, at least the mean application rates observed in our sample do not point at an overuse of chemical pesticides.

To gain a better understanding of the institutional factors that contribute to higher agrochemical input use, we ran auxiliary regressions where we included farmers' access to and use of various cooperative services as additional explanatory variables. Results of these auxiliary regressions are shown in Table B9 in the Appendix. As expected, access to agricultural credit and participation in agricultural training increase the likelihood of using fertilizer significantly. 
Similarly, the availability of subsidized fertilizer and pesticides through the cooperatives also increases the likelihood of using these inputs. Furthermore, access to cooperative spraying services increases the pesticide and fertilizer quantities used. All of these services are more likely to be offered in Fairtrade certified cooperatives, as we will show in more detail further below. At the same time, cocoa prices do not seem to affect agrochemical input use significantly, probably because cocoa prices are regulated by the state and actually observed price differences are small (Sellare et al., 2020).

\subsubsection{Effects of Fairtrade on aggregated pesticide toxicity}

Table 9 shows the effects of Fairtrade certification on the aggregated EIQ and HQ. Both indicators are calculated based on the quantities of pesticides applied. As shown above, certification does not affect the probability of using pesticides. Hence, it is not surprising that the first-hurdle estimates of the toxicity models do not show significant effects either. For EIQ, the second-hurdle results are positive but statistically insignificant. However, for HQ the second-hurdle results are significant and quite large in magnitude. The unconditional ME of 259 points suggests that Fairtrade certification increases the HQ by $40 \%$ in comparison to the mean value observed for non-certified farmers.

Table 9. Effects of certification on aggregated pesticide toxicity (double-hurdle marginal effects)

\begin{tabular}{lllcc}
\hline & & & $(1)$ & $(2)$ \\
& & & EIQ & HQ \\
\hline & \multirow{2}{*}{ First hurdle (1/0) } & Probit ME & $-6 \mathrm{e}-3$ & $-6 \mathrm{e}-3$ \\
Certification & & $(0.03)$ & $(0.03)$ \\
\cline { 2 - 4 }$(1 / 0)$ & & Conditional ME & 5.86 & $285.00^{* *}$ \\
& Second hurdle & & $(4.31)$ & $(112.37)$ \\
& (continuous) & Unconditional ME & 5.24 & $258.87^{* *}$ \\
\hline Observations & & & $(4.16)$ & $(106.96)$ \\
\hline
\end{tabular}

Note: Average marginal effects (ME) are shown with delta-method standard errors in parentheses. EIQ, environmental impact quotient; HQ, hazard quotient. ${ }^{*} p<0.1,{ }^{* *} p<0.05,{ }^{* * *} p<0.01$

All regressions include household and cooperative-level control variables. Full results are shown in Tables B10 and B11 in the Appendix.

That certification has significant effects on the HQ but not on the EIQ can be explained by the differences in what exactly these two indicators measure (see above). The relatively large Fairtrade effect on HQ is not only due to higher overall pesticide quantity but also to differences in the pesticide mix that certified and non-certified farmers use. Figure B1 in the Appendix shows that certification is positively correlated with active ingredients such as Thiacloprid and Lambda-cyhalothrin. Especially the latter is very toxic for mammalian species in terms of its $\mathrm{LD}_{50}$ (Table 2). The use of Lambda-cyhalothrin is not recommended by Fairtrade, but it seems 
that through certain mechanisms certified farmers have better access to this active ingredient than non-certified farmers. In fact, Lambda-cyhalothrin is flagged 'orange' in the Fairtrade list of hazardous materials and its use by certified farmers should be phased out by 2020 (Fairtrade, 2019a).

\subsubsection{Effects of Fairtrade on pesticide-related health symptoms}

Aggregated toxicity, as analyzed above, is a measure of the potential impact of pesticides on the environment and human health. Actual health effects may differ, as these also depend on the level of exposure to the toxic substances. Table 10 shows the effect of Fairtrade certification on the number of pesticide-related health symptoms reported by farmers and rural workers. Fairtrade reduces the number of health problems significantly, in spite of the fact that larger quantities of pesticides and active ingredients with higher mammalian toxicity are used. This positive health effect can likely be explained by better training about the safe use of pesticides and more widespread use of protective devices among Fairtrade certified farmers and workers. The marginal Fairtrade effect of -0.92 shown in Table 10 implies a $40 \%$ reduction in the annual number of pesticide-related health symptoms.

Table 10. Effects of certification on the number of pesticide-related acute health symptoms

\begin{tabular}{lc}
\hline $\begin{array}{c}\text { Number of reported } \\
\text { health symptoms } \\
\text { (marginal effect) }\end{array}$ \\
\hline Certified (1/0) \\
\hline Observations \\
$\begin{array}{l}\text { Note: Clustered standard error shown in parentheses. Estimates based on exponential IV-GMM model. }{ }^{* *} p<0.05 \\
\text { Regression includes household and cooperative-level control variables. Full results are shown in Table B3 in the Appendix. }\end{array}$
\end{tabular}

\subsubsection{Effects of Fairtrade at the cooperative level}

As argued above, effects of Fairtrade on farmers' agrochemical input use and environmental and health impacts are likely channeled through mechanisms at the cooperative level, at least to a large extent. In particular, expected cooperative-level mechanisms include improved services related to input provision and training, which are partly funded through the Fairtrade premium. Figure 3 shows the share of cooperatives in our sample that offer certain types of services to their members, differentiating between cooperatives with and without Fairtrade certification. We compare the 25 certified with the 25 non-certified cooperatives and test for significant differences using Fisher's exact test. In addition, we compare the 25 certified 
cooperatives before and after they became Fairtrade certified, building on cooperative records and leadership recall data. We use McNemar's test for paired data to test for significant differences in this within-cooperative comparison.

As can be seen in Figure 3, certified cooperatives are more likely than non-certified cooperatives to provide fertilizers and pesticides to their members at subsidized rates and to offer training on input use and the safe handling of pesticides, protective clothing, and spraying services. Most of these differences are statistically significant. We showed above that agricultural training and the provision of inputs at subsidized rates contribute to higher agrochemical input use. However, by also offering spraying services, protective clothing, and training on occupational health and safety, cooperatives can reduce negative health impacts in terms pesticide-related health symptoms. Comparing the 25 certified cooperatives before and after certification, significant differences are observed for all variables shown in Figure 3. This means that the differences between certified and non-certified cooperatives can probably be interpreted as Fairtrade effects. 


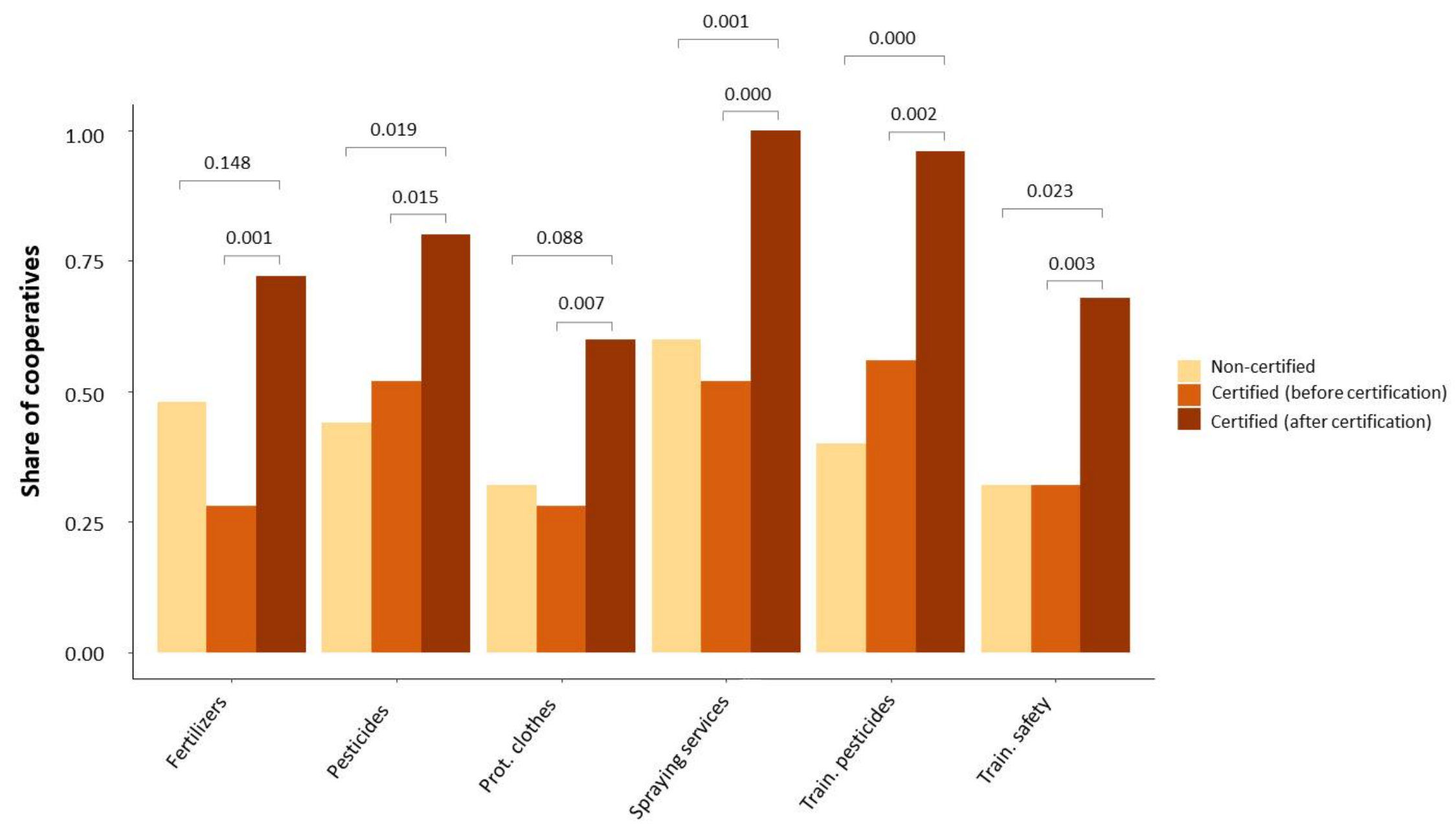

Figure 3. Share of cooperatives offering services related to input provision and training by certification status.

Each group includes 25 cooperative observations. Differences are tested for statistical significance with $p$-values shown above the respective bars. 


\subsubsection{Role of other standards}

So far, we concentrated only on Fairtrade certification. However, there are two other sustainability standards that are also widely observed for cocoa production in the Southeast of Cote d'Ivoire, namely UTZ and Rainforest Alliance (RA). As mentioned above, of the 25 Fairtrade certified cooperatives in our sample, 16 were also certified under UTZ and/or RA standards. Similar to Fairtrade, UTZ and RA have certain regulations concerning the use of agrochemicals and promote alternative practices of pest and disease control. However, in terms of pesticide regulations, Fairtrade standards are stricter than those of UTZ and RA (Rainforest Alliance, 2020). In this subsection, we test whether UTZ and RA have additional effects on any of the outcome variables considered or significantly change the effects of Fairtrade. We do so by re-estimating our regression models and including an UTZ/RA dummy as an additional explanatory variable. This dummy takes a value of one if the respondent certified under Fairtrade was additionally also certified under UTZ and/or RA, and zero otherwise. As mentioned, we do not have any farmers or workers in our sample that were certified under UTZ/RA and not also under Fairtrade. Results of these additional regressions are summarized in Table 11.

Columns (1) and (2) of Table 11 suggest that UTZ/RA leads to a reduction in the use of fertilizer. In all other models, the coefficients of the UTZ/RA dummy are small in magnitude and statistically insignificant. The Fairtrade effects, on the other hand, remain very similar to those estimated above. For fertilizer quantity, the Fairtrade effect increases and turns statistically significant after controlling for UTZ/RA (column 2 of Table 11). For pesticide quantity, the Fairtrade effect turns statistically insignificant, but remains similar in magnitude. For pesticide-related health symptoms, both the magnitude and the significance level of the Fairtrade effect remain unchanged. Hence, the main findings for Fairtrade are quite robust: Fairtrade certification leads to an increase in agrochemical input use and aggregated toxicity, but reduces the incidence of pesticide-related health problems. 
Table 11. Effects of Fairtrade on agrochemical input use, toxicity, and health controlling for UTZ/RA

\begin{tabular}{|c|c|c|c|c|c|c|c|c|c|}
\hline & \multicolumn{2}{|c|}{$\begin{array}{c}\text { Fertilizer } \\
(\mathrm{kg} / \mathrm{ha})\end{array}$} & \multicolumn{2}{|c|}{$\begin{array}{l}\text { Total pesticide use } \\
(\mathrm{kg} / \mathrm{ha})\end{array}$} & \multicolumn{2}{|c|}{ EIQ } & \multicolumn{2}{|c|}{ HQ } & \multirow{2}{*}{$\begin{array}{c}\text { Health } \\
\text { symptoms } \\
\mathrm{ME}^{\mathrm{b}} \\
(9)\end{array}$} \\
\hline & $\begin{array}{l}\text { Cond. } \\
\mathrm{ME}^{\mathrm{a}} \\
\text { (1) }\end{array}$ & $\begin{array}{l}\text { Uncond. } \\
\mathrm{ME}^{\mathrm{a}} \\
(2)\end{array}$ & $\begin{array}{l}\text { Cond. } \\
\text { ME }^{\text {a }} \\
\text { (3) }\end{array}$ & $\begin{array}{l}\text { Uncond. } \\
\mathrm{ME}^{\mathrm{a}} \\
\text { (4) }\end{array}$ & $\begin{array}{l}\text { Cond. } \\
\mathrm{ME}^{\mathrm{a}} \\
(5)\end{array}$ & $\begin{array}{l}\text { Uncond. } \\
\mathrm{ME}^{\mathrm{a}} \\
\text { (6) }\end{array}$ & $\begin{array}{l}\text { Cond. } \\
\mathrm{ME}^{\mathrm{a}} \\
(7)\end{array}$ & $\begin{array}{l}\text { Uncond. } \\
\mathrm{ME}^{\mathrm{a}} \\
\text { (8) }\end{array}$ & \\
\hline Fairtrade $(1 / 0)$ & 36.87 & $37.59^{* *}$ & 0.38 & 0.29 & 3.99 & 2.96 & $282.95^{*}$ & 239.63 & $-1.03^{* *}$ \\
\hline & $(25.63)$ & $(18.01)$ & $(0.24)$ & $(0.24)$ & $(5.28)$ & $(5.05)$ & $(169.22)$ & $(157.86)$ & $(0.51)$ \\
\hline UTZ/RA $(1 / 0)$ & $\begin{array}{l}-67.68^{* *} \\
(29.29)\end{array}$ & $\begin{array}{l}-33.97^{*} \\
(19.13)\end{array}$ & $\begin{array}{l}-0.05 \\
(0.27)\end{array}$ & $\begin{array}{c}0.04 \\
(0.26)\end{array}$ & $\begin{array}{l}3.46 \\
(6.27)\end{array}$ & $\begin{array}{c}4.19 \\
(6.16)\end{array}$ & $\begin{array}{c}3.79 \\
(181.65)\end{array}$ & $\begin{array}{c}34.47 \\
(164.88)\end{array}$ & $\begin{array}{c}0.25 \\
(0.73)\end{array}$ \\
\hline Observations & 492 & 492 & 469 & 469 & 469 & 469 & 469 & 469 & 255 \\
\hline
\end{tabular}

\subsection{Conclusion}

In this article, we have analyzed the effects of Fairtrade certification on agrochemical input use and related impacts on the environment and human health. Even though Fairtrade focuses primarily on the social dimension of sustainability, it also has certain environmental objectives and related rules and regulations. For instance, Fairtrade bans certain pesticides that are particularly toxic and requires certified farmers to be trained in the safe handling of agrochemicals. Very few previous studies have evaluated the effects of Fairtrade on agrochemical input use (Elder et al., 2013). We are not aware of any study that has looked at environmental and health impacts beyond pesticide quantity. Hence, our study adds to the existing literature.

Conceptually, we have discussed different mechanisms how Fairtrade certification can either increase or decrease fertilizer and pesticide use and related externalities. While the Fairtrade regulations as such may rather reduce the use of toxic agrochemicals, the Fairtrade premium and related services offered by certified cooperatives may facilitate and incentivize higher input intensities. Indeed, our empirical results from Cote d'Ivoire show that Fairtrade increases agrochemical input use. Fairtrade also leads to higher aggregated levels of toxicity, which proxy potential negative impacts on the environment and human health. At least to some extent, these effects are driven by Fairtrade cooperatives being more active in agricultural training and in facilitating chemical input provision to their member farmers.

However, interestingly, higher pesticide quantities among Fairtrade certified farmers do not lead to more health problems. On the contrary, our data show that Fairtrade significantly reduces the incidence of pesticide-related acute health issues experienced by farmers and rural workers. This is plausible against the background of Fairtrade cooperatives being more likely to provide 
protective devices and other services for spraying, as well as training on the safe handling of pesticides.

These empirical results cannot be generalized beyond Cote d'Ivoire, as the role of the underlying mechanisms may differ from one place to another. However, a conclusion that can be generalized is that simplistic assumptions about the health and environmental effects of Fairtrade and other sustainability standards are inappropriate, as there are various possible mechanisms that can work in opposite directions. Cooperatives and the services they offer play an important role and should be the key entry point for interventions to further improve the outcomes of sustainability certification.

Our study has two limitations that should be addressed in follow-up research. First, while we went beyond pesticide quantities and also analyzed aggregated levels of toxicity, the environmental impact quotient (EIQ) and the hazard quotient (HQ) only capture potential and not actual environmental and health impacts of pesticide use. Actual health impacts were additionally analyzed by looking at pesticide-related symptoms, but we were not able to examine actual environmental effects, which would require soil, water, and biodiversity measurements. Second, the cooperative-level effects deserve further scrutiny. We improved upon previous research by sampling a larger number of cooperatives, but our main focus was on the farmer and worker level. Future research should focus more on the cooperative level, possibly with panel data to be able to analyze possible changes through sustainability certification over time. 


\title{
4. New insights on the use of the Fairtrade social premium
}

\begin{abstract}
Fairtrade standards differentiate themselves from other sustainability standards such as Rainforest Alliance and UTZ by demanding that buyers pay to farmers at least a minimum price and a Fairtrade social premium - a sum that is paid to cooperatives in addition to the agreed price to be used in projects to strengthen the cooperative and to benefit the community in the villages more broadly. The latter is often mentioned in the literature as one of the key mechanisms through which Fairtrade engenders changes in the small farm sector. However, no previous study has explicitly analyzed what the social premium is used for, which factors affect the decision-making processes, and whether farmers, workers, and the local communities more broadly benefit from projects implemented with the premium money. In this article, I use multivariate statistical techniques to analyze how patterns in the use of the premium are related to cooperatives' organizational characteristics. To illustrate the potential benefits of the social premium to the local community, I use regression analyses to evaluate the effects of certification and educational projects financed with the social premium on household education expenditure. I find evidence that living in a village where an educational project was implemented has a positive effect on education expenditure among farmers, but does not have an effect among rural workers.
\end{abstract}

Key words: certification; cooperatives; Fairtrade premium; social premium; sustainability standards 


\subsection{Introduction}

Developing countries in Latin America, Southeast Asia, and especially Africa still face major challenges to achieve the Sustainable Development Goals (SDGs) by 2030, despite some progress in recent years (Moyer \& Hedden, 2020). In the absence of government funds, mobilization of necessary financial resources for investment in public goods via the private sector can have positive impacts (Aust et al., 2020). Given the potential of the agricultural sector to deliver broad scale economic growth in developing countries (Christiaensen \& Martin, 2018), initiatives that foster the development of global value chains, are an important private-sectorled option to support rural development and overall economic growth (World Bank, 2020a). In this context, sustainability standards emerged as a mechanism to ensure that farmers in developing countries have access to higher value markets and receive a better price for their produce while addressing consumers' concerns about social injustice and environmental degradation (Ladhari \& Tchetgna, 2015).

Fairtrade standards use mainly three mechanisms to foster sustainable development. The first are the standards themselves. These standards provide guidance, for instance, on how to develop democratic governance structures within small producer organizations and how to implement agricultural practices that are environmentally friendly and less dangerous to farmers and workers (Sellare, Meemken, \& Qaim, 2020). The second is the minimum price, which aims to mitigate the risks related to price volatility in international markets (Fairtrade, 2016). Whenever the international market price drops below the minimum price established by Fairtrade, buyers must pay the latter. ${ }^{17}$ The third mechanism is the Fairtrade social premium ${ }^{18}$, which is a sum of money paid in addition to the agreed price for cooperatives, farmers, and workers to use in projects to address their social, economic, and environmental needs (Fairtrade, 2019a). These projects include but are not limited to direct payments to farmers, investments in operations and production, and improvements in community infrastructure. Decisions related to how the premium is spent are supposed to take place in a democratic arena, with structures in place to ensure that individual and collective interests are heard (Loconto et al., 2019). As such, the Fairtrade social premium has a significant potential to be used as a means to privately finance community-led investments in infrastructure.

\footnotetext{
${ }^{17}$ The minimum price for conventional cocoa beans in 2020 is 2,400 USD/MT.

${ }^{18}$ Fairtrade refer to it simply as "Fairtrade premium" while the term "Fairtrade social premium" is more often used in the academic literature.
} 
The social premium has been pointed out by many studies as one of the main mechanisms through which Fairtrade benefits farmers and workers (Jena \& Grote, 2017; Meemken et al., 2017; Sellare, Meemken, \& Qaim, 2020; Van den Broeck et al., 2017; van Rijn et al., 2019), but it has not received explicit focus in the literature. Little is known about what exactly the premium money is used for, how the decision-making processes take place, and if the projects implemented actually benefit certified farmers, workers, and the local community more broadly. The lack of attention dedicated to these issues can be at least partially explained by the data that researchers work with. Most studies use data from household surveys only, where farmers and workers are sampled from a few purposefully selected cooperatives or commercial farms. The two exceptions in the literature are the studies by Meemken et al. (2019) and Sellare et al. (2020). Without data from a sufficiently large number of cooperatives, it is impossible to make generalizable statements about how cooperatives spend the premium and to analyze to what extent the use of the premium is associated with the organizational structure of the cooperatives. A better understanding of these issues can help us learn to what extent cooperatives are willing to invest their money in public goods and support them to implement such projects effectively.

In this paper, we use data from 1,000 farmers and rural workers (cooperative workers and farm workers) sampled from 50 cocoa cooperatives of Côte d'Ivoire to address the following research questions: 1) What is the Fairtrade social premium used for? 2) Are there associations between the organizational structure of cooperatives and how the premium money is used? 3) Who benefits from the projects implemented with the Fairtrade social premium?

We start by describing how cooperatives have spent the premium and then use principal component analysis (PCA) to analyze if the organizational structure of the cooperatives is correlated with the allocation of the premium into different kinds of projects. To illustrate how the local community might benefit from the social premium, we discuss in more detail about projects focused on child education. We analyze whether (i) being certified and (ii) living in a village where an education project was implemented have effects on household education expenditures by using regression analysis with instrumental variables to account for selfselection into certification

\subsection{Fairtrade, the social premium, and child education}

According to Fairtrade International, in 2016, more than 150 million euros have been paid to small producer organizations as social premium (Fairtrade, 2018b), while the cocoa sector alone 
received 44 million euros in 2018 (Fairtrade, 2019b). Around 40\% of all Fairtrade certified cooperatives choose to invest part of the premium in community infrastructure and services (Loconto et al., 2019). The literature on Fairtrade certification often mentions these projects aimed at improving community welfare. These include investments in child education, promotion of health campaigns, improvements in the infrastructure of health clinics, construction of roads and bridges, installation of clean water facilities, construction of tanks and latrines (Darko et al., 2017; Dragusanu \& Nunn, 2018; Jena \& Grote, 2017; Meemken et al., 2017; Ruben \& Fort, 2012; Valkila \& Nygren, 2010).

The wide range of projects and investments supported through the Fairtrade social premium suggests that certified producers and workers, as well as the local community in general, can benefit from the social premium. However, some studies have been critical of the social premium, and have pointed out that not everyone benefits equally from these projects and that there are problems in the decision-making processes. Cramer et al (2017), for instance, noted that often the poorest did not benefit from community projects as they were not granted access to certain facilities. Other studies have pointed out that even when farmers and workers do benefit from these projects, the processes through which they are implemented are marked by patronage and exclusion (Dolan, 2010), and many farmers undervalue investments that are made to benefit the community as a whole (Ruben \& Fort, 2012).

Earlier studies have highlighted how the effectiveness of projects financed with the social premium and the processes through which decisions are made often depend on the organizational structure of the cooperatives (Valkila \& Nygren, 2010). More precisely, premium management structure and the form of participation can directly affect what the premium money is spent on. A formal separation between the premium decision-making processes from ordinary business decisions might support more investments in social projects. However, embedded decision-making can lead to a prioritization of projects aimed at improving the cooperatives themselves (Loconto et al., 2019). This relationship between the organizational structure of cooperatives and the use of the social premium has been neglected in the literature.

Among the projects that are often implemented with the social premium, those related to education are of particular importance. Child labor is a well-known issue in the production of many tropical commodities (Akoyi et al., 2018; Ruggeri \& Corsi, 2019; Van den Broeck et al., 2017), especially in the cocoa sector (Luckstead et al., 2019; Nkamleu \& Kielland, 2006). Despite Fairtrade prohibiting child labor, its effects on education are not very clear, as it creates 
an income and a substitution effect that might affect education adversely. The income effect relates to households experiencing income gains from participating in certified value chains and facing lower volatility in terms of income. These benefits might encourage higher investments in education and thus positively affect education (Gitter et al., 2012). The substitution effect describes a potential increase in the opportunity cost of a child's time in school (Becchetti et al., 2013; Gitter et al., 2012). Besides these two effects, Fairtrade can also affect education through investments of the social premium. A large number of studies mention investments of the social premium in projects focused on child education, such as building schools, providing financial assistance to cover school-related expenses, or supporting awareness campaigns about the importance of child education (Akoyi et al., 2018; Dragusanu \& Nunn, 2018; Karki et al., 2016; Meemken et al., 2017; Ruben \& Fort, 2012).

Seeing community-led investments to improve schools and having access to information about the importance of child education can encourage households to use a larger share of their income for education-related expenditures. Most studies that look at the effects of Fairtrade on education find positive relationships. Meemken et al. (2017), for example, found that Fairtrade certification increases education expenditure by 64\%. Similarly, Gitter et al. (2012) concluded that Fairtrade participation contributed to a 0.7 year increase in schooling for girls, while Becchetti et al. (2013) found that Fairtrade increases schooling ratio (the average ratio between potential and effective schooling) by 2.6\%. Akoyi et al. (2018) also found that Fairtrade increases the likelihood of children being enrolled and they explain that this positive effect is likely the result of increased awareness and higher investments in child education. It is important to note, however, that none of these studies explicitly analyze whether these effects on child education are the result of higher incomes from certification or from community projects paid by the social premium.

\subsection{Materials and methods}

\subsubsection{Study area}

This study was conducted in the Southeast of Côte d'Ivoire, an area that includes the traditional cocoa belt of West Africa. This area was purposefully selected because of its high number of Fairtrade certified cooperative and non-certified cooperatives. Since the late 1970s, Côte d'Ivoire has been the leading cocoa producing country, currently accounting for over $40 \%$ of the global cocoa production (FAO, 2020). The cocoa sector, marked by smallholder farmers, 
has been one of the major drives of the economic growth of Côte d'Ivoire, but this economic success has not translated into higher equality. Around $50 \%$ of the rural population still lives below the poverty line (IFAD, 2017) and the families that rely on cocoa production for their livelihoods face serious threats to production, such as a myriad of pest and diseases, degraded soils, and old trees, all of which keep yields low (Wessel \& Quist-Wessel, 2015).

The rural population faces several other challenges. According to data from the World Bank (2020b), around $64 \%$ of the rural population does not have electricity in their homes and $44 \%$ still practice open defecation. Access to water services is very deficient, as $43 \%$ of the rural population does not have access to basic drinking water services, while only $10 \%$ have access in their homes to basic hand-washing facilities, including soap and water. These figures show that the region still faces serious problems related to the provision of basic services.

Côte d'Ivoire has more than 600 cocoa cooperatives (MADR, 2017). Out of these, in 2017, 152 were Fairtrade certified, with a total of 129,783 registered members (Fairtrade, 2019b). These cooperatives vary substantially in terms of size and many of them have registered members living in several villages. Their headquarters, however, are usually located in bigger towns. Together, these cooperatives sold over 150,000 MT of cocoa as Fairtrade certified, which has generated more than 26 million euros in Fairtrade social premium. This represents $70 \%$ of the social premium that has been paid to the world's cocoa sector in that year (Fairtrade, 2019b).

\subsubsection{Sampling and data}

For the empirical analyses, we use primary data collected between May and June 2018 from 500 farmers and 500 rural workers (cooperative workers and farm workers) randomly sampled from 50 cocoa cooperatives. With the help of local extension agencies, Fairtrade International, and other international organizations, we compiled a list of all cooperatives in the Southeast of Côte d'Ivoire. From this list, we randomly selected 25 certified cooperatives and 25 noncertified cooperatives. We conducted an interview with the leader of each cooperative using a structured questionnaire, in which we collected detailed data about the organizational structure of the cooperative, including number of members and employees, volumes of cocoa commercialized, provision of services to members, assets owned, among others.

For the 25 certified cooperatives, we also collected data on the use of the Fairtrade social premium. More specifically, we asked the cooperative leadership to list all projects financed with the social premium that had been implemented between 2013 and 2017. For each project, 
we collected information about the purpose of the project, the total amount that was spent in West African Francs (CFA), the names of the villages where the projects were implemented, and whether everyone in the villages could benefit from the projects or if they were exclusive to those associated with the cooperative. Cooperatives often have members in many different villages and the catchment area of these cooperatives tend to overlap. Therefore, projects with public goods characteristics can benefit farmers from multiple cooperatives.

In addition to the cooperative leaders, from each cooperative we randomly sampled and interviewed 10 farmers, 5 cooperative workers and 5 farm workers (locally known as aboussant). We designed specific questionnaires for each group of respondent in which we captured data on socioeconomic characteristics, agricultural production, off-farm employment, among others. In all questionnaires we included identical modules to capture information about life in their villages. We asked respondents to name the top three issues that should be addressed in their villages and how satisfied they were with the provision of basic services (e.g. health and education) in a scale from 1-10. By calculating the village mean of these variables, we obtain a rough picture of the perceived quality of the infrastructure and services available in the villages.

\subsubsection{Classification of projects and education expenditure}

The Fairtrade social premium can be used in a broad variety of projects. Since cooperatives have to report on what exactly the social premium was used, Fairtrade International keeps records of all the projects that are implemented and classifies them into five major categories: (i) services to farmer members; (ii) investment in producer organizations; (iii) services to communities; (iv) services for workers and their families; and (v) training and empowerment of worker. These are further disaggregated into minor categories and subsequently into subcategories (Loconto et al., 2019). Although their categorization is certainly useful for internal monitoring purposes, we found that neither their major, minor, nor sub-categories fit well to our data, either because the total number of projects was too small in any given category or because the total amount spent was not substantial. Therefore, for our analyses we let the data guide the process of categorization. Table 12 shows the ten categories that we used and describes what kind of project falls into each category. 
Table 12. Classification of projects financed with the Fairtrade social premium

\begin{tabular}{l|l}
\hline Project categories & \multicolumn{1}{c}{ Description } \\
\hline Ag. Inputs & Purchase of fertilizers, pesticides, protective clothes, machetes and other tools \\
\hline Cooperative & $\begin{array}{l}\text { Purchase of land, computers, vehicles, and other assets; construction / improvement of } \\
\text { storage rooms, and headquarters' facilities; strengthening of the financial capacity of the } \\
\text { cooperative }\end{array}$ \\
\hline Credit & Provision of credit \\
\hline Direct payments & Cash payment to farmers \\
\hline Education & $\begin{array}{l}\text { Construction / improvement of schools; promotion of education campaigns; provision of } \\
\text { financial support for families to pay for education-related expenses }\end{array}$ \\
\hline Health & Construction / improvement of health care centers; promotion of health campaigns \\
\hline Other community infrastructure & Construction of radio towers, latrines, improvement of housing, purchase of generator \\
\hline Roads / Transportation & Construction / improvement of roads and bridges \\
\hline Water & Construction of wells and hydraulic pumps \\
\hline Miscellaneous & $\begin{array}{l}\text { Provision of training for farmers and the cooperative staff; payment of certification fees; } \\
\text { finance of reforestation and waste management projects }\end{array}$ \\
\hline
\end{tabular}

As explained in section 4.2, several sources report that the social premium is often used to finance projects related to child education and these kinds of projects are even more relevant in the cocoa sector of West Africa, where child labor is a well-known issue. Therefore, we want to focus on education projects to illustrate whether the social premium can benefit the local community in the villages. In our analyses, we will use household education expenditure per child as a proxy to educational quality, which has been used before in other studies that look on the effect of certification on child education (Becchetti et al., 2013; Meemken et al., 2017). This variable is defined as the total amount of money that a household spends in one year with child education, such as uniforms, school materials, and fees. This value is then divided by the number of children in schooling age (between 6 and 18 years) present in the household. In our data, 288 respondents reported not having any children in schooling age; hence they were omitted from the analyses.

\subsubsection{Data analysis}

\section{Principal Component Analysis (PCA)}

Agricultural cooperatives can be very heterogeneous in their characteristics and rather complex in terms of how they benefit their members. Characteristics that would be beneficial to their members at first glance can actually result in negative outcomes. Some studies have shown that inclusiveness and marketing performance, for example, are negatively correlated (Bernard \& Spielman, 2009), while others have shown that cooperatives that provide too many services to their members can become less competitive in the market because of their higher coordination 
and management costs (Tadesse et al., 2018). Therefore, to group cooperatives together and understand how different characteristics are related to each other can be challenging given the high number of factors one would have to take into account.

Principal component analysis (PCA) is an appropriate methodological tool to analyze how cooperative characteristics are correlated with the use of the Fairtrade social premium. PCA is a technique for multivariate statistical analysis that allows us to deal with high-dimensional data by converting a larger number of correlated variables into a set of linearly uncorrelated variables, i.e. the principal components, also referred to as dimensions (Abdi \& Williams, 2010). Furthermore, this technique allows us to use biplots and circles of correlations to visualize the data in a two-dimensional space and thus easily interpret how the variables are correlated with one another and to what degree the observations are (dis)similar.

In order to run a PCA, we first have to select the active individuals and active variables that will be used in the computations. In our case, these are respectively the certified cooperatives and the characteristics of these cooperatives. Out of the 25 sampled certified cooperatives, 3 were excluded from the analysis because they had not yet implemented any project using the premium. The choice of variables was made taking into consideration different aspects of these cooperatives that might play a role in determining how well they function. Therefore, we chose variables that describe the cooperatives in terms of their governance structure, human, physical, and social capital. The complete list of variables can be seen in Table 14.

In addition to the active variables, we can use supplementary variables to enrich the interpretation of the analyses. Supplementary variables do not influence the calculation of the principal components but can be plotted onto the two-dimensional space and interpreted in relation to the active variables. In our case, the supplementary variables are the share of the social premium that the cooperatives spent on the different kinds of projects, which were categorized according to Table 12. The PCA and all corresponding graphical representations were carried out in $\mathrm{R}$ using the FactoMineR package, which by default standardizes the variables used in the analysis (Lê et al., 2008).

\section{$\underline{\text { Regression analysis }}$}

To analyze the effects of Fairtrade certification and education projects on household expenditure with child education, we estimate separate regression models for the full sample, farmers, cooperative workers, and farm workers of the following type: 


$$
\log \left(1+E E_{i j l k}\right)=\alpha+\beta F T_{j l k}+\gamma E P_{l k}+\delta \boldsymbol{X}_{i j l k}+\theta \boldsymbol{W}_{j l k}++\varphi \boldsymbol{V}_{l \boldsymbol{k}}+\omega \boldsymbol{D}_{\boldsymbol{k}}+\varepsilon_{i j l k}
$$

$E E_{i j l k}$ represents our outcome variable, the education expenditure per child for household $i$ in cooperative $j$, village $l$, and district $k$. To reduce the effect of outliers and facilitate de interpretation of the results, we log-transform the outcome variable. However, around $10 \%$ of the observations in our sample have reported zero expenditure with education, despite having school-aged children in the household. Since the natural logarithm of zero is undefined, to retain these observations for the analyses, we add a one to the outcome variable before taking the logarithm. $F T_{j l k}$ and $E P_{l k}$ are our dummy variables of interest; the former represents if the respondent is Fairtrade certified (i.e. if member of a certified cooperative in the case of farmers and if works for a certified employer in the case of workers) and the latter if the respondent lives in a village where an education project financed with the Fairtrade social premium was implemented. Previous studies have reported that Fairtrade certification has positive effects on child education and attributed such effects to the use of the social premium. With our model specification, we can analyze if (i) participating in certified value chains and (ii) living in a village where an education project was implemented with the social premium have an effect on child education. If the coefficients $\beta$ and $\gamma$ are positive and statistically significant, we can conclude, respectively, that certification and the social premium have positive effects on education expenditure.

In all regression models we control for vectors of household, cooperative, and village-level variables that might influence the certification status of respondents and expenditure with education, here represented respectively by $\boldsymbol{X}_{\boldsymbol{i j l k} \boldsymbol{k}}, \boldsymbol{W}_{\boldsymbol{j} \boldsymbol{l} \boldsymbol{k}}$, and $\boldsymbol{V}_{\boldsymbol{l k}}$. It is noteworthy that since we did not collect village-level data, the variables in $\boldsymbol{V}_{\boldsymbol{l} \boldsymbol{k}}$ were constructed calculating the village mean of variables captured in the farmer and worker questionnaires that proxy the perceived quality of the infrastructure and services provided in the villages. Furthermore, we include a set of district dummies $\boldsymbol{D}_{\boldsymbol{k}}$ to control for differences at a larger geographical scale. In all estimations the error term, $\varepsilon_{i j l k}$, is clustered at the village level. For these regressions, we excluded the respondents that did not have any children between 6 and 18 years old in the household. Therefore, we used a total of 712 observations: 433 farmers, 147 cooperative workers, and 132 farm workers.

Whether cooperatives, farmers, and workers participate in a certified value chain is not determined at random. Although we control for a broad range of variables that might simultaneously influence (i) cooperatives' and households' ability and willingness to participate 
in a certified value chain, and (ii) expenditures with education, it is possible that we do not capture all factors. Therefore, we estimate the models above using an instrumental variable (IV) approach to test and control for endogeneity. We use three instruments that have been used in other studies conducted in the same setting (Meemken et al., 2019; Sellare et al., 2020): (i) the share of Fairtrade certified farmers in a $5 \mathrm{~km}$ radius ${ }^{19}$, (ii) the distance to the closest Fairtrade certified cooperative; and (iii) the mobile phone provider of the cooperative leader. These instruments are further explained and tested for validity below.

The first instrument captures social network effects at the household level. We argue that the more certified neighbors a farmer has, the more likely he or she is to learn about the benefits of joining a certified cooperative. Our data indeed shows a positive correlation between the number of certified neighbors a farmer has and own certification status, which indicates that our instrument is relevant. However, for an instrument to be valid it is important that it does not affect the outcome variable other than through the treatment. One could expect that areas with a higher concentration of certified farmers are more likely to receive information about the importance of child education. However, child labor is a well-known issue in the cocoa sector and both the government and NGOs have implemented campaigns throughout the country to raise awareness about child labor and the importance of child education.

Our second instrument is defined as the distance from the respondent's house to the headquarters of the closest Fairtrade certified cooperative. Farmers who live close to the headquarters of a certified cooperative are more likely to learn about Fairtrade and join this cooperative. Similarly, the closer a farm or cooperative worker lives to the headquarters of a certified cooperative, the higher is the likelihood to work for a certified employer. Although living closer to the headquarters of a certified cooperative could mean easier access to information about child education, as explained above, child labor and child education are issues that the local population is very aware about, regardless of where they live.

The third instrument is defined as the primary cellphone network provider that the cooperative leader is subscribed to. In our study area there are three network providers: Orange, MTN, and Moov. All of them offer similar services at similar costs, so the choice of which provider to subscribe to is mostly a matter of the strength of the network in a particular location and which provider the others in one's own social network are subscribed to. There are economic

\footnotetext{
${ }^{19}$ For the analyses in which we use data from workers, we do not consider the location of the own household. Instead, we use the cooperative mean of the share of certified farmers in a $5 \mathrm{~km}$ radius.
} 
advantages of communicating with people within the same network provider, since companies offer discounts for calls and messages exchanged between their subscribers. Our data show that cooperatives whose leader is subscribed to the network Orange are more likely to be certified. Therefore, it is likely that there is a more intense flow of information about certification within the Orange network than between networks. One could argue that the decision to become certified might have influenced the leader's decision of to which network to subscribe to. However, our data show that people do not switch their main cellphone provider often. In fact, only three out of the 25 certified cooperative leaders interviewed switched their main provider after the cooperative became certified.

Using a falsification test as proposed by Di Falco et al. (2011), we show that none of our instruments are correlated with household education expenditure (Table C1). Furthermore, we show that our instruments pass the test of weak instruments $(p<0.01)$. As we have more instruments than endogenous regressors, we can also test whether our instruments are uncorrelated with the error term with a test of over-identifying restrictions. Hansen's $\mathrm{J}$ test statistic indicates that our instruments are valid. The results of these tests are shown in Table $\mathrm{C} 2$ in the Appendix. It is important to notice that we do not instrument the variable $E P_{l k}$. However, in our regression specifications, we control for variables at the village level that describe the perceived quality of education in the villages and the presence of schools. With these variables, we proxy factors that could simultaneously affect the likelihood of a given village having an education project and household expenditure with education. Nevertheless, since these variables capture perceived quality of infrastructure and services in the villages at the time of data collection, endogeneity at the village level cannot be completely ruled out. This should be kept in mind when interpreting the results.

\subsection{Results and discussion}

\subsubsection{Village needs and participation in the premium's decision-making}

As explained in subsection 4.3.1., despite its economic growth, the rural population of Côte d'Ivoire still faces some serious constraints in terms of access to education, sanitation, electricity, and other basic services. In our survey, we asked respondents to name the top three types of services, infrastructure, and investments that are needed in their villages to have a better 
overview of their main challenges. ${ }^{20}$ We grouped their answers into the same categories that we used to group the projects financed with the Fairtrade social premium (Table 12) so that we could draw a parallel between the needs of the villages and the investments that have been made with the social premium. The answers are shown in Figure $\mathrm{C} 1$ in the Appendix.

Most respondents mentioned education as one of the main needs of their villages. Although most villages that we visited have some sort of infrastructure available that is used for schooling, these are often of very poor quality. In the smaller villages, it is not uncommon to see that the schools are simply small spaces with a rooftop but without walls, with some chairs for the students and an old chalkboard for the teacher. The second category mentioned most often was roads/transportation, followed by health in third place. The quality of the roads in Côte d'Ivoire is indeed very poor and during data collection several farmers mentioned them as one of the main constraints for cocoa commercialization.

When we look at the disaggregated data, we see a few differences in the answers between groups. electricity and water have been mentioned as major issues by around $29 \%$ and $48 \%$ of the farm workers respectively. Among farmers, these were mentioned as major issues by around $22 \%$ and $35 \%$ of the respondents, while among cooperative workers only by $12 \%$ and $27 \%$. These figures show that there are substantial differences in the places where these groups live. Cooperative workers usually live closer to the cooperatives, whose headquarters tend to be located in bigger cities, with better services and infrastructure. Farmers usually live in villages where the provision of services and infrastructure can vary substantially depending on their size and proximity to bigger towns. Meanwhile, most farm workers live on the farms or in camps dedicated to farm workers, where basic infrastructure such as electricity and water is usually missing.

Some of these issues related to infrastructure and basic service provision could be mitigated with the use of the Fairtrade premium, either through direct investments in infrastructure or in awareness campaign regarding education, sanitation, water treatment, etc. In fact several cooperatives use the social premium for community development projects and these tend to be highly appreciated by the members of the cooperatives (Loconto et al., 2019). In order to implement effective projects to address the most urgent needs of these villages, it is essential that farmers participate in the decision-making processes and voice their needs. The leaders of

\footnotetext{
${ }^{20}$ Although we specifically asked about needs of the village, around $20 \%$ of cooperative workers and $10 \%$ of farmers mentioned issues related to the cooperative in their answers.
} 
the cooperatives that we interviewed told us that decisions regarding the use of the premium are done in the general assemblies, which all farmers are supposed to attend. Nevertheless, our data show that only $48 \%$ of the certified farmers participate in the general assembly. One could argue that farmers make their voices heard by sending delegates to these assemblies. However, only $55 \%$ of the certified farmers are aware of the existence of the social premium and $35 \%$ claim to have voted on how the social premium should be used.

\subsubsection{Projects implemented with the Fairtrade social premium}

In Table 13 we show a summary of all the projects that have been implemented with the Fairtrade social premium between 2013 and 2017. As explained in subsection 4.3.2., for each one of the projects we asked what its purpose was, how much was spent, and whether the whole village had access to the benefits of the project (as opposed to only the registered members of the cooperative and its staff). The 22 cooperatives who had implemented projects by the time of the interview reported using the social premium to finance 96 different projects, which totaled 1.4 billion CFA. ${ }^{21}$ The categories with the largest number of projects were cooperative, education, and miscellaneous, which includes projects related to training, reforestation, waste management, and certification fees. Projects related to agricultural production such as ag. inputs, credit, and direct payments were restricted to the members of the cooperatives, while all projects in the categories health, roads/transportation, and water were accessible to the whole village. Out of the 18 projects in the category education, five were restricted to the members of the cooperatives. The goal of these projects was to give financial assistance to families to pay for costs related to education. The projects on education related awareness campaigns and investments in infrastructure were accessible to the whole village.

Table 13. Use of the Fairtrade social premium between 2013-2017

\begin{tabular}{|c|c|c|c|c|c|}
\hline Project categories & $\begin{array}{l}\text { Number of } \\
\text { projects } \\
\text { implemented }\end{array}$ & $\begin{array}{l}\text { Number of } \\
\text { cooperatives that } \\
\text { invested in each } \\
\text { project category }\end{array}$ & $\begin{array}{c}\text { Total value } \\
\text { spent } \\
\text { (in } 1 \mathrm{M} \mathrm{CFA} \text { ) }\end{array}$ & $\begin{array}{c}\text { Mean value } \\
\text { spent } \\
\text { (in } 1 \mathrm{M} \mathrm{CFA} \text { ) }\end{array}$ & $\begin{array}{l}\% \text { of projects } \\
\text { that the whole } \\
\text { village has } \\
\text { access to }\end{array}$ \\
\hline Ag. inputs & 8 & 7 & 165.2 & 20.7 & 0 \\
\hline Cooperative & 39 & 17 & 630.4 & 16.2 & $7 \%$ \\
\hline Credit & 2 & 2 & 20.6 & 10.3 & 0 \\
\hline Direct payments & 5 & 5 & 220.6 & 44.1 & 0 \\
\hline Education & 18 & 12 & 175.5 & 9.7 & $72 \%$ \\
\hline Health & 2 & 2 & 43.7 & 21.9 & $100 \%$ \\
\hline Miscellaneous & 10 & 6 & 19.7 & 2.0 & $10 \%$ \\
\hline Other community infrastructure & 3 & 2 & 42.9 & 14.3 & $33 \%$ \\
\hline Roads/transportation & 5 & 5 & 43.2 & 8.6 & $100 \%$ \\
\hline Water & 4 & 4 & 60.6 & 15.2 & $100 \%$ \\
\hline Total & 96 & 22 & $1,422.5$ & 14.8 & $29 \%$ \\
\hline
\end{tabular}

\footnotetext{
${ }^{21}$ At the time of the survey, the exchange rate was 1 Euro $=656 \mathrm{CFA}$.
} 
Despite the large number of projects on education that were implemented, these represent only a small percentage of the total premium that was used by the cooperatives. The 39 projects related to investments in the cooperative account for almost $45 \%$ of the total money spent on projects between 2013 and 2017. The 18 projects on education account for less than $15 \%$ of the total. Investments in other projects with public goods characteristics, such as health, roads/transportation, and water, have also received only a fraction of the total social premium, with less than $5 \%$ each. These figures point towards a mismatch between what the local population deems to be urgent needs in their villages and how the premium is being allocated to different kinds of projects. We should not immediately conclude that farmers are not being heard in the decision-making process, but this indicates the need to investigate in more detail how these processes take place inside the cooperatives.

\subsubsection{Cooperative characteristics and the use of the Fairtrade social premium}

One common hypothesis in the literature is that how the Fairtrade social premium is used depends on the organizational structure of the cooperatives that receive this money. Our data show that certified cooperatives can be rather heterogeneous in terms of their characteristics. In Table 14 we show descriptive statistics for some selected variables that describe these cooperatives in terms of their governance structure, human, physical, and social capital. The certified cooperatives in our sample are very large and most of them have male leaders who have attended at least technical training post high school. The boards of directors have on average 9.6 members and $70 \%$ of the members own farms larger than 5 ha. ${ }^{22}$ Regarding the decision-making processes, we presented the leaders of the cooperatives with a list of issues that are important for the functioning of the cooperative (e.g. choosing a new president, choosing the members of the board of directors, accepting new members, excluding members, hiring employees, etc.) and asked them to indicate which of these issues were decided democratically in the general assembly. On average, 39\% of these issues were decided in general assemblies. Some of these variables have very large standard deviations, which indicates that these cooperatives are very heterogeneous.

\footnotetext{
${ }^{22}$ In our data, the average cocoa farm has 4.9 ha. Other sources report that the average cocoa farm in West Africa has between 3 and 4 ha (Wessel \& Quist-Wessel, 2015).
} 
Table 14. Descriptive statistics for the cooperative characteristics used in the PCA $(N=25)$

\begin{tabular}{|c|c|c|c|}
\hline $\begin{array}{l}\text { Cooperative } \\
\text { characteristics }\end{array}$ & Description & Mean & SD \\
\hline Board big farms & $\begin{array}{l}\text { Share of members in the board of directors who } \\
\text { own farms larger than } 5 \text { ha }\end{array}$ & 0.70 & 0.29 \\
\hline Board size & Number of members in the board of directors & 9.68 & 2.15 \\
\hline Business plan & $\begin{array}{l}\text { Cooperative has a business plan prepared for the } \\
\text { following cocoa season }\end{array}$ & 0.73 & 0.46 \\
\hline Computer & Number of computers owned by the cooperative & 6.32 & 3.82 \\
\hline Democratic decisions & $\begin{array}{l}\text { Share of issues that are discussed and decided } \\
\text { democratically in the general assembly }\end{array}$ & 0.39 & 0.17 \\
\hline Edu leader & Education of the leader of the cooperative in years & 15.68 & 2.92 \\
\hline Female leader & Leader of the cooperative is female & 0.18 & 0.39 \\
\hline Members & Number of members registered in the cooperative & 948.73 & 807.98 \\
\hline Service providers & $\begin{array}{l}\text { Number of actors (NGOs, extension agencies, } \\
\text { commercial partner, etc.) who help the } \\
\text { cooperatives provide services to their members }\end{array}$ & 2.36 & 1.50 \\
\hline Vehicles & Number of vehicles owned by the cooperative & 9.32 & 6.78 \\
\hline Years certified & $\begin{array}{l}\text { Number of years that the cooperative has been } \\
\text { Fairtrade certified }\end{array}$ & 4.45 & 1.68 \\
\hline
\end{tabular}

We follow by analyzing the relationship between the cooperative characteristics described in Table 14 and the use of the social premium. The results from the PCA show that almost $70 \%$ of the variation in the data can be explained by the first three dimensions (Figure C2 in the Appendix). The first dimension captures mostly the assets owned by the cooperatives, their size, and how long they have been Fairtrade certified, while the second dimension is better described by the education of the leader, the share of board members who own big farms, and the existence of a business plan for the following cocoa season (Table 14). Furthermore, in Table 15 we see that investments in water $(\mathrm{p}<0.00)$ and investments in education and other community infrastructure $(\mathrm{p}<0.10)$ are also positively correlated with the first dimension. In Figure C3 in the Appendix we show a biplot of the cooperatives and the variables used in the PCA, where we can see that most cooperatives have negative scores on the first component, but positive scores on the second component. In other words, most cooperatives have low values for the variables associated with the first component and high values for those associated with the second component. 
Table 15. Correlation between variables and the five main dimensions of the PCA.

\begin{tabular}{|c|c|c|c|c|c|}
\hline & $\begin{array}{c}(1) \\
\text { Dim. } 1\end{array}$ & $\begin{array}{c}(2) \\
\text { Dim. } 2\end{array}$ & $\begin{array}{c}(3) \\
\text { Dim. } 3\end{array}$ & $\begin{array}{c}(4) \\
\text { Dim. } 4\end{array}$ & $\begin{array}{c}(5) \\
\text { Dim. } 5\end{array}$ \\
\hline \multicolumn{6}{|l|}{ Active variables } \\
\hline Board big farms & -0.095 & $0.642^{* * *}$ & $0.679^{* * *}$ & -0.020 & 0.125 \\
\hline Board members & $0.595^{* * *}$ & 0.265 & 0.061 & $0.601^{* * *}$ & $0.375^{*}$ \\
\hline Business plan & 0.193 & $0.852^{* * *}$ & -0.205 & -0.288 & 0.228 \\
\hline Computers & $0.843^{* * *}$ & 0.142 & -0.064 & $-0.396^{*}$ & -0.074 \\
\hline Democratic decisions & $0.420^{*}$ & -0.323 & $0.650^{* * *}$ & -0.271 & 0.303 \\
\hline Edu leader & $0.423^{* *}$ & $0.551^{* * *}$ & 0.324 & 0.204 & -0.201 \\
\hline Female leader & $0.532^{* *}$ & -0.026 & $-0.649^{* * *}$ & -0.019 & $0.450^{* *}$ \\
\hline Members & $0.568^{* * *}$ & $0.396^{*}$ & -0.305 & 0.154 & $-0.444^{* *}$ \\
\hline Service providers & $0.397^{*}$ & $-0.789^{* * *}$ & 0.065 & 0.119 & 0.060 \\
\hline Vehicles & $0.906^{* * *}$ & -0.211 & 0.067 & -0.205 & -0.170 \\
\hline Years certified & $0.625^{* * *}$ & -0.296 & 0.228 & 0.189 & -0.149 \\
\hline \multicolumn{6}{|l|}{ Supplementary variables } \\
\hline Ag. inputs & -0.211 & 0.137 & -0.328 & -0.082 & 0.128 \\
\hline Cooperative & -0.201 & 0.062 & 0.317 & -0.210 & $0.445^{* *}$ \\
\hline Credit & -0.197 & 0.157 & 0.070 & -0.147 & 0.159 \\
\hline Dir. payments & 0.199 & 0.079 & -0.243 & 0.233 & -0.336 \\
\hline Education & $0.383^{*}$ & -0.088 & -0.218 & 0.094 & -0.024 \\
\hline Health & -0.067 & 0.116 & 0.139 & -0.147 & -0.113 \\
\hline Misc. & 0.051 & 0.045 & 0.260 & 0.040 & 0.121 \\
\hline Other infrastr. & $0.388^{*}$ & -0.336 & 0.161 & 0.188 & -0.018 \\
\hline Roads & -0.198 & 0.356 & -0.150 & 0.015 & -0.028 \\
\hline Water & $0.659^{* * *}$ & 0.087 & -0.044 & -0.333 & -0.239 \\
\hline
\end{tabular}

In Figure 4 we show a circle of correlations, where we can see the relationship between cooperative characteristics (vectors in black) and the use of the social premium (vectors in blue). When two vectors are close, forming a small angle, the two variables they represent are positively correlated, while vectors that form an angle close to $180^{\circ}$ are negatively correlated. The length of the vectors on the plot represents how well the variables are represented by the two dimensions on which the variables are being plotted. If a variable is perfectly represented by only two dimensions, its vector will touch the circle; when more than two dimensions are needed, the length of the vector will be shorter. The closer to the center of the plot a variable is, the less important it is for those two dimensions and its interpretation should be done carefully.

Among the variables that represent the share of the social premium used, the ones that are better described by the two first dimensions are water, other infrastr., education, and roads. The first three are positively correlated with the number of assets owned by the cooperative, the share of 
issues decided democratically, the number of years the cooperative has been certified, and having a female leader. Roads is negatively correlated with these variables, as they are in opposite quadrants on the circle of correlations (Figure 4). Given that a large share of respondents indicated the need for projects related to basic community infrastructure, seeing that cooperatives with more democratic decision-making processes invest a larger share of the premium in projects related to water, education, and other community infrastructure is a welcoming finding.

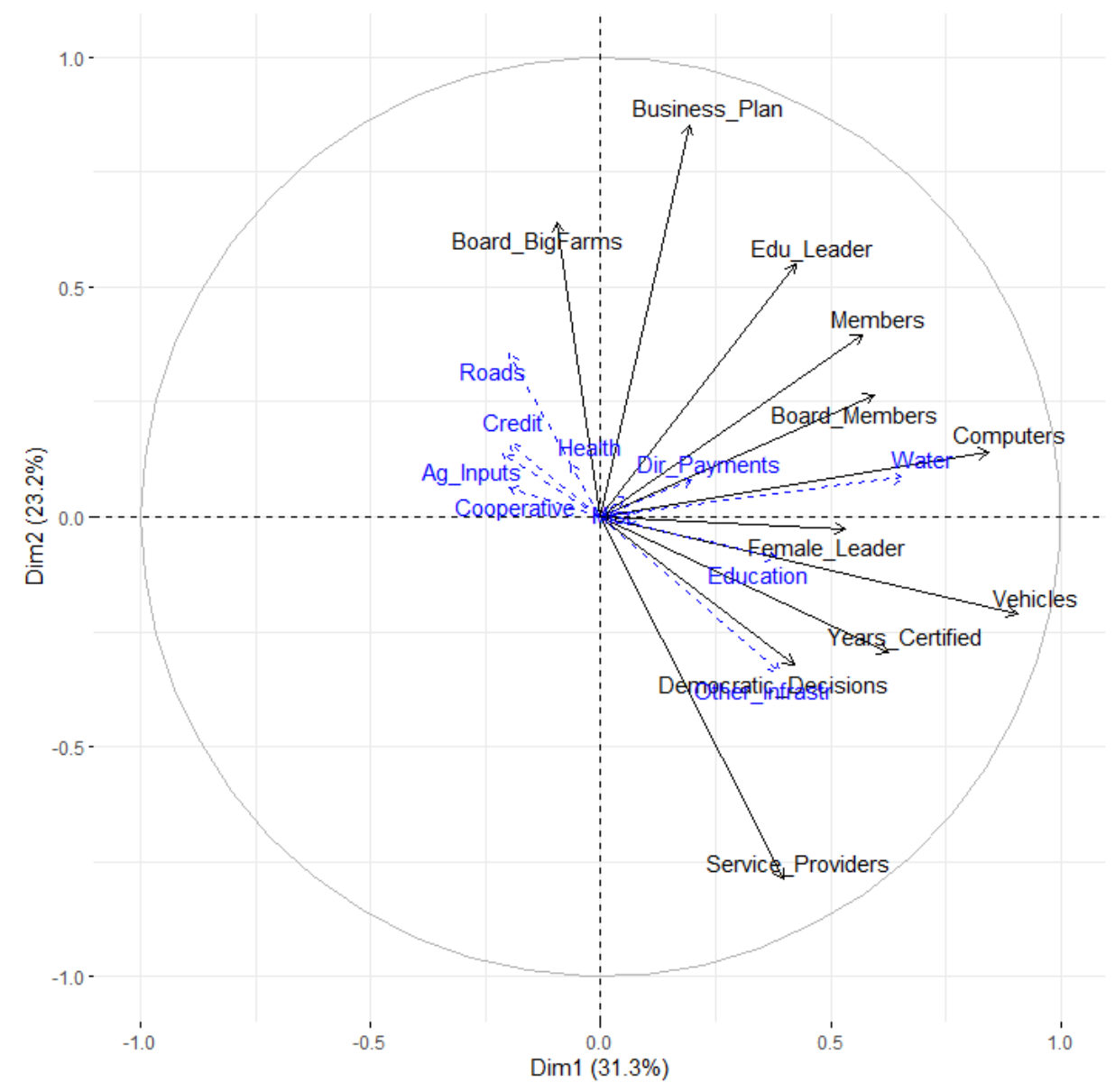

Figure 4. Principal component analysis on cooperative characteristics (in black) and their correlation with cooperatives' investments using the Fairtrade social premium (in blue) (Dim. 1 and Dim. 2)

It is important to note that the variables that represent the uses of the social premium are not particularly well-projected on the circle of correlations, since most of them are closer to center of the circle than to its edges. This means that the relationship between these variables could be different if they were projected using other dimensions of the PCA. Figure 5 shows the circle of correlations using the first and third dimensions, and Figure 6 using the second and third dimensions. The relationships shown in Figure 5 are mostly similar to those shown in Figure 4 but not all of them hold in Figure 6. These results indicate that while there are certainly 
important relationships between cooperative characteristics and how these cooperatives use the premium, we should be careful in concluding exactly which sets of characteristics are correlated with which uses of the social premium.

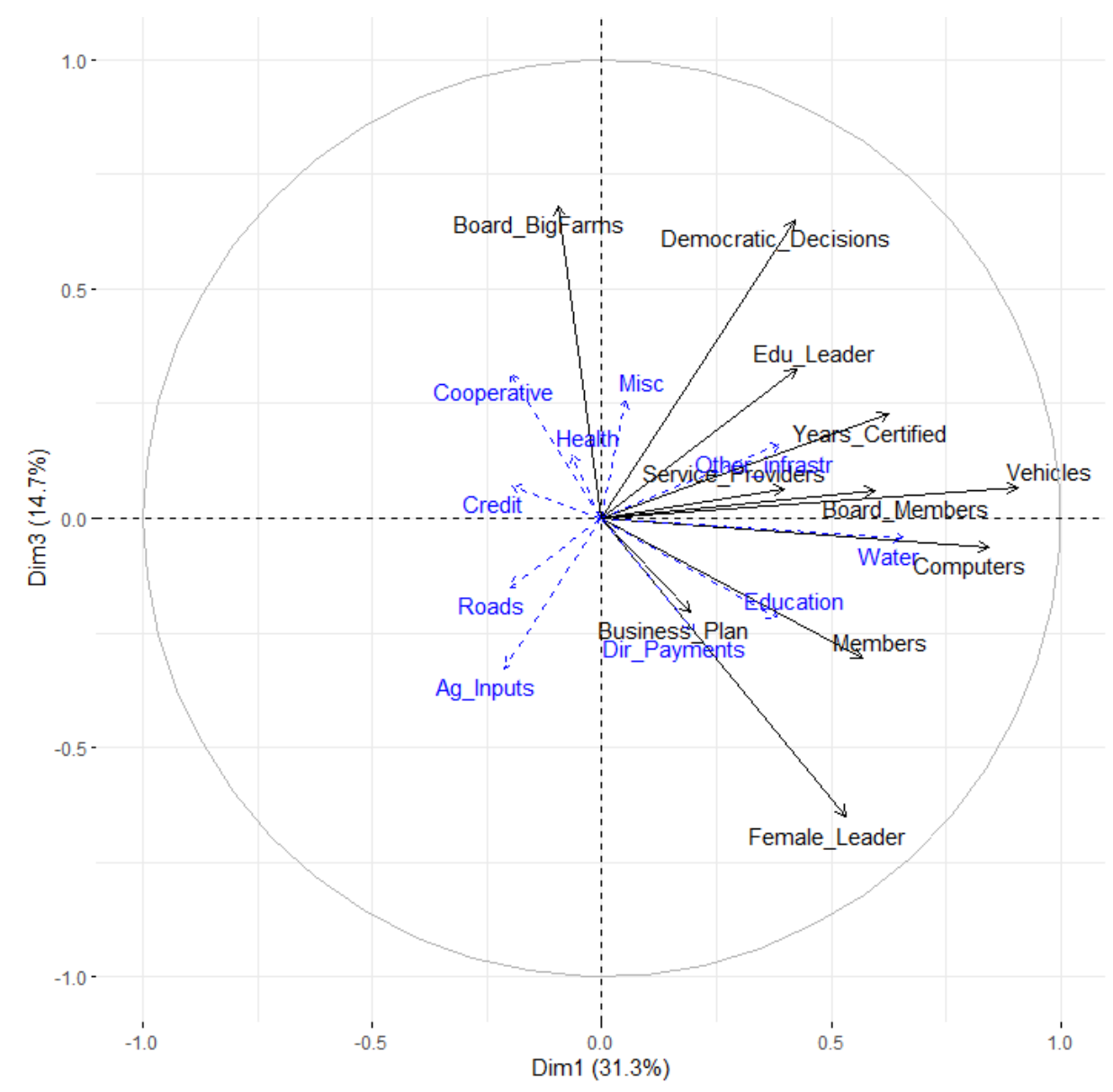

Figure 5. Principal component analysis on cooperative characteristics (in black) and their correlation with cooperatives' investments using the Fairtrade social premium (in blue) (Dim. 1 and Dim. 3) 


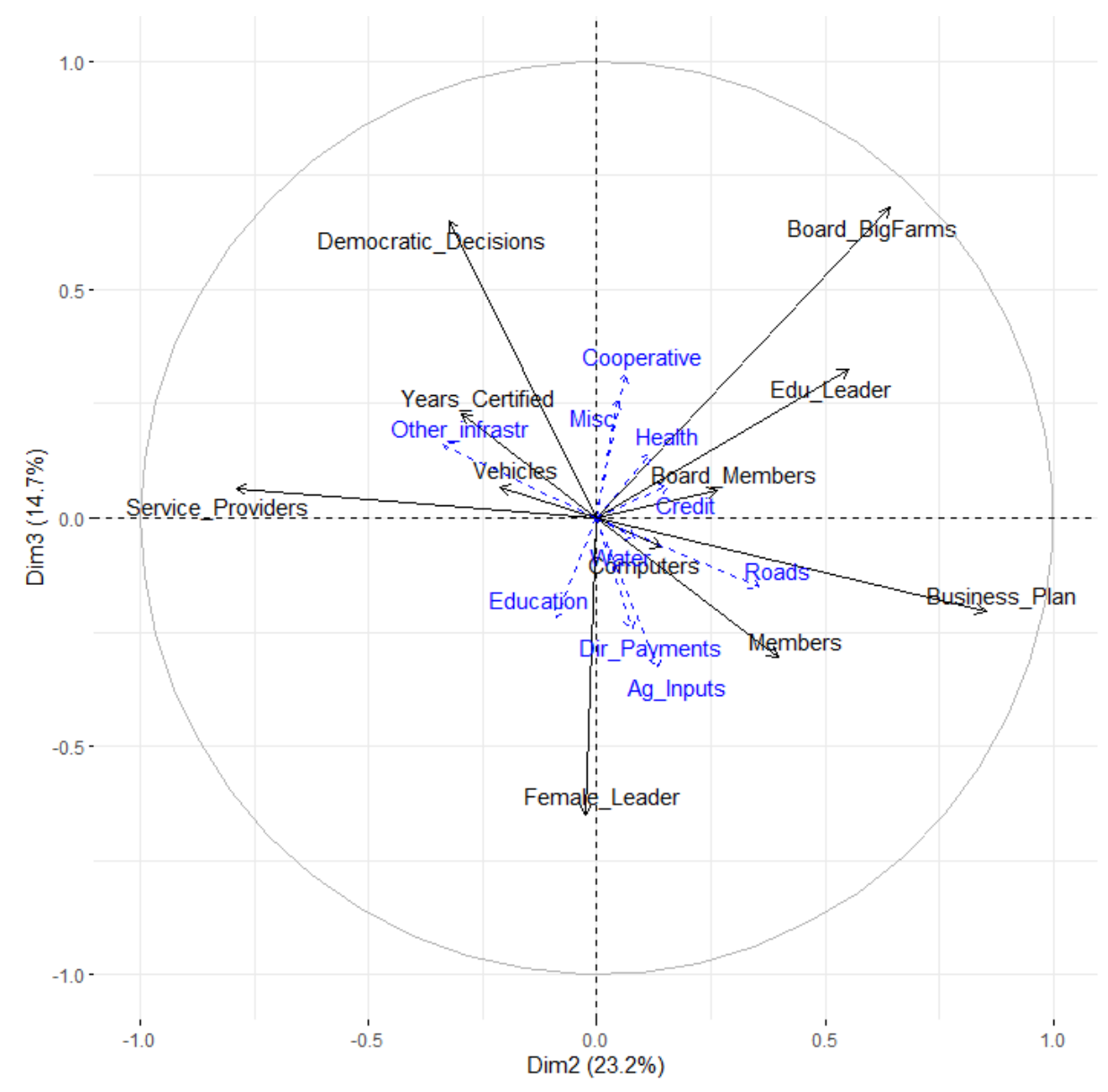

Figure 6. Principal component analysis on cooperative characteristics (in black) and their correlation with cooperatives' investments using the Fairtrade social premium (in blue) (Dim. 2 and Dim. 3)

\subsubsection{Effects on education}

In the previous section we have seen some evidence that cooperative characteristics matter for the allocation of the Fairtrade social premium into different kinds of projects. However, the question whether these projects are beneficial to the local communities is at least equally important. Given that more than half of the respondents indicated that improvements in education are among the most pressing needs of their communities, we want to take education as an example to further analyze the possible benefits of living in a village where an education project financed with the social premium was implemented.

In Table 16 we show descriptive statistics for variables related to child education, disaggregating them by whether the respondent is certified and whether he/she lives in a village with an education project financed with the social premium. We observe that certified 
households, either living in a village where an education project was implemented or not, have higher education expenditure per child than non-certified households living in villages without a project. We find no statistically significant differences between groups for distance to the nearest primary school nor for satisfaction with education system, measured in a 10-points likert scale.

Table 16. Descriptive statistics for variables at the household level

\begin{tabular}{|c|c|c|c|c|c|}
\hline & $\begin{array}{c}\text { (1) } \\
\text { Full sample }\end{array}$ & $\begin{array}{c}(2) \\
\text { Non-certified } \\
\text { and } \\
\text { no project }\end{array}$ & $\begin{array}{c}\text { (3) } \\
\text { Non-certified } \\
\text { and } \\
\text { project }^{\text {a }}\end{array}$ & $\begin{array}{c}(4) \\
\text { Certified } \\
\text { and } \\
\text { no project }^{\text {a }}\end{array}$ & $\begin{array}{l}(5) \\
\text { Certified } \\
\text { and } \\
\text { project }^{\text {a }}\end{array}$ \\
\hline Education expenditure per child & 122.74 & 85.10 & 127.26 & $143.66^{* *}$ & $236.55^{* * *}$ \\
\hline (in $1,000 \mathrm{CFA} /$ child) ${ }^{\mathrm{b}}$ & $(246.74)$ & $(141.54)$ & $(236.74)$ & $(309.11)$ & $(293.18)$ \\
\hline \multirow[t]{2}{*}{ Distance to primary school $(\mathrm{km})$} & 1.68 & 1.72 & 1.03 & 1.74 & 1.57 \\
\hline & $(4.29)$ & $(4.41)$ & $(1.49)$ & $(4.30)$ & $(4.95)$ \\
\hline \multirow[t]{2}{*}{ Distance to secondary school $(\mathrm{km})$} & 9.37 & 10.76 & $3.09^{* * *}$ & $8.25^{* * *}$ & 12.74 \\
\hline & $(10.79)$ & $(12.36)$ & $(2.95)$ & $(9.13)$ & $(10.88)$ \\
\hline Satisfaction with education system & 5.19 & 5.08 & 5.37 & 5.21 & 5.72 \\
\hline$(1-10)$ & $(2.18)$ & $(2.07)$ & $(2.06)$ & $(2.28)$ & $(2.32)$ \\
\hline Observations & 1,000 & 448 & 52 & 442 & 58 \\
\hline
\end{tabular}

In Table 17 we show the results of our regression analyses. Here we analyze the effect of being certified and the effect of living in a village where an education project was implemented on household education expenditure. We first run the analysis on the full sample of respondents, followed by sub-sample analyses using each group of respondents at a time (i.e. farmers, cooperative workers, farm workers). Then, we rerun these regressions using only data from the respondents who are not certified. This last set of regressions allows us to analyze spillover effects of the social premium on non-certified households. These results are shown in Table 18.

Looking at the model where we use the full sample, we see positive statistically significant effects for both our variables of interest. However, when we run sub-sample analyses for each group of respondents, we see that the effects on the full sample were driven by the farmer subgroup. Being certified does have a positive effect on education expenditure for farmers and cooperative workers, but not for farm workers. However, living in a village where an education project was implemented is only beneficial for farmers. These results are in line with previous findings conducted in Côte d'Ivoire that show that while Fairtrade has a positive financial effect on farmers and cooperative workers, it does not benefit farm workers (Meemken et al., 2019; Sellare et al., 2020). Studies conducted elsewhere have also reported that Fairtrade only has limited benefits to hired laborers (Valkila \& Nygren, 2010; van Rijn et al., 2019). Therefore, 
since certification does not have an effect on overall income among farm workers, it is not surprising that it does not have an effect on education expenditure either. While living in a village with an education project also benefits farmers, it has no effect among cooperative workers. This might be explained by the fact that most cooperative workers live in towns with better infrastructure for schooling and better access to information about the importance of investing in child education, thus having a project implemented in such places has no added benefit.

Table 17. Effects of certification and education projects on household education expenditure (log)

\begin{tabular}{|c|c|c|c|c|c|c|c|c|}
\hline & \multicolumn{2}{|c|}{ Full sample } & \multicolumn{2}{|c|}{ Farmers } & \multicolumn{2}{|c|}{ Coop workers } & \multicolumn{2}{|c|}{ Farm workers } \\
\hline & OLS & IV & OLS & IV & OLS & IV & OLS & IV \\
\hline & (1) & (2) & (3) & (4) & $(5)$ & (6) & $(7)$ & (8) \\
\hline \multirow[t]{2}{*}{ Certification $(1 / 0)$} & $0.43^{* * *}$ & $0.52^{* * *}$ & $0.35^{* *}$ & $0.46^{* *}$ & $0.82^{* *}$ & $0.89^{* *}$ & 0.33 & 0.29 \\
\hline & $(0.12)$ & $(0.15)$ & $(0.15)$ & $(0.18)$ & $(0.32)$ & $(0.40)$ & $(0.32)$ & $(0.38)$ \\
\hline \multirow[t]{2}{*}{ Education project $(1 / 0)$} & $0.41^{* *}$ & $0.43^{* * *}$ & $0.71^{* * *}$ & $0.73^{* * *}$ & -0.24 & -0.21 & 0.52 & 0.51 \\
\hline & $(0.16)$ & $(0.16)$ & $(0.14)$ & $(0.14)$ & $(0.51)$ & $(0.47)$ & $(0.41)$ & $(0.37)$ \\
\hline Observations & 712 & 712 & 433 & 433 & 147 & 147 & 132 & 132 \\
\hline
\end{tabular}

Note: Clustered standard error shown in parentheses. ${ }^{*} p<0.1,{ }^{* *} p<0.05,{ }^{* * *} p<0.01$

Regressions include household, cooperative, and village-level control variables. Full results are shown in Table C2 in the Appendix.

Focusing only on non-certified households, we do not observe statistically significant effects of living in a village with an education project, neither for the full sample nor for the sub-groups. This suggests that only households that participate in certified value chains benefit from the social premium, despite the public good nature of these education projects. However, it is important to note that the estimates are all positive in magnitude. A larger sample size might have resulted in significant estimates. Therefore, we should be careful in concluding that community development projects implemented with the social premium have no benefit at all for non-certified households.

Table 18. Spillover effects of education projects on household education expenditure (log)

\begin{tabular}{|c|c|c|c|c|}
\hline & Full sample & Farmers & Coop workers & Farm workers \\
\hline & $\begin{array}{c}\text { OLS } \\
(1)\end{array}$ & $\begin{array}{c}\text { OLS } \\
(2)\end{array}$ & $\begin{array}{c}\text { OLS } \\
\text { (3) }\end{array}$ & $\begin{array}{c}\text { OLS } \\
(4) \\
\end{array}$ \\
\hline Education project (1/0) & $\begin{array}{c}0.31 \\
(0.20) \\
\end{array}$ & $\begin{array}{c}0.39 \\
(0.34) \\
\end{array}$ & $\begin{array}{c}0.42 \\
(0.54) \\
\end{array}$ & $\begin{array}{c}0.79 \\
(0.52) \\
\end{array}$ \\
\hline Observations & 353 & 210 & 78 & 65 \\
\hline
\end{tabular}

Note: Clustered standard error shown in parentheses. Regressions include household, cooperative, and village-level control variables. Full results are shown in Table $\mathrm{C} 3$ in the Appendix.

\subsection{Conclusion}

In this article, we have discussed how the Fairtrade social premium can be used to address some needs of rural communities related to basic infrastructure and the provision of services. Using 
data from cocoa cooperatives from Côte d'Ivoire, we have analyzed what kinds of projects are financed with the social premium and how its allocation into different kinds of projects is correlated with the organizational structure of these cooperatives. We show that certified cooperatives are very heterogeneous in terms of their characteristics and our results suggest that larger investments into projects related to education, water, and other community infrastructure are positively correlated with having a female leader, being certified for many years, and having more democratic decision-making processes. Although we should be careful in concluding that these are the specific characteristics that are more likely to result into higher investments in projects that can benefit the local community, we observe some evidence that cooperative heterogeneity is indeed important.

To illustrate the possible benefits of projects financed with the Fairtrade social premium, we used data from cocoa farmers, cooperative workers, and farm workers to analyze the effects of certification and education projects on household education expenditure. Our results suggest that while being certified has a positive effect on education expenditure among farmers and cooperative workers, only farmers benefit from living in a village where an education project financed with the social premium had been implemented. It is not surprising that cooperative workers do not benefit from education projects, given that most of them live in places with better infrastructure and better information about the importance of child education. However, the fact that we do not see an effect among farm workers might be due to financial constraints to spend more on child education.

Our study has two limitations that should be addressed in follow-up research. First, because we have cross-sectional data, we cannot observe time trends in how the social premium is used. There is likely a dynamic interaction over time between how the cooperatives develop and what they spend the social premium. To further explore the relationship between cooperative characteristics and the use of the premium, it would be important to have panel data and preferably count with an even larger number of cooperatives. Second, our analyses of the effects of education projects on household education expenditure should not be interpreted as causal. Although we control in the model specification for some variables at the village level, these were subjective measures, calculated using data from the farmers and workers surveys. Better data and more robust econometric approaches should be used in the future to estimate the causal effects of projects financed with the Fairtrade social premium. 


\section{General conclusions}

During the last decade, voluntary sustainability standards have significantly grown in importance for the production and marketing of all major tropical commodities, such as cocoa, coffee, cotton, and palm oil. These standards address several economic, environmental, and social issues - such as poverty alleviation, reduced deforestation, and improvements in labor conditions - and have the potential to engender changes in agricultural value chains to make them more sustainable. Several studies have tried to quantify the effect of sustainability standards on economic, environmental, and social outcomes in the small farm sector. However, these studies have almost completely neglected the role of agricultural cooperatives in certified value chains, both in their sampling strategy and in their empirical analyses. Because certification in the small farm sector is usually done through cooperatives, smallholder participation in certification schemes and the benefits from certification may both be affected by cooperative characteristics. The articles included in this dissertation are the first attempt to explicitly account for cooperative heterogeneity and how this can affect the impact of sustainability standards on economic, environmental, and social outcomes.

\subsection{Main conclusions}

There are at least two main conclusions drawn from this dissertation that should be highlighted. First, participating in a certified value chain has benefits for smallholder farmers, even when taking into account possible cooperative effects. This finding reinforces the potential that sustainability standards have for fostering sustainable development in the small farm sector, and suggests that these effects are not exclusively driven by membership in agricultural cooperatives with specific characteristics. I find evidence that certification has significant economic benefits for farmers, such as improvements in yields, higher prices, and overall better livelihoods. These are benefits that are also often associated with membership in well-functioning cooperatives, which is why the literature on sustainability standards has emphasized the need to disentangle cooperative effects from certification effects. I have shown that certification has positive economic effects on smallholder farmers even after controlling for cooperative characteristics in the regression analyses. Similar results were found for social outcomes. Certification has health benefits for farmers and rural workers, as it reduces the acute health symptoms commonly associated with pesticide use. Furthermore, I have found evidence that certification has positive effects on household expenditures for child education. From an environmental perspective, I 
could not identify positive effects of certification. On the contrary, I showed that certified farmers use larger quantities of agrochemicals, with higher overall levels of toxicity. Nonetheless, it is important to notice that the quantities of pesticide used by certified farmers are much closer to the recommendations of local authorities than the quantities used by non-certified farmers. This suggests that in spite of increases in quantity, certification does not necessarily induce farmers to overuse agrochemicals.

Second, cooperatives are highly heterogeneous and they are a key mechanism through which sustainability standards benefit farmers and workers. It is not surprising that there are important differences between certified and non-certified cooperatives, as one would expect certified cooperatives to have more members, commercialize larger volumes of produce, have more stable business relationships, etc. However, the data used in this dissertation shows that there is also significant heterogeneity within the groups of certified and non-certified cooperatives. This highlights the importance of using data from a large number of cooperatives when assessing the effects of sustainability standards in the small farm sector. Otherwise, it is impossible to ensure that the estimated effects would hold for cooperatives beyond those being analyzed. In other words, external validity would be quite limited. Because in the small farm sector, standards are usually managed and implemented by these cooperatives, there can be significant differences in terms of what kind of investments the cooperatives prioritize. Some cooperatives might choose to invest the premium they obtain from certification in providing inputs and training to their members, while others might prefer to pass this premium directly to farmers as bonus payments. These issues are even more relevant when analyzing the effects of Fairtrade certification. Because Fairtrade mandates that buyers pay to cooperatives an additional sum of money on top of the agreed price to be used for business and/or community development projects, how this money is used can affect some of the mechanisms through which farmers and workers benefit from certification. Therefore, I conclude that cooperative heterogeneity matters to correctly estimate the effects of certification in the small farm sector and its many pathways.

\subsection{Limitations and considerations for future research}

Some studies on sustainability standards reach far less positive conclusions about their effects on the small farm sector. Many of these studies highlight the high costs associated with certification (Latynskiy \& Berger, 2017; Snider et al., 2017), small price premiums (Minten et al., 2018; Ruben \& Fort, 2012), no significant increases in yields and overall low productivity (Akoyi \& Maertens, 2018; Beuchelt \& Zeller, 2011), undemocratic decision-making processes 
(Cramer et al., 2017; Dolan, 2010), and farmers' lack of knowledge about certification (Jena \& Grote, 2017). These are all issues that could be affected by how the standards are managed at the cooperative level. However, since previous studies do not provide good descriptions of the characteristics and functioning of the cooperatives selected, it is not possible to know if these negative conclusions are the result of some idiosyncratic features of these cooperatives. Other contextual conditions could also explain why other studies fail to find effects. For example, the structure of value chains can affect how much of the money paid by consumers trickles down to farmers. Moreover, the presence of a well-functioning network of NGOs, development agencies, and extension agencies can also affect how effectively farmers are able to meet the requirements set in standards. These are issues that have received little to no attention by the literature on sustainability standards, although they could significantly affect the findings regarding the effects of certification. To empirically test how different contextual factors affect certification is very challenging as it would require very specific and rich datasets. However, giving readers a better explanation of such factors could already be quite enlightening.

It is important to note that although the external validity of my findings is considerably higher than in previous studies, my concrete results might be specific to the cocoa sector of Côte d'Ivoire and should therefore not be extrapolated to other contexts. The Ivorian cocoa sector is marked by a series of policies and institutional arrangements that could also influence how sustainability standards affect farmers, workers, and cooperatives. The floor price set by the government, for example, adds complexity to the conceptual and empirical analysis, especially when considering Fairtrade standards that also set a floor price. The organization of the cocoa sector is also particular to Côte d'Ivoire and it is significantly different from what we can observe in Ghana, for instance. In Côte d'Ivoire, cooperatives are important actors who provide many services to their members and have substantial autonomy to trade directly with exporters or processors. In Ghana, cooperatives are much weaker and the government-led Cocoa Board (COCOBOD) is the most powerful actor in the sector and absorbs a significant share of the value that is exported to implement several programs to support farmers (e.g. production of seeds, provision of inputs, quality control, pest and disease management) (Amankwah-Amoah et al., 2018; Foundjem-Tita et al., 2016). Therefore, despite being neighboring countries with many similar characteristics, a thorough analysis of the effects of certification in the Ghanaian cocoa sector would probably result in different findings than those I have reported for Côte d'Ivoire. These considerations notwithstanding, the main conclusion of this dissertation is 
certainly true beyond specific case studies: cooperatives matter and they deserve more explicit focus in future studies about the effects of sustainability standards in the small farm sector.

This dissertation has some additional limitations that are noteworthy. First, the use of crosssectional data raises some concerns regarding self-selection bias. To mitigate this problem, I have used several econometric techniques that rely on instrumental variables defined both at the household and cooperative levels, such as two-stage least squares, control function, and generalized method of moments techniques. However, all of these approaches have limitations. Panel data would allow using more robust econometric techniques, which might further increase the validity of the results. Although randomized control trials are still seen as the gold standard to deal with issues of self-selection bias, designing such study to analyze the effects of certification in a large number of cooperatives (to capture institutional heterogeneity) would be highly challenging, as this would require the cooperation of many different actors, such as all the cooperatives, buyers, and certification agencies.

Second, reverse causality at the cooperative level cannot be ruled out completely. On the one hand, we expect certification to improve the functioning of cooperatives, but, on the other hand, the better functioning cooperatives are the ones more likely to become certified. In my analyses, I have controlled for cooperative characteristics that are less likely to suffer from reverse causality issues, such as the age of the cooperative and the number of members before certification. However, to fully address possible issues of reverse causality would require panel data containing information about farm, household, and cooperative characteristics before and after certification.

Third, in my analyses I only control for cooperative characteristics, without further exploring this source of heterogeneity. It is possible that certification has heterogeneous effects across different types of cooperatives. A better understanding of which kinds of organizational setups are more likely to reap the benefits of certification could lead to important recommendations for local stakeholders. However, as mentioned above, controlling for a full set of cooperative characteristics would increase the risk of suffering from reverse causality. Furthermore, to find out which organizational setup best maximizes the benefits from certification would probably require considering complex non-linear relationships between different cooperative characteristics. 


\section{References}

Abdi, H., \& Williams, L. J. (2010). Principal component analysis. WIREs Computational Statistics, 2(4), 433-459. https://doi.org/10.1002/wics.101

Abdul-Rahaman, A., \& Abdulai, A. (2018). Do farmer groups impact on farm yield and efficiency of smallholder farmers? Evidence from rice farmers in northern Ghana. Food Policy, 81, 95-105. https://doi.org/10.1016/j.foodpol.2018.10.007

Abedullah, Kouser, S., \& Qaim, M. (2015). Bt Cotton, Pesticide Use and Environmental Efficiency in Pakistan. Journal of Agricultural Economics, 66(1), 66-86. https://doi.org/10.1111/1477-9552.12072

Akoyi, K. T., \& Maertens, M. (2018). Walk the Talk: Private Sustainability Standards in the Ugandan Coffee Sector. The Journal of Development Studies, 54(10), 1792-1818. https://doi.org/10.1080/00220388.2017.1327663

Akoyi, K. T., Mitiku, F., \& Maertens, M. (2018). Is prohibiting child labour enough? Coffee certification and child schooling in Ethiopia and Uganda. 30th International Conference of Agricultural Economists, Vancouver, British Columbia. https://ideas.repec.org/p/ags/iaae18/275958.html

Amankwah-Amoah, J., Debrah, Y. A., \& Nuertey, D. (2018). Institutional Legitimacy, CrossBorder Trade and Institutional Voids: Insights from the Cocoa Industry in Ghana. Journal of Rural Studies, 58, 136-145. https://doi.org/10.1016/j.jrurstud.2018.01.002

Ansah, E. O., Kaplowitz, M. D., Lupi, F., \& Kerr, J. (2020). Smallholder participation and procedural compliance with sustainable cocoa certification programs. Agroecology and Sustainable Food Systems, 44(1), 54-87. https://doi.org/10.1080/21683565.2019.1579776

Asfaw, S., Mithöfer, D., \& Waibel, H. (2010). Agrifood supply chain, private-sector standards, and farmers' health: Evidence from Kenya. Agricultural Economics, 41(34), 251-263. https://doi.org/10.1111/j.1574-0862.2010.00443.x 
Aust, V., Morais, A. I., \& Pinto, I. (2020). How does foreign direct investment contribute to Sustainable Development Goals? Evidence from African countries. Journal of Cleaner Production, 245, 118823. https://doi.org/10.1016/j.jclepro.2019.118823

Bacon, C. (2005). Confronting the Coffee Crisis: Can Fair Trade, Organic, and Specialty Coffees Reduce Small-Scale Farmer Vulnerability in Northern Nicaragua? World Development, 33(3), 497-511. https://doi.org/10.1016/j.worlddev.2004.10.002

Becchetti, L., Castriota, S., \& Michetti, M. (2013). The effect of fair trade affiliation on child schooling: Evidence from a sample of Chilean honey producers. Applied Economics, 45(25), 3552-3563. https://doi.org/10.1080/00036846.2012.727980

Becchetti, L., \& Costantino, M. (2008). The Effects of Fair Trade on Affiliated Producers: An Impact Analysis on Kenyan Farmers. World Development, 36(5), 823-842. https://doi.org/10.1016/j.worlddev.2007.05.007

Benali, M., Brümmer, B., \& Afari-Sefa, V. (2018). Smallholder participation in vegetable exports and age-disaggregated labor allocation in Northern Tanzania. Agricultural Economics, 49(5), 549-562. https://doi.org/10.1111/agec.12441

Bennett, E. A. (2017). Who Governs Socially-Oriented Voluntary Sustainability Standards? Not the Producers of Certified Products. World Development, 91, 53-69. https://doi.org/10.1016/j.worlddev.2016.10.010

Bernard, T., \& Spielman, D. J. (2009). Reaching the rural poor through rural producer organizations? A study of agricultural marketing cooperatives in Ethiopia. Food Policy, 34(1), 60-69. https://doi.org/10.1016/j.foodpol.2008.08.001

Beuchelt, T. D., \& Zeller, M. (2011). Profits and poverty: Certification's troubled link for Nicaragua's organic and fairtrade coffee producers. Ecological Economics, 70(7), 1316-1324. https://doi.org/10.1016/j.ecolecon.2011.01.005 
Blackman, A., \& Naranjo, M. A. (2012a). Does eco-certification have environmental benefits? Organic coffee in Costa Rica. Ecological Economics, 83, 58-66. https://doi.org/10.1016/j.ecolecon.2012.08.001

Blackman, A., \& Naranjo, M. A. (2012b). Does eco-certification have environmental benefits? Organic coffee in Costa Rica. Ecological Economics, 83, 58-66. https://doi.org/10.1016/j.ecolecon.2012.08.001

Bonroy, O., \& Constantatos, C. (2015). On the Economics of Labels: How Their Introduction Affects the Functioning of Markets and the Welfare of All Participants. American Journal of Agricultural Economics, 97(1), 239-259. https://doi.org/10.1093/ajae/aau088

Cameron, A. C., \& Trivedi, P. K. (2013). Regression Analysis of Count Data (2nd ed.). Cambridge University Press. https://doi.org/10.1017/CBO9781139013567

Chiputwa, B., \& Qaim, M. (2016). Sustainability Standards, Gender, and Nutrition among Smallholder Farmers in Uganda. The Journal of Development Studies, 52(9), 12411257. https://doi.org/10.1080/00220388.2016.1156090

Chiputwa, B., Spielman, D. J., \& Qaim, M. (2015). Food Standards, Certification, and Poverty among Coffee Farmers in Uganda. World Development, 66, 400-412. https://doi.org/10.1016/j.worlddev.2014.09.006

Christiaensen, L. (2017). Agriculture in Africa - Telling myths from facts: A synthesis. Food Policy, 67, 1-11. https://doi.org/10.1016/j.foodpol.2017.02.002

Christiaensen, L., \& Martin, W. (2018). Agriculture, structural transformation and poverty reduction: Eight new insights. World Development, 109, 413-416. https://doi.org/10.1016/j.worlddev.2018.05.027

Cramer, C., Johnston, D., Mueller, B., Oya, C., \& Sender, J. (2017). Fairtrade and Labour Markets in Ethiopia and Uganda. The Journal of Development Studies, 53(6), 841856. https://doi.org/10.1080/00220388.2016.1208175 
Darko, E., Lynch, A., \& Smith, W. (2017). The impact of Fairtrade: A review of research evidence 2009-2015. Overseas Development Institute. https://www.odi.org/publications/10891-impact-fairtrade-review-research-evidence2009-2015

DeFries, R. S., Fanzo, J., Mondal, P., Remans, R., \& Wood, S. A. (2017). Is voluntary certification of tropical agricultural commodities achieving sustainability goals for small-scale producers? A review of the evidence. Environmental Research Letters, 12(3), 033001. https://doi.org/10.1088/1748-9326/aa625e

Di Falco, S., Veronesi, M., \& Yesuf, M. (2011). Does Adaptation to Climate Change Provide Food Security? A Micro-Perspective from Ethiopia. American Journal of Agricultural Economics, 93(3), 829-846. https://doi.org/10.1093/ajae/aar006

Dietz, T., Auffenberg, J., Estrella Chong, A., Grabs, J., \& Kilian, B. (2018). The Voluntary Coffee Standard Index (VOCSI). Developing a Composite Index to Assess and Compare the Strength of Mainstream Voluntary Sustainability Standards in the Global Coffee Industry. Ecological Economics, 150, 72-87. https://doi.org/10.1016/j.ecolecon.2018.03.026

Dohmen, T., Falk, A., Huffman, D., Sunde, U., Schupp, J., \& Wagner, G. G. (2011). Individual Risk Attitudes: Measurement, Determinants, and Behavioral Consequences. Journal of the European Economic Association, 9(3), 522-550. https://doi.org/10.1111/j.1542-4774.2011.01015.x

Dolan, C. S. (2010). Virtual moralities: The mainstreaming of Fairtrade in Kenyan tea fields. Geoforum, 41(1), 33-43. https://doi.org/10.1016/j.geoforum.2009.01.002

Dragusanu, R., Giovannucci, D., \& Nunn, N. (2014). The Economics of Fair Trade. Journal of Economic Perspectives, 28(3), 217-236. https://doi.org/10.1257/jep.28.3.217 
Dragusanu, R., \& Nunn, N. (2018). The Effects of Fair Trade Certification: Evidence from Coffee Producers in Costa Rica (Working Paper No. 24260). National Bureau of Economic Research. https://doi.org/10.3386/w24260

Ehlert, C. R., Mithöfer, D., \& Waibel, H. (2014). Worker welfare on Kenyan export vegetable farms. Food Policy, 46, 66-73. https://doi.org/10.1016/j.foodpol.2014.01.004

Elahi, E., Weijun, C., Zhang, H., \& Nazeer, M. (2019). Agricultural intensification and damages to human health in relation to agrochemicals: Application of artificial intelligence. Land Use Policy, 83, 461-474.

https://doi.org/10.1016/j.landusepol.2019.02.023

Elder, S. D., Zerriffi, H., \& Le Billon, P. (2013). Is Fairtrade certification greening agricultural practices? An analysis of Fairtrade environmental standards in Rwanda. Journal of Rural Studies, 32, 264-274. https://doi.org/10.1016/j.jrurstud.2013.07.009

Fairtrade. (2014). Fairtrade Standard for Hired Labour. Fairtrade International.

Fairtrade. (2016). Journeys to Change: Fairtrade Theory of Change. Fairtrade International. Fairtrade. (2017). Fairtrade Standard for Cocoa. Fairtrade International.

Fairtrade. (2018a). Hazardous materials list. Fairtrade International.

Fairtrade. (2018b). Monitoring the Scope and Benefits of Fairtrade: Monitoring Report 9th Edition. Fairtrade International.

https://files.fairtrade.net/publications/FairtradeMonitoringReport_9thEdition_lores.pdf

Fairtrade. (2019a). Fairtrade Standard for Smallscale Producer Organizations. Fairtrade International.

Fairtrade. (2019b). Monitoring the Scope and Benefits of Fairtrade: Cocoa. Monitoring Report 10th Edition. Fairtrade International. https://files.fairtrade.net/publications/2019_Monitoring_Cocoa_10thEd.pdf FAO. (2020). FAOSTAT Statistical Database. http://www.fao.org/faostat/en/\#data/QC 
Fenger, N. A., Bosselmann, A. S., Asare, R., \& Neergaard, A. de. (2017). The impact of certification on the natural and financial capitals of Ghanaian cocoa farmers. Agroecology and Sustainable Food Systems, 41(2), 143-166. https://doi.org/10.1080/21683565.2016.1258606

Foundjem-Tita, D., Degrande, A., Donovan, J., Stoian, D., \& Kouamé, C. (2017). Baseline for Assessing the Impact of Fairtrade Certification on Cocoa Growers and Cooperatives in Côte d'Ivoire. World Agroforestry Center.

https://www.researchgate.net/publication/327272734_Baseline_for_Assessing_the_Im pact_of_Fairtrade_Certification_on_Cocoa_Growers_and_Cooperatives_in_Cote_d $\%$ 27Ivoire

Foundjem-Tita, D., Donovan, J., Stoian, D., \& Degrande, A. (2016). Baseline for Assessing the Impact of Fairtrade Certification on Cocoa Farmers and Cooperatives in Ghana. World Agroforestry Center. https://www.researchgate.net/publication/316209784_Baseline_for_Assessing_the_Im pact_of_Fairtrade_Certification_on_Cocoa_Farmers_and_Cooperatives_in_Ghana

Gitter, S. R., Weber, J. G., Barham, B. L., Callenes, M., \& Valentine, J. L. (2012). Fair TradeOrganic Coffee Cooperatives, Migration, and Secondary Schooling in Southern Mexico. The Journal of Development Studies, 48(3), 445-463. https://doi.org/10.1080/00220388.2011.598511

Gouel, C., \& Guimbard, H. (2019). Nutrition Transition and the Structure of Global Food Demand. American Journal of Agricultural Economics, 101(2), 383-403. https://doi.org/10.1093/ajae/aay030

Grashuis, J., \& Su, Y. (2019). A Review of the Empirical Literature on Farmer Cooperatives: Performance, Ownership and Governance, Finance, and Member Attitude. Annals of Public and Cooperative Economics, 90(1), 77-102. https://doi.org/10.1111/apce.12205 
Haggar, J., Soto, G., Casanoves, F., \& Virginio, E. de M. (2017). Environmental-economic benefits and trade-offs on sustainably certified coffee farms. Ecological Indicators, 79, 330-337. https://doi.org/10.1016/j.ecolind.2017.04.023

Hardt, E., Borgomeo, E., dos Santos, R. F., Pinto, L. F. G., Metzger, J. P., \& Sparovek, G. (2015). Does certification improve biodiversity conservation in Brazilian coffee farms? Forest Ecology and Management, 357, 181-194. https://doi.org/10.1016/j.foreco.2015.08.021

Hirvonen, K., \& Hoddinott, J. (2017). Agricultural production and children's diets: Evidence from rural Ethiopia. Agricultural Economics, 48(4), 469-480. https://doi.org/10.1111/agec.12348

Ibanez, M., \& Blackman, A. (2016). Is Eco-Certification a Win-Win for Developing Country Agriculture? Organic Coffee Certification in Colombia. World Development, 82, 14 27. https://doi.org/10.1016/j.worlddev.2016.01.004

ICCO. (2018). Quarterly Bulletin of Cocoa Statistics, Cocoa year 2017/18. International Cocoa Organization. https://www.icco.org/about-us/icco-news/384-february-2018quarterly-bulletin-of-cocoa-statistics.html

IFAD. (2017). République de Côte d'Ivoire: Note de stratégie pays. IFAD.

Iweala, S., Spiller, A., \& Meyerding, S. (2019). Buy good, feel good? The influence of the warm glow of giving on the evaluation of food items with ethical claims in the U.K. and Germany. Journal of Cleaner Production, 215, 315-328. https://doi.org/10.1016/j.jclepro.2018.12.266

Jena, P. R., Chichaibelu, B. B., Stellmacher, T., \& Grote, U. (2012). The impact of coffee certification on small-scale producers' livelihoods: A case study from the Jimma Zone, Ethiopia. Agricultural Economics, 43(4), 429-440. https://doi.org/10.1111/j.15740862.2012.00594.x 
Jena, P. R., \& Grote, U. (2017). Fairtrade Certification and Livelihood Impacts on Small-scale Coffee Producers in a Tribal Community of India. Applied Economic Perspectives and Policy, 39(1), 87-110. https://doi.org/10.1093/aepp/ppw006

Jena, P. R., Stellmacher, T., \& Grote, U. (2017). Can coffee certification schemes increase incomes of smallholder farmers? Evidence from Jinotega, Nicaragua. Environment, Development and Sustainability, 19(1), 45-66. https://doi.org/10.1007/s10668-015$9732-0$

Karki, S. K., Jena, P. R., \& Grote, U. (2016). Fair Trade Certification and Livelihoods: A Panel Data Analysis of Coffee-growing Households in India. Agricultural and Resource Economics Review, 45(3), 436-458. https://doi.org/10.1017/age.2016.3

Kersting, S., \& Wollni, M. (2012). New institutional arrangements and standard adoption: Evidence from small-scale fruit and vegetable farmers in Thailand. Food Policy, 37(4), 452-462. https://doi.org/10.1016/j.foodpol.2012.04.005

Klasen, S. (2000). Measuring Poverty and Deprivation in South Africa. Review of Income and Wealth, 46(1), 33-58. https://doi.org/10.1111/j.1475-4991.2000.tb00390.x

Kniss, A. R. (2017). Long-term trends in the intensity and relative toxicity of herbicide use. Nature Communications, 8,14865 . https://doi.org/10.1038/ncomms14865

Kniss, A. R., \& Coburn, C. W. (2015). Quantitative Evaluation of the Environmental Impact Quotient (EIQ) for Comparing Herbicides. PLOS ONE, 10(6), e0131200. https://doi.org/10.1371/journal.pone.0131200

Kouser, S., \& Qaim, M. (2011). Impact of Bt cotton on pesticide poisoning in smallholder agriculture: A panel data analysis. Ecological Economics, 70(11), 2105-2113. https://doi.org/10.1016/j.ecolecon.2011.06.008

Kovach, J., Petzoldt, C., Degni, J., \& Tette, J. (1992). A Method to Measure the Environmental Impact of Pesticides. NYS IPM, 139. https://ecommons.cornell.edu/handle/1813/55750 
Kromann, P., Pradel, W., Cole, D., Taipe, A., \& Forbes, G. A. (2011). Use of the Environmental Impact Quotient to Estimate Health and Environmental Impacts of Pesticide Usage in Peruvian and Ecuadorian Potato Production. Journal of Environmental Protection, 02, 581. https://doi.org/10.4236/jep.2011.25067

Ladhari, R., \& Tchetgna, N. M. (2015). The influence of personal values on Fair Trade consumption. Journal of Cleaner Production, 87, 469-477. https://doi.org/10.1016/j.jclepro.2014.10.068

Latynskiy, E., \& Berger, T. (2017). Assessing the Income Effects of Group Certification for Smallholder Coffee Farmers: Agent-based Simulation in Uganda. Journal of Agricultural Economics, 68(3), 727-748. https://doi.org/10.1111/1477-9552.12212

Lau, H., Shum, P. K. C., Nakandala, D., Fan, Y., \& Lee, C. (2020). A game theoretic decision model for organic food supplier evaluation in the global supply chains. Journal of Cleaner Production, 242, 118536. https://doi.org/10.1016/j.jclepro.2019.118536

Lê, S., Josse, J., \& Husson, F. (2008). FactoMineR: An R Package for Multivariate Analysis. Journal of Statistical Software, 25(1), 1-18. https://doi.org/10.18637/jss.v025.i01

Lernoud, J., Potts, J., Sampson, G., Schlatter, B., Huppé, G., Voora, V., Willer, H., Wozniak, J., \& Dang, D. (2018). The State of Sustainable Markets - Statistics and Emerging Trends 2018. ITC.

http://www.intracen.org/uploadedFiles/intracenorg/Content/Publications/Sustainibility \%202018\%20layout-FIN-web2.pdf

Li, M., Wiedmann, T., \& Hadjikakou, M. (2019). Towards meaningful consumption-based planetary boundary indicators: The phosphorus exceedance footprint. Global Environmental Change, 54, 227-238. https://doi.org/10.1016/j.gloenvcha.2018.12.005

Loconto, A., Silva-Castañeda, L., Arnold, N., \& Jimenez, A. (2019). Participatory Analysis of the Use and Impact of the Fairtrade Premium. Laboratoire Interdisciplinaire Sciences Innovations Sociétés. 
Luckstead, J., Tsiboe, F., \& Nalley, L. L. (2019). Estimating the economic incentives necessary for eliminating child labor in Ghanaian cocoa production. PLOS ONE, 14(6), e0217230. https://doi.org/10.1371/journal.pone.0217230

MADR. (2017). Répertoire de Sociétés Coopératives. Ministère de l'Agriculture et du Développement Rural. http://www.agriculture.gouv.ci/uploads/Repertoire_des_soci\%C3\%A9t\%C3\%A9s_co op\%C3\%A9ratives_FILIERES_2017_(2).pdf

Meemken, E.-M. (2020). Do smallholder farmers benefit from sustainability standards? A systematic review and meta-analysis. Global Food Security, 26, 100373. https://doi.org/10.1016/j.gfs.2020.100373

Meemken, E.-M., \& Qaim, M. (2018a). Organic Agriculture, Food Security, and the Environment. Annual Review of Resource Economics, 10(1), 39-63. https://doi.org/10.1146/annurev-resource-100517-023252

Meemken, E.-M., \& Qaim, M. (2018b). Can private food standards promote gender equality in the small farm sector? Journal of Rural Studies, 58, 39-51. https://doi.org/10.1016/j.jrurstud.2017.12.030

Meemken, E.-M., Sellare, J., Kouame, C. N., \& Qaim, M. (2019). Effects of Fairtrade on the livelihoods of poor rural workers. Nature Sustainability, 2(7), 635-642. https://doi.org/10.1038/s41893-019-0311-5

Meemken, E.-M., Spielman, D. J., \& Qaim, M. (2017). Trading off nutrition and education? A panel data analysis of the dissimilar welfare effects of Organic and Fairtrade standards. Food Policy, 71, 74-85. https://doi.org/10.1016/j.foodpol.2017.07.010

Midingoyi, S. G., Kassie, M., Muriithi, B., Diiro, G., \& Ekesi, S. (2019). Do Farmers and the Environment Benefit from Adopting Integrated Pest Management Practices? Evidence from Kenya. Journal of Agricultural Economics, 70(2), 452-470. https://doi.org/10.1111/1477-9552.12306 
Minten, B., Dereje, M., Engida, E., \& Tamru, S. (2018). Tracking the Quality Premium of Certified Coffee: Evidence from Ethiopia. World Development, 101, 119-132. https://doi.org/10.1016/j.worlddev.2017.08.010

Mitiku, F., De Mey, Y., Nyssen, J., \& Maertens, M. (2017). Do Private Sustainability Standards Contribute to Income Growth and Poverty Alleviation? A Comparison of Different Coffee Certification Schemes in Ethiopia. Sustainability, 9(2), 246. https://doi.org/10.3390/su9020246

Möhring, N., Bozzola, M., Hirsch, S., \& Finger, R. (2020). Are pesticides risk decreasing? The relevance of pesticide indicator choice in empirical analysis. Agricultural Economics, $n / a(\mathrm{n} / \mathrm{a}) . \mathrm{https}: / /$ doi.org/10.1111/agec.12563

Möhring, N., Gaba, S., \& Finger, R. (2019). Quantity based indicators fail to identify extreme pesticide risks. Science of The Total Environment, 646, 503-523. https://doi.org/10.1016/j.scitotenv.2018.07.287

Moyer, J. D., \& Hedden, S. (2020). Are we on the right path to achieve the sustainable development goals? World Development, 127, 104749. https://doi.org/10.1016/j.worlddev.2019.104749

Mullahy, J. (1997). Instrumental-Variable Estimation of Count Data Models: Applications to Models of Cigarette Smoking Behavior. The Review of Economics and Statistics, 79(4), 586-593. https://doi.org/10.1162/003465397557169

Muradian, R., \& Pelupessy, W. (2005). Governing the coffee chain: The role of voluntary regulatory Systems. World Development, 33(12), 2029-2044. https://doi.org/10.1016/j.worlddev.2005.06.007

Naef, M., \& Schupp, J. (2009). Measuring Trust: Experiments and Surveys in Contrast and Combination. IZA Discussion Paper, 4087. http://ftp.iza.org/dp4087.pdf 
Nelson, G. C., \& Bullock, D. S. (2003). Simulating a relative environmental effect of glyphosate-resistant soybeans. Ecological Economics, 45(2), 189-202. https://doi.org/10.1016/S0921-8009(03)00011-9

Newton, P., Alves-Pinto, H. N., \& Pinto, L. F. G. (2015). Certification, Forest Conservation, and Cattle: Theories and Evidence of Change in Brazil. Conservation Letters, 8(3), 206-213. https://doi.org/10.1111/conl.12116

Nkamleu, G. B., \& Kielland, A. (2006). Modeling farmers' decisions on child labor and schooling in the cocoa sector: A multinomial logit analysis in Côte d'Ivoire. Agricultural Economics, 35(3), 319-333. https://doi.org/10.1111/j.15740862.2006.00165.x

Oelofse, M., Høgh-Jensen, H., Abreu, L. S., Almeida, G. F., Hui, Q. Y., Sultan, T., \& de Neergaard, A. (2010). Certified organic agriculture in China and Brazil: Market accessibility and outcomes following adoption. Ecological Economics, 69(9), 17851793. https://doi.org/10.1016/j.ecolecon.2010.04.016

Oya, C., Schaefer, F., \& Skalidou, D. (2018). The effectiveness of agricultural certification in developing countries: A systematic review. World Development, 112, 282-312. https://doi.org/10.1016/j.worlddev.2018.08.001

Peterson, R. K. D., \& Iii, J. J. S. (2014). A probabilistic analysis reveals fundamental limitations with the environmental impact quotient and similar systems for rating pesticide risks. PeerJ, 2, e364. https://doi.org/10.7717/peerj.364

Potts, J., Lynch, M., Wilkings, A., Huppé, G., Cunningham, M., \& Voora, V. (2014). The State of Sustainability Initiatives Review 2014: Standards and the Green Economy. IISD. https://www.iisd.org/pdf/2014/ssi 2014.pdf

Ragasa, C., \& Golan, J. (2014). The role of rural producer organizations for agricultural service provision in fragile states. Agricultural Economics, 45(5), 537-553. https://doi.org/10.1111/agec.12105 
Rainforest Alliance. (2020). Annex 5: Rainforest Alliance development of the new agrochemicals approach (Public Consultation Draft Version 2.0). Rainforest Alliance. https://www.rainforest-alliance.org/business/wp-content/uploads/2019/06/annex-5draft-rainforest-alliance-development-of-new-agrochemicals-approach.pdf

Rao, E. J. O., \& Qaim, M. (2013). Supermarkets and agricultural labor demand in Kenya: A gendered perspective. Food Policy, 38, 165-176. https://doi.org/10.1016/j.foodpol.2012.11.008

Raynolds, L. T. (2002). Consumer/Producer Links in Fair Trade Coffee Networks. Sociologia Ruralis, 42(4), 404-424. https://doi.org/10.1111/1467-9523.00224

Raynolds, L. T., Murray, D., \& Taylor, P. L. (2004). Fair trade coffee: Building producer capacity via global networks. Journal of International Development, 16(8), 11091121. https://doi.org/10.1002/jid.1136

Ricker-Gilbert, J., Jayne, T. S., \& Chirwa, E. (2011). Subsidies and Crowding Out: A DoubleHurdle Model of Fertilizer Demand in Malawi. American Journal of Agricultural Economics, 93(1), 26-42. https://doi.org/10.1093/ajae/aaq122

Ruben, R., \& Fort, R. (2012). The Impact of Fair Trade Certification for Coffee Farmers in Peru. World Development, 40(3), 570-582. https://doi.org/10.1016/j.worlddev.2011.07.030

Ruggeri, G., \& Corsi, S. (2019). An analysis of the Fairtrade cane sugar small producer organizations network. Journal of Cleaner Production, 240, 118191. https://doi.org/10.1016/j.jclepro.2019.118191

Sellare, J., Meemken, E.-M., Kouamé, C., \& Qaim, M. (2020). Do Sustainability Standards Benefit Smallholder Farmers Also When Accounting For Cooperative Effects? Evidence from Côte d'Ivoire. American Journal of Agricultural Economics, 102(2), 681-695. https://doi.org/10.1002/ajae.12015 
Sellare, J., Meemken, E.-M., \& Qaim, M. (2020). Fairtrade, Agrochemical Input Use, and Effects on Human Health and the Environment. GlobalFood Discussion Papers, 136. Sheahan, M., Barrett, C. B., \& Goldvale, C. (2017). Human health and pesticide use in SubSaharan Africa. Agricultural Economics, 48(S1), 27-41. https://doi.org/10.1111/agec.12384

Snider, A., Gutiérrez, I., Sibelet, N., \& Faure, G. (2017). Small farmer cooperatives and voluntary coffee certifications: Rewarding progressive farmers of engendering widespread change in Costa Rica? Food Policy, 69, 231-242. https://doi.org/10.1016/j.foodpol.2017.04.009

Ssebunya, B. R., Morawetz, U. B., Schader, C., Stolze, M., \& Schmid, E. (2018). Group membership and certification effects on incomes of coffee farmers in Uganda. European Review of Agricultural Economics. https://doi.org/10.1093/erae/jby022

Stoner, K. A., \& Eitzer, B. D. (2013). Using a Hazard Quotient to Evaluate Pesticide Residues Detected in Pollen Trapped from Honey Bees (Apis mellifera) in Connecticut. PLOS ONE, 8(10), e77550. https://doi.org/10.1371/journal.pone.0077550

Swinnen, J. (2016). Economics and politics of food standards, trade, and development\#. Agricultural Economics, 47(S1), 7-19. https://doi.org/10.1111/agec.12316

Swinnen, J., Deconinck, K., Vandemoortele, T., \& Vandeplas, A. (2015). Quality Standards, Value Chains, and International Development: Economic and Political Theory. Cambridge University Press.

Tadesse, G., Abate, G. T., \& Ergano, K. (2018). The Boundary of Smallholder Producers' Cooperatives: A Conceptual and Empirical Analysis. Journal of Agricultural Economics, $O(0)$. https://doi.org/10.1111/1477-9552.12310

Takahashi, R., \& Todo, Y. (2013). The impact of a shade coffee certification program on forest conservation: A case study from a wild coffee forest in Ethiopia. Journal of 
Environmental Management, 130, 48-54.

https://doi.org/10.1016/j.jenvman.2013.08.025

Tayleur, C., Balmford, A., Buchanan, G. M., Butchart, S. H. M., Ducharme, H., Green, R. E., Milder, J. C., Sanderson, F. J., Thomas, D. H. L., Vickery, J., \& Phalan, B. (2017). Global Coverage of Agricultural Sustainability Standards, and Their Role in Conserving Biodiversity. Conservation Letters, 10(5), 610-618. https://doi.org/10.1111/conl.12314

Tran, D., \& Goto, D. (2019). Impacts of sustainability certification on farm income: Evidence from small-scale specialty green tea farmers in Vietnam. Food Policy, 83, 70-82. https://doi.org/10.1016/j.foodpol.2018.11.006

Tscharntke, T., Milder, J. C., Schroth, G., Clough, Y., DeClerck, F., Waldron, A., Rice, R., \& Ghazoul, J. (2015). Conserving Biodiversity Through Certification of Tropical Agroforestry Crops at Local and Landscape Scales. Conservation Letters, 8(1), 14-23. https://doi.org/10.1111/conl.12110

Valkila, J. (2009). Fair Trade organic coffee production in Nicaragua-Sustainable development or a poverty trap? Ecological Economics, 68(12), 3018-3025. https://doi.org/10.1016/j.ecolecon.2009.07.002

Valkila, J., \& Nygren, A. (2010). Impacts of Fair Trade certification on coffee farmers, cooperatives, and laborers in Nicaragua. Agriculture and Human Values, 27(3), 321333. https://doi.org/10.1007/s10460-009-9208-7

Van den Broeck, G., Vlaeminck, P., Raymaekers, K., Vande Velde, K., Vranken, L., \& Maertens, M. (2017). Rice farmers' preferences for fairtrade contracting in Benin: Evidence from a discrete choice experiment. Journal of Cleaner Production, 165, 846-854. https://doi.org/10.1016/j.jclepro.2017.07.128 
van Rijn, F., Fort, R., Ruben, R., Koster, T., \& Beekman, G. (2019). Does certification improve hired labour conditions and wageworker conditions at banana plantations? Agriculture and Human Values. https://doi.org/10.1007/s10460-019-09990-7

van Rijsbergen, B., Elbers, W., Ruben, R., \& Njuguna, S. N. (2016). The Ambivalent Impact of Coffee Certification on Farmers' Welfare: A Matched Panel Approach for Cooperatives in Central Kenya. World Development, 77, 277-292. https://doi.org/10.1016/j.worlddev.2015.08.021

Vanderhaegen, K., Akoyi, K. T., Dekoninck, W., Jocqué, R., Muys, B., Verbist, B., \& Maertens, M. (2018). Do private coffee standards 'walk the talk' in improving socioeconomic and environmental sustainability? Global Environmental Change, 51, 1-9. https://doi.org/10.1016/j.gloenvcha.2018.04.014

Veettil, P. C., Krishna, V. V., \& Qaim, M. (2017). Ecosystem impacts of pesticide reductions through Bt cotton adoption. Australian Journal of Agricultural and Resource Economics, 61(1), 115-134. https://doi.org/10.1111/1467-8489.12171

Verhofstadt, E., \& Maertens, M. (2014). Smallholder cooperatives and agricultural performance in Rwanda: Do organizational differences matter? Agricultural Economics, 45(S1), 39-52. https://doi.org/10.1111/agec.12128

Wessel, M., \& Quist-Wessel, P. M. F. (2015). Cocoa production in West Africa, a review and analysis of recent developments. NJAS - Wageningen Journal of Life Sciences, 74-75, 1-7. https://doi.org/10.1016/j.njas.2015.09.001

Willer, H., Sampson, G., Voora, V., Dang, D., \& Lernoud, J. (2019). The State of Sustainable Markets 2019: Statistics and Emerging Trends. ITC. http://www.intracen.org/uploadedFiles/intracenorg/Content/Publications/Sustainabile \%20markets\%202019\%20web.pdf 
Woldeyohanes, T., Heckelei, T., \& Surry, Y. (2017). Effect of off-farm income on smallholder commercialization: Panel evidence from rural households in Ethiopia. Agricultural Economics, 48(2), 207-218. https://doi.org/10.1111/agec.12327

Wooldridge, J. M. (2001). Applications of Generalized Method of Moments Estimation. The Journal of Economic Perspectives, 15(4), 87-100.

Wooldridge, J. M. (2015). Control Function Methods in Applied Econometrics. Journal of Human Resources, 50(2), 420-445. https://doi.org/10.3368/jhr.50.2.420

World Bank. (2018). Poverty and Equity Brief. Sub-Saharan Africa. Cote d'Ivoire. World Bank Group. https://databank.worldbank.org/data/download/poverty/33EF03BB-97224AE2-ABC7-AA2972D68AFE/Global_POVEQ_CIV.pdf

World Bank. (2020a). Trading for Development in the Age of Global value Chains. World Bank. https://www.worldbank.org/en/publication/wdr2020

World Bank. (2020b). World Bank Development Indicators. https://databank.worldbank.org/source/world-development-indicators

Wossen, T., Abdoulaye, T., Alene, A., Haile, M. G., Feleke, S., Olanrewaju, A., \& Manyong, V. (2017). Impacts of extension access and cooperative membership on technology adoption and household welfare. Journal of Rural Studies, 54, 223-233. https://doi.org/10.1016/j.jrurstud.2017.06.022 


\section{Appendices}

\section{A. Appendix for chapter 2}

Table A1. Agroecological characteristics by district

\begin{tabular}{|c|c|c|c|}
\hline & $\begin{array}{c}(1) \\
\text { Comoe }\end{array}$ & $\begin{array}{c}(2) \\
\text { Lacs }\end{array}$ & $\begin{array}{c}(3) \\
\text { Lagunes }\end{array}$ \\
\hline Annual mean temperature $\left({ }^{\circ} \mathrm{C}\right)$ & $\begin{array}{l}26.54 \\
(0.17)\end{array}$ & $\begin{array}{l}26.65 \\
(0.12)\end{array}$ & $\begin{array}{l}26.65 \\
(0.12)\end{array}$ \\
\hline Mean temperature of wettest quarter $\left({ }^{\circ} \mathrm{C}\right)$ & $\begin{array}{l}26.99 \\
(0.28)\end{array}$ & $\begin{array}{l}27.19 \\
(0.13)\end{array}$ & $\begin{array}{l}27.19 \\
(0.12)\end{array}$ \\
\hline Mean temperature of driest quarter $\left({ }^{\circ} \mathrm{C}\right)$ & $\begin{array}{l}27.03 \\
(0.18)\end{array}$ & $\begin{array}{l}27.10 \\
(0.10)\end{array}$ & $\begin{array}{l}27.15 \\
(0.11)\end{array}$ \\
\hline Annual precipitation (mm) & $\begin{array}{l}1,390.17 \\
(167.89)\end{array}$ & $\begin{array}{c}1,118.38 \\
(30.97)\end{array}$ & $\begin{array}{c}1,328.78 \\
(39.17)\end{array}$ \\
\hline Precipitation of wettest quarter (mm) & $\begin{array}{l}582.58 \\
(85.84)\end{array}$ & $\begin{array}{l}475.30 \\
(11.21)\end{array}$ & $\begin{array}{l}572.75 \\
(21.09)\end{array}$ \\
\hline Precipitation of driest quarter (mm) & $\begin{array}{c}100.48 \\
(25.31)\end{array}$ & $\begin{array}{l}70.95 \\
(4.29)\end{array}$ & $\begin{array}{l}96.59 \\
(6.21)\end{array}$ \\
\hline Good soil (1/0) & $\begin{array}{c}0.81 \\
(0.39)\end{array}$ & $\begin{array}{c}0.72 \\
(0.45)\end{array}$ & $\begin{array}{c}0.73 \\
(0.45)\end{array}$ \\
\hline Steep terrain $(1 / 0)$ & $\begin{array}{c}0.37 \\
(0.48)\end{array}$ & $\begin{array}{c}0.45 \\
(0.50)\end{array}$ & $\begin{array}{c}0.46 \\
(0.50) \\
\end{array}$ \\
\hline Observations & 260 & 40 & 200 \\
\hline
\end{tabular}

Notes: Mean values are shown with standard deviations in parentheses. Temperature and precipitation data were obtained from WorldClim (Fick, S.E., \& Hijmans, R.J. (2017). WorldClim 2: new 1-km spatial resolution climate surfaces for global land areas. International Journal of Climatology, 37(12), 4302-4315) and matched with the GPS coordinates of the sample farmers. These variables represent historical averages for the years 1970-2000.

Table A2. Correlation matrix between certification and instruments

\begin{tabular}{|c|c|c|c|}
\hline & $\begin{array}{c}(1) \\
\text { Certified } \\
(1 / 0)\end{array}$ & $\begin{array}{c}(2) \\
\text { Share of certified } \\
\text { farmers } \\
(5 \mathrm{~km} \text { radius })\end{array}$ & $\begin{array}{c}(3) \\
\text { Network provider of coop } \\
\text { leader }(1=\text { Orange })\end{array}$ \\
\hline Certified $(1 / 0)$ & 1.00 & & \\
\hline Share of certified farmers ( $5 \mathrm{~km}$ radius $)$ & $0.85^{* * *}$ & 1.00 & \\
\hline Network provider of coop leader $(1=$ Orange $)$ & $0.19^{* * *}$ & $0.15^{* * *}$ & 1.00 \\
\hline
\end{tabular}

Note: Spearman's correlation coefficients are shown. ${ }^{*} p<0.1, * * p<0.05, * * * p<0.01$ 
Table A3. First-stage IV regression and instrument falsification tests

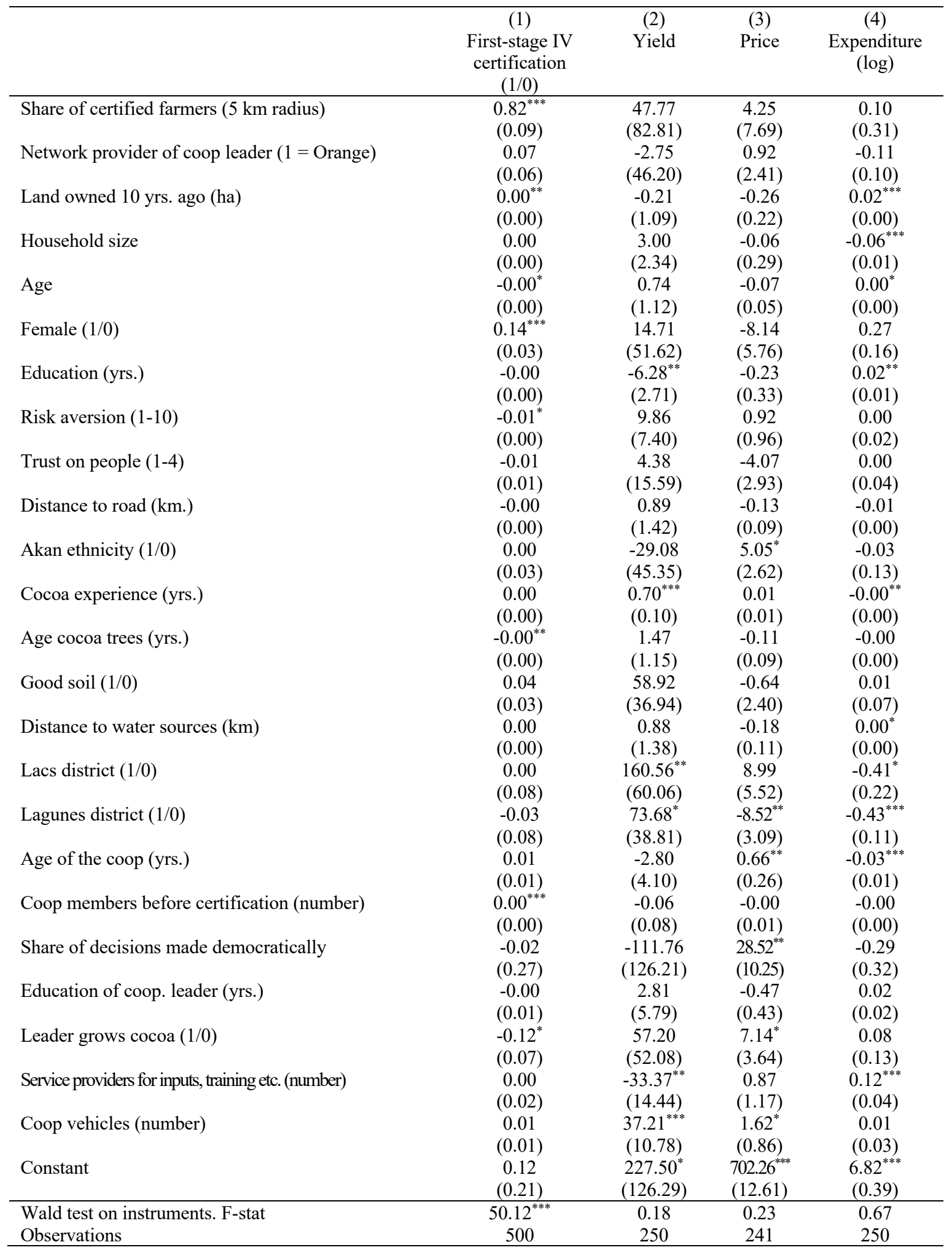

Note: Clustered standard errors are shown in parentheses. ${ }^{*} p<0.1,{ }^{* *} p<0.05,{ }^{* * *} p<0.01$ 
Table A4. Correlation between instruments and other regional factors that could influence welfare

\begin{tabular}{|c|c|c|c|}
\hline & $\begin{array}{c}\text { (1) } \\
\text { Distance to secondary } \\
\text { school }\end{array}$ & $\begin{array}{c}\text { (2) } \\
\text { Distance to } \\
\text { tarmac road }\end{array}$ & $\begin{array}{c}(3) \\
\text { Annual precipitation }\end{array}$ \\
\hline Share of certified farmers ( $5 \mathrm{~km}$ radius) & $\begin{array}{l}-3.60 \\
(2.89)\end{array}$ & $\begin{array}{c}4.53 \\
(4.52)\end{array}$ & $\begin{array}{l}-5.30 \\
(46.40)\end{array}$ \\
\hline Network provider of coop leader $(1=$ Orange $)$ & $\begin{array}{l}-1.56 \\
(2.17)\end{array}$ & $\begin{array}{l}-4.24 \\
(3.45)\end{array}$ & $\begin{array}{l}-65.35^{*} \\
(38.61)\end{array}$ \\
\hline Land owned 10 yrs. ago (ha) & $\begin{array}{c}-0.10^{* * *} \\
(0.03)\end{array}$ & $\begin{array}{c}0.05 \\
(0.04)\end{array}$ & $\begin{array}{c}0.60 \\
(0.52)\end{array}$ \\
\hline Household size & $\begin{array}{c}0.06 \\
(0.12)\end{array}$ & $\begin{array}{l}-0.10 \\
(0.18)\end{array}$ & $\begin{array}{l}-2.82^{* *} \\
(1.34)\end{array}$ \\
\hline Age & $\begin{array}{l}-0.01 \\
(0.05)\end{array}$ & $\begin{array}{l}-0.02 \\
(0.06)\end{array}$ & $\begin{array}{l}-0.44 \\
(0.48)\end{array}$ \\
\hline Female $(1 / 0)$ & $\begin{array}{l}-1.25 \\
(1.79)\end{array}$ & $\begin{array}{l}-0.79 \\
(2.91)\end{array}$ & $\begin{array}{l}-25.02 \\
(20.18)\end{array}$ \\
\hline Education (yrs.) & $\begin{array}{c}0.14 \\
(0.12)\end{array}$ & $\begin{array}{l}-0.22^{*} \\
(0.13)\end{array}$ & $\begin{array}{l}-3.23 \\
(1.97)\end{array}$ \\
\hline Risk aversion (1-10) & $\begin{array}{c}0.12 \\
(0.21)\end{array}$ & $\begin{array}{l}-0.08 \\
(0.26)\end{array}$ & $\begin{array}{c}1.60 \\
(1.86)\end{array}$ \\
\hline Trust on people (1-4) & $\begin{array}{c}0.43 \\
(0.46)\end{array}$ & $\begin{array}{c}0.63 \\
(0.68)\end{array}$ & $\begin{array}{c}7.33 \\
(5.82)\end{array}$ \\
\hline Distance to road (km.) & $\begin{array}{c}0.16 \\
(0.10)\end{array}$ & & $\begin{array}{l}2.19^{*} \\
(1.20)\end{array}$ \\
\hline Akan ethnicity $(1 / 0)$ & $\begin{array}{c}0.21 \\
(1.32)\end{array}$ & $\begin{array}{l}-2.20 \\
(1.99)\end{array}$ & $\begin{array}{l}12.17 \\
(11.75)\end{array}$ \\
\hline Cocoa experience (yrs.) & $\begin{array}{l}0.03^{* * *} \\
(0.00)\end{array}$ & $\begin{array}{l}-0.01 \\
(0.00)\end{array}$ & $\begin{array}{l}-0.06 \\
(0.04)\end{array}$ \\
\hline Age cocoa trees (yrs.) & $\begin{array}{l}-0.02 \\
(0.03)\end{array}$ & $\begin{array}{l}0.11^{* *} \\
(0.05)\end{array}$ & $\begin{array}{l}-0.62 \\
(0.48)\end{array}$ \\
\hline Good soil $(1 / 0)$ & $\begin{array}{l}-0.07 \\
(0.97)\end{array}$ & $\begin{array}{l}-0.00 \\
(1.68)\end{array}$ & $\begin{array}{c}9.67 \\
(13.80)\end{array}$ \\
\hline Distance to water sources $(\mathrm{km})$ & $\begin{array}{c}0.01 \\
(0.03)\end{array}$ & $\begin{array}{c}0.05 \\
(0.05)\end{array}$ & $\begin{array}{l}-0.47 \\
(0.32)\end{array}$ \\
\hline Lacs district $(1 / 0)$ & $\begin{array}{l}-2.50 \\
(4.03)\end{array}$ & $\begin{array}{c}-19.55^{* * *} \\
(4.85)\end{array}$ & $\begin{array}{c}-259.88^{* * *} \\
(44.90)\end{array}$ \\
\hline Lagunes district $(1 / 0)$ & $\begin{array}{l}1.03 \\
(2.22)\end{array}$ & $\begin{array}{l}-9.05^{*} \\
(4.73)\end{array}$ & $\begin{array}{l}-57.61 \\
(36.28)\end{array}$ \\
\hline Age of the coop (yrs.) & $\begin{array}{c}0.16 \\
(0.19)\end{array}$ & $\begin{array}{l}-0.28 \\
(0.28)\end{array}$ & $\begin{array}{l}-2.61 \\
(3.05)\end{array}$ \\
\hline Coop members before certification (number) & $\begin{array}{c}0.00 \\
(0.00)\end{array}$ & $\begin{array}{c}0.01^{*} \\
(0.00)\end{array}$ & $\begin{array}{l}-0.01 \\
(0.03)\end{array}$ \\
\hline Share of decisions made democratically & $\begin{array}{c}4.03 \\
(7.01)\end{array}$ & $\begin{array}{l}14.15 \\
(12.83)\end{array}$ & $\begin{array}{c}-56.92 \\
(166.01)\end{array}$ \\
\hline Education of coop. leader (yrs.) & $\begin{array}{l}-0.52 \\
(0.44)\end{array}$ & $\begin{array}{c}0.09 \\
(0.81)\end{array}$ & $\begin{array}{l}-2.29 \\
(6.23)\end{array}$ \\
\hline Leader grows cocoa $(1 / 0)$ & $\begin{array}{c}0.32 \\
(2.00)\end{array}$ & $\begin{array}{c}13.07^{* * *} \\
(3.09)\end{array}$ & $\begin{array}{l}-21.37 \\
(40.65)\end{array}$ \\
\hline Service providers for inputs, training etc. (number) & $\begin{array}{l}-1.06 \\
(1.02)\end{array}$ & $\begin{array}{l}1.43 \\
(1.54)\end{array}$ & $\begin{array}{l}-13.35 \\
(13.67)\end{array}$ \\
\hline Coop vehicles (number) & $\begin{array}{c}0.21 \\
(0.21)\end{array}$ & $\begin{array}{l}-0.27 \\
(0.36)\end{array}$ & $\begin{array}{c}1.70 \\
(3.69)\end{array}$ \\
\hline Constant & $\begin{array}{l}13.07 \\
(8.35) \\
\end{array}$ & $\begin{array}{c}4.29 \\
(15.33) \\
\end{array}$ & $\begin{array}{c}1547.19^{* * *} \\
(131.65) \\
\end{array}$ \\
\hline $\begin{array}{l}\text { Wald test on instruments. F-stat } \\
\text { Observations }\end{array}$ & $\begin{array}{l}1.20 \\
500\end{array}$ & $\begin{array}{l}1.59 \\
500\end{array}$ & $\begin{array}{l}1.48 \\
500\end{array}$ \\
\hline
\end{tabular}

Note: Clustered standard errors are shown in parentheses. ${ }^{*} p<0.1,{ }^{* *} p<0.05,{ }^{* * *} p<0.01$ 
Table A5. Effects of Fairtrade certification on cocoa yield $(\mathrm{kg} / \mathrm{ha})$

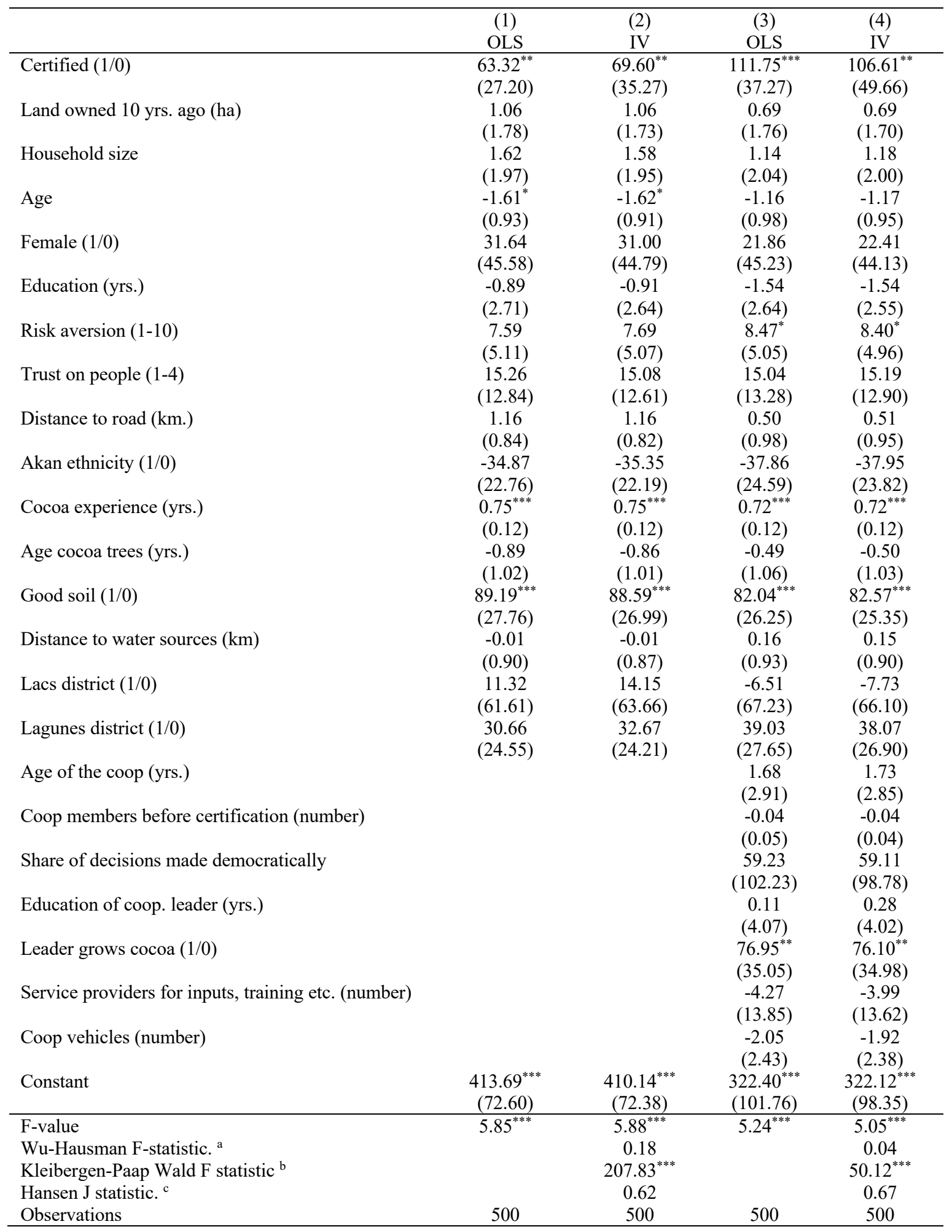

Note: Cluster robust standard errors shown in parentheses. First-stage results for the IV regressions are shown in Table A3 (column 1). ${ }^{*} p<0.1,{ }^{* *} p<0.05,{ }^{* * *} p<0.01$

Test of endogeneity ( $\mathrm{H}_{0}$ : certified variable is exogenous)

${ }^{\mathrm{b}}$ Test for weak instruments $\left(\mathrm{H}_{0}\right.$ : coefficients of instruments in first stage are not different from zero)

${ }^{c}$ Test of over-identifying restrictions $\left(\mathrm{H}_{0}\right.$ : instruments are uncorrelated with the error term) 
Table A6. Effects of Fairtrade certification on cocoa price (CFA/kg)

\begin{tabular}{|c|c|c|c|c|}
\hline & $\begin{array}{c}\text { (1) } \\
\text { OLS }\end{array}$ & $\begin{array}{l}\text { (2) } \\
\text { IV }\end{array}$ & $\begin{array}{c}(3) \\
\text { OLS }\end{array}$ & $\begin{array}{l}\text { (4) } \\
\text { IV }\end{array}$ \\
\hline Certified $(1 / 0)$ & $\begin{array}{c}26.52^{* * *} \\
(3.86)\end{array}$ & $\begin{array}{c}29.27^{* * *} \\
(4.23)\end{array}$ & $\begin{array}{c}22.11^{* * *} \\
(3.38)\end{array}$ & $\begin{array}{c}25.18^{* * *} \\
(3.69)\end{array}$ \\
\hline Land owned 10 yrs. ago (ha) & $\begin{array}{l}-0.10 \\
(0.12)\end{array}$ & $\begin{array}{l}-0.10 \\
(0.11)\end{array}$ & $\begin{array}{l}-0.09 \\
(0.10)\end{array}$ & $\begin{array}{l}-0.10 \\
(0.10)\end{array}$ \\
\hline Household size & $\begin{array}{c}0.24 \\
(0.31)\end{array}$ & $\begin{array}{c}0.23 \\
(0.30)\end{array}$ & $\begin{array}{c}0.30 \\
(0.28)\end{array}$ & $\begin{array}{c}0.28 \\
(0.26)\end{array}$ \\
\hline Age & $\begin{array}{l}-0.05 \\
(0.16)\end{array}$ & $\begin{array}{l}-0.05 \\
(0.15)\end{array}$ & $\begin{array}{l}-0.04 \\
(0.15)\end{array}$ & $\begin{array}{l}-0.03 \\
(0.14)\end{array}$ \\
\hline Female $(1 / 0)$ & $\begin{array}{l}-5.57 \\
(4.73)\end{array}$ & $\begin{array}{l}-5.86 \\
(4.68)\end{array}$ & $\begin{array}{l}-6.47 \\
(4.12)\end{array}$ & $\begin{array}{l}-6.82^{*} \\
(4.11)\end{array}$ \\
\hline Education (yrs.) & $\begin{array}{c}0.25 \\
(0.31)\end{array}$ & $\begin{array}{c}0.24 \\
(0.30)\end{array}$ & $\begin{array}{c}0.11 \\
(0.31)\end{array}$ & $\begin{array}{c}0.11 \\
(0.30)\end{array}$ \\
\hline Risk aversion (1-10) & $\begin{array}{l}-0.35 \\
(0.71)\end{array}$ & $\begin{array}{l}-0.31 \\
(0.69)\end{array}$ & $\begin{array}{l}-0.06 \\
(0.71)\end{array}$ & $\begin{array}{l}-0.03 \\
(0.68)\end{array}$ \\
\hline Trust on people (1-4) & $\begin{array}{l}-5.38^{*} \\
(2.78)\end{array}$ & $\begin{array}{l}-5.48^{* *} \\
(2.70)\end{array}$ & $\begin{array}{l}-5.48^{* *} \\
(2.60)\end{array}$ & $\begin{array}{l}-5.59^{* *} \\
(2.51)\end{array}$ \\
\hline Distance to road (km.) & $\begin{array}{l}-0.13 \\
(0.13)\end{array}$ & $\begin{array}{l}-0.13 \\
(0.13)\end{array}$ & $\begin{array}{l}-0.13 \\
(0.11)\end{array}$ & $\begin{array}{l}-0.13 \\
(0.10)\end{array}$ \\
\hline Akan ethnicity $(1 / 0)$ & $\begin{array}{c}1.48 \\
(3.07)\end{array}$ & $\begin{array}{c}1.25 \\
(2.94)\end{array}$ & $\begin{array}{c}1.98 \\
(2.54)\end{array}$ & $\begin{array}{c}2.03 \\
(2.47)\end{array}$ \\
\hline Cocoa experience (yrs.) & $\begin{array}{c}0.00 \\
(0.01)\end{array}$ & $\begin{array}{c}0.01 \\
(0.01)\end{array}$ & $\begin{array}{c}0.01 \\
(0.01)\end{array}$ & $\begin{array}{c}0.01 \\
(0.01)\end{array}$ \\
\hline Age cocoa trees (yrs.) & $\begin{array}{c}-0.36^{* *} \\
(0.15)\end{array}$ & $\begin{array}{l}-0.35^{* *} \\
(0.15)\end{array}$ & $\begin{array}{l}-0.30^{*} \\
(0.16)\end{array}$ & $\begin{array}{l}-0.29^{*} \\
(0.16)\end{array}$ \\
\hline Good soil $(1 / 0)$ & $\begin{array}{c}1.77 \\
(2.77)\end{array}$ & $\begin{array}{c}1.52 \\
(2.71)\end{array}$ & $\begin{array}{c}1.90 \\
(2.55)\end{array}$ & $\begin{array}{c}1.58 \\
(2.53)\end{array}$ \\
\hline Distance to water sources $(\mathrm{km})$ & $\begin{array}{l}-0.15 \\
(0.10)\end{array}$ & $\begin{array}{l}-0.14 \\
(0.09)\end{array}$ & $\begin{array}{l}-0.25^{* *} \\
(0.10)\end{array}$ & $\begin{array}{l}-0.24^{* *} \\
(0.10)\end{array}$ \\
\hline Lacs district $(1 / 0)$ & $\begin{array}{c}-0.56 \\
(11.44)\end{array}$ & $\begin{array}{c}0.68 \\
(11.73)\end{array}$ & $\begin{array}{c}2.02 \\
(5.23)\end{array}$ & $\begin{array}{c}2.77 \\
(5.60)\end{array}$ \\
\hline Lagunes district $(1 / 0)$ & $\begin{array}{l}-7.55 \\
(4.71)\end{array}$ & $\begin{array}{l}-6.65 \\
(4.62)\end{array}$ & $\begin{array}{l}-5.84^{*} \\
(2.97)\end{array}$ & $\begin{array}{l}-5.24^{*} \\
(2.79)\end{array}$ \\
\hline Age of the coop (yrs.) & & & $\begin{array}{l}0.74^{* * * *} \\
(0.26)\end{array}$ & $\begin{array}{l}0.71^{* * *} \\
(0.24)\end{array}$ \\
\hline Coop members before certification (number) & & & $\begin{array}{c}-0.01^{* * *} \\
(0.00)\end{array}$ & $\begin{array}{c}-0.01^{* * *} \\
(0.00)\end{array}$ \\
\hline Share of decisions made democratically & & & $\begin{array}{c}23.57^{* *} \\
(9.45)\end{array}$ & $\begin{array}{c}23.55^{* *} \\
(9.62)\end{array}$ \\
\hline Education of coop. leader (yrs.) & & & $\begin{array}{c}-1.47^{* * *} \\
(0.42)\end{array}$ & $\begin{array}{c}-1.58^{* * * *} \\
(0.40)\end{array}$ \\
\hline Leader grows cocoa $(1 / 0)$ & & & $\begin{array}{l}-1.22 \\
(3.39)\end{array}$ & $\begin{array}{l}-0.75 \\
(3.34)\end{array}$ \\
\hline Service providers for inputs, training etc. (number) & & & $\begin{array}{l}2.04^{*} \\
(1.17)\end{array}$ & $\begin{array}{l}1.87^{*} \\
(1.11)\end{array}$ \\
\hline Coop vehicles (number) & & & $\begin{array}{c}0.64^{*} \\
(0.33)\end{array}$ & $\begin{array}{c}0.57^{*} \\
(0.34)\end{array}$ \\
\hline Constant & $\begin{array}{c}730.10^{* * *} \\
(14.28)\end{array}$ & $\begin{array}{c}728.55^{* * *} \\
(14.16) \\
\end{array}$ & $\begin{array}{c}734.69^{* * *} \\
(15.80)\end{array}$ & $\begin{array}{c}735.01^{* * * *} \\
(15.51)\end{array}$ \\
\hline F-value & $9.25^{* * *}$ & $13.50^{* * *}$ & $24.24^{* * *}$ & $50.35^{* * *}$ \\
\hline Wu-Hausman F-statistic. ${ }^{\text {a }}$ & & 1.40 & & 0.69 \\
\hline Kleibergen-Paap Wald F statistic ${ }^{b}$ & & $201.57^{* * *}$ & & $49.33^{* * *}$ \\
\hline Hansen J statistic. ${ }^{c}$ & & 0.16 & & 0.00 \\
\hline Observations & 490 & 490 & 490 & 490 \\
\hline
\end{tabular}

Note: Cluster robust standard errors shown in parentheses. First-stage results for the IV regressions are shown in Table A3 (column 1). ${ }^{*} p<0.1,{ }^{* *} p<0.05,{ }^{* * *} p<0.01$

${ }^{a}$ Test of endogeneity ( $\mathrm{H}_{0}$ : certified variable is exogenous)

${ }^{\text {b }}$ Test for weak instruments $\left(\mathrm{H}_{0}\right.$ : coefficients of instruments in first stage are not different from zero)

${ }^{c}$ Test of over-identifying restrictions $\left(\mathrm{H}_{0}\right.$ : instruments are uncorrelated with the error term) 
Table A7. Effects of Fairtrade certification on per capita consumption expenditure (log)

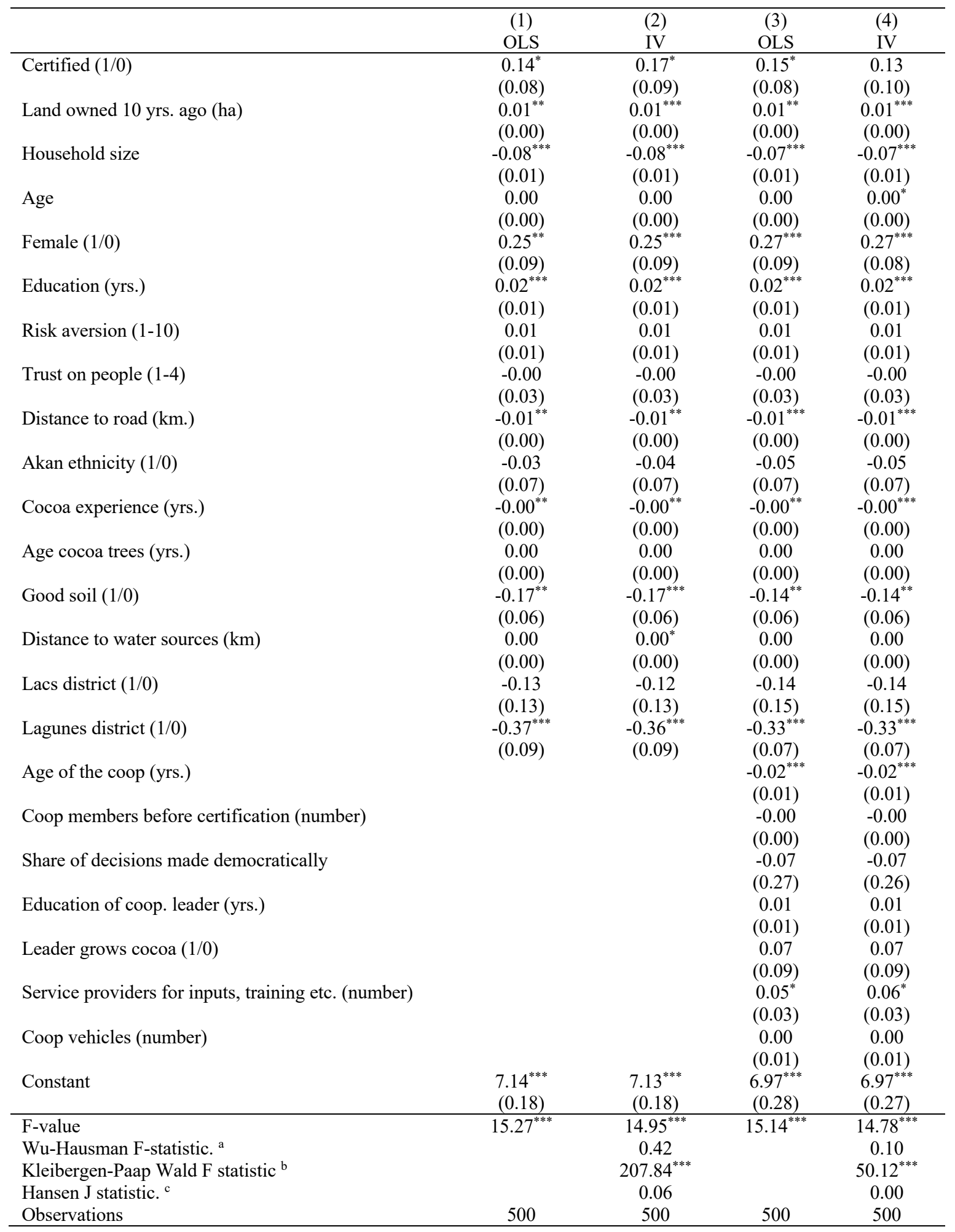

Note: Cluster robust standard errors shown in parentheses. First-stage results for the IV regressions are shown in Table A3 (column 1). ${ }^{*} p<0.1,{ }^{* *} p<0.05,{ }^{* * *} p<0.01$

a Test of endogeneity ( $\mathrm{H}_{0}$ : certified variable is exogenous)

${ }^{\mathrm{b}}$ Test for weak instruments ( $\mathrm{H}_{0}$ : coefficients of instruments in first stage are not different from zero)

${ }^{c}$ Test of over-identifying restrictions $\left(\mathrm{H}_{0}\right.$ : instruments are uncorrelated with the error term) 
Table A8. descriptive statistics for household characteristics by certification status

\begin{tabular}{|c|c|c|c|c|}
\hline & $\begin{array}{c}(1) \\
\text { Full sample }\end{array}$ & $\begin{array}{c}(2) \\
\text { Certified }\end{array}$ & $\begin{array}{c}(3) \\
\text { Non-certified } \\
\end{array}$ & $\begin{array}{c}\text { (4) } \\
\text { Mean diff. }\end{array}$ \\
\hline Age of household head (yrs.) & $\begin{array}{c}49.51 \\
(10.90)\end{array}$ & $\begin{array}{c}49.67 \\
(10.56)\end{array}$ & $\begin{array}{c}49.34 \\
(11.24)\end{array}$ & 0.33 \\
\hline Education of household head (yrs.) & $\begin{array}{c}6.11 \\
(4.90)\end{array}$ & $\begin{array}{c}5.87 \\
(4.82)\end{array}$ & $\begin{array}{c}6.34 \\
(4.98)\end{array}$ & -0.48 \\
\hline Female household head $(1 / 0)$ & $\begin{array}{c}0.06 \\
(0.24)\end{array}$ & $\begin{array}{c}0.08 \\
(0.27)\end{array}$ & $\begin{array}{c}0.04 \\
(0.21)\end{array}$ & $0.04^{*}$ \\
\hline Household size & $\begin{array}{c}7.13 \\
(3.92)\end{array}$ & $\begin{array}{c}7.31 \\
(3.85)\end{array}$ & $\begin{array}{c}6.94 \\
(3.99)\end{array}$ & 0.36 \\
\hline Akan ethnicity $(1 / 0)$ & $\begin{array}{c}0.70 \\
(0.46)\end{array}$ & $\begin{array}{c}0.68 \\
(0.47)\end{array}$ & $\begin{array}{c}0.72 \\
(0.45)\end{array}$ & 0.04 \\
\hline Risk aversion (1-10) & $\begin{array}{c}6.13 \\
(2.34)\end{array}$ & $\begin{array}{c}5.99 \\
(2.31)\end{array}$ & $\begin{array}{c}6.28 \\
(2.36)\end{array}$ & -0.29 \\
\hline Trust on people (1-4) & $\begin{array}{c}2.30 \\
(0.81)\end{array}$ & $\begin{array}{c}2.35 \\
(0.79)\end{array}$ & $\begin{array}{c}2.25 \\
(0.83)\end{array}$ & 0.10 \\
\hline Off-farm employment (1/0) & $\begin{array}{c}0.36 \\
(0.48)\end{array}$ & $\begin{array}{c}0.39 \\
(0.49)\end{array}$ & $\begin{array}{c}0.33 \\
(0.47)\end{array}$ & 0.06 \\
\hline Access to credit $(1 / 0)$ & $\begin{array}{c}0.80 \\
(0.40)\end{array}$ & $\begin{array}{c}0.82 \\
(0.38)\end{array}$ & $\begin{array}{c}0.78 \\
(0.42)\end{array}$ & 0.04 \\
\hline Distance to road $(\mathrm{km})$ & $\begin{array}{c}14.92 \\
(15.79)\end{array}$ & $\begin{array}{c}16.56 \\
(16.01)\end{array}$ & $\begin{array}{c}13.27 \\
(15.41)\end{array}$ & $3.28^{* *}$ \\
\hline Land owned (ha) & $\begin{array}{c}9.81 \\
(10.12)\end{array}$ & $\begin{array}{c}9.62 \\
(11.29)\end{array}$ & $\begin{array}{l}10.00 \\
(8.82)\end{array}$ & -0.38 \\
\hline Land owned 10 yrs. ago (ha) & $\begin{array}{c}8.76 \\
(10.82)\end{array}$ & $\begin{array}{c}8.80 \\
(12.17)\end{array}$ & $\begin{array}{c}8.72 \\
(9.29)\end{array}$ & 0.08 \\
\hline Land under cocoa (ha) & $\begin{array}{l}4.95 \\
(4.55)\end{array}$ & $\begin{array}{c}5.35 \\
(5.63)\end{array}$ & $\begin{array}{c}4.56 \\
(3.10)\end{array}$ & $0.79^{*}$ \\
\hline Age cocoa trees (yrs.) & $\begin{array}{c}20.32 \\
(10.64)\end{array}$ & $\begin{array}{c}19.79 \\
(10.79)\end{array}$ & $\begin{array}{c}20.85 \\
(10.47)\end{array}$ & -1.06 \\
\hline Distance to water source (walking min.) & $\begin{array}{c}10.00 \\
(13.75)\end{array}$ & $\begin{array}{c}9.46 \\
(12.41)\end{array}$ & $\begin{array}{l}10.55 \\
(14.97)\end{array}$ & -1.09 \\
\hline Good soil $(1 / 0)$ & $\begin{array}{c}0.77 \\
(0.42)\end{array}$ & $\begin{array}{c}0.82 \\
(0.39)\end{array}$ & $\begin{array}{c}0.73 \\
(0.45)\end{array}$ & $0.09^{* *}$ \\
\hline Soil steep $(1 / 0)$ & $\begin{array}{c}0.41 \\
(0.49)\end{array}$ & $\begin{array}{c}0.38 \\
(0.49) \\
\end{array}$ & $\begin{array}{c}0.44 \\
(0.50) \\
\end{array}$ & -0.05 \\
\hline Observations & 500 & 250 & 250 & 500 \\
\hline
\end{tabular}

Note: Mean values are shown with standard deviations in parentheses. $* \mathrm{p}<0.1,{ }^{*} \mathrm{p}<0.05, * * * \mathrm{p}<0.01$ 
Table A9. Effects of Fairtrade certification on outcome variables controlling for other standards

\begin{tabular}{|c|c|c|c|c|c|c|}
\hline & \multicolumn{2}{|c|}{ Cocoa yield (kg/ha) } & \multicolumn{2}{|c|}{ Cocoa price $(\mathrm{CFA} / \mathrm{kg})$} & \multicolumn{2}{|c|}{$\begin{array}{c}\text { Per capita expenditure } \\
(\log )\end{array}$} \\
\hline & OLS & IV & OLS & IV & OLS & IV \\
\hline \multirow[t]{2}{*}{ Fairtrade certified $(1 / 0)$} & $116.92^{* * *}$ & $109.21^{* *}$ & $22.74^{* * *}$ & $25.95^{* * *}$ & $0.17^{* *}$ & 0.14 \\
\hline & $(41.60)$ & $(54.52)$ & $(3.57)$ & $(4.32)$ & $(0.08)$ & $(0.11)$ \\
\hline \multirow[t]{2}{*}{ UTZ and/or RA certified } & -15.98 & -11.91 & -1.93 & -3.60 & -0.09 & -0.07 \\
\hline & $(49.49)$ & $(49.72)$ & $(4.10)$ & $(4.76)$ & $(0.14)$ & $(0.13)$ \\
\hline \multirow[t]{2}{*}{ Land owned 10 yrs. ago (ha) } & 0.69 & 0.70 & -0.09 & -0.09 & $0.01^{* *}$ & $0.01^{* * *}$ \\
\hline & $(1.76)$ & $(1.70)$ & $(0.10)$ & $(0.10)$ & $(0.00)$ & $(0.00)$ \\
\hline \multirow[t]{2}{*}{ Household size } & 1.18 & 1.22 & 0.30 & 0.29 & $-0.07^{* * *}$ & $-0.07^{* * *}$ \\
\hline & $(2.04)$ & $(1.98)$ & $(0.28)$ & $(0.26)$ & $(0.01)$ & $(0.01)$ \\
\hline \multirow[t]{2}{*}{ Age } & -1.21 & -1.21 & -0.04 & -0.04 & 0.00 & 0.00 \\
\hline & $(1.00)$ & $(0.97)$ & $(0.15)$ & $(0.15)$ & $(0.00)$ & $(0.00)$ \\
\hline \multirow[t]{2}{*}{ Female $(1 / 0)$} & 22.16 & 22.77 & -6.44 & $-6.72^{*}$ & $0.27^{* * *}$ & $0.27^{* * *}$ \\
\hline & $(45.40)$ & $(44.26)$ & $(4.08)$ & $(4.02)$ & $(0.09)$ & $(0.08)$ \\
\hline \multirow[t]{2}{*}{ Education (yrs.) } & -1.55 & -1.54 & 0.11 & 0.11 & $0.02^{* * *}$ & $0.02^{* * *}$ \\
\hline & $(2.64)$ & $(2.55)$ & $(0.31)$ & $(0.30)$ & $(0.01)$ & $(0.01)$ \\
\hline \multirow[t]{2}{*}{ Risk aversion (1-10) } & $8.41^{*}$ & $8.34^{*}$ & -0.07 & -0.04 & 0.01 & 0.01 \\
\hline & (4.99) & $(4.86)$ & $(0.71)$ & $(0.68)$ & $(0.01)$ & $(0.01)$ \\
\hline \multirow[t]{2}{*}{ Trust on people (1-4) } & 14.72 & 14.99 & $-5.52^{* *}$ & $-5.65^{* *}$ & -0.01 & -0.00 \\
\hline & $(13.28)$ & $(12.92)$ & $(2.63)$ & $(2.53)$ & $(0.03)$ & $(0.03)$ \\
\hline \multirow[t]{2}{*}{ Distance to road (km.) } & 0.50 & 0.51 & -0.13 & -0.13 & $-0.01^{* * *}$ & $-0.01^{* * *}$ \\
\hline & $(0.98)$ & $(0.95)$ & $(0.11)$ & $(0.10)$ & $(0.00)$ & $(0.00)$ \\
\hline \multirow[t]{2}{*}{ Akan ethnicity $(1 / 0)$} & -37.53 & -37.72 & 2.01 & 2.08 & -0.04 & -0.05 \\
\hline & $(24.73)$ & $(23.96)$ & $(2.58)$ & $(2.52)$ & $(0.07)$ & $(0.07)$ \\
\hline \multirow[t]{2}{*}{ Cocoa experience (yrs.) } & $0.72^{* * *}$ & $0.72^{* * * *}$ & 0.01 & 0.01 & $-0.00^{* *}$ & $-0.00^{* * *}$ \\
\hline & $(0.12)$ & $(0.12)$ & $(0.01)$ & $(0.01)$ & $(0.00)$ & $(0.00)$ \\
\hline \multirow[t]{2}{*}{ Age cocoa trees (yrs.) } & -0.50 & -0.52 & $-0.30^{*}$ & $-0.30^{*}$ & 0.00 & 0.00 \\
\hline & $(1.06)$ & $(1.03)$ & $(0.16)$ & $(0.16)$ & $(0.00)$ & $(0.00)$ \\
\hline \multirow[t]{2}{*}{ Good soil (1/0) } & $81.77^{* * *}$ & $82.49^{* * *}$ & 1.87 & 1.56 & $-0.14^{* *}$ & $-0.14^{* *}$ \\
\hline & $(26.43)$ & $(25.42)$ & $(2.55)$ & $(2.55)$ & $(0.06)$ & $(0.06)$ \\
\hline \multirow[t]{2}{*}{ Distance to water source $(\mathrm{km})$} & 0.15 & 0.14 & $-0.25^{* *}$ & $-0.25^{* *}$ & 0.00 & 0.00 \\
\hline & $(0.93)$ & $(0.89)$ & $(0.10)$ & $(0.10)$ & $(0.00)$ & $(0.00)$ \\
\hline \multirow[t]{2}{*}{ Lacs district (1/0) } & -10.25 & -10.82 & 1.57 & 1.83 & -0.16 & -0.16 \\
\hline & $(66.15)$ & $(63.22)$ & $(5.28)$ & $(5.55)$ & $(0.16)$ & $(0.15)$ \\
\hline \multirow[t]{2}{*}{ Lagunes district $(1 / 0)$} & 38.37 & 37.34 & $-5.92^{*}$ & $-5.46^{*}$ & $-0.33^{* * *}$ & $-0.33^{* * *}$ \\
\hline & $(27.79)$ & (26.99) & (3.01) & (2.87) & $(0.08)$ & $(0.07)$ \\
\hline \multirow[t]{2}{*}{ Constant } & $327.65^{* * *}$ & $325.97^{* * *}$ & $735.32^{* * *}$ & $736.16^{* * *}$ & $7.00^{* * *}$ & $6.99^{* * *}$ \\
\hline & (103.32) & (99.09) & $(16.10)$ & $(15.62)$ & $(0.29)$ & $(0.28)$ \\
\hline F-value & $5.15^{* * *}$ & $4.84^{* * *}$ & $30.99^{* * *}$ & $42.35^{* * *}$ & $15.25^{* * *}$ & $14.43^{* * *}$ \\
\hline Cooperative controls & Yes & Yes & Yes & Yes & Yes & Yes \\
\hline Observations & 500 & 500 & 490 & 490 & 500 & 500 \\
\hline
\end{tabular}

Note: Cluster robust standard errors shown in parentheses. ${ }^{*} p<0.1,{ }^{* *} p<0.05,{ }^{* * *} p<0.01$ 
Table A10. Effects of Fairtrade certification on outcome variables without controlling for number of service providers

\begin{tabular}{|c|c|c|c|c|c|c|}
\hline & \multicolumn{2}{|c|}{ Cocoa yield (kg/ha) } & \multicolumn{2}{|c|}{ Cocoa price $(\mathrm{CFA} / \mathrm{kg})$} & \multicolumn{2}{|c|}{$\begin{array}{c}\text { Per capita } \\
\text { expenditure }(\log )\end{array}$} \\
\hline & OLS & IV & OLS & IV & OLS & IV \\
\hline Certified (1/0) & $\begin{array}{l}109.73^{* * *} \\
(35.07)\end{array}$ & $\begin{array}{l}103.90^{* *} \\
(46.65)\end{array}$ & $\begin{array}{c}23.14^{* * *} \\
(3.53)\end{array}$ & $\begin{array}{c}26.49^{* * *} \\
(3.75)\end{array}$ & $\begin{array}{l}0.17^{* *} \\
(0.09)\end{array}$ & $\begin{array}{c}0.17 \\
(0.11)\end{array}$ \\
\hline Land owned 10 yrs. ago (ha) & $\begin{array}{c}0.70 \\
(1.76)\end{array}$ & $\begin{array}{c}0.70 \\
(1.70)\end{array}$ & $\begin{array}{l}-0.10 \\
(0.10)\end{array}$ & $\begin{array}{l}-0.10 \\
(0.10)\end{array}$ & $\begin{array}{l}0.01^{* *} \\
(0.00)\end{array}$ & $\begin{array}{l}0.01^{* * *} \\
(0.00)\end{array}$ \\
\hline Household size & $\begin{array}{l}1.19 \\
(2.05)\end{array}$ & $\begin{array}{l}1.23 \\
(2.00)\end{array}$ & $\begin{array}{c}0.28 \\
(0.28)\end{array}$ & $\begin{array}{c}0.26 \\
(0.26)\end{array}$ & $\begin{array}{c}-0.07^{* * *} \\
(0.01)\end{array}$ & $\begin{array}{l}-0.07^{* * *} \\
(0.01)\end{array}$ \\
\hline Age & $\begin{array}{l}-1.19 \\
(0.96)\end{array}$ & $\begin{array}{l}-1.20 \\
(0.93)\end{array}$ & $\begin{array}{l}-0.02 \\
(0.15)\end{array}$ & $\begin{array}{l}-0.01 \\
(0.15)\end{array}$ & $\begin{array}{l}0.00^{*} \\
(0.00)\end{array}$ & $\begin{array}{l}0.00^{*} \\
(0.00)\end{array}$ \\
\hline Female $(1 / 0)$ & $\begin{array}{c}22.17 \\
(45.10)\end{array}$ & $\begin{array}{c}22.79 \\
(43.97)\end{array}$ & $\begin{array}{l}-6.64 \\
(4.15)\end{array}$ & $\begin{array}{l}-7.02^{*} \\
(4.16)\end{array}$ & $\begin{array}{l}0.27^{* * *} \\
(0.09)\end{array}$ & $\begin{array}{l}0.27^{* * *} \\
(0.09)\end{array}$ \\
\hline Education (yrs.) & $\begin{array}{l}-1.57 \\
(2.62)\end{array}$ & $\begin{array}{l}-1.56 \\
(2.53)\end{array}$ & $\begin{array}{c}0.12 \\
(0.31)\end{array}$ & $\begin{array}{c}0.12 \\
(0.30)\end{array}$ & $\begin{array}{l}0.02^{* * *} \\
(0.01)\end{array}$ & $\begin{array}{l}0.02^{* * *} \\
(0.01)\end{array}$ \\
\hline Risk aversion (1-10) & $\begin{array}{l}8.66^{*} \\
(5.12)\end{array}$ & $\begin{array}{l}8.56^{*} \\
(5.03)\end{array}$ & $\begin{array}{l}-0.16 \\
(0.70)\end{array}$ & $\begin{array}{l}-0.11 \\
(0.68)\end{array}$ & $\begin{array}{c}0.01 \\
(0.01)\end{array}$ & $\begin{array}{c}0.01 \\
(0.01)\end{array}$ \\
\hline Trust on people (1-4) & $\begin{array}{c}15.02 \\
(13.32)\end{array}$ & $\begin{array}{c}15.19 \\
(12.94)\end{array}$ & $\begin{array}{l}-5.50^{* *} \\
(2.63)\end{array}$ & $\begin{array}{l}-5.62^{* *} \\
(2.54)\end{array}$ & $\begin{array}{l}-0.00 \\
(0.03)\end{array}$ & $\begin{array}{l}-0.00 \\
(0.03)\end{array}$ \\
\hline Distance to road (km.) & $\begin{array}{c}0.46 \\
(0.98)\end{array}$ & $\begin{array}{c}0.47 \\
(0.96)\end{array}$ & $\begin{array}{l}-0.11 \\
(0.11)\end{array}$ & $\begin{array}{l}-0.12 \\
(0.11)\end{array}$ & $\begin{array}{l}-0.01^{* *} \\
(0.00)\end{array}$ & $\begin{array}{l}-0.01^{* *} \\
(0.00)\end{array}$ \\
\hline Akan ethnicity $(1 / 0)$ & $\begin{array}{l}-38.68 \\
(24.68)\end{array}$ & $\begin{array}{l}-38.71 \\
(23.92)\end{array}$ & $\begin{array}{l}2.40 \\
(2.61)\end{array}$ & $\begin{array}{l}2.41 \\
(2.53)\end{array}$ & $\begin{array}{l}-0.04 \\
(0.07)\end{array}$ & $\begin{array}{l}-0.04 \\
(0.07)\end{array}$ \\
\hline Cocoa experience (yrs.) & $\begin{array}{l}0.72^{* * *} \\
(0.12)\end{array}$ & $\begin{array}{l}0.72^{* * *} \\
(0.12)\end{array}$ & $\begin{array}{c}0.01 \\
(0.01)\end{array}$ & $\begin{array}{c}0.01 \\
(0.01)\end{array}$ & $\begin{array}{c}-0.00^{* * * *} \\
(0.00)\end{array}$ & $\begin{array}{l}-0.00^{* * * *} \\
(0.00)\end{array}$ \\
\hline Age cocoa trees (yrs.) & $\begin{array}{l}-0.49 \\
(1.06)\end{array}$ & $\begin{array}{l}-0.51 \\
(1.03)\end{array}$ & $\begin{array}{l}-0.30^{*} \\
(0.16)\end{array}$ & $\begin{array}{l}-0.29^{*} \\
(0.16)\end{array}$ & $\begin{array}{c}0.00 \\
(0.00)\end{array}$ & $\begin{array}{c}0.00 \\
(0.00)\end{array}$ \\
\hline Good soil $(1 / 0)$ & $\begin{array}{l}82.76^{* * *} \\
(26.80)\end{array}$ & $\begin{array}{l}83.32^{* * *} \\
(25.95)\end{array}$ & $\begin{array}{l}1.55 \\
(2.62)\end{array}$ & $\begin{array}{l}1.23 \\
(2.58)\end{array}$ & $\begin{array}{l}-0.15^{* *} \\
(0.07)\end{array}$ & $\begin{array}{l}-0.15^{* *} \\
(0.06)\end{array}$ \\
\hline Distance to water sources $(\mathrm{km})$ & $\begin{array}{c}0.12 \\
(0.93)\end{array}$ & $\begin{array}{c}0.12 \\
(0.90)\end{array}$ & $\begin{array}{l}-0.23^{* *} \\
(0.10)\end{array}$ & $\begin{array}{l}-0.23^{* *} \\
(0.10)\end{array}$ & $\begin{array}{c}0.00 \\
(0.00)\end{array}$ & $\begin{array}{c}0.00 \\
(0.00)\end{array}$ \\
\hline Lacs district (1/0) & $\begin{array}{l}-8.36 \\
(62.83)\end{array}$ & $\begin{array}{l}-9.65 \\
(61.44)\end{array}$ & $\begin{array}{c}2.91 \\
(6.06)\end{array}$ & $\begin{array}{l}3.67 \\
(6.42)\end{array}$ & $\begin{array}{l}-0.11 \\
(0.15)\end{array}$ & $\begin{array}{l}-0.11 \\
(0.14)\end{array}$ \\
\hline Lagunes district $(1 / 0)$ & $\begin{array}{l}40.50 \\
(26.71)\end{array}$ & $\begin{array}{l}39.27 \\
(26.24)\end{array}$ & $\begin{array}{l}-6.54^{* *} \\
(2.98)\end{array}$ & $\begin{array}{l}-5.80^{* *} \\
(2.81)\end{array}$ & $\begin{array}{c}-0.35^{* * *} \\
(0.07)\end{array}$ & $\begin{array}{l}-0.35^{* * *} \\
(0.07)\end{array}$ \\
\hline Age of the coop (yrs.) & $\begin{array}{c}1.31 \\
(2.88)\end{array}$ & $\begin{array}{l}1.41 \\
(2.83)\end{array}$ & $\begin{array}{l}0.91^{* * *} \\
(0.30)\end{array}$ & $\begin{array}{l}0.86^{* * *} \\
(0.29)\end{array}$ & $\begin{array}{l}-0.02^{* *} \\
(0.01)\end{array}$ & $\begin{array}{l}-0.02^{* * *} \\
(0.01)\end{array}$ \\
\hline $\begin{array}{l}\text { Coop members before } \\
\text { certification (number) }\end{array}$ & $\begin{array}{l}-0.04 \\
(0.05)\end{array}$ & $\begin{array}{l}-0.04 \\
(0.04)\end{array}$ & $\begin{array}{c}-0.01^{* * *} \\
(0.00)\end{array}$ & $\begin{array}{c}-0.01^{* * * *} \\
(0.00)\end{array}$ & $\begin{array}{l}-0.00 \\
(0.00)\end{array}$ & $\begin{array}{l}-0.00 \\
(0.00)\end{array}$ \\
\hline $\begin{array}{l}\text { Share of decisions made } \\
\text { democratically }\end{array}$ & $\begin{array}{c}53.34 \\
(96.36)\end{array}$ & $\begin{array}{c}53.66 \\
(93.37)\end{array}$ & $\begin{array}{c}26.47^{* * *} \\
(9.61)\end{array}$ & $\begin{array}{c}26.17^{* * *} \\
(9.74)\end{array}$ & $\begin{array}{c}0.01 \\
(0.28)\end{array}$ & $\begin{array}{c}0.01 \\
(0.27)\end{array}$ \\
\hline Education of coop. leader (yrs.) & $\begin{array}{c}0.57 \\
(3.94)\end{array}$ & $\begin{array}{c}0.73 \\
(3.88)\end{array}$ & $\begin{array}{c}-1.70^{* * *} \\
(0.47)\end{array}$ & $\begin{array}{c}-1.80^{* * *} \\
(0.43)\end{array}$ & $\begin{array}{c}0.01 \\
(0.01)\end{array}$ & $\begin{array}{c}0.01 \\
(0.01)\end{array}$ \\
\hline Leader grows cocoa $(1 / 0)$ & $\begin{array}{l}78.80^{* *} \\
(37.05)\end{array}$ & $\begin{array}{l}77.67^{* *} \\
(36.87)\end{array}$ & $\begin{array}{l}-2.10 \\
(3.62)\end{array}$ & $\begin{array}{l}-1.48 \\
(3.58)\end{array}$ & $\begin{array}{c}0.05 \\
(0.10)\end{array}$ & $\begin{array}{c}0.05 \\
(0.10)\end{array}$ \\
\hline Coop vehicles (number) & $\begin{array}{l}-2.43 \\
(1.99)\end{array}$ & $\begin{array}{l}-2.26 \\
(2.03)\end{array}$ & $\begin{array}{l}0.82^{* *} \\
(0.31)\end{array}$ & $\begin{array}{l}0.73^{* *} \\
(0.33)\end{array}$ & $\begin{array}{c}0.01 \\
(0.01)\end{array}$ & $\begin{array}{c}0.01 \\
(0.01)\end{array}$ \\
\hline Constant & $\begin{array}{l}316.13^{* * *} \\
(107.02)\end{array}$ & $\begin{array}{c}316.28^{* * *} \\
(103.94)\end{array}$ & $\begin{array}{c}737.78^{* * *} \\
(16.36)\end{array}$ & $\begin{array}{c}737.85^{* * *} \\
(16.05)\end{array}$ & $\begin{array}{l}7.05^{* * *} \\
(0.28)\end{array}$ & $\begin{array}{l}7.05^{* * *} \\
(0.27)\end{array}$ \\
\hline F-value & $5.34^{* * *}$ & $5.15^{* * *}$ & $33.58^{* * *}$ & $63.32^{* * *}$ & $16.18^{* * *}$ & $15.81^{* * * *}$ \\
\hline Observations & 500 & 500 & 490 & 490 & 500 & 500 \\
\hline
\end{tabular}

Note: Cluster robust standard errors shown in parentheses. ${ }^{*} p<0.1,{ }^{* *} p<0.05,{ }^{* * *} p<0.01$ 


\section{B. Appendix for chapter 3}

Table B1. Comparison between tobit and double-hurdle models (likelihood ratio tests)

\begin{tabular}{lccccc}
\hline & Tobit & \multicolumn{3}{c}{ Double Hurdle } & \multirow{2}{*}{ LR $\chi^{2}$} \\
\cline { 3 - 4 } & & First hurdle & Second hurdle & Total & \\
\hline Fertilizer (kg/ha) & -3696.10 & -308.92 & -370.69 & -679.61 & $6032.97^{* * *}$ \\
Total pesticide use (kg/ha) & -503.73 & -104.21 & -390.57 & -494.78 & 17.89 \\
EIQ & -842.44 & -106.14 & -106.14 & -212.28 & $1260.30^{* * *}$ \\
Hazard quotient $(\mathrm{HQ})$ & -1002.48 & -106.14 & -616.65 & -722.79 & $559.38^{* * *}$ \\
\hline Note: Log pseudo-likelihood values are shown. $* \mathrm{p}<0.1,{ }^{* *} \mathrm{p}<0.05, * * * \mathrm{p}<0.01$ & &
\end{tabular}


Table B2. First-stage of IV models and instrument falsification tests

\begin{tabular}{|c|c|c|c|c|c|c|}
\hline & $\begin{array}{c}(1) \\
\text { Certification } \\
(1 / 0) \\
\end{array}$ & $\begin{array}{c}(2) \\
\text { Fertilizer } \\
(\mathrm{kg} / \mathrm{ha})^{\mathrm{a}}\end{array}$ & $\begin{array}{c}(3) \\
\text { Total pesticide } \\
\text { use }(\mathrm{kg} / \mathrm{ha})^{\mathrm{a}}\end{array}$ & $\begin{array}{c}(4) \\
\text { EIQ }^{a}\end{array}$ & $\begin{array}{c}(5) \\
\text { Hazard } \\
\text { Quotient }^{\mathrm{a}} \\
\end{array}$ & $\begin{array}{c}(6) \\
\text { Health } \\
\text { symptoms }^{\text {a }}\end{array}$ \\
\hline Share of certified farmers ( $5 \mathrm{~km}$ radius) & $\begin{array}{c}19.72^{* * *} \\
(1.92)\end{array}$ & $\begin{array}{c}-9.80 \\
(24.36)\end{array}$ & $\begin{array}{c}0.71 \\
(0.73)\end{array}$ & $\begin{array}{c}10.17 \\
(11.78)\end{array}$ & $\begin{array}{c}413.30 \\
(392.93)\end{array}$ & $\begin{array}{l}-2.58^{* *} \\
(0.94)\end{array}$ \\
\hline $\begin{array}{l}\text { Phone provider of coop leader } \\
\text { (1=Orange) }\end{array}$ & $\begin{array}{c}8.27^{* * *} \\
(1.10)\end{array}$ & $\begin{array}{l}-0.22 \\
(9.12)\end{array}$ & $\begin{array}{c}0.08 \\
(0.13)\end{array}$ & $\begin{array}{l}0.67 \\
(2.29)\end{array}$ & $\begin{array}{l}163.82 \\
(98.05)\end{array}$ & $\begin{array}{c}0.42 \\
(0.59)\end{array}$ \\
\hline Dist. to the closest certified coop & $\begin{array}{c}-27.74^{* * *} \\
(9.39)\end{array}$ & $\begin{array}{c}20.87 \\
(59.02)\end{array}$ & $\begin{array}{l}3.91^{*} \\
(2.10)\end{array}$ & $\begin{array}{l}27.63 \\
(35.61)\end{array}$ & $\begin{array}{c}1639.24 \\
(1218.00)\end{array}$ & $\begin{array}{l}-3.51 \\
(4.44)\end{array}$ \\
\hline Resp. $=$ coop. worker & & & & & & $\begin{array}{l}-0.74 \\
(1.08)\end{array}$ \\
\hline Resp. $=$ aboussant & & & & & & $\begin{array}{l}-0.42 \\
(0.64)\end{array}$ \\
\hline Female $(1 / 0)$ & $\begin{array}{l}1.60^{* * *} \\
(0.51)\end{array}$ & $\begin{array}{c}55.39 \\
(57.80)\end{array}$ & $\begin{array}{c}0.21 \\
(0.39)\end{array}$ & $\begin{array}{c}1.88 \\
(7.83)\end{array}$ & $\begin{array}{c}0.85 \\
(188.61)\end{array}$ & $\begin{array}{c}-2.31^{* * *} \\
(0.65)\end{array}$ \\
\hline Age & $\begin{array}{c}-0.06^{* * *} \\
(0.02)\end{array}$ & $\begin{array}{l}-0.53 \\
(0.54)\end{array}$ & $\begin{array}{l}-0.01 \\
(0.01)\end{array}$ & $\begin{array}{l}-0.01 \\
(0.14)\end{array}$ & $\begin{array}{l}-3.27 \\
(5.49)\end{array}$ & $\begin{array}{l}-0.01 \\
(0.03)\end{array}$ \\
\hline Education (yrs.) & $\begin{array}{c}-0.14^{* * *} \\
(0.02)\end{array}$ & $\begin{array}{l}-0.10 \\
(0.85)\end{array}$ & $\begin{array}{l}-0.02 \\
(0.02)\end{array}$ & $\begin{array}{l}-0.27 \\
(0.32)\end{array}$ & $\begin{array}{l}-9.25 \\
(9.72)\end{array}$ & $\begin{array}{l}-0.05 \\
(0.04)\end{array}$ \\
\hline Risk aversion (1-10) & $\begin{array}{c}0.00 \\
(0.06)\end{array}$ & $\begin{array}{l}-0.37 \\
(1.26)\end{array}$ & $\begin{array}{c}0.02 \\
(0.04)\end{array}$ & $\begin{array}{c}0.47 \\
(0.55)\end{array}$ & $\begin{array}{c}24.49 \\
(20.50)\end{array}$ & $\begin{array}{l}-0.09 \\
(0.11)\end{array}$ \\
\hline Household size & $\begin{array}{l}-0.10^{*} \\
(0.06)\end{array}$ & $\begin{array}{c}3.22^{*} \\
(1.76)\end{array}$ & $\begin{array}{c}0.01 \\
(0.03)\end{array}$ & $\begin{array}{c}0.32 \\
(0.61)\end{array}$ & $\begin{array}{c}2.72 \\
(23.20)\end{array}$ & $\begin{array}{c}0.07 \\
(0.04)\end{array}$ \\
\hline Dist. to input market (km.) & $\begin{array}{c}0.07 \\
(0.05)\end{array}$ & $\begin{array}{l}-0.31 \\
(0.31)\end{array}$ & $\begin{array}{c}0.00 \\
(0.01)\end{array}$ & $\begin{array}{c}0.01 \\
(0.16)\end{array}$ & $\begin{array}{l}-6.84 \\
(5.48)\end{array}$ & $\begin{array}{l}-0.03 \\
(0.04)\end{array}$ \\
\hline Dist. to road (km.) & $\begin{array}{c}-0.08^{* * *} \\
(0.02)\end{array}$ & $\begin{array}{l}-0.11 \\
(0.23)\end{array}$ & $\begin{array}{c}0.01 \\
(0.01)\end{array}$ & $\begin{array}{c}0.02 \\
(0.13)\end{array}$ & $\begin{array}{c}2.99 \\
(4.58)\end{array}$ & $\begin{array}{l}-0.01 \\
(0.02)\end{array}$ \\
\hline Land owned 10 yrs. ago (ha) & $\begin{array}{l}-0.02 \\
(0.03)\end{array}$ & $\begin{array}{l}1.24^{*} \\
(0.72)\end{array}$ & $\begin{array}{c}0.02 \\
(0.02)\end{array}$ & $\begin{array}{c}0.44 \\
(0.27)\end{array}$ & $\begin{array}{c}12.40 \\
(10.08)\end{array}$ & $\begin{array}{l}-0.02 \\
(0.03)\end{array}$ \\
\hline (Log) Total value of assets $10 \mathrm{yrs.}$ ago & $\begin{array}{c}0.05 \\
(0.10)\end{array}$ & $\begin{array}{l}-2.75 \\
(4.47)\end{array}$ & $\begin{array}{c}0.07 \\
(0.06)\end{array}$ & $\begin{array}{c}0.37 \\
(1.14)\end{array}$ & $\begin{array}{c}24.23 \\
(45.34)\end{array}$ & $\begin{array}{l}-0.26 \\
(0.22)\end{array}$ \\
\hline Infected with mirids $(1 / 0)$ & $\begin{array}{l}1.21^{* * *} \\
(0.30)\end{array}$ & $\begin{array}{c}-25.22^{* *} \\
(11.24)\end{array}$ & $\begin{array}{l}-0.40 \\
(0.49)\end{array}$ & $\begin{array}{l}-4.04 \\
(6.37)\end{array}$ & $\begin{array}{c}16.64 \\
(278.40)\end{array}$ & \\
\hline Infected with black pod $(1 / 0)$ & $\begin{array}{l}-0.78 \\
(0.69)\end{array}$ & $\begin{array}{l}-6.90 \\
(8.14)\end{array}$ & $\begin{array}{l}-0.02 \\
(0.38)\end{array}$ & $\begin{array}{c}1.54 \\
(4.66)\end{array}$ & $\begin{array}{c}113.03 \\
(149.54)\end{array}$ & \\
\hline Infected with stem borer $(1 / 0)$ & 0.25 & 8.07 & $0.61^{* *}$ & $8.85^{* *}$ & $250.22^{* *}$ & \\
\hline
\end{tabular}




\begin{tabular}{|c|c|c|c|c|c|c|}
\hline \multirow{3}{*}{ Age cocoa trees (yrs.) } & $(0.36)$ & $(9.46)$ & $(0.24)$ & $(3.51)$ & (118.28) & \\
\hline & $-0.02^{*}$ & 0.63 & -0.02 & -0.14 & -5.42 & \\
\hline & $(0.01)$ & $(0.48)$ & $(0.01)$ & $(0.23)$ & $(8.19)$ & \\
\hline \multirow[t]{2}{*}{ Number of shade trees per hectare } & -0.00 & -0.13 & $0.05^{* *}$ & $0.85^{*}$ & $41.12^{*}$ & \\
\hline & $(0.03)$ & $(0.60)$ & $(0.02)$ & $(0.44)$ & $(23.22)$ & \\
\hline \multirow[t]{2}{*}{ District $=$ Lacs } & -0.06 & $-51.08^{*}$ & -0.45 & -10.38 & $-469.59^{*}$ & 1.25 \\
\hline & $(1.63)$ & $(29.26)$ & $(0.49)$ & $(6.75)$ & $(262.55)$ & $(1.36)$ \\
\hline \multirow[t]{2}{*}{ District $=$ Lagunes } & -0.69 & $-33.06^{*}$ & $-0.93^{* *}$ & $-11.16^{* *}$ & $-524.60^{* *}$ & 0.05 \\
\hline & $(0.73)$ & $(17.94)$ & $(0.38)$ & $(4.85)$ & $(201.72)$ & $(0.55)$ \\
\hline \multirow[t]{2}{*}{ Age of the coop (yrs.) } & $0.48^{* * *}$ & -1.21 & -0.01 & -0.01 & 1.83 & 0.07 \\
\hline & $(0.09)$ & $(0.72)$ & $(0.01)$ & $(0.23)$ & $(7.83)$ & $(0.05)$ \\
\hline Share of decisions made & -0.47 & $-111.60^{* *}$ & -1.05 & -18.72 & -975.11 & 0.87 \\
\hline Democratically & $(1.63)$ & $(48.08)$ & $(1.05)$ & $(17.52)$ & $(588.02)$ & $(1.45)$ \\
\hline \multirow[t]{2}{*}{ \# service/inputs/training providers } & $3.56^{* * *}$ & 4.92 & 0.02 & 0.25 & 22.22 & $-0.61^{* *}$ \\
\hline & $(0.59)$ & $(5.96)$ & $(0.07)$ & $(1.08)$ & $(37.02)$ & $(0.24)$ \\
\hline \multirow[t]{2}{*}{ Constant } & $-17.51^{* * *}$ & $133.02^{*}$ & 0.97 & 5.90 & 71.89 & $6.89^{* *}$ \\
\hline & $(2.22)$ & $(71.47)$ & $(1.29)$ & $(22.45)$ & $(768.62)$ & $(2.58)$ \\
\hline Wald test on instruments & $\chi^{2}=116.22^{* * *}$ & $\mathrm{~F}=0.11$ & $\mathrm{~F}=1.32$ & $\mathrm{~F}=0.29$ & $\mathrm{~F}=1.34$ & $\mathrm{~F}=2.97^{*}$ \\
\hline Observations & 500 & 248 & 244 & 244 & 244 & 146 \\
\hline
\end{tabular}

${ }^{a}$ In these regressions we use the subsample of non-certified respondents. 
Table B3. Effects of certification on the number of pesticide-related acute health symptoms

\begin{tabular}{|c|c|c|}
\hline & $\begin{array}{c}(1) \\
\text { IV-GMM }\end{array}$ & $\begin{array}{c}(2) \\
d y / d x\end{array}$ \\
\hline Certified (1/0) & $\begin{array}{c}-0.50^{* *} \\
(0.20)\end{array}$ & $\begin{array}{l}-0.92^{* *} \\
(0.36)\end{array}$ \\
\hline Resp.=Aboussant $(1 / 0)$ & $\begin{array}{l}-0.41 \\
(0.36)\end{array}$ & $\begin{array}{l}-0.60 \\
(0.47)\end{array}$ \\
\hline Resp. $=$ Coop. worker $(1 / 0)$ & $\begin{array}{c}0.12 \\
(0.28)\end{array}$ & $\begin{array}{c}0.23 \\
(0.53)\end{array}$ \\
\hline Female $(1 / 0)$ & $\begin{array}{l}-0.68 \\
(1.26)\end{array}$ & $\begin{array}{l}-1.24 \\
(2.32)\end{array}$ \\
\hline Age & $\begin{array}{c}0.00 \\
(0.01)\end{array}$ & $\begin{array}{c}0.01 \\
(0.02)\end{array}$ \\
\hline Education (yrs.) & $\begin{array}{l}-0.01 \\
(0.01)\end{array}$ & $\begin{array}{l}-0.02 \\
(0.03)\end{array}$ \\
\hline Household size & $\begin{array}{c}0.00 \\
(0.02)\end{array}$ & $\begin{array}{c}0.01 \\
(0.03)\end{array}$ \\
\hline Risk aversion (1-10) & $\begin{array}{l}-0.02 \\
(0.04)\end{array}$ & $\begin{array}{l}-0.03 \\
(0.07)\end{array}$ \\
\hline Dist. to input market (km) & $\begin{array}{l}-0.02 \\
(0.02)\end{array}$ & $\begin{array}{l}-0.04 \\
(0.03)\end{array}$ \\
\hline Dist. to road $(\mathrm{km})$ & $\begin{array}{c}0.00 \\
(0.01)\end{array}$ & $\begin{array}{c}0.00 \\
(0.02)\end{array}$ \\
\hline Land owned 10 years. ago (ha) & $\begin{array}{c}0.00 \\
(0.01)\end{array}$ & $\begin{array}{c}0.01 \\
(0.03)\end{array}$ \\
\hline (Log) Total value of assets 10 years ago & $\begin{array}{l}-0.09 \\
(0.07)\end{array}$ & $\begin{array}{l}-0.17 \\
(0.13)\end{array}$ \\
\hline District $=$ Lacs & $\begin{array}{c}0.36 \\
(0.22)\end{array}$ & $\begin{array}{c}0.77 \\
(0.49)\end{array}$ \\
\hline District $=$ Lagunes & $\begin{array}{l}-0.06 \\
(0.23)\end{array}$ & $\begin{array}{l}-0.10 \\
(0.40)\end{array}$ \\
\hline Age of the coop (yrs.) & $\begin{array}{l}0.03^{*} \\
(0.02)\end{array}$ & $\begin{array}{c}0.06 \\
(0.04)\end{array}$ \\
\hline Share of decisions made democratically & $\begin{array}{c}1.00 \\
(0.64)\end{array}$ & $\begin{array}{c}1.83 \\
(1.21)\end{array}$ \\
\hline \# service/inputs/training providers & $\begin{array}{c}-0.31^{* * *} \\
(0.08)\end{array}$ & $\begin{array}{c}-0.57^{* * *} \\
(0.16)\end{array}$ \\
\hline Constant & $\begin{array}{l}1.59^{*} \\
(0.93) \\
\end{array}$ & \\
\hline Test of over-identifying restrictions: Hansen's $\mathrm{J} \chi^{2}$ & 1.44 & \\
\hline Observations & 255 & 255 \\
\hline
\end{tabular}


Table B4. Significance of generalized residuals in double-hurdle models ( $p$-values)

\begin{tabular}{lcc}
\hline & $(1)$ & $(2)$ \\
& First hurdle & Second hurdle \\
\hline Fertilizer (kg/ha) & 0.252 & 0.045 \\
Total pesticide use (kg/ha) & 0.146 & 0.281 \\
EIQ & 0.154 & 0.848 \\
Hazard quotient (HQ) & 0.154 & 0.479 \\
\hline
\end{tabular}

Table B5. Descriptive statistics for control variables by certification status (farmer sample)

\begin{tabular}{|c|c|c|c|c|}
\hline & $\begin{array}{l}\text { (1) } \\
\text { Full sample }\end{array}$ & $\begin{array}{c}(2) \\
\text { Certified }\end{array}$ & $\begin{array}{c}(3) \\
\text { Non-certified }\end{array}$ & $\begin{array}{c}(4) \\
\text { Mean } \\
\text { differences }\end{array}$ \\
\hline Female $(1 / 0)$ & $\begin{array}{l}0.06 \\
(0.24)\end{array}$ & $\begin{array}{l}0.08 \\
(0.27)\end{array}$ & $\begin{array}{c}0.04 \\
(0.21)\end{array}$ & $0.04^{*}$ \\
\hline Age & $\begin{array}{c}49.51 \\
(10.90)\end{array}$ & $\begin{array}{c}49.67 \\
(10.56)\end{array}$ & $\begin{array}{c}49.34 \\
(11.24)\end{array}$ & 0.33 \\
\hline Education (yrs.) & $\begin{array}{c}6.11 \\
(4.90)\end{array}$ & $\begin{array}{c}5.87 \\
(4.82)\end{array}$ & $\begin{array}{c}6.34 \\
(4.98)\end{array}$ & -0.48 \\
\hline Risk aversion (1-10) & $\begin{array}{c}6.13 \\
(2.34)\end{array}$ & $\begin{array}{c}5.99 \\
(2.31)\end{array}$ & $\begin{array}{c}6.28 \\
(2.36)\end{array}$ & -0.29 \\
\hline Household size & $\begin{array}{c}7.13 \\
(3.92)\end{array}$ & $\begin{array}{c}7.31 \\
(3.85)\end{array}$ & $\begin{array}{c}6.94 \\
(3.99)\end{array}$ & 0.36 \\
\hline Dist. to input market (km) & $\begin{array}{l}2.75 \\
(5.28)\end{array}$ & $\begin{array}{c}2.11 \\
(3.61)\end{array}$ & $\begin{array}{l}3.39 \\
(6.48)\end{array}$ & $-1.28^{* * *}$ \\
\hline Dist. to road (km) & $\begin{array}{c}14.92 \\
(15.79)\end{array}$ & $\begin{array}{c}16.56 \\
(16.01)\end{array}$ & $\begin{array}{l}13.27 \\
(15.41)\end{array}$ & $3.28^{* *}$ \\
\hline Land owned 10 years ago (ha) & $\begin{array}{c}8.76 \\
(10.82)\end{array}$ & $\begin{array}{c}8.80 \\
(12.17)\end{array}$ & $\begin{array}{c}8.72 \\
(9.29)\end{array}$ & 0.08 \\
\hline (Log) Total value of assets 10 yrs. ago & $\begin{array}{l}12.25 \\
(1.23)\end{array}$ & $\begin{array}{l}12.38 \\
(1.19)\end{array}$ & $\begin{array}{l}12.12 \\
(1.26)\end{array}$ & $0.26^{* *}$ \\
\hline Infected with mirids $(1 / 0)$ & $\begin{array}{c}0.88 \\
(0.32)\end{array}$ & $\begin{array}{c}0.86 \\
(0.35)\end{array}$ & $\begin{array}{c}0.90 \\
(0.30)\end{array}$ & -0.04 \\
\hline Infected with black pod (1/0) & $\begin{array}{c}0.87 \\
(0.33)\end{array}$ & $\begin{array}{l}0.85 \\
(0.36)\end{array}$ & $\begin{array}{c}0.90 \\
(0.30)\end{array}$ & $-0.05^{*}$ \\
\hline Infected with stem borer (1/0) & $\begin{array}{c}0.82 \\
(0.38)\end{array}$ & $\begin{array}{c}0.83 \\
(0.38)\end{array}$ & $\begin{array}{c}0.82 \\
(0.39)\end{array}$ & 0.01 \\
\hline Age cocoa trees (yrs.) & $\begin{array}{c}20.32 \\
(10.64)\end{array}$ & $\begin{array}{c}19.79 \\
(10.79)\end{array}$ & $\begin{array}{l}20.85 \\
(10.47)\end{array}$ & -1.06 \\
\hline Number of shade trees per hectare & $\begin{array}{c}6.09 \\
(5.72)\end{array}$ & $\begin{array}{c}5.88 \\
(5.45)\end{array}$ & $\begin{array}{c}6.30 \\
(5.99)\end{array}$ & -0.43 \\
\hline Age of the coop (yrs.) & $\begin{array}{l}7.70 \\
(5.00)\end{array}$ & $\begin{array}{c}9.48 \\
(4.46)\end{array}$ & $\begin{array}{c}5.92 \\
(4.88)\end{array}$ & $3.56^{* * *}$ \\
\hline $\begin{array}{l}\text { Share of decisions made } \\
\text { democratically }\end{array}$ & $\begin{array}{c}0.39 \\
(0.15)\end{array}$ & $\begin{array}{c}0.41 \\
(0.16)\end{array}$ & $\begin{array}{c}0.37 \\
(0.13)\end{array}$ & $0.04^{* * *}$ \\
\hline \# service/inputs/training providers & $\begin{array}{c}1.56 \\
(1.47)\end{array}$ & $\begin{array}{c}2.24 \\
(1.42)\end{array}$ & $\begin{array}{c}0.88 \\
(1.18)\end{array}$ & $1.36^{* * *}$ \\
\hline Observations & 500 & 250 & 250 & 500 \\
\hline
\end{tabular}


Table B6. Descriptive statistics for control variables by certification status (worker sample)

\begin{tabular}{lcccc}
\hline & \multicolumn{2}{c}{ Aboussant } & \multicolumn{2}{c}{ Cooperative worker } \\
\cline { 2 - 5 } & Certified & Non-certified ${ }^{\text {a }}$ & Certified & Non-certified ${ }^{\text {a }}$ \\
& $(1)$ & $(2)$ & $(3)$ & $(4)$ \\
\hline Female (1/0) & 0.00 & 0.00 & 0.00 & 0.00 \\
Age & $(0.00)$ & $(0.00)$ & $(0.00)$ & $(0.00)$ \\
& 36.98 & 36.17 & 42.86 & 40.93 \\
Education (yrs.) & $(10.62)$ & $(9.89)$ & $(8.11)$ & $(9.16)$ \\
Risk aversion (1-10) & 2.64 & $4.42^{*}$ & 11.43 & 9.57 \\
& $(3.84)$ & $(5.02)$ & $(5.65)$ & $(6.88)$ \\
Household size & 6.40 & 6.49 & 7.00 & 6.36 \\
& $(2.56)$ & $(2.47)$ & $(2.58)$ & $(2.79)$ \\
Dist. to input market (km) & 4.64 & 4.73 & 6.29 & 5.43 \\
Dist. to road (km) & $(2.90)$ & $(2.95)$ & $(3.59)$ & $(3.72)$ \\
Land owned 10 years ago (ha) & 5.71 & 5.05 & 1.90 & 1.31 \\
& $(6.26)$ & $(6.76)$ & $(1.85)$ & $(3.13)$ \\
(Log) Total value of assets 10 yrs. ago & 14.89 & 13.32 & 9.50 & 11.46 \\
& $(14.13)$ & $(13.38)$ & $(11.97)$ & $(15.69)$ \\
Age of the coop (yrs.) & 0.54 & 1.08 & 7.00 & 6.07 \\
Share of decisions made democratically & $(2.26)$ & $(4.16)$ & $(14.73)$ & $(6.15)$ \\
\# service/inputs/training providers & 10.61 & 10.92 & 13.13 & 12.55 \\
& $(1.28)$ & $(1.29)$ & $(1.35)$ & $(0.95)$
\end{tabular}

Note: Mean values are shown with standard deviations in parentheses. $* \mathrm{p}<0.1, * * \mathrm{p}<0.05, * * * \mathrm{p}<0.01$

${ }^{a}$ Asterisks in these columns indicate significance level for mean differences between certified and non-certified aboussant and cooperative workers respectively. 
Table B7. Effect of certification on agrochemical input use (double-hurdle models)

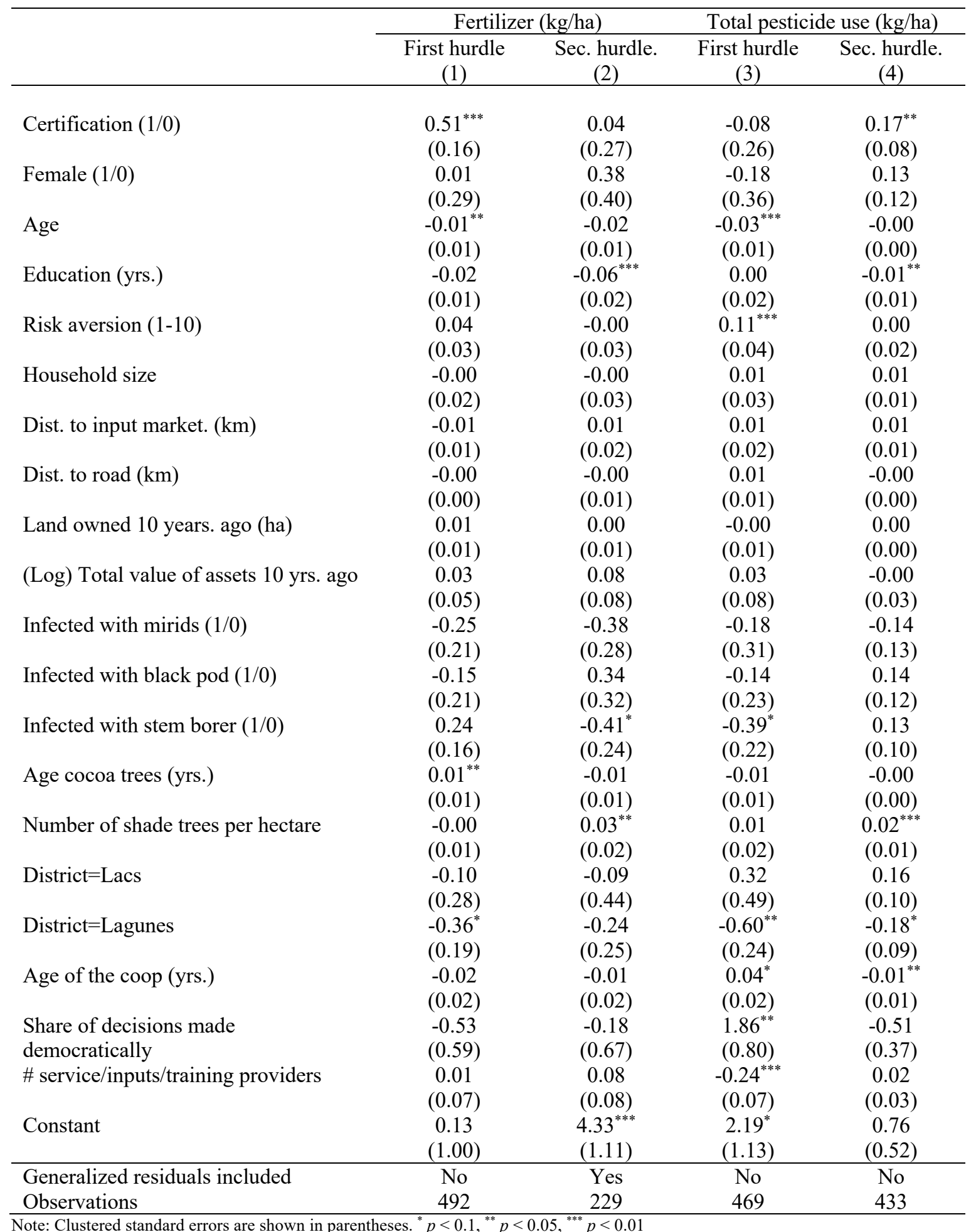


Table B8. Marginal effects of certification on agrochemical input use (double-hurdle models)

\begin{tabular}{|c|c|c|c|c|}
\hline & \multicolumn{2}{|c|}{ Fertilizer $(\mathrm{kg} / \mathrm{ha})$} & \multicolumn{2}{|c|}{ Total pesticide use $(\mathrm{kg} / \mathrm{ha})$} \\
\hline & $\begin{array}{l}\text { Cond. } \\
\mathrm{dy} / \mathrm{dx} \\
(1)\end{array}$ & $\begin{array}{l}\text { Uncond. } \\
\mathrm{dy} / \mathrm{dx} \\
(2)\end{array}$ & $\begin{array}{l}\text { Cond. } \\
\mathrm{dy} / \mathrm{dx} \\
(3)\end{array}$ & $\begin{array}{l}\text { Uncond. } \\
\mathrm{dy} / \mathrm{dx} \\
(4)\end{array}$ \\
\hline Certification $(1 / 0)$ & $\begin{array}{c}4.33 \\
(26.96)\end{array}$ & $\begin{array}{c}21.12 \\
(14.55)\end{array}$ & $\begin{array}{l}0.35^{* *} \\
(0.18)\end{array}$ & $\begin{array}{l}0.31^{*} \\
(0.18)\end{array}$ \\
\hline Female $(1 / 0)$ & $\begin{array}{c}39.09 \\
(42.54)\end{array}$ & $\begin{array}{c}19.58 \\
(22.14)\end{array}$ & $\begin{array}{c}0.26 \\
(0.25)\end{array}$ & $\begin{array}{c}0.20 \\
(0.26)\end{array}$ \\
\hline Age & $\begin{array}{l}-1.57 \\
(1.08)\end{array}$ & $\begin{array}{c}-1.30^{* *} \\
(0.60)\end{array}$ & $\begin{array}{l}-0.01 \\
(0.01)\end{array}$ & $\begin{array}{c}-0.01^{* *} \\
(0.01)\end{array}$ \\
\hline Education (yrs.) & $\begin{array}{c}-6.27^{* *} \\
(2.53)\end{array}$ & $\begin{array}{c}-3.83^{* * *} \\
(1.32)\end{array}$ & $\begin{array}{l}-0.03^{*} \\
(0.02)\end{array}$ & $\begin{array}{l}-0.03^{*} \\
(0.02)\end{array}$ \\
\hline Risk aversion (1-10) & $\begin{array}{l}-0.00 \\
(2.73)\end{array}$ & $\begin{array}{c}1.47 \\
(1.97)\end{array}$ & $\begin{array}{c}0.00 \\
(0.04)\end{array}$ & $\begin{array}{c}0.03 \\
(0.04)\end{array}$ \\
\hline Household size & $\begin{array}{l}-0.49 \\
(2.71)\end{array}$ & $\begin{array}{l}-0.36 \\
(1.71)\end{array}$ & $\begin{array}{c}0.01 \\
(0.02)\end{array}$ & $\begin{array}{c}0.01 \\
(0.02)\end{array}$ \\
\hline Dist. to input market (km) & $\begin{array}{c}0.73 \\
(1.82)\end{array}$ & $\begin{array}{c}0.03 \\
(1.00)\end{array}$ & $\begin{array}{c}0.01 \\
(0.02)\end{array}$ & $\begin{array}{c}0.01 \\
(0.02)\end{array}$ \\
\hline Dist. to road $(\mathrm{km})$ & $\begin{array}{l}-0.01 \\
(0.60)\end{array}$ & $\begin{array}{l}-0.07 \\
(0.36)\end{array}$ & $\begin{array}{l}-0.01 \\
(0.01)\end{array}$ & $\begin{array}{l}-0.01 \\
(0.01)\end{array}$ \\
\hline Land owned 10 yrs. ago (ha) & $\begin{array}{c}0.40 \\
(0.91)\end{array}$ & $\begin{array}{c}0.68 \\
(0.53)\end{array}$ & $\begin{array}{c}0.00 \\
(0.01)\end{array}$ & $\begin{array}{c}0.00 \\
(0.01)\end{array}$ \\
\hline (Log) Total value of assets 10 yrs. ago & $\begin{array}{c}8.10 \\
(8.71)\end{array}$ & $\begin{array}{c}5.19 \\
(5.18)\end{array}$ & $\begin{array}{l}-0.01 \\
(0.06)\end{array}$ & $\begin{array}{c}0.00 \\
(0.06)\end{array}$ \\
\hline Infected with mirids $(1 / 0)$ & $\begin{array}{l}-38.65 \\
(29.03)\end{array}$ & $\begin{array}{l}-28.39^{*} \\
(16.97)\end{array}$ & $\begin{array}{l}-0.29 \\
(0.28)\end{array}$ & $\begin{array}{l}-0.31 \\
(0.27)\end{array}$ \\
\hline Infected with black pod $(1 / 0)$ & $\begin{array}{c}34.63 \\
(34.28)\end{array}$ & $\begin{array}{c}11.75 \\
(17.52)\end{array}$ & $\begin{array}{c}0.29 \\
(0.24)\end{array}$ & $\begin{array}{c}0.23 \\
(0.23)\end{array}$ \\
\hline Infected with stem borer $(1 / 0)$ & $\begin{array}{l}-41.98 \\
(25.83)\end{array}$ & $\begin{array}{l}-11.86 \\
(12.02)\end{array}$ & $\begin{array}{c}0.27 \\
(0.21)\end{array}$ & $\begin{array}{c}0.15 \\
(0.20)\end{array}$ \\
\hline Age cocoa trees (yrs.) & $\begin{array}{l}-1.21 \\
(1.12)\end{array}$ & $\begin{array}{l}-0.09 \\
(0.54)\end{array}$ & $\begin{array}{l}-0.01 \\
(0.01)\end{array}$ & $\begin{array}{l}-0.01 \\
(0.01)\end{array}$ \\
\hline Number of shade trees per hectare & $\begin{array}{l}3.26^{* *} \\
(1.63)\end{array}$ & $\begin{array}{c}1.55^{*} \\
(0.86)\end{array}$ & $\begin{array}{l}0.05^{* * *} \\
(0.01)\end{array}$ & $\begin{array}{l}0.05^{* * *} \\
(0.01)\end{array}$ \\
\hline District $=$ Lacs & $\begin{array}{c}-9.92 \\
(45.57)\end{array}$ & $\begin{array}{c}-9.22 \\
(20.33)\end{array}$ & $\begin{array}{c}0.37 \\
(0.25)\end{array}$ & $\begin{array}{c}0.41 \\
(0.25)\end{array}$ \\
\hline District $=$ Lagunes & $\begin{array}{l}-23.94 \\
(24.55)\end{array}$ & $\begin{array}{c}-24.20 \\
(15.21)\end{array}$ & $\begin{array}{l}-0.36^{*} \\
(0.19)\end{array}$ & $\begin{array}{c}-0.49^{* *} \\
(0.20)\end{array}$ \\
\hline Age of the coop (yrs.) & $\begin{array}{l}-1.00 \\
(2.30)\end{array}$ & $\begin{array}{l}-1.09 \\
(1.38)\end{array}$ & $\begin{array}{l}-0.03^{*} \\
(0.01)\end{array}$ & $\begin{array}{l}-0.02 \\
(0.01)\end{array}$ \\
\hline $\begin{array}{l}\text { Share of decisions made } \\
\text { democratically } \\
\text { \# service/inputs/training providers }\end{array}$ & $\begin{array}{c}-17.90 \\
(68.05) \\
8.62 \\
(8.76)\end{array}$ & $\begin{array}{c}-28.54 \\
(35.64) \\
4.77 \\
(5.60)\end{array}$ & $\begin{array}{c}-1.05 \\
(0.77) \\
0.05 \\
(0.06)\end{array}$ & $\begin{array}{l}-0.53 \\
(0.71) \\
-0.01 \\
(0.06)\end{array}$ \\
\hline Constant & & & & \\
\hline $\begin{array}{l}\text { Generalized residuals included } \\
\text { Observations }\end{array}$ & $\begin{array}{l}\text { No } \\
492\end{array}$ & $\begin{array}{l}\text { Yes } \\
492 \\
\end{array}$ & $\begin{array}{l}\text { No } \\
469\end{array}$ & $\begin{array}{l}\text { No } \\
469\end{array}$ \\
\hline
\end{tabular}


Table A9. Marginal effects of certification on agrochemical input use controlling for potential pathways (double-hurdle models)

\begin{tabular}{|c|c|c|c|c|c|c|}
\hline & \multicolumn{3}{|c|}{ Fertilizer (kg/ha) } & \multicolumn{3}{|c|}{ Total pesticide use $(\mathrm{kg} / \mathrm{ha})$} \\
\hline & $\begin{array}{l}\text { Probit } \\
\mathrm{dy} / \mathrm{dx} \\
(1)\end{array}$ & $\begin{array}{l}\text { Cond. } \\
\mathrm{dy} / \mathrm{dx} \\
(2)\end{array}$ & $\begin{array}{l}\text { Uncond. } \\
\mathrm{dy} / \mathrm{dx} \\
(3)\end{array}$ & $\begin{array}{l}\text { Probit } \\
\mathrm{dy} / \mathrm{dx} \\
(4)\end{array}$ & $\begin{array}{l}\text { Cond. } \\
\mathrm{dy} / \mathrm{dx} \\
(5)\end{array}$ & $\begin{array}{l}\text { Uncond. } \\
\mathrm{dy} / \mathrm{dx} \\
(6)\end{array}$ \\
\hline \multirow[t]{2}{*}{ Fairtrade $(1 / 0)$} & $0.30^{*}$ & -20.91 & -0.51 & $-0.50^{*}$ & $0.38^{* *}$ & 0.25 \\
\hline & $(0.17)$ & $(30.05)$ & $(15.37)$ & $(0.27)$ & $(0.18)$ & $(0.18)$ \\
\hline \multirow[t]{2}{*}{ Cocoa price $(\mathrm{CFA} / \mathrm{kg})$} & 0.00 & 0.19 & 0.12 & -0.00 & -0.00 & $-0.00^{*}$ \\
\hline & $(0.00)$ & $(0.15)$ & $(0.10)$ & $(0.00)$ & $(0.00)$ & $(0.00)$ \\
\hline \multirow[t]{2}{*}{ Access to credit $(1 / 0)$} & $0.46^{* * *}$ & -31.19 & 0.01 & -0.21 & 0.13 & 0.08 \\
\hline & $(0.16)$ & $(19.90)$ & $(10.22)$ & $(0.29)$ & $(0.21)$ & $(0.19)$ \\
\hline \multirow[t]{2}{*}{ Participated in ag. training $(1 / 0)$} & $0.43^{* * *}$ & 24.14 & $26.80^{* *}$ & 0.38 & -0.21 & -0.12 \\
\hline & $(0.13)$ & $(23.88)$ & $(12.96)$ & $(0.28)$ & $(0.16)$ & $(0.16)$ \\
\hline \multirow[t]{2}{*}{ Received pesticides $(1 / 0)$} & -0.08 & 37.00 & 16.04 & $0.85^{* * *}$ & -0.12 & 0.06 \\
\hline & $(0.16)$ & $(26.49)$ & $(14.67)$ & $(0.22)$ & $(0.19)$ & $(0.17)$ \\
\hline \multirow[t]{2}{*}{ Received fertilizer $(1 / 0)$} & $0.60^{* * *}$ & 16.07 & $28.67^{* *}$ & 0.43 & 0.19 & 0.27 \\
\hline & $(0.18)$ & $(21.65)$ & $(11.72)$ & $(0.26)$ & $(0.21)$ & $(0.21)$ \\
\hline \multirow[t]{2}{*}{ Received spraying services $(1 / 0)$} & -0.04 & $43.69^{*}$ & $20.63^{*}$ & $0.60^{* *}$ & 0.26 & $0.37^{*}$ \\
\hline & $(0.14)$ & $(23.40)$ & $(11.35)$ & $(0.25)$ & $(0.20)$ & $(0.19)$ \\
\hline \multirow[t]{2}{*}{ Female $(1 / 0)$} & 0.09 & 33.11 & 19.93 & -0.39 & 0.12 & 0.03 \\
\hline & $(0.29)$ & $(37.29)$ & $(20.85)$ & $(0.39)$ & $(0.26)$ & $(0.27)$ \\
\hline \multirow[t]{2}{*}{ Age } & -0.01 & -1.48 & $-1.13^{* *}$ & $-0.03^{* * *}$ & -0.01 & $-0.01^{*}$ \\
\hline & $(0.01)$ & $(0.93)$ & $(0.53)$ & $(0.01)$ & $(0.01)$ & $(0.01)$ \\
\hline \multirow[t]{2}{*}{ Education (yrs.) } & -0.02 & $-6.35^{* *}$ & $-4.05^{* * *}$ & 0.00 & $-0.03^{*}$ & -0.02 \\
\hline & $(0.02)$ & $(2.56)$ & $(1.29)$ & $(0.02)$ & $(0.02)$ & $(0.02)$ \\
\hline \multirow[t]{2}{*}{ Risk aversion (1-10) } & 0.04 & -1.61 & 0.56 & 0.09 & -0.00 & 0.01 \\
\hline & $(0.03)$ & $(3.46)$ & $(2.20)$ & $(0.06)$ & $(0.04)$ & $(0.04)$ \\
\hline \multirow[t]{2}{*}{ Household size } & -0.01 & -1.37 & -1.17 & 0.02 & 0.01 & 0.01 \\
\hline & $(0.02)$ & $(2.80)$ & $(1.69)$ & $(0.03)$ & $(0.02)$ & $(0.02)$ \\
\hline \multirow[t]{2}{*}{ Dist. to input mkt. (km.) } & -0.01 & -0.38 & -0.43 & 0.00 & 0.01 & 0.01 \\
\hline & $(0.01)$ & $(1.88)$ & $(1.06)$ & $(0.02)$ & $(0.02)$ & $(0.02)$ \\
\hline \multirow[t]{2}{*}{ Dist. to road (km.) } & -0.00 & -0.18 & -0.19 & 0.01 & $-0.01^{*}$ & -0.01 \\
\hline & $(0.01)$ & $(0.56)$ & $(0.35)$ & $(0.01)$ & $(0.01)$ & $(0.01)$ \\
\hline \multirow[t]{2}{*}{ Land owned 10 yrs. ago (ha) } & $0.01^{*}$ & 0.47 & 0.74 & 0.00 & 0.01 & 0.00 \\
\hline & $(0.01)$ & $(0.95)$ & $(0.56)$ & $(0.01)$ & $(0.01)$ & $(0.01)$ \\
\hline \multirow[t]{2}{*}{ (Log) Total value of assets 10 yrs. ago } & -0.00 & 1.20 & 0.59 & 0.03 & -0.05 & -0.04 \\
\hline & $(0.06)$ & $(9.76)$ & $(5.68)$ & $(0.08)$ & $(0.06)$ & $(0.06)$ \\
\hline Infected with mirids $(1 / 0)$ & -0.22 & -38.38 & -26.95 & -0.07 & -0.30 & -0.29 \\
\hline & $(0.23)$ & $(27.04)$ & $(16.82)$ & $(0.29)$ & $(0.26)$ & $(0.27)$ \\
\hline Infected with black pod (1/0) & -0.12 & 37.59 & 14.83 & -0.20 & 0.28 & 0.22 \\
\hline & $(0.22)$ & $(33.02)$ & $(16.17)$ & $(0.27)$ & $(0.23)$ & $(0.22)$ \\
\hline Infected with stem borer (1/0) & 0.23 & $-44.05^{*}$ & -14.46 & $-0.50^{*}$ & 0.24 & 0.12 \\
\hline & $(0.15)$ & $(25.20)$ & $(11.62)$ & $(0.27)$ & $(0.21)$ & $(0.21)$ \\
\hline Age cocoa trees (yrs.) & $0.01^{* *}$ & -0.80 & 0.08 & -0.01 & -0.01 & -0.01 \\
\hline & $(0.01)$ & $(1.13)$ & $(0.56)$ & $(0.01)$ & $(0.01)$ & $(0.01)$ \\
\hline Number of shade trees per hectare & -0.01 & 2.00 & 0.73 & 0.01 & $0.05^{* * *}$ & $0.05^{* * *}$ \\
\hline & $(0.01)$ & $(1.73)$ & $(0.96)$ & $(0.02)$ & $(0.02)$ & $(0.01)$ \\
\hline District $=$ Lacs & -0.08 & -1.02 & -3.32 & 0.32 & 0.35 & $0.39^{*}$ \\
\hline & $(0.30)$ & $(43.21)$ & $(19.73)$ & $(0.57)$ & $(0.23)$ & $(0.23)$ \\
\hline District $=$ Lagunes & -0.31 & -11.67 & -16.07 & -0.31 & $-0.41^{* *}$ & $-0.44^{* *}$ \\
\hline & $(0.21)$ & $(23.15)$ & $(14.42)$ & $(0.27)$ & $(0.18)$ & $(0.19)$ \\
\hline Age of the coop (yrs.) & -0.02 & -1.31 & -1.18 & $0.04^{*}$ & $-0.03^{* *}$ & -0.02 \\
\hline & $(0.02)$ & $(2.29)$ & $(1.30)$ & $(0.02)$ & $(0.01)$ & $(0.01)$ \\
\hline Share of decisions made democratically & -0.80 & -44.31 & -49.53 & $1.40^{*}$ & -1.14 & -0.77 \\
\hline & $(0.62)$ & $(63.08)$ & $(34.08)$ & $(0.75)$ & $(0.74)$ & $(0.67)$ \\
\hline \# service/inputs/training providers & -0.04 & 2.18 & -0.17 & $-0.33^{* * *}$ & 0.04 & -0.03 \\
\hline & $(0.07)$ & $(7.92)$ & $(5.23)$ & $(0.07)$ & $(0.06)$ & $(0.06)$ \\
\hline Constant & -0.38 & & & 3.27 & & \\
\hline
\end{tabular}




\begin{tabular}{lcccccc}
\multicolumn{7}{c}{$(1.52)$} \\
\hline Generalized residuals included & No & Yes & Yes & No & No & No \\
Observations & 482 & 482 & 482 & 459 & 459 & 459 \\
\hline Note: Clustered standard errors are shown in parentheses. ${ }^{*} p<0.1,{ }^{* *} p<0.05,{ }^{* * *} p<0.01$ & &
\end{tabular}

Table B10. Effects of certification on aggregated toxicity (double-hurdle models)

\begin{tabular}{|c|c|c|c|c|}
\hline & \multicolumn{2}{|c|}{ EIQ } & \multicolumn{2}{|c|}{ Hazard quotient } \\
\hline & $\begin{array}{c}\text { First hurdle } \\
\text { (1) }\end{array}$ & $\begin{array}{c}\text { Sec. hurdle. } \\
(2)\end{array}$ & $\begin{array}{c}\text { First hurdle } \\
\text { (3) }\end{array}$ & $\begin{array}{c}\text { Sec. hurdle. } \\
\text { (4) }\end{array}$ \\
\hline \multirow[t]{2}{*}{ Certification $(1 / 0)$} & -0.05 & 0.23 & -0.05 & $0.35^{* * *}$ \\
\hline & $(0.25)$ & $(0.17)$ & $(0.25)$ & $(0.13)$ \\
\hline \multirow[t]{2}{*}{ Female $(1 / 0)$} & -0.19 & 0.08 & -0.19 & 0.03 \\
\hline & $(0.36)$ & $(0.25)$ & $(0.36)$ & $(0.18)$ \\
\hline \multirow[t]{2}{*}{ Age } & $-0.03^{* * *}$ & -0.00 & $-0.03^{* * *}$ & -0.00 \\
\hline & $(0.01)$ & $(0.01)$ & $(0.01)$ & $(0.00)$ \\
\hline \multirow[t]{2}{*}{ Education (yrs.) } & -0.00 & $-0.04^{* *}$ & -0.00 & $-0.02^{*}$ \\
\hline & $(0.02)$ & $(0.01)$ & $(0.02)$ & $(0.01)$ \\
\hline \multirow[t]{2}{*}{ Risk aversion (1-10) } & $0.11^{* * *}$ & 0.01 & $0.11^{* * * *}$ & 0.02 \\
\hline & $(0.04)$ & $(0.03)$ & $(0.04)$ & $(0.02)$ \\
\hline \multirow[t]{2}{*}{ Household size } & 0.01 & -0.01 & 0.01 & -0.00 \\
\hline & $(0.02)$ & $(0.02)$ & $(0.02)$ & $(0.02)$ \\
\hline \multirow[t]{2}{*}{ Dist. to input market (km) } & 0.01 & 0.02 & 0.01 & 0.01 \\
\hline & $(0.02)$ & $(0.01)$ & $(0.02)$ & $(0.01)$ \\
\hline \multirow[t]{2}{*}{ Dist. to road $(\mathrm{km})$} & 0.01 & $-0.01^{* *}$ & 0.01 & -0.00 \\
\hline & $(0.01)$ & $(0.00)$ & $(0.01)$ & $(0.00)$ \\
\hline \multirow[t]{2}{*}{ Land owned 10 yrs. ago (ha) } & -0.00 & $0.01^{* *}$ & -0.00 & 0.00 \\
\hline & $(0.01)$ & $(0.01)$ & $(0.01)$ & $(0.00)$ \\
\hline \multirow[t]{2}{*}{ (Log) Total value of assets 10 yrs. ago } & 0.05 & $-0.11^{* *}$ & 0.05 & -0.06 \\
\hline & $(0.08)$ & $(0.05)$ & $(0.08)$ & $(0.04)$ \\
\hline \multirow[t]{2}{*}{ Infected with mirids $(1 / 0)$} & -0.17 & -0.31 & -0.17 & -0.19 \\
\hline & $(0.31)$ & $(0.27)$ & $(0.31)$ & $(0.18)$ \\
\hline \multirow[t]{2}{*}{ Infected with black pod (1/0) } & -0.15 & $0.33^{*}$ & -0.15 & $0.30^{*}$ \\
\hline & $(0.23)$ & $(0.19)$ & $(0.23)$ & $(0.17)$ \\
\hline \multirow[t]{2}{*}{ Infected with stem borer $(1 / 0)$} & $-0.41^{*}$ & $0.32^{* *}$ & $-0.41^{*}$ & $0.24^{*}$ \\
\hline & $(0.22)$ & $(0.16)$ & $(0.22)$ & $(0.14)$ \\
\hline \multirow[t]{2}{*}{ Age cocoa trees (yrs.) } & -0.01 & 0.00 & -0.01 & -0.01 \\
\hline & $(0.01)$ & $(0.01)$ & $(0.01)$ & $(0.01)$ \\
\hline \multirow[t]{2}{*}{ Number of shade trees per hectare } & 0.01 & $0.03^{* * *}$ & 0.01 & $0.03^{* * *}$ \\
\hline & $(0.02)$ & $(0.01)$ & $(0.02)$ & $(0.01)$ \\
\hline \multirow[t]{2}{*}{ District $=$ Lacs } & 0.35 & -0.03 & 0.35 & 0.03 \\
\hline & $(0.48)$ & $(0.27)$ & $(0.48)$ & $(0.16)$ \\
\hline \multirow[t]{2}{*}{ District $=$ Lagunes } & $-0.59^{* *}$ & -0.14 & $-0.59^{* *}$ & -0.14 \\
\hline & $(0.24)$ & $(0.21)$ & $(0.24)$ & $(0.14)$ \\
\hline \multirow[t]{2}{*}{ Age of the coop (yrs.) } & $0.04^{* *}$ & 0.01 & $0.04^{* *}$ & -0.02 \\
\hline & $(0.02)$ & $(0.02)$ & $(0.02)$ & $(0.01)$ \\
\hline \multirow{4}{*}{$\begin{array}{l}\text { Share of decisions made } \\
\text { democratically } \\
\text { \# service/inputs/training providers }\end{array}$} & $1.81^{* *}$ & -0.80 & $1.81^{* *}$ & -0.66 \\
\hline & $(0.79)$ & $(0.64)$ & $(0.79)$ & $(0.54)$ \\
\hline & $-0.23^{* * *}$ & 0.03 & $-0.23^{* * *}$ & -0.00 \\
\hline & $(0.07)$ & $(0.07)$ & $(0.07)$ & $(0.05)$ \\
\hline \multirow[t]{2}{*}{ Constant } & $2.01^{*}$ & $3.67^{* * *}$ & $2.01^{*}$ & $6.92^{* * *}$ \\
\hline & $(1.08)$ & $(0.86)$ & $(1.08)$ & $(0.63)$ \\
\hline Generalized residuals included & No & No & No & No \\
\hline Observations & 492 & 492 & 469 & 469 \\
\hline
\end{tabular}


Table B11. Marginal effects of certification on aggregated toxicity (double-hurdle models)

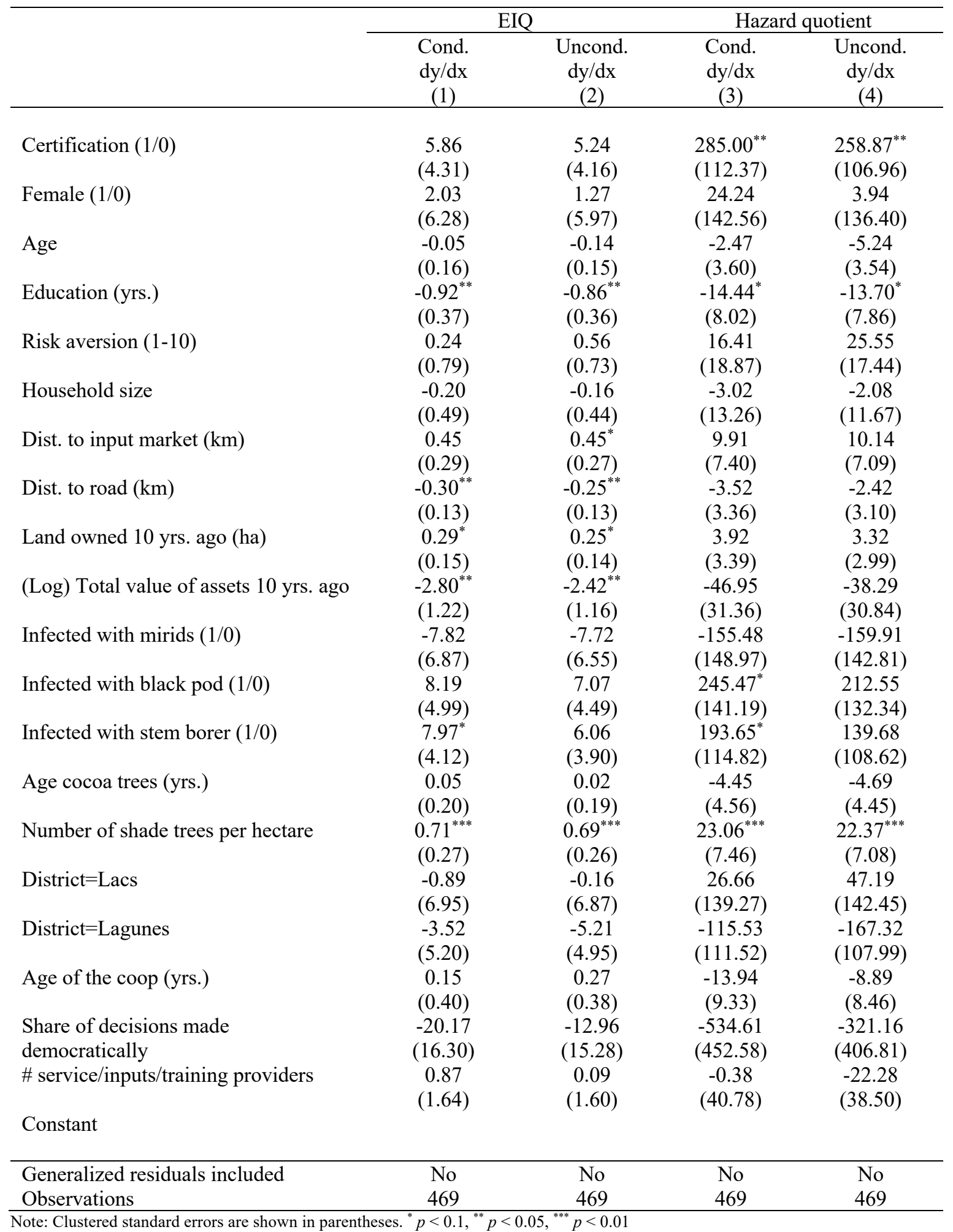


Table B12. Marginal effects of Fairtrade on agrochemical input use controlling for UTZ/RA (doublehurdle models)

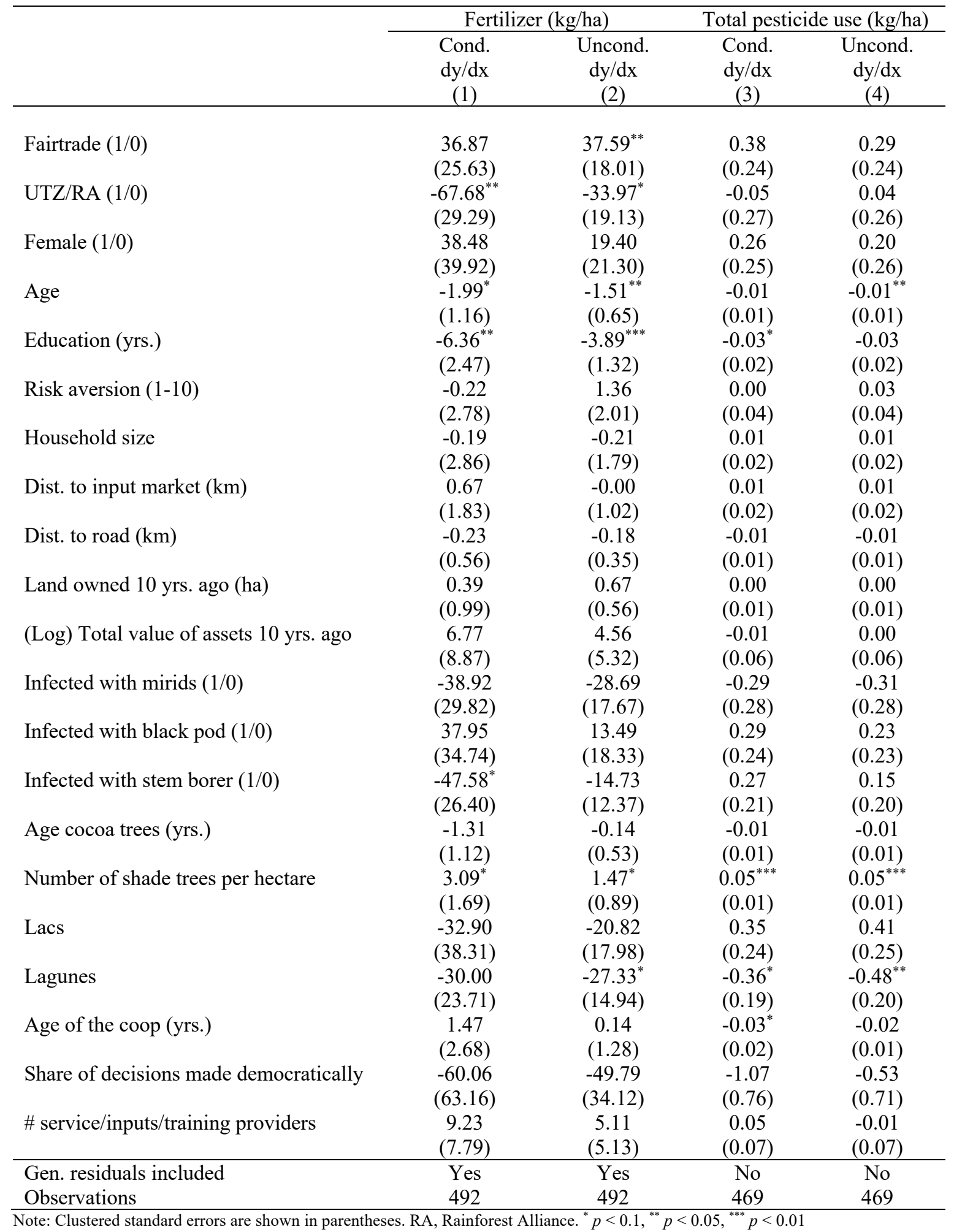


Table B13. Marginal effects of Fairtrade on aggregated toxicity controlling for UTZ/RA (double-hurdle model)

\begin{tabular}{|c|c|c|c|c|}
\hline & \multicolumn{2}{|c|}{ EIQ } & \multicolumn{2}{|c|}{ HQ } \\
\hline & $\begin{array}{l}\text { Cond. } \\
\mathrm{dy} / \mathrm{dx} \\
(1)\end{array}$ & $\begin{array}{l}\text { Uncond. } \\
\mathrm{dy} / \mathrm{dx} \\
(2)\end{array}$ & $\begin{array}{l}\text { Cond. } \\
\mathrm{dy} / \mathrm{dx} \\
(3)\end{array}$ & $\begin{array}{c}\text { Uncond. } \\
\mathrm{dy} / \mathrm{dx} \\
(4)\end{array}$ \\
\hline Fairtrade $(1 / 0)$ & $\begin{array}{c}3.99 \\
(5.28)\end{array}$ & $\begin{array}{c}2.96 \\
(5.05)\end{array}$ & $\begin{array}{c}282.95^{*} \\
(169.22)\end{array}$ & $\begin{array}{c}239.63 \\
(157.86)\end{array}$ \\
\hline UTZ/RA $(1 / 0)$ & $\begin{array}{c}3.46 \\
(6.27)\end{array}$ & $\begin{array}{c}4.19 \\
(6.16)\end{array}$ & $\begin{array}{c}3.79 \\
(181.65)\end{array}$ & $\begin{array}{c}34.47 \\
(164.88)\end{array}$ \\
\hline Female $(1 / 0)$ & $\begin{array}{c}1.96 \\
(6.25)\end{array}$ & $\begin{array}{c}1.25 \\
(5.95)\end{array}$ & $\begin{array}{c}24.17 \\
(141.58)\end{array}$ & $\begin{array}{c}5.04 \\
(135.58)\end{array}$ \\
\hline Age & $\begin{array}{l}-0.05 \\
(0.16)\end{array}$ & $\begin{array}{l}-0.14 \\
(0.15)\end{array}$ & $\begin{array}{l}-2.46 \\
(3.62)\end{array}$ & $\begin{array}{l}-5.17 \\
(3.56)\end{array}$ \\
\hline Education (yrs.) & $\begin{array}{l}-0.92^{* *} \\
(0.37)\end{array}$ & $\begin{array}{l}-0.85^{* *} \\
(0.36)\end{array}$ & $\begin{array}{c}-14.44^{*} \\
(8.02)\end{array}$ & $\begin{array}{c}-13.52^{*} \\
(7.83)\end{array}$ \\
\hline Risk aversion (1-10) & $\begin{array}{c}0.24 \\
(0.79)\end{array}$ & $\begin{array}{c}0.56 \\
(0.73)\end{array}$ & $\begin{array}{c}16.41 \\
(18.87)\end{array}$ & $\begin{array}{c}25.64 \\
(17.42)\end{array}$ \\
\hline Household size & $\begin{array}{l}-0.21 \\
(0.49)\end{array}$ & $\begin{array}{l}-0.17 \\
(0.44)\end{array}$ & $\begin{array}{c}-3.03 \\
(13.23)\end{array}$ & $\begin{array}{c}-1.97 \\
(11.67)\end{array}$ \\
\hline Dist. to input market (km) & $\begin{array}{c}0.45 \\
(0.29)\end{array}$ & $\begin{array}{c}0.44 \\
(0.27)\end{array}$ & $\begin{array}{c}9.90 \\
(7.39)\end{array}$ & $\begin{array}{c}9.99 \\
(7.12)\end{array}$ \\
\hline Dist. to road (km) & $\begin{array}{l}-0.29^{* *} \\
(0.13)\end{array}$ & $\begin{array}{l}-0.24^{*} \\
(0.12)\end{array}$ & $\begin{array}{l}-3.51 \\
(3.34)\end{array}$ & $\begin{array}{l}-2.36 \\
(3.14)\end{array}$ \\
\hline Land owned 10 yrs. ago (ha) & $\begin{array}{c}0.29^{*} \\
(0.15)\end{array}$ & $\begin{array}{l}0.26^{*} \\
(0.13)\end{array}$ & $\begin{array}{c}3.92 \\
(3.38)\end{array}$ & $\begin{array}{c}3.36 \\
(2.99)\end{array}$ \\
\hline (Log) Total value of assets 10 yrs. ago & $\begin{array}{l}-2.79^{* *} \\
(1.22)\end{array}$ & $\begin{array}{l}-2.40^{* *} \\
(1.15)\end{array}$ & $\begin{array}{l}-46.93 \\
(31.36)\end{array}$ & $\begin{array}{l}-38.06 \\
(30.85)\end{array}$ \\
\hline Infected with mirids $(1 / 0)$ & $\begin{array}{l}-8.01 \\
(6.93)\end{array}$ & $\begin{array}{l}-7.91 \\
(6.65)\end{array}$ & $\begin{array}{l}-155.68 \\
(149.60)\end{array}$ & $\begin{array}{l}-160.43 \\
(144.12)\end{array}$ \\
\hline Infected with black pod $(1 / 0)$ & $\begin{array}{c}8.01 \\
(5.00)\end{array}$ & $\begin{array}{c}6.87 \\
(4.50)\end{array}$ & $\begin{array}{c}245.28^{*} \\
(143.39)\end{array}$ & $\begin{array}{c}211.08 \\
(134.40)\end{array}$ \\
\hline Infected with stem borer $(1 / 0)$ & $\begin{array}{l}7.96^{*} \\
(4.10)\end{array}$ & $\begin{array}{c}6.03 \\
(3.89)\end{array}$ & $\begin{array}{c}193.65^{*} \\
(114.80)\end{array}$ & $\begin{array}{c}138.60 \\
(108.25)\end{array}$ \\
\hline Age cocoa trees (yrs.) & $\begin{array}{c}0.05 \\
(0.20)\end{array}$ & $\begin{array}{c}0.03 \\
(0.19)\end{array}$ & $\begin{array}{l}-4.44 \\
(4.44)\end{array}$ & $\begin{array}{l}-4.66 \\
(4.35)\end{array}$ \\
\hline Number of shade trees per hectare & $\begin{array}{l}0.71^{* * *} \\
(0.27)\end{array}$ & $\begin{array}{c}0.69^{* * * *} \\
(0.26)\end{array}$ & $\begin{array}{c}23.06^{* * *} \\
(7.46)\end{array}$ & $\begin{array}{c}22.31^{* * *} \\
(7.10)\end{array}$ \\
\hline Lacs & $\begin{array}{c}0.19 \\
(6.90)\end{array}$ & $\begin{array}{c}1.01 \\
(6.87)\end{array}$ & $\begin{array}{c}27.88 \\
(140.30)\end{array}$ & $\begin{array}{c}52.49 \\
(143.31)\end{array}$ \\
\hline Lagunes & $\begin{array}{l}-3.47 \\
(5.20)\end{array}$ & $\begin{array}{l}-5.05 \\
(4.95)\end{array}$ & $\begin{array}{c}-115.47 \\
(111.38)\end{array}$ & $\begin{array}{c}-164.22 \\
(107.95)\end{array}$ \\
\hline Age of the coop (yrs.) & $\begin{array}{c}0.06 \\
(0.42)\end{array}$ & $\begin{array}{c}0.16 \\
(0.39)\end{array}$ & $\begin{array}{c}-14.04 \\
(9.51)\end{array}$ & $\begin{array}{l}-9.88 \\
(8.20)\end{array}$ \\
\hline Share of decisions made democratically & $\begin{array}{l}-18.91 \\
(16.82)\end{array}$ & $\begin{array}{l}-11.69 \\
(15.83)\end{array}$ & $\begin{array}{l}-533.22 \\
(457.68)\end{array}$ & $\begin{array}{l}-315.32 \\
(413.14)\end{array}$ \\
\hline \# service/inputs/training providers & $\begin{array}{c}0.74 \\
(1.72)\end{array}$ & $\begin{array}{l}-0.04 \\
(1.67)\end{array}$ & $\begin{array}{c}-0.52 \\
(42.74)\end{array}$ & $\begin{array}{l}-22.80 \\
(40.62)\end{array}$ \\
\hline Observations & 469 & 469 & 469 & 469 \\
\hline
\end{tabular}


Table B14. Effects of Fairtrade on health symptoms controlling for UTZ/RA

\begin{tabular}{|c|c|c|}
\hline & $\begin{array}{c}(1) \\
\text { IV-GMM }\end{array}$ & $\begin{array}{c}(2) \\
d y / d x\end{array}$ \\
\hline Fairtrade $(1 / 0)$ & $\begin{array}{c}-0.56^{* *} \\
(0.28)\end{array}$ & $\begin{array}{c}-1.03^{* *} \\
(0.51)\end{array}$ \\
\hline UTZ/RA (1/0) & $\begin{array}{c}0.14 \\
(0.40)\end{array}$ & $\begin{array}{c}0.25 \\
(0.73)\end{array}$ \\
\hline Resp.=Aboussant $(1 / 0)$ & $\begin{array}{l}-0.40 \\
(0.36)\end{array}$ & $\begin{array}{l}-0.59 \\
(0.47)\end{array}$ \\
\hline Resp.=Coop. worker $(1 / 0)$ & $\begin{array}{c}0.12 \\
(0.28)\end{array}$ & $\begin{array}{c}0.22 \\
(0.54)\end{array}$ \\
\hline Female $(1 / 0)$ & $\begin{array}{l}-0.72 \\
(1.31)\end{array}$ & $\begin{array}{l}-1.31 \\
(2.39)\end{array}$ \\
\hline Age & $\begin{array}{c}0.00 \\
(0.01)\end{array}$ & $\begin{array}{c}0.01 \\
(0.02)\end{array}$ \\
\hline Education (yrs.) & $\begin{array}{l}-0.01 \\
(0.01)\end{array}$ & $\begin{array}{l}-0.02 \\
(0.03)\end{array}$ \\
\hline Household size & $\begin{array}{c}0.00 \\
(0.02)\end{array}$ & $\begin{array}{c}0.01 \\
(0.03)\end{array}$ \\
\hline Risk aversion (1-10) & $\begin{array}{l}-0.02 \\
(0.04)\end{array}$ & $\begin{array}{l}-0.03 \\
(0.07)\end{array}$ \\
\hline Dist. to input market (km) & $\begin{array}{l}-0.02 \\
(0.02)\end{array}$ & $\begin{array}{l}-0.04 \\
(0.03)\end{array}$ \\
\hline Dist. to road $(\mathrm{km})$ & $\begin{array}{c}0.00 \\
(0.01)\end{array}$ & $\begin{array}{c}0.00 \\
(0.02)\end{array}$ \\
\hline Land owned 10 yrs. ago (ha) & $\begin{array}{c}0.00 \\
(0.01)\end{array}$ & $\begin{array}{c}0.01 \\
(0.03)\end{array}$ \\
\hline (Log) Total value of assets 10 yrs. ago & $\begin{array}{l}-0.09 \\
(0.07)\end{array}$ & $\begin{array}{l}-0.17 \\
(0.13)\end{array}$ \\
\hline Lacs & $\begin{array}{c}0.39 \\
(0.25)\end{array}$ & $\begin{array}{c}0.85 \\
(0.58)\end{array}$ \\
\hline Lagunes & $\begin{array}{l}-0.05 \\
(0.23)\end{array}$ & $\begin{array}{l}-0.09 \\
(0.39)\end{array}$ \\
\hline Age of the coop (yrs.) & $\begin{array}{l}0.03^{*} \\
(0.02)\end{array}$ & $\begin{array}{c}0.06 \\
(0.04)\end{array}$ \\
\hline Share of decisions made democratically & $\begin{array}{c}1.02 \\
(0.64)\end{array}$ & $\begin{array}{c}1.86 \\
(1.22)\end{array}$ \\
\hline \# service/inputs/training providers & $\begin{array}{c}-0.32^{* * *} \\
(0.08)\end{array}$ & $\begin{array}{c}-0.58^{* * *} \\
(0.17)\end{array}$ \\
\hline Constant & $\begin{array}{l}1.61^{*} \\
(0.95) \\
\end{array}$ & \\
\hline Test of overidentifying restrictions: Hansen's J $\chi^{2}$ & $\begin{array}{l}1.41 \\
255\end{array}$ & 255 \\
\hline
\end{tabular}




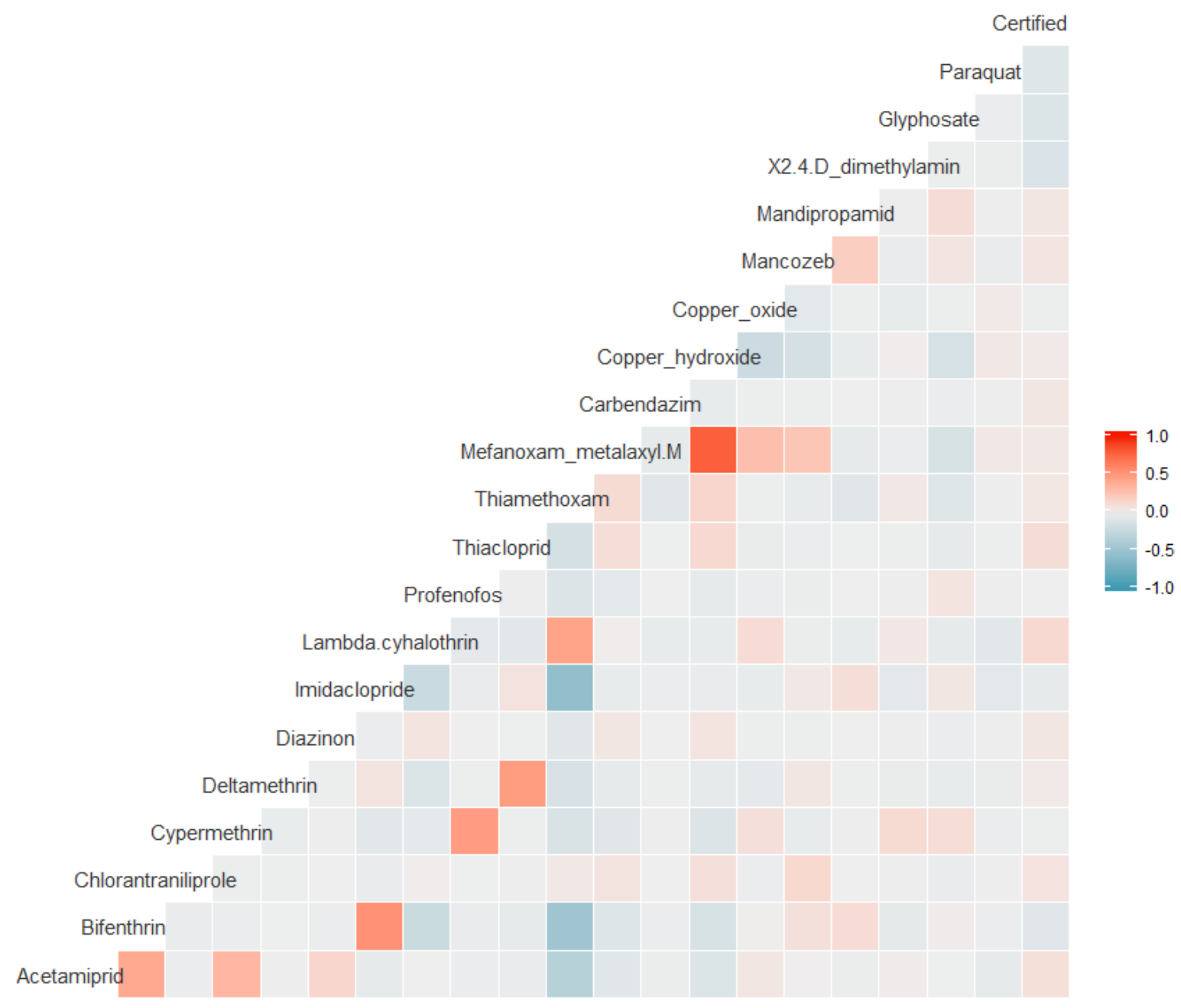

Figure B1. Correlation matrix between certification and all active ingredients in the dataset 


\section{Appendix for chapter 4}

Table C1. Instrument falsification test

\begin{tabular}{|c|c|c|c|c|}
\hline & $\begin{array}{c}\text { (1) } \\
\text { OLS } \\
\text { Full sample }\end{array}$ & $\begin{array}{c}(2) \\
\text { OLS } \\
\text { Farmers }\end{array}$ & $\begin{array}{c}(3) \\
\text { OLS } \\
\text { Coop workers }\end{array}$ & $\begin{array}{c}\text { (4) } \\
\text { OLS } \\
\text { Farm workers }\end{array}$ \\
\hline Share of certified farmers ( $5 \mathrm{~km}$ radius $)$ & & $\begin{array}{c}0.34 \\
(0.77)\end{array}$ & & \\
\hline Share of certified farmers ( $5 \mathrm{~km}$ radius; coop mean) & $\begin{array}{c}0.70 \\
(0.54)\end{array}$ & & $\begin{array}{c}0.63 \\
(1.20)\end{array}$ & $\begin{array}{l}-0.90 \\
(2.20)\end{array}$ \\
\hline Phone operator of coop leader ( $1=$ Orange $)$ & $\begin{array}{l}-0.17 \\
(0.23)\end{array}$ & $\begin{array}{l}-0.07 \\
(0.28)\end{array}$ & $\begin{array}{l}-0.39 \\
(0.79)\end{array}$ & $\begin{array}{c}0.05 \\
(0.56)\end{array}$ \\
\hline Dist. to the closest certified coop & $\begin{array}{c}0.12 \\
(1.05)\end{array}$ & $\begin{array}{l}-0.09 \\
(1.84)\end{array}$ & $\begin{array}{l}-0.91 \\
(2.32)\end{array}$ & $\begin{array}{c}0.55 \\
(5.05)\end{array}$ \\
\hline Education project $(1 / 0)$ & $\begin{array}{c}0.16 \\
(0.22)\end{array}$ & $\begin{array}{c}0.30 \\
(0.31)\end{array}$ & $\begin{array}{c}0.25 \\
(0.63)\end{array}$ & $\begin{array}{c}0.96 \\
(0.72)\end{array}$ \\
\hline Resp. $=$ coop. worker & $\begin{array}{c}-0.50^{* *} \\
(0.20)\end{array}$ & & & \\
\hline Resp. $=$ coop. farm worker & $\begin{array}{c}-0.64^{* * *} \\
(0.24)\end{array}$ & & & \\
\hline Female $(1 / 0)$ & $\begin{array}{l}-0.75 \\
(0.47)\end{array}$ & $\begin{array}{l}-0.54 \\
(0.54)\end{array}$ & $\begin{array}{c}-1.66^{* *} \\
(0.61)\end{array}$ & $\begin{array}{c}0.00 \\
(.)\end{array}$ \\
\hline Age & $\begin{array}{c}0.17^{* * *} \\
(0.05)\end{array}$ & $\begin{array}{l}0.17^{* *} \\
(0.08)\end{array}$ & $\begin{array}{c}0.29^{* * *} \\
(0.08)\end{array}$ & $\begin{array}{c}0.17 \\
(0.22)\end{array}$ \\
\hline Age squared & $\begin{array}{c}-0.00^{* * *} \\
(0.00)\end{array}$ & $\begin{array}{l}-0.00^{*} \\
(0.00)\end{array}$ & $\begin{array}{c}-0.00^{* *} \\
(0.00)\end{array}$ & $\begin{array}{l}-0.00 \\
(0.00)\end{array}$ \\
\hline Education (yrs.) & $\begin{array}{l}0.07^{* * *} \\
(0.02)\end{array}$ & $\begin{array}{l}0.06^{* *} \\
(0.02)\end{array}$ & $\begin{array}{l}0.12^{* *} \\
(0.05)\end{array}$ & $\begin{array}{c}0.10 \\
(0.07)\end{array}$ \\
\hline Risk aversion (1-10) & $\begin{array}{c}0.03 \\
(0.05)\end{array}$ & $\begin{array}{c}0.06 \\
(0.06)\end{array}$ & $\begin{array}{l}-0.12 \\
(0.07)\end{array}$ & $\begin{array}{c}0.13 \\
(0.11)\end{array}$ \\
\hline Household size & $\begin{array}{l}-0.04 \\
(0.02)\end{array}$ & $\begin{array}{c}-0.06^{* *} \\
(0.02)\end{array}$ & $\begin{array}{l}-0.09 \\
(0.07)\end{array}$ & $\begin{array}{c}0.01 \\
(0.07)\end{array}$ \\
\hline Dist. to input mkt. (km.) & $\begin{array}{l}-0.03 \\
(0.02)\end{array}$ & $\begin{array}{l}-0.03 \\
(0.02)\end{array}$ & $\begin{array}{l}-0.01 \\
(0.15)\end{array}$ & $\begin{array}{c}0.03 \\
(0.07)\end{array}$ \\
\hline Dist. to road $(\mathrm{km})$. & $\begin{array}{l}-0.00 \\
(0.01)\end{array}$ & $\begin{array}{l}-0.00 \\
(0.01)\end{array}$ & $\begin{array}{c}0.00 \\
(0.01)\end{array}$ & $\begin{array}{c}0.02 \\
(0.02)\end{array}$ \\
\hline Dist. to the closest primary school (km.) & $\begin{array}{c}0.02 \\
(0.02)\end{array}$ & $\begin{array}{c}0.01 \\
(0.03)\end{array}$ & $\begin{array}{l}-0.47^{*} \\
(0.27)\end{array}$ & $\begin{array}{c}0.03 \\
(0.08)\end{array}$ \\
\hline Dist. to the closest secondary school (km.) & $\begin{array}{c}0.00 \\
(0.01)\end{array}$ & $\begin{array}{c}0.00 \\
(0.01)\end{array}$ & $\begin{array}{l}-0.02 \\
(0.02)\end{array}$ & $\begin{array}{c}0.02 \\
(0.02)\end{array}$ \\
\hline (Log) Total value of assets 10 yrs. ago & $\begin{array}{c}0.10 \\
(0.08)\end{array}$ & $\begin{array}{c}0.15 \\
(0.11)\end{array}$ & $\begin{array}{l}-0.01 \\
(0.12)\end{array}$ & $\begin{array}{c}0.11 \\
(0.22)\end{array}$ \\
\hline Satisfaction w/ education (village mean) & $\begin{array}{c}0.04 \\
(0.18)\end{array}$ & $\begin{array}{l}-0.06 \\
(0.20)\end{array}$ & $\begin{array}{c}0.47 \\
(0.58)\end{array}$ & $\begin{array}{c}0.58 \\
(0.67)\end{array}$ \\
\hline Satisfaction w/ life (village mean) & $\begin{array}{l}0.45^{* *} \\
(0.17)\end{array}$ & $\begin{array}{l}0.42^{* *} \\
(0.17)\end{array}$ & $\begin{array}{l}-0.13 \\
(0.61)\end{array}$ & $\begin{array}{c}0.20 \\
(0.81)\end{array}$ \\
\hline Satisfaction w/ health (village mean) & $\begin{array}{l}-0.29 \\
(0.21)\end{array}$ & $\begin{array}{l}-0.30 \\
(0.32)\end{array}$ & $\begin{array}{c}0.35 \\
(1.11)\end{array}$ & $\begin{array}{l}-1.22^{*} \\
(0.60)\end{array}$ \\
\hline Age of the coop (yrs.) & $\begin{array}{l}-0.03^{*} \\
(0.02)\end{array}$ & $\begin{array}{l}-0.03 \\
(0.02)\end{array}$ & $\begin{array}{l}-0.05 \\
(0.05)\end{array}$ & $\begin{array}{l}-0.02 \\
(0.05)\end{array}$ \\
\hline Share of decisions made democratically & $\begin{array}{c}-1.45^{* * *} \\
(0.47)\end{array}$ & $\begin{array}{l}-0.82 \\
(0.82)\end{array}$ & $\begin{array}{c}-3.81^{* * *} \\
(1.23)\end{array}$ & $\begin{array}{c}0.61 \\
(1.62)\end{array}$ \\
\hline \# service/inputs/training providers & $\begin{array}{c}-0.05 \\
(0.08)\end{array}$ & $\begin{array}{c}0.04 \\
(0.12)\end{array}$ & $\begin{array}{c}-0.33 \\
(0.29)\end{array}$ & $\begin{array}{c}0.11 \\
(0.35)\end{array}$ \\
\hline District $=$ Lacs & $\begin{array}{c}-0.05 \\
(0.37)\end{array}$ & $\begin{array}{l}-0.09 \\
(0.60)\end{array}$ & $\begin{array}{c}-0.99 \\
(1.30)\end{array}$ & $\begin{array}{c}-0.77 \\
(1.12)\end{array}$ \\
\hline District $=$ Lagunes & $\begin{array}{c}-0.36 \\
(0.22)\end{array}$ & $\begin{array}{l}-0.44 \\
(0.31)\end{array}$ & $\begin{array}{l}-1.03 \\
(0.72)\end{array}$ & $\begin{array}{c}-0.43 \\
(0.57)\end{array}$ \\
\hline Constant & $\begin{array}{l}-2.67 \\
(1.92) \\
\end{array}$ & $\begin{array}{l}-2.68 \\
(2.84) \\
\end{array}$ & $\begin{array}{l}-3.51 \\
(6.51) \\
\end{array}$ & $\begin{array}{l}-1.98 \\
(9.16) \\
\end{array}$ \\
\hline Observations & 353 & 210 & 78 & 65 \\
\hline
\end{tabular}

Note: Cluster robust standard errors shown in parentheses. ${ }^{*} p<0.1,{ }^{* *} p<0.05,{ }^{* * *} p<0.01$ 
Table C2. Effects of certification and education projects on household education expenditure (log)

\begin{tabular}{|c|c|c|c|c|c|c|c|c|}
\hline & \multicolumn{2}{|c|}{ Full sample } & \multicolumn{2}{|c|}{ Farmers } & \multicolumn{2}{|c|}{ Coop workers } & \multicolumn{2}{|c|}{ Farm workers } \\
\hline & $\begin{array}{c}\text { OLS } \\
\text { (1) }\end{array}$ & $\begin{array}{l}\text { IV } \\
(2) \\
\end{array}$ & $\begin{array}{c}\text { OLS } \\
(3)\end{array}$ & $\begin{array}{l}\text { IV } \\
(4) \\
\end{array}$ & $\begin{array}{c}\text { OLS } \\
(5)\end{array}$ & $\begin{array}{l}\text { IV } \\
(6) \\
\end{array}$ & $\begin{array}{c}\text { OLS } \\
(7)\end{array}$ & $\begin{array}{l}\text { IV } \\
(8) \\
\end{array}$ \\
\hline Certification (1/0) & $\begin{array}{l}0.43^{* * *} \\
(0.12)\end{array}$ & $\begin{array}{c}0.52^{* * *} \\
(0.15)\end{array}$ & $\begin{array}{l}0.35^{* *} \\
(0.15)\end{array}$ & $\begin{array}{l}0.46^{* *} \\
(0.18)\end{array}$ & $\begin{array}{l}0.82^{* *} \\
(0.32)\end{array}$ & $\begin{array}{l}0.89^{* *} \\
(0.40)\end{array}$ & $\begin{array}{c}0.33 \\
(0.32)\end{array}$ & $\begin{array}{c}0.29 \\
(0.38)\end{array}$ \\
\hline Education project (1/0) & $\begin{array}{l}0.41^{* *} \\
(0.16)\end{array}$ & $\begin{array}{l}0.43^{* * *} \\
(0.16)\end{array}$ & $\begin{array}{l}0.71^{* * *} \\
(0.14)\end{array}$ & $\begin{array}{c}0.73^{* * *} \\
(0.14)\end{array}$ & $\begin{array}{c}-0.24 \\
(0.51)\end{array}$ & $\begin{array}{l}-0.21 \\
(0.47)\end{array}$ & $\begin{array}{c}0.52 \\
(0.41)\end{array}$ & $\begin{array}{c}0.51 \\
(0.37)\end{array}$ \\
\hline Resp. $=$ coop. worker & $\begin{array}{l}-0.30^{*} \\
(0.17)\end{array}$ & $\begin{array}{l}-0.30^{*} \\
(0.17)\end{array}$ & & & & & & \\
\hline Resp. $=$ coop. farm worker & $\begin{array}{c}-0.54^{* * * *} \\
(0.16)\end{array}$ & $\begin{array}{c}-0.54^{* * * *} \\
(0.16)\end{array}$ & & & & & & \\
\hline Female $(1 / 0)$ & $\begin{array}{c}-0.24 \\
(0.30)\end{array}$ & $\begin{array}{l}-0.26 \\
(0.29)\end{array}$ & $\begin{array}{c}-0.36 \\
(0.34)\end{array}$ & $\begin{array}{c}-0.36 \\
(0.32)\end{array}$ & $\begin{array}{c}-0.40 \\
(0.50)\end{array}$ & $\begin{array}{c}-0.42 \\
(0.43)\end{array}$ & $\begin{array}{c}0.00 \\
(.)\end{array}$ & $\begin{array}{c}0.00 \\
(.)\end{array}$ \\
\hline Age & $\begin{array}{l}0.18^{* * *} \\
(0.03)\end{array}$ & $\begin{array}{l}0.18^{* * *} \\
(0.03)\end{array}$ & $\begin{array}{l}0.18^{* * *} \\
(0.06)\end{array}$ & $\begin{array}{c}0.18^{* * *} \\
(0.05)\end{array}$ & $\begin{array}{c}0.23^{* * *} \\
(0.07)\end{array}$ & $\begin{array}{l}0.23^{* * *} \\
(0.06)\end{array}$ & $\begin{array}{c}0.16 \\
(0.10)\end{array}$ & $\begin{array}{c}0.16^{*} \\
(0.09)\end{array}$ \\
\hline Age squared & $\begin{array}{c}-0.00^{* * * *} \\
(0.00)\end{array}$ & $\begin{array}{c}-0.00^{* * * *} \\
(0.00)\end{array}$ & $\begin{array}{c}-0.00^{* * * *} \\
(0.00)\end{array}$ & $\begin{array}{c}-0.00^{* * * *} \\
(0.00)\end{array}$ & $\begin{array}{c}-0.00^{* * * *} \\
(0.00)\end{array}$ & $\begin{array}{c}-0.00^{* * * *} \\
(0.00)\end{array}$ & $\begin{array}{c}-0.00 \\
(0.00)\end{array}$ & $\begin{array}{c}-0.00 \\
(0.00)\end{array}$ \\
\hline Education (yrs.) & $\begin{array}{c}0.06^{* * *} \\
(0.01)\end{array}$ & $\begin{array}{c}0.06^{* * *} \\
(0.01)\end{array}$ & $\begin{array}{c}0.03 \\
(0.02)\end{array}$ & $\begin{array}{l}0.03^{*} \\
(0.02)\end{array}$ & $\begin{array}{l}0.09^{* *} \\
(0.04)\end{array}$ & $\begin{array}{l}0.09^{* * *} \\
(0.03)\end{array}$ & $\begin{array}{l}0.12^{* *} \\
(0.05)\end{array}$ & $\begin{array}{c}0.12^{* * * *} \\
(0.04)\end{array}$ \\
\hline Risk aversion (1-10) & $\begin{array}{l}0.06^{* *} \\
(0.03)\end{array}$ & $\begin{array}{l}0.06^{* *} \\
(0.03)\end{array}$ & $\begin{array}{c}0.05 \\
(0.03)\end{array}$ & $\begin{array}{c}0.05 \\
(0.03)\end{array}$ & $\begin{array}{l}-0.04 \\
(0.04)\end{array}$ & $\begin{array}{c}-0.04 \\
(0.04)\end{array}$ & $\begin{array}{c}0.14^{*} \\
(0.08)\end{array}$ & $\begin{array}{l}0.14^{* *} \\
(0.07)\end{array}$ \\
\hline Household size & $\begin{array}{c}-0.04^{* *} \\
(0.02)\end{array}$ & $\begin{array}{c}-0.04^{* *} \\
(0.02)\end{array}$ & $\begin{array}{c}-0.04^{* *} \\
(0.02)\end{array}$ & $\begin{array}{c}-0.04^{* *} \\
(0.02)\end{array}$ & $\begin{array}{l}-0.05 \\
(0.04)\end{array}$ & $\begin{array}{l}-0.06^{*} \\
(0.03)\end{array}$ & $\begin{array}{l}-0.02 \\
(0.05)\end{array}$ & $\begin{array}{c}-0.02 \\
(0.05)\end{array}$ \\
\hline Dist. to input mkt. (km.) & $\begin{array}{l}-0.00 \\
(0.01)\end{array}$ & $\begin{array}{l}-0.00 \\
(0.01)\end{array}$ & $\begin{array}{l}-0.02 \\
(0.02)\end{array}$ & $\begin{array}{l}-0.02 \\
(0.01)\end{array}$ & $\begin{array}{l}-0.04 \\
(0.05)\end{array}$ & $\begin{array}{l}-0.04 \\
(0.05)\end{array}$ & $\begin{array}{c}0.02 \\
(0.03)\end{array}$ & $\begin{array}{c}0.02 \\
(0.03)\end{array}$ \\
\hline Dist. to road (km.) & $\begin{array}{c}0.00 \\
(0.00)\end{array}$ & $\begin{array}{c}0.00 \\
(0.00)\end{array}$ & $\begin{array}{c}-0.00 \\
(0.00)\end{array}$ & $\begin{array}{c}-0.00 \\
(0.00)\end{array}$ & $\begin{array}{c}0.00 \\
(0.01)\end{array}$ & $\begin{array}{c}0.00 \\
(0.01)\end{array}$ & $\begin{array}{c}0.00 \\
(0.01)\end{array}$ & $\begin{array}{c}0.00 \\
(0.01)\end{array}$ \\
\hline Dist. to the closest primary school (km.) & $\begin{array}{c}0.01 \\
(0.02)\end{array}$ & $\begin{array}{c}0.01 \\
(0.02)\end{array}$ & $\begin{array}{c}0.02 \\
(0.02)\end{array}$ & $\begin{array}{c}0.02 \\
(0.02)\end{array}$ & $\begin{array}{l}-0.01 \\
(0.13)\end{array}$ & $\begin{array}{l}-0.01 \\
(0.12)\end{array}$ & $\begin{array}{l}-0.01 \\
(0.03)\end{array}$ & $\begin{array}{c}-0.01 \\
(0.03)\end{array}$ \\
\hline Dist. to the closest secondary school (km.) & $\begin{array}{c}-0.00 \\
(0.01)\end{array}$ & $\begin{array}{c}-0.00 \\
(0.01)\end{array}$ & $\begin{array}{c}-0.00 \\
(0.01)\end{array}$ & $\begin{array}{c}-0.00 \\
(0.01)\end{array}$ & $\begin{array}{l}-0.04^{*} \\
(0.02)\end{array}$ & $\begin{array}{l}-0.04^{*} \\
(0.02)\end{array}$ & $\begin{array}{c}0.02 \\
(0.02)\end{array}$ & $\begin{array}{c}0.02^{*} \\
(0.01)\end{array}$ \\
\hline (Log) Total value of assets 10 yrs. ago & $\begin{array}{l}0.09^{*} \\
(0.05)\end{array}$ & $\begin{array}{c}0.09^{*} \\
(0.05)\end{array}$ & $\begin{array}{c}0.04 \\
(0.07)\end{array}$ & $\begin{array}{c}0.04 \\
(0.07)\end{array}$ & $\begin{array}{c}0.03 \\
(0.12)\end{array}$ & $\begin{array}{c}0.03 \\
(0.11)\end{array}$ & $\begin{array}{c}0.11 \\
(0.14)\end{array}$ & $\begin{array}{c}0.11 \\
(0.13)\end{array}$ \\
\hline Religion $=$ Catholic & $\begin{array}{c}0.11 \\
(0.12)\end{array}$ & $\begin{array}{c}0.11 \\
(0.12)\end{array}$ & $\begin{array}{c}0.23 \\
(0.17)\end{array}$ & $\begin{array}{c}0.22 \\
(0.17)\end{array}$ & $\begin{array}{c}0.11 \\
(0.35)\end{array}$ & $\begin{array}{c}0.11 \\
(0.31)\end{array}$ & $\begin{array}{l}-0.05 \\
(0.57)\end{array}$ & $\begin{array}{c}-0.05 \\
(0.51)\end{array}$ \\
\hline Religion $=$ Muslim & $\begin{array}{c}0.21 \\
(0.18)\end{array}$ & $\begin{array}{c}0.21 \\
(0.18)\end{array}$ & $\begin{array}{c}0.09 \\
(0.28)\end{array}$ & $\begin{array}{c}0.08 \\
(0.28)\end{array}$ & $\begin{array}{c}0.43 \\
(0.50)\end{array}$ & $\begin{array}{c}0.44 \\
(0.43)\end{array}$ & $\begin{array}{c}0.46 \\
(0.38)\end{array}$ & $\begin{array}{c}0.46 \\
(0.33)\end{array}$ \\
\hline Satisfaction w/ education (village mean) & $\begin{array}{l}-0.04 \\
(0.09)\end{array}$ & $\begin{array}{c}-0.04 \\
(0.09)\end{array}$ & $\begin{array}{l}-0.07 \\
(0.09)\end{array}$ & $\begin{array}{l}-0.08 \\
(0.09)\end{array}$ & $\begin{array}{l}-0.07 \\
(0.38)\end{array}$ & $\begin{array}{l}-0.07 \\
(0.34)\end{array}$ & $\begin{array}{l}-0.03 \\
(0.21)\end{array}$ & $\begin{array}{c}-0.03 \\
(0.19)\end{array}$ \\
\hline Satisfaction w/ life (village mean) & $\begin{array}{c}0.43^{* * *} \\
(0.11)\end{array}$ & $\begin{array}{l}0.42^{* * *} \\
(0.11)\end{array}$ & $\begin{array}{l}0.47^{* * *} \\
(0.12)\end{array}$ & $\begin{array}{l}0.45^{* * *} \\
(0.11)\end{array}$ & $\begin{array}{c}0.43 \\
(0.33)\end{array}$ & $\begin{array}{c}0.43 \\
(0.29)\end{array}$ & $\begin{array}{c}0.28 \\
(0.26)\end{array}$ & $\begin{array}{c}0.29 \\
(0.24)\end{array}$ \\
\hline Satisfaction w/ health (village mean) & $\begin{array}{c}-0.14 \\
(0.09)\end{array}$ & $\begin{array}{l}-0.14 \\
(0.09)\end{array}$ & $\begin{array}{c}-0.16 \\
(0.11)\end{array}$ & $\begin{array}{l}-0.16 \\
(0.10)\end{array}$ & $\begin{array}{c}0.27 \\
(0.29)\end{array}$ & $\begin{array}{c}0.27 \\
(0.26)\end{array}$ & $\begin{array}{l}-0.37 \\
(0.23)\end{array}$ & $\begin{array}{l}-0.37^{*} \\
(0.21)\end{array}$ \\
\hline Age of the coop (yrs.) & $\begin{array}{l}-0.02^{*} \\
(0.01)\end{array}$ & $\begin{array}{l}-0.03^{* *} \\
(0.01)\end{array}$ & $\begin{array}{l}-0.01 \\
(0.01)\end{array}$ & $\begin{array}{l}-0.01 \\
(0.01)\end{array}$ & $\begin{array}{c}-0.08^{* *} \\
(0.04)\end{array}$ & $\begin{array}{c}-0.08^{* *} \\
(0.03)\end{array}$ & $\begin{array}{l}-0.02 \\
(0.04)\end{array}$ & $\begin{array}{c}-0.01 \\
(0.03)\end{array}$ \\
\hline
\end{tabular}




\begin{tabular}{|c|c|c|c|c|c|c|c|c|}
\hline Share of decisions made democratically & $\begin{array}{c}-0.74^{* *} \\
(0.32)\end{array}$ & $\begin{array}{l}-0.74^{* *} \\
(0.32)\end{array}$ & $\begin{array}{l}-0.41 \\
(0.44)\end{array}$ & $\begin{array}{c}-0.42 \\
(0.41)\end{array}$ & $\begin{array}{c}-1.52 \\
(1.18)\end{array}$ & $\begin{array}{l}-1.53 \\
(1.06)\end{array}$ & $\begin{array}{c}0.14 \\
(1.10)\end{array}$ & $\begin{array}{c}0.14 \\
(0.99)\end{array}$ \\
\hline \# service/inputs/training providers & 0.06 & 0.05 & 0.03 & 0.02 & 0.03 & 0.02 & 0.06 & 0.06 \\
\hline & $(0.05)$ & $(0.05)$ & $(0.06)$ & $(0.05)$ & $(0.12)$ & $(0.11)$ & $(0.14)$ & $(0.12)$ \\
\hline District $=$ Lacs & $\begin{array}{c}0.01 \\
(0.33)\end{array}$ & $\begin{array}{c}0.04 \\
(0.31)\end{array}$ & $\begin{array}{c}0.19 \\
(0.37)\end{array}$ & $\begin{array}{c}0.23 \\
(0.33)\end{array}$ & $\begin{array}{c}-0.79 \\
(0.77)\end{array}$ & $\begin{array}{c}-0.76 \\
(0.70)\end{array}$ & $\begin{array}{c}-0.16 \\
(0.58)\end{array}$ & $\begin{array}{c}-0.17 \\
(0.53)\end{array}$ \\
\hline District $=$ Lagunes & $\begin{array}{l}-0.27^{*} \\
(0.14)\end{array}$ & $\begin{array}{l}-0.24^{*} \\
(0.14)\end{array}$ & $\begin{array}{c}-0.29^{*} \\
(0.15)\end{array}$ & $\begin{array}{l}-0.27^{*} \\
(0.14)\end{array}$ & $\begin{array}{l}-0.47 \\
(0.43)\end{array}$ & $\begin{array}{l}-0.45 \\
(0.37)\end{array}$ & $\begin{array}{c}-0.35 \\
(0.41)\end{array}$ & $\begin{array}{c}-0.36 \\
(0.38)\end{array}$ \\
\hline Constant & $\begin{array}{c}-4.06^{* * *} \\
(1.26)\end{array}$ & $\begin{array}{c}-4.04^{* * *} \\
(1.23)\end{array}$ & $\begin{array}{l}-3.20 \\
(2.00) \\
\end{array}$ & $\begin{array}{c}-3.13 \\
(1.94)\end{array}$ & $\begin{array}{l}-5.54^{*} \\
(2.95) \\
\end{array}$ & $\begin{array}{c}-5.58^{* *} \\
(2.61)\end{array}$ & $\begin{array}{c}-3.98 \\
(2.67) \\
\end{array}$ & $\begin{array}{l}-3.99^{*} \\
(2.40) \\
\end{array}$ \\
\hline Wu-Hausman F-statistic. ${ }^{\text {a }}$ & & 0.97 & & 0.73 & & 0.08 & & 0.02 \\
\hline Kleibergen-Paap Wald F statistic ${ }^{b}$ & & $112.05^{* * *}$ & & $72.88^{* * *}$ & & $60.44^{* * *}$ & & $78.02^{* * *}$ \\
\hline Hansen J statistic. $^{c}$ & & 1.18 & & 0.68 & & 2.11 & & 1.49 \\
\hline Observations & 712 & 712 & 433 & 433 & 147 & 147 & 132 & 132 \\
\hline
\end{tabular}

Note: Cluster robust standard errors shown in parentheses. ${ }^{*} p<0.1,{ }^{* *} p<0.05,{ }^{* * *} p<0.01$

${ }^{a}$ Test of endogeneity $\left(\mathrm{H}_{0}\right.$ : certified variable is exogenous)

${ }^{b}$ Test for weak instruments ( $\mathrm{H}_{0}$ : coefficients of instruments in first stage are not different from zero)

${ }^{c}$ Test of over-identifying restrictions ( $\mathrm{H}_{0}$ : instruments are uncorrelated with the error term) 
Table C3. Spillover effects of education projects on household education expenditure (log)

\begin{tabular}{|c|c|c|c|c|}
\hline & $\begin{array}{c}\text { (1) } \\
\text { Full sample }\end{array}$ & $\begin{array}{c}(2) \\
\text { Farmers }\end{array}$ & $\begin{array}{c}\text { (3) } \\
\text { Coop workers }\end{array}$ & $\begin{array}{c}\text { (4) } \\
\text { Farm workers }\end{array}$ \\
\hline Education project (1/0) & $\begin{array}{c}0.31 \\
(0.20)\end{array}$ & $\begin{array}{c}0.39 \\
(0.34)\end{array}$ & $\begin{array}{c}0.42 \\
(0.54)\end{array}$ & $\begin{array}{c}0.79 \\
(0.52)\end{array}$ \\
\hline Resp. $=$ coop. worker & $\begin{array}{l}-0.55^{* *} \\
(0.22)\end{array}$ & & & \\
\hline Resp. = coop. farm worker & $\begin{array}{c}-0.67^{* * *} \\
(0.24)\end{array}$ & & & \\
\hline Female $(1 / 0)$ & $\begin{array}{l}-0.75 \\
(0.49)\end{array}$ & $\begin{array}{l}-0.48 \\
(0.57)\end{array}$ & $\begin{array}{c}-1.80^{* * *} \\
(0.57)\end{array}$ & $\begin{array}{c}0.00 \\
(.)\end{array}$ \\
\hline Age & $\begin{array}{l}0.17^{* * *} \\
(0.04)\end{array}$ & $\begin{array}{l}0.17^{* *} \\
(0.08)\end{array}$ & $\begin{array}{l}0.28^{* * *} \\
(0.07)\end{array}$ & $\begin{array}{c}0.18 \\
(0.23)\end{array}$ \\
\hline Age squared & $\begin{array}{c}-0.00^{* * * *} \\
(0.00)\end{array}$ & $\begin{array}{l}-0.00^{* *} \\
(0.00)\end{array}$ & $\begin{array}{c}-0.00^{* * * *} \\
(0.00)\end{array}$ & $\begin{array}{l}-0.00 \\
(0.00)\end{array}$ \\
\hline Education (yrs.) & $\begin{array}{l}0.07^{* * *} \\
(0.02)\end{array}$ & $\begin{array}{l}0.06^{* *} \\
(0.03)\end{array}$ & $\begin{array}{l}0.12^{* *} \\
(0.05)\end{array}$ & $\begin{array}{c}0.13 \\
(0.08)\end{array}$ \\
\hline Risk aversion (1-10) & $\begin{array}{c}0.04 \\
(0.05)\end{array}$ & $\begin{array}{c}0.06 \\
(0.06)\end{array}$ & $\begin{array}{l}-0.09 \\
(0.07)\end{array}$ & $\begin{array}{c}0.11 \\
(0.11)\end{array}$ \\
\hline Household size & $\begin{array}{l}-0.04 \\
(0.02)\end{array}$ & $\begin{array}{l}-0.06^{* *} \\
(0.03)\end{array}$ & $\begin{array}{l}-0.10 \\
(0.08)\end{array}$ & $\begin{array}{c}0.03 \\
(0.09)\end{array}$ \\
\hline Akan ethnicity $(1 / 0)$ & $\begin{array}{l}-0.21 \\
(0.26)\end{array}$ & $\begin{array}{l}-0.40 \\
(0.37)\end{array}$ & $\begin{array}{l}-0.29 \\
(0.90)\end{array}$ & $\begin{array}{l}-0.18 \\
(0.82)\end{array}$ \\
\hline Dist. to input mkt. (km.) & $\begin{array}{l}-0.03^{*} \\
(0.02)\end{array}$ & $\begin{array}{l}-0.04 \\
(0.02)\end{array}$ & $\begin{array}{l}-0.07 \\
(0.10)\end{array}$ & $\begin{array}{c}0.01 \\
(0.06)\end{array}$ \\
\hline Dist. to road (km.) & $\begin{array}{c}0.00 \\
(0.01)\end{array}$ & $\begin{array}{l}-0.00 \\
(0.01)\end{array}$ & $\begin{array}{c}0.01 \\
(0.01)\end{array}$ & $\begin{array}{c}0.01 \\
(0.02)\end{array}$ \\
\hline Dist. to the closest primary school (km.) & $\begin{array}{c}0.03 \\
(0.02)\end{array}$ & $\begin{array}{c}0.02 \\
(0.03)\end{array}$ & $\begin{array}{l}-0.51^{*} \\
(0.25)\end{array}$ & $\begin{array}{c}0.04 \\
(0.05)\end{array}$ \\
\hline Dist. to the closest secondary school (km.) & $\begin{array}{l}-0.00 \\
(0.01)\end{array}$ & $\begin{array}{l}-0.00 \\
(0.01)\end{array}$ & $\begin{array}{l}-0.01 \\
(0.02)\end{array}$ & $\begin{array}{c}0.03 \\
(0.02)\end{array}$ \\
\hline (Log) Total value of assets $10 \mathrm{yrs}$. ago & $\begin{array}{c}0.09 \\
(0.08)\end{array}$ & $\begin{array}{c}0.15 \\
(0.10)\end{array}$ & $\begin{array}{l}-0.03 \\
(0.13)\end{array}$ & $\begin{array}{c}0.13 \\
(0.20)\end{array}$ \\
\hline Religion $=$ Catholic & $\begin{array}{c}0.17 \\
(0.19)\end{array}$ & $\begin{array}{c}0.21 \\
(0.26)\end{array}$ & $\begin{array}{l}-0.27 \\
(0.64)\end{array}$ & $\begin{array}{c}0.19 \\
(0.74)\end{array}$ \\
\hline Religion $=$ Muslim & $\begin{array}{l}-0.01 \\
(0.29)\end{array}$ & $\begin{array}{l}-0.13 \\
(0.42)\end{array}$ & $\begin{array}{l}-0.31 \\
(0.81)\end{array}$ & $\begin{array}{c}0.63 \\
(0.77)\end{array}$ \\
\hline Satisfaction w/ education (village mean) & $\begin{array}{c}0.09 \\
(0.16)\end{array}$ & $\begin{array}{l}-0.05 \\
(0.16)\end{array}$ & $\begin{array}{c}0.28 \\
(0.41)\end{array}$ & $\begin{array}{c}0.33 \\
(0.44)\end{array}$ \\
\hline Satisfaction w/ life (village mean) & $\begin{array}{l}0.41^{* *} \\
(0.16)\end{array}$ & $\begin{array}{l}0.37^{* *} \\
(0.15)\end{array}$ & $\begin{array}{l}-0.01 \\
(0.50)\end{array}$ & $\begin{array}{c}0.33 \\
(0.71)\end{array}$ \\
\hline Satisfaction w/ health (village mean) & $\begin{array}{l}-0.31 \\
(0.18)\end{array}$ & $\begin{array}{l}-0.31 \\
(0.26)\end{array}$ & $\begin{array}{c}0.73 \\
(0.66)\end{array}$ & $\begin{array}{l}-1.05^{* *} \\
(0.40)\end{array}$ \\
\hline Age of the coop (yrs.) & $\begin{array}{l}-0.02 \\
(0.02)\end{array}$ & $\begin{array}{l}-0.02 \\
(0.02)\end{array}$ & $\begin{array}{l}-0.05 \\
(0.05)\end{array}$ & $\begin{array}{l}-0.04 \\
(0.06)\end{array}$ \\
\hline Share of decisions made democratically & $\begin{array}{c}-1.38^{* *} \\
(0.51)\end{array}$ & $\begin{array}{c}-0.74 \\
(0.82)\end{array}$ & $\begin{array}{c}-4.01^{* * * *} \\
(1.28)\end{array}$ & $\begin{array}{c}0.84 \\
(1.81)\end{array}$ \\
\hline \# service/inputs/training providers & $\begin{array}{l}-0.04 \\
(0.08)\end{array}$ & $\begin{array}{c}0.05 \\
(0.11)\end{array}$ & $\begin{array}{l}-0.27 \\
(0.28)\end{array}$ & $\begin{array}{c}0.25 \\
(0.41)\end{array}$ \\
\hline Ditrict $=$ Lacs & $\begin{array}{c}0.04 \\
(0.38)\end{array}$ & $\begin{array}{l}-0.05 \\
(0.50)\end{array}$ & $\begin{array}{l}-0.55 \\
(0.94)\end{array}$ & $\begin{array}{l}-0.27 \\
(0.82)\end{array}$ \\
\hline District $=$ Lagunes & $\begin{array}{l}-0.29 \\
(0.21)\end{array}$ & $\begin{array}{l}-0.40 \\
(0.24)\end{array}$ & $\begin{array}{l}-0.93 \\
(0.58)\end{array}$ & $\begin{array}{l}-0.28 \\
(0.53)\end{array}$ \\
\hline Constant & $\begin{array}{l}-2.62 \\
(1.71)\end{array}$ & $\begin{array}{l}-2.22 \\
(2.61)\end{array}$ & $\begin{array}{l}-4.89 \\
(5.38)\end{array}$ & $\begin{array}{l}-3.21 \\
(8.83)\end{array}$ \\
\hline Observations & 353 & 210 & 78 & 65 \\
\hline
\end{tabular}

Standard errors in parentheses

${ }^{*} p<0.1,{ }^{* *} p<0.05,{ }^{* * *} p<0.01$ 


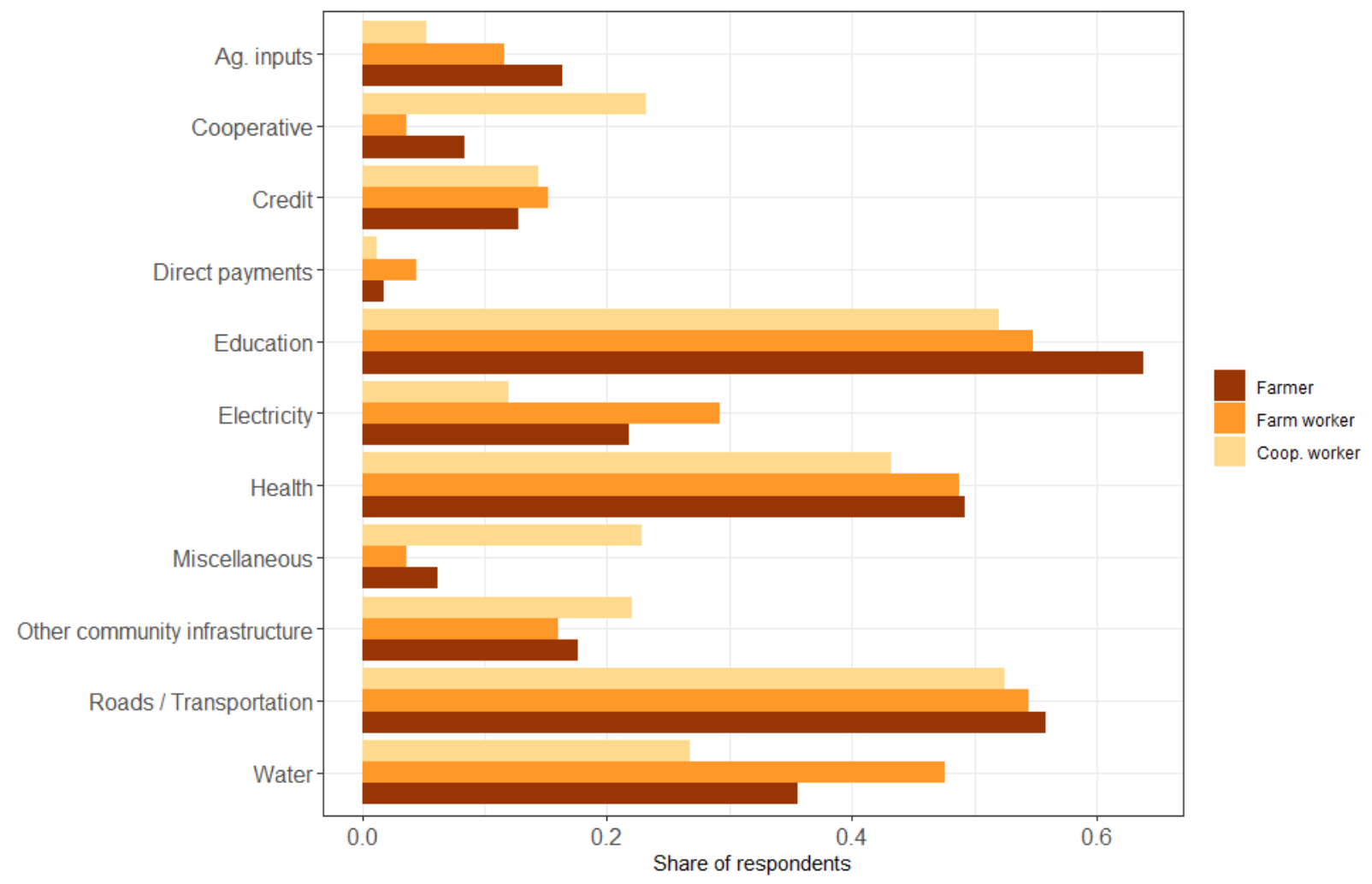

Figure C1. Most pressing needs of the villages that should be addressed

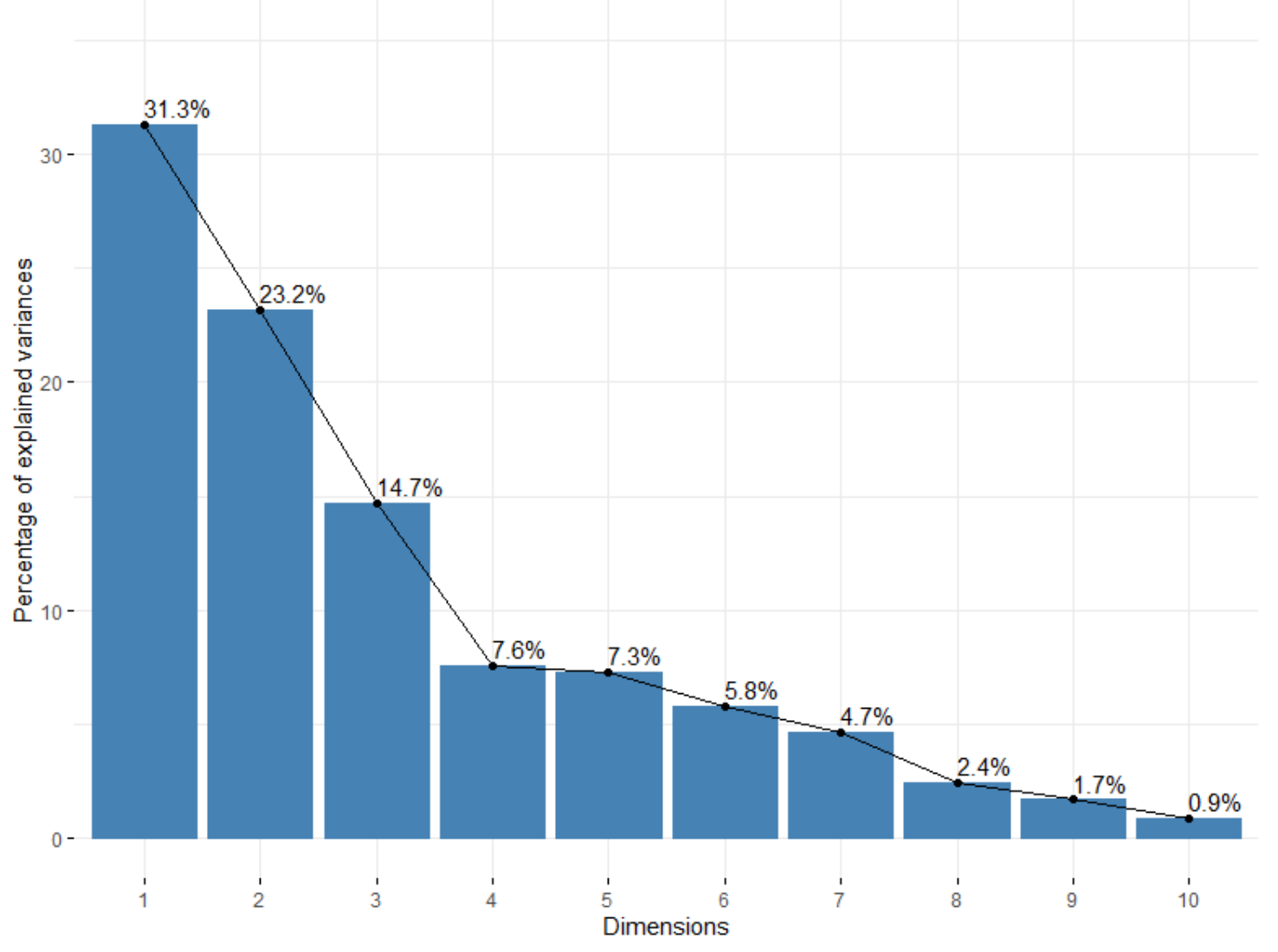

Figure C2. Scree plot of the principal component analysis 


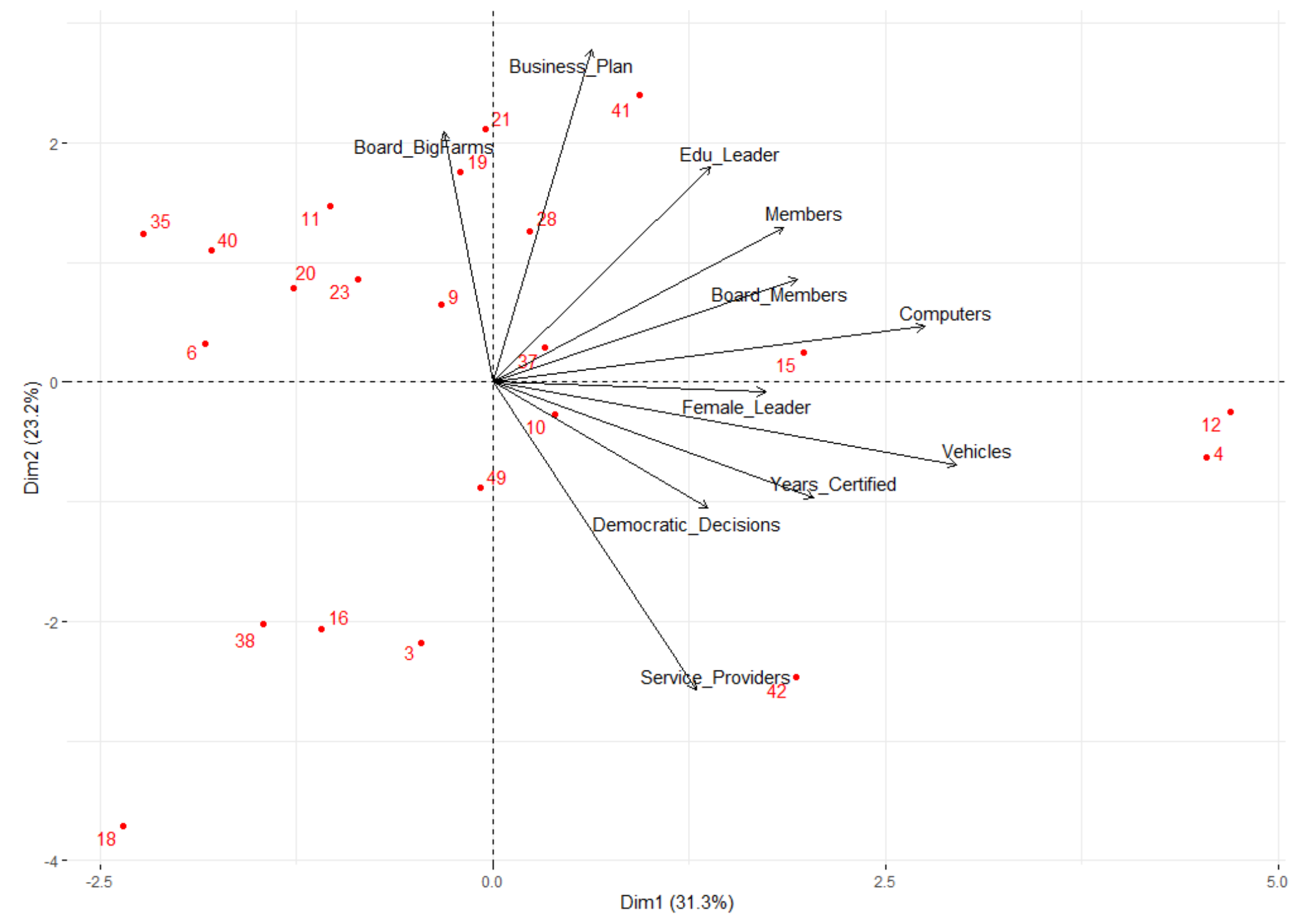

Figure C3. Biplot of the principal component analysis. Cooperatives are indicated by red dots. 


\section{DECLARATIONS}

1. I, hereby, declare that this Ph.D. dissertation has not been presented to any other examining body either in its present or similar form.

Furthermore, I also affirm that I have not applied for a Ph.D. at any other higher school of education.

Göttingen,

(Signature)

(Name in block capitals)

2. I, hereby, solemnly declare that this dissertation was undertaken independently and without any unauthorized aid.

Göttingen,

(Signature)

(Name in block capitals) 